\title{
Republic of Mozambique: Poverty Reduction Strategy Paper- Annual Progress Report-Review of the Economic and Social Plan for 2007
}

Poverty Reduction Strategy Papers (PRSPs) are prepared by member countries in broad consultation with stakeholders and development partners, including the staffs of the World Bank and the IMF. Updated every three years with annual progress reports, they describe the country's macroeconomic, structural, and social policies in support of growth and poverty reduction, as well as associated external financing needs and major sources of financing. This country document for the Republic of Mozambique, dated February 2008, is being made available on the IMF website by agreement with the member country as a service to users of the IMF website.

Copies of this report are available to the public from

International Monetary Fund • Publication Services

$70019^{\text {th }}$ Street, N.W. • Washington, D.C. 20431

Telephone: (202) 623-7430 • Telefax: (202) 623-7201

E-mail: publications@imf.org • Internet: http://www.imf.org

\section{International Monetary Fund Washington, D.C.}





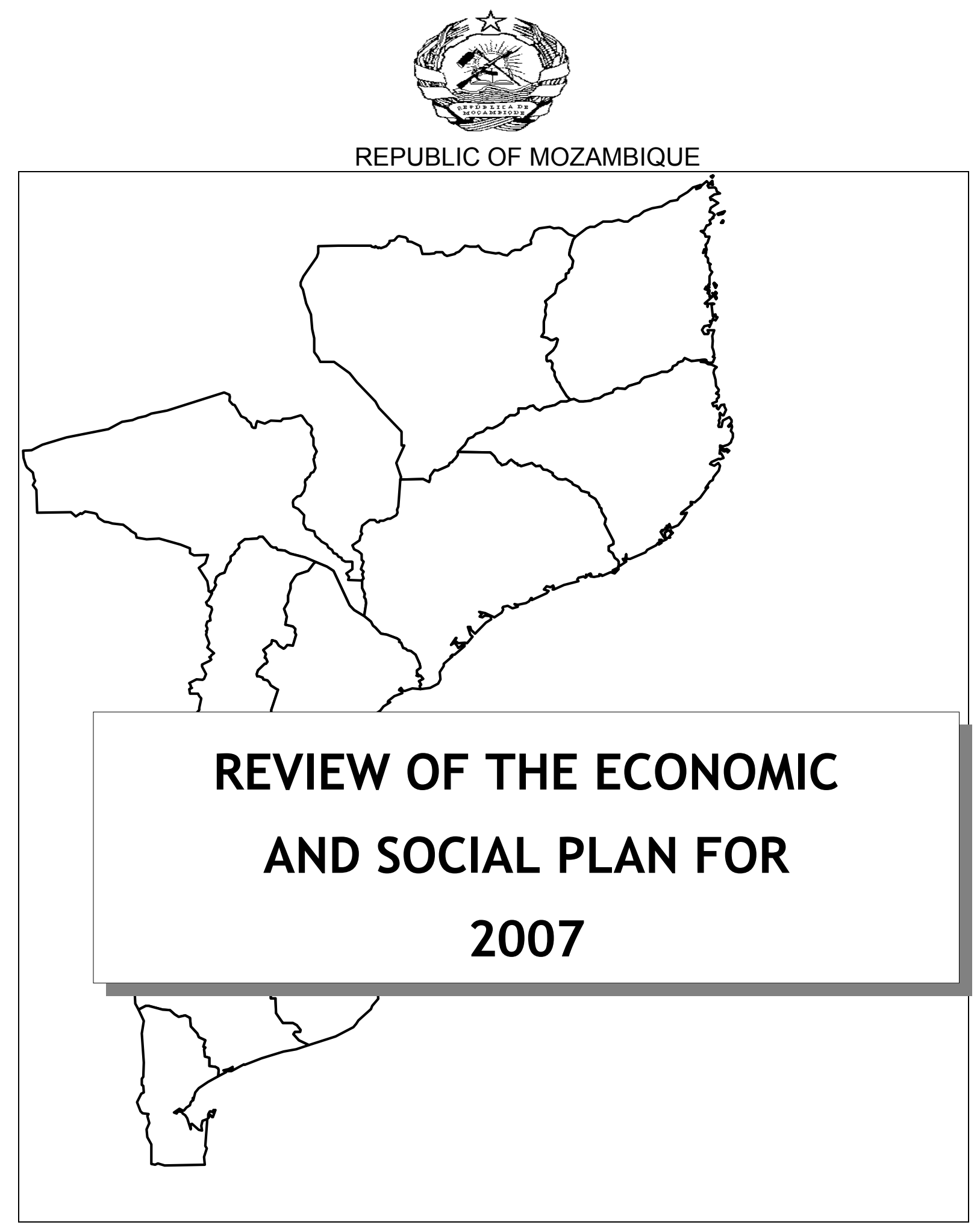

MAPUTO, FEBRUARY 2008 


\section{CONTENTS}

I. INTRODUCTORY NOTE 5

II. INTERNATIONAL CONTEXT .5

III. NATIONAL SOCIO-ECONOMIC AND DEMOGRAPHIC CONTEXT ..........................................8

III.1 EVALUATION OF THE MILLENNIUM DEVELOPMENT OBJECTIVES ..............8

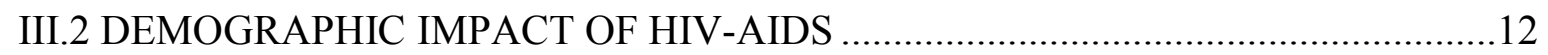

III.3 MAIN OBJECTIVES OF THE ECONOMIC AND SOCIAL PLAN .........................14

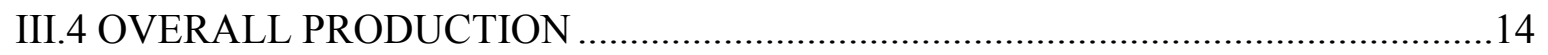

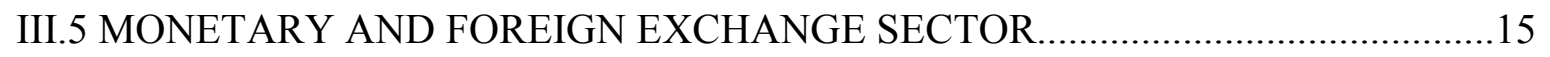

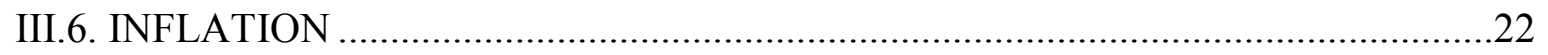

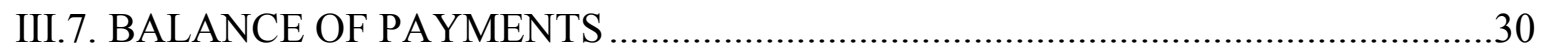

IV. MAIN LINES OF DEVELOPMENT BY PILLAR

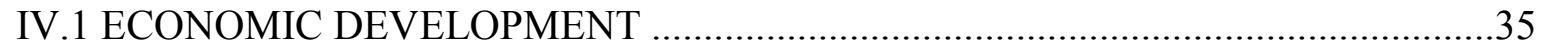

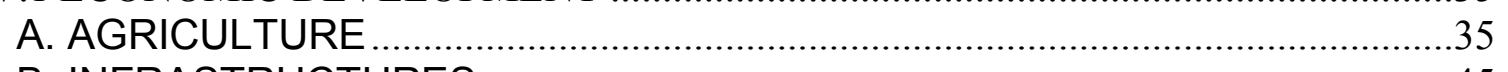

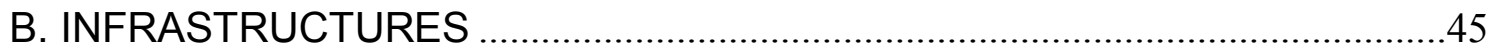

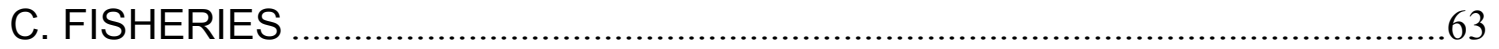

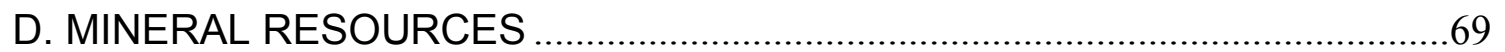

E. INDUSTRY AND TRADE

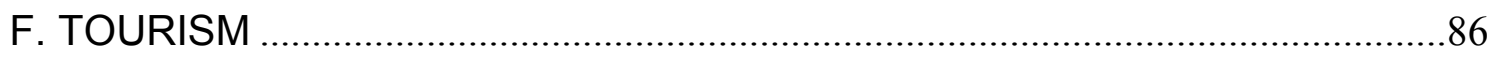

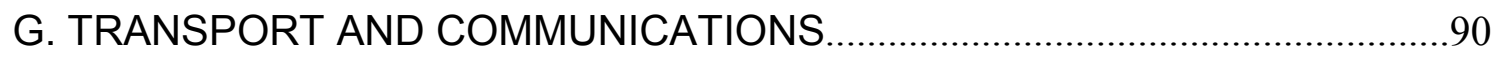

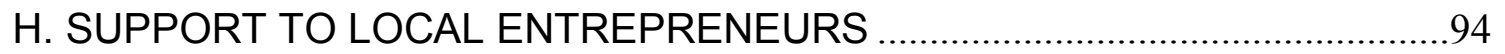

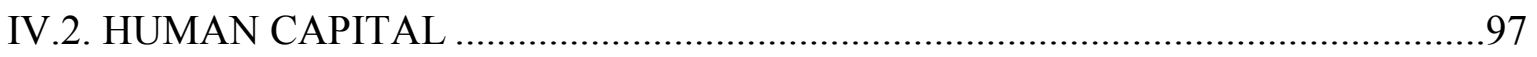

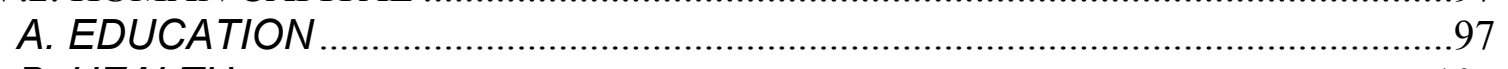

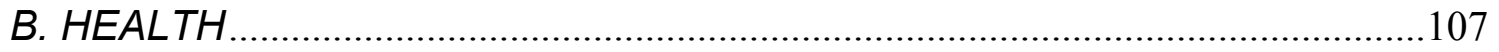

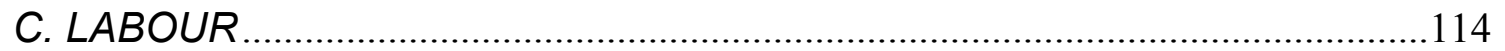

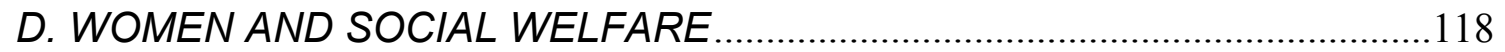

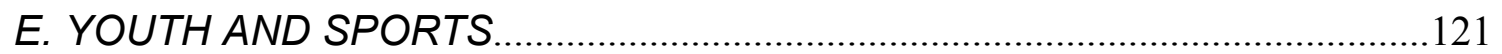

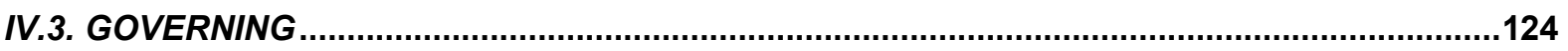

A. PUBLIC SECTOR REFORM, DECENTRALIZATION AND

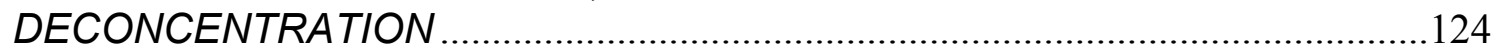

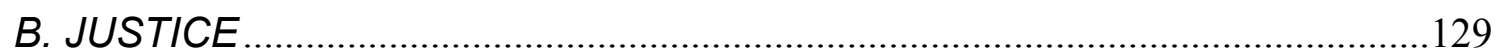

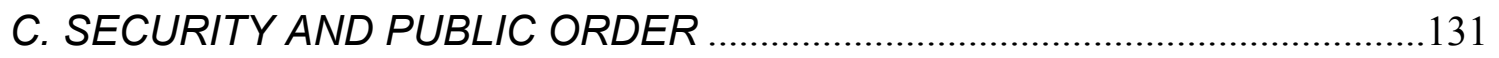

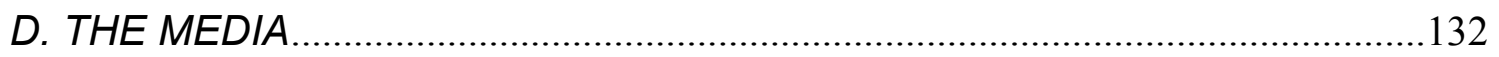

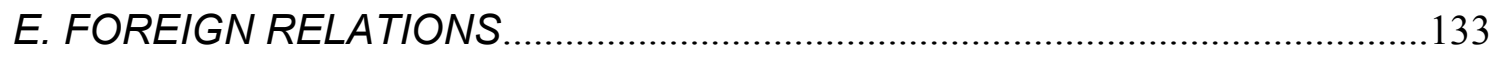

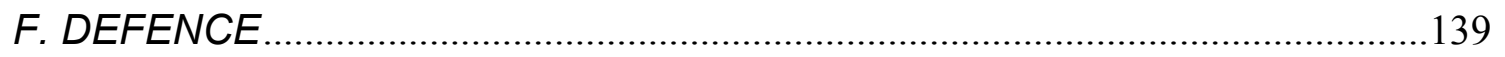

G. NATIONAL LIBERATION, THE DEFENCE OF SOVEREIGNTY AND

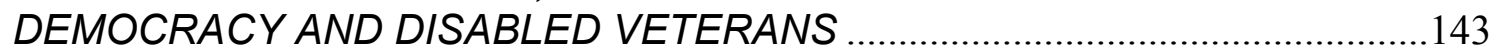

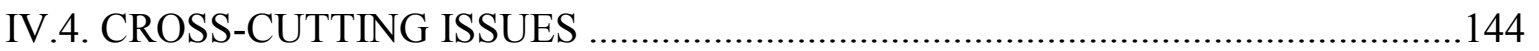

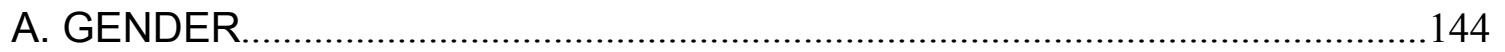

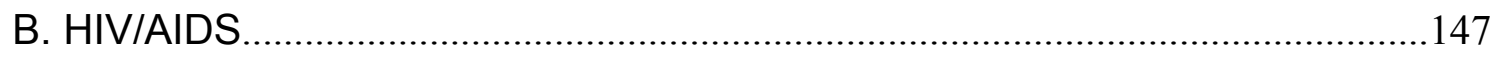

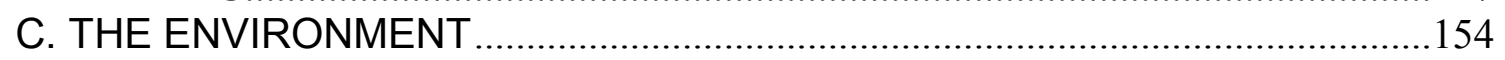

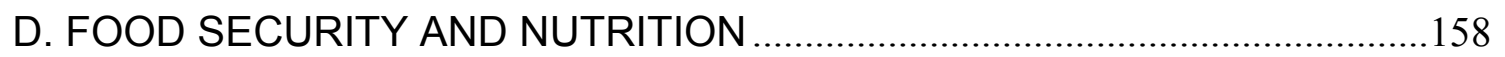

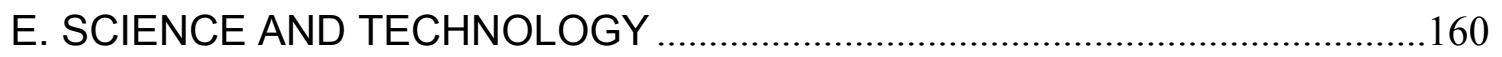

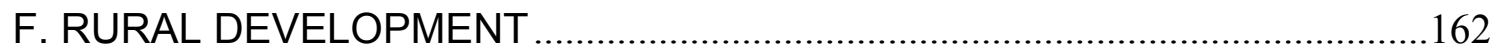

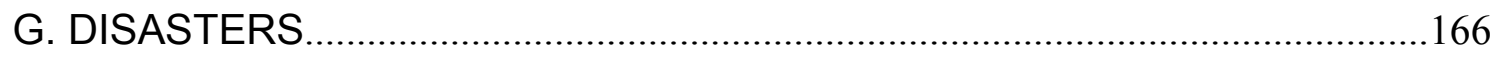

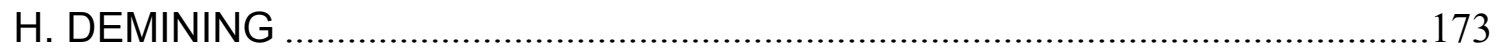

V. PUBLIC FINANCE

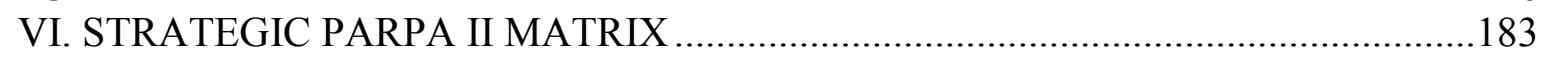


List of Tables

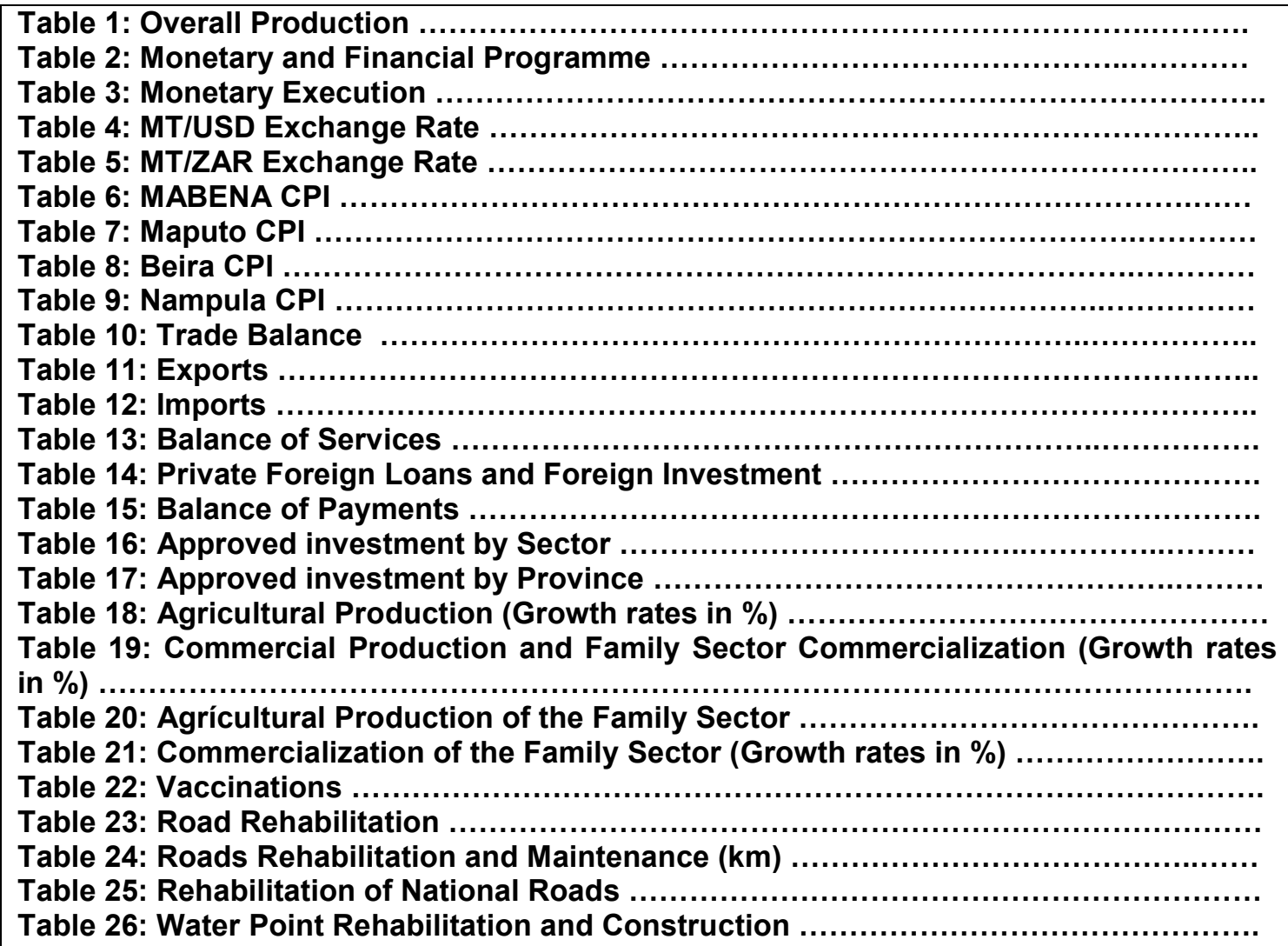

Table 27: Urban Water Supply

Table 28: Overall Fish Productio (Growth rates in \%)

Table 29: Commercial Fish Production

Table 30: Aquaculture Production

Table 31: Traditional Fish Production

Table 32: Mineral Production

Table 33: Evolution of Industrial Production by Division

Table 34: Transport and Communications - Growth rates (\%)

Table 36: Evolution of the Number of Students

Table 37: Evolution of the School Network

Table 38: Number of schools that opened and/or introduced levels of education ...........

Table 39: Evolution of Overall Health Care

Table 40: Evolution of Maternal and Neonatal Health Coverage Rates

Table 41: Evolution of the Coverage Rate of visits of $0-11$ month and $0-4$ year old children

Table 42: Evolution of the PAV Coverage Rates

Table 43: Professional Training of Unemployed Workers

Table 44: Unemployed workers by province

Table 45: Employment of unemployed job seekers

Table 46 Family Location and Reunification Programme

Table 47: Preschool Education

Table 48: Attendance of deprived children in a difficult situation

Table 49: Attendance of elderly

Table 50: Attendance of handicapped persons

Table 51: Social Assistance Programme - Distribution by Province

Table 52: ARVT Indicators

Table 53: VTP Indicators

Table 54: Financing of HIVIAIDS projects 
Table 55: Population in risk of disasters and affected in the 2006/07 season

Table 56: Distribution of Local Disaster Risk Management Committees

Table 57: Emergency food aid supplied to disaster victims

Table 58: Demarcated and attributed plots, until 9 June

Table 59: Construction of houses by province, until 9 November

Table 60: Reconstruction of houses in Maputo City

Table 61: Reconstruction of houses in Maputo Province

Table 62: 2007 Budget Balance

Table 63: 2007 State Revenue

Table 64: Operating Expenditure

Table 65: Investment Expenditure

Table 66: Expenditure in the PARPA Priority Sectors

Table 67: Percentage Distribution of Expenditure in the PARPA Priority Sectors 


\section{INTRODUCTORY NOTE}

This Review of the Economic and Social Plan for 2007 is an evaluation of the implementation of the Five-Year Government Programme for 2005-2009, in its third year of execution.

The document presents the new simplified structure adopted in the Review of the First Half of 2007, and aims at adjusting the Review of the Economic and Social Plan as main monitoring and evaluation instrument of Government action. It consists of 4 big chapters: International Context, National Socio-Economic and Demographic Context, Main Lines of Development by Pillar, and Public Finance.

In the international context the evolution of the international economy is presented, which allows a visualization of the international economic conditions in which the country has implemented its economic and social policy; in the national socioeconomic and demographic context the socio-economic and demographic situation of the country is presented; in the chapter on the main lines of development by pillar the main political measures and activities implemented by the various sectors are presented, including those of a cross-cutting nature.

The cross-cutting issues have a multi-sector dimension and impact, thus going beyond sector level. The evaluation of the activities performed in this area is made in a single chapter, to achieve a better impact visualization. On this basis, the activities of the environment and the science and technology sectors are described in this chapter, in which the activities implemented by the other sectors are equally integrated.

In the chapter on public finance the budget policy is presented, as well as the envelope of resources and their appropriation with a view to the accomplishment of the activities foreseen in the Economic and Social Plan for 2007.

In annex, the strategic PARPA II matrix is presented.

This review evaluates real economic performance with 1996 as base year, considering that the rebasing process of the statistical series to the new 2003 base year is still in progress. Thus, there may be discrepancies of the results here presented compared to those that will be presented by the National Statistics Institute, after the verification of the final results from this new base year.

\section{INTERNATIONAL CONTEXT}

Initially, the estimate for overall economic growth in 2007 was $4.7 \%$. In the second half of 2007 , this estimate was revised upwards to $4.9 \%$ in view of the first half year's performance.

Various economic publications of specialized bodies in the whole world have emphasized the continuation of good global economic performance in the last few years. The IMF (International Monetary Fund), in its April 2007 World Economic Outlook, forecasted an overall GDP growth of $4.9 \%$ in 2007.

The information available for the first half of 2007 shows that in spite of the financial market turbulence, the world economy has grown considerably, with a growth of 
more than $5 \%$. This positive economic performance was basically due to the strong growth occurred in the emerging markets, especially in China, Russia and India.

The IMF points out, however, that the risks related to the financial crisis and the inflationary pressures resulting from the petroleum price volatility have had a negative influence on world economic performance in the course of the second half of 2007. In this context, and according to the IMF, in 2007 the world economy grew by about $5.2 \%, 0.2$ percentage points less than in 2006 .

With respect to the unemployment rate, the preliminary IMF estimates indicate a slight decrease in 2007 for the advanced economies (5.3\%), 0.3 percentage points less than in 2006. By country, it is estimated that in 2007 France had the highest unemployment rate in the euro zone, about $8.6 \%$, followed by Greece $(8.5 \%)$ and Spain (8.1\%). The IMF estimates that in 2007 the unemployment rate in the Netherlands (3.2\%) and in Austria (4.3\%) should be the lowest in the euro zone, similar to the situation of the two previous years.

The monetary policy aimed at the containment of short-term inflationary pressures limited the performance of the main world economies' Central Banks. The monetary policy, unrestricted by inflation-related targets, has contributed significantly to the consolidation of a favourable macroeconomic environment on more distant horizons.

The price of crude attained the historical maximum of about $\$ 100$ per barrel, following the imposition of new sanctions by the USA to Iran (the fourth largest petroleum exporter of the world) and an attack on a Nigerian oil rig, reducing production by 50,000 barrels per day.

Another significant event in 2007 was the financial turbulence occurred in February and March, on account of the Shanghai Stock Exchange crash and the uncertainties relative to the deceleration speed of the North American economy. The Shanghai crisis hit the Asian markets, spread over Europe and reached the North American and the emerging markets. On top of this came the statement of an ex-FED President, pointing out that the North American economy was running the risk of recession.

Among the main risks for global economic performance stand out the following:

- The deceleration of the American economy in view of the housing market behaviour;

- The great financial market volatility, which decreased investment in this area; and

- The inflationary process caused above all by the sudden increase of petroleum prices.

The productivity gains that have sustained good recent economic performance were compromised in 2007 due to:

- the aging of the population and the anti-globalisation movements;

- rapid economic growth of some emerging countries with environmental consequences. 


\section{UNITED STATES OF AMERICA}

Preliminary estimates indicate a 2007 growth for the United States of America in the order of $1.9 \%$, which is a slow-down compared to the previous year, when GDP increased by $2.9 \%$.

The crisis in the North American financial market influenced the nonfulfilment of the targets initially set for 2007 . This crisis had a strong impact on the World Financial Market, with the historical minimum of $\$ 1,4393$ against the euro and a devaluation of the dollar against a basket of main world exchange rates due to the interest rate cutbacks on the part of the North American Federal Reserve.

Performance on the North American housing market increased the preoccupations as to a sudden decline of the North American economy, with reflexes on the world economy.

In October the North American consumers' confidence indicator (University of Michigan) fell more than expected to last year's lowest level, due to preoccupations with the fall of the housing market, which shook the perspectives regarding the country's economic growth.

\section{EURO ZONE}

In the Euro Zone there was a deceleration of growth due to the implementation of public expenditure containment measures and the correction of a few imbalances in the region. GDP growth in 2007 is estimated at 2.5\%. We recall that in 2006 the Euro Zone economy enjoyed a growth of $2.8 \%$.

The appreciation of the Euro against the North American dollar was a hindrance to the development of foreign trade in the Euro Zone, mainly regarding trading relations with the United States of America.

\section{JAPAN}

According to recent estimates in 2007 the Japanese economy grew by $2.0 \%$, after an already moderate growth in $2006(2.2 \%)$.

\section{CHINA}

The economic performance shown by China also deserves attention, as in the last few years it has enjoyed annual growth rates of over $10 \%$. Indeed, GDP in this Asian country increased by $10.4 \%$ and $11.1 \%$ in 2005 and 2006 , respectively. Recent IMF estimates indicate a continuation of the growth grate in 2007 , in the order of $11.5 \%$.

\section{AFRICA}

The year 2007 was important for Africa. The continent continues having one of the highest sustainable growth rates. GDP growth in Sub-Saharan Africa was strong with the lowest inflation rate of the last 30 years.

An average real growth rate of $6 \%$ and a one-digit inflation rate characterize the improvement of the African countries' performance. These targets result from the improvement of policies and structural reform. 


\section{NATIONAL SOCIO-ECONOMIC AND DEMOGRAPHIC CONTEXT}

\section{III.1 EVALUATION OF THE MILLENNIUM DEVELOPMENT OBJECTIVES}

The commitment assumed in the Millennium Declaration, adopted in September 2000 at the Millennium Summit, defines 8 Millennium Development Goals (MDGs) related to 14 targets and 48 indicators to be reached until 2015. They emphasize issues relative to peace, security and development, as well as preoccupations related to the environment, human rights, democracy and good governance.

For the period in analysis, this review presents a summary of the situation of a few selected indicators and a few activities carried out for the accomplishment of the Millennium Development Goals, since the indicators are in general collected annually through the various sector reviews, while others are only verifiable at medium and long term.

\section{Eradicate Extreme Poverty and Hunger}

The main target of this goal is to reduce by half the proportion of people living in extreme poverty or who suffer from hunger.

The incidence of poverty in Mozambique went down from $70 \%$ in 1997 to $54 \%$ in 2003. The current challenge laid down in PARPA II is to reduce poverty to $45 \%$ in 2009. In spite of the significant progress in several areas, there remain enormous challenges to reduce absolute poverty and promote rapid sustainable and comprehensive economic growth, considered an essential aspect related to this and all other MDGs.

From 1996 to 2006 average economic growth amounted to $8 \%$. In 2007 there was a $7.3 \%$ growth (target: $7 \%$ ), in which the growth of agricultural production, the main source of income for the population, amounted to $7.8 \%$ (target: $12 \%$ ).

In 2007, the production of cereals amounted to 2.2 million tons (target: 2.4 million tons) which means a growth of $3.4 \%$ compared to the previous 2005/06 campaign; The production of beans amounted to 367,000 tons (target: 392,000 tons), representing a growth of $0.6 \%$. The production of cassava amounted to about 8.1 million tons (target: 8.2 million tons), representing an increase of $8.1 \%$ (target: $8.4 \%$ ). The production of beef, pork and chickens attained a volume of 19,829.5 tons (target: 14.553 tons), representing a growth in the order of $41 \%$.

In the scope of the reduction of the prevalence and impact of malnutrition and contrary to the plan, the implementation of the Nutritional Observation and Monitoring Posts (2007 target: $55 \%$ of the observation posts operational) did not start, due to the need to revise the proposed methodology. Concerning the creation of capacity for nutritional rehabilitation, in the last quarter of $2007 \ldots$... was realized. In the scope of the Nutritional Rehabilitation Programme (NRP), there is still a need to intensify training in the next few years, so as to cover all districts of the country for the improvement of NRP implementation and the respective monitoring that should be continuous to allow an accurate diagnosis of the current situation of the Programme in the country and evaluate its impact on child malnutrition rates.

\section{Achieve Universal Primary Education}


The target is to ensure that until 2015 all boys and girls complete a full course of primary schooling.

There is significant progress in the country regarding the expansion of education with significant increases of enrolment, of girls as well as boys. At EP1 level, the net enrolment rate increased from $44 \%$ to $88.3 \%$ in 1997 and 2006 , respectively.

In the period in analysis, in terms of schooling coverage, the net schooling rate in Primary Education (EP1+EP2) was $94.1 \%$ (against $88 \%$ planned), with $90.9 \%$ for girls, well above the target of $67 \%$ defined for 2007 . A total of $3,866,906$ students were enrolled in EP1, corresponding to a growth of $7.5 \%$ compared to 2006 . The gross enrolment rate increased from $52.5 \%$ in 2006 to $70.7 \%$ in 2007 , exceeding the plan $(67.3 \%)$ by $3.4 \%$. In Second Level Primary Education, the number of students increased by $24.2 \%$ compared to 2006 , i.e., an addition of more than 120 thousand students compared to the number enrolled in 2006.

\section{Promote Gender Equality and Empower Women}

The target is to reduce gender disparity in all levels of education by 2015, prioritising the primary and secondary levels.

In the scope of the efforts to sensitise people for greater access and retention of girls at school, work was done with School Councils, community leaders and influential people in the communities in 51 districts in which the percentage of girls in primary education was below $45 \%$. In this sense, in the period in analysis the net schooling rate of 6 -year old girls in Grade 1 was $70.0 \%$ in 2007, having exceeded the target by $3.0 \%$ (67\% planned). The percentage of girls concluding EP2 in 2006 was $28.8 \%$.

\section{Reduce Child Mortality}

The target defines the reduction by two thirds of the mortality rate among children under five, by 2015.

From 1997 to 2003, there was a reduction of under fives mortality from 147 to 125 per thousand live births.

In the scope of the improvement of newborn baby care, through the increase of visits, in 2007 the coverage rate of the first preventive visit of 0-11 months old babies was $100 \%$ (exceeding the $98 \%$ planned for 2007 ) and has remained stable from 2005 to 2007 . The coverage for $0-4$ year old children was $59.2 \%$ (against $74 \%$ planned).

In terms of vaccination coverage, with the exception of BCG, the rates decreased slightly compared to the same period of 2006 (the data refer to the first quarter), due to problems in the acquisition and distribution of vaccines, mainly for BCG and VAS, especially to the provinces. In BCG coverage (100\%, against a forecast of $90 \%$ ) there were no big changes in the last two years, which means that although the rate of institutional deliveries is not very high, most of the children are vaccinated. In 2007 there was a decrease of VAS coverage $(93.7 \%$ ) in the order of $7.6 \%$, but this did not compromise the attainment of the 2007 target (75\%). The same tendency occurred regarding DPT/Anti-Polio and $\mathrm{HB}\left(3^{\text {rd }}\right)$, where coverage decreased from $100 \%$ in 2006 to $95 \%$ in 2007 (target $75 \%$ ).

Regarding paediatric ARVT, the expansion is very slow, with only 6,320 children covered in 2007 (target 11,820 children $<15$ years), representing $53 \%$ of the plan. 


\section{Improve Maternal Health}

The target is to reduce by three quarters the maternal mortality rate, by 2015.

The intra-hospital maternal mortality rate has had an upward trend. From January to December 2007 the rate was 198/100,000 live births, against 191/100,000 live births in 2006. This increase may be justified by the fact that more women come to the Health Units due to the improvement of the services provided (BEOC). On the other hand, there has been an effort on the part of the providers to improve service and registration system quality.

In terms of the coverage of deliveries, performance was $51.9 \%$ (against $52 \%$ planned). It should be noted that the coverage of institutional deliveries is a weak point of sexual and reproductive health sector performance and remains a challenge to the sector. In this field the importance of the evaluation of the need for maternal and neonatal health should be reiterated, which among other findings may guide the strategy for the promotion of institutional deliveries.

\section{Combat HIVIAIDS, malaria and other diseases}

The target is to halt and begin to reverse the spread of HIV/AIDS, by 2015. Halt and begin to reverse the incidence of malaria and other major diseases, by 2015.

With a view to the reduction of the weight and impact of malaria, in 2007 the sector continued the vector control programme through intra-domiciliary spraying (PIDOM) (occurred in 45 districts, 1,537,825 houses were covered and $35 \%$ of the population protected, but the targets defined for 2007 were not achieved), larvae control (only Maputo City and Province have been carrying out more or less regular larvae control last year) and the distribution of long-duration mosquito nets (a total of 938,950) where there were no spraying activities. The new standards for handling cases of malaria (change of the $1^{\text {st }}$ and $2^{\text {nd }}$ lines of treatment) were prepared and submitted for approval. The expansion of the Rapid Diagnosis Tests (TDRs) was introduced and started and 2,000,000 tests were distributed.

In the scope of HIVIAIDS, the sector carried out several activities contributing to the strengthening of preventive measures, the expansion of ARVT and VTP. In the period in analysis, there was an increase of the number of ARVT centres in Niassa, Nampula and Gaza Provinces, and the sector now has 211 centres (a number that exceeds the PEN/AIDS target). On the other hand, the number of patients in ARVT also increased from 44,100 to 86,000 (an increase of $51 \%$ ), but the annual target of 96,000 patients was not achieved. Of these, $6,320(7.3 \%)$ are children representing an increase of $54 \%$ compared to 2006 . The ATSs attended 383,301 users $(60 \%$ of them female) from January to September 2007, against 297,623 in the same period of 2006 , representing an increase of $28.8 \%$.

In the scope of the reduction of the weight and impact of tuberculosis (TB), from January to September the cure rate was $82.0 \%$ against $78.9 \%$ in the same period of 2005 , which shows a positive evolution in the order of $3.1 \%$. This improvement is attributed to the implementation of the direct observation of treatment (DOT), which guarantees the regular taking of drugs and greater adherence to the treatment. The DOTs continue in expansion at all levels. Coverage of the institutional DOTs (real access to these services) increased to $76.6 \%$.

\section{Ensure Environmental Sustainability}


The target is to integrate the principles of sustainable development into sector policies and programmes and reverse the loss of environmental resources

Reduce by half the proportion of people without sustainable access to safe drinking water, until 2015

In the last few years, there was significant progress in the approach of the environmental issue as being of a cross-cutting nature. In the period in analysis the Environmental Strategy for Sustainable Development (EADS) was approved as an important document for the orientation and preparation of action plans at sector level, ensuring the integration of the principles of sustainable development.

A total of 1,641 water points (target: 1,055) were also built, of which 182 wells (target: 48) and 1,459 drilled wells (target: 1,007), and 795 wells were rehabilitated (target: 805), which will benefit another 1,1218,000 people (target: 930,000 people), contributing to the increase of the coverage rate from 43.1 to $49.7 \%$.

Regarding sanitation in the rural areas 11,352 improved latrines were built and accounted for, against the 2,000 latrines planned for 2007 at national level, benefiting 56,760 people. There was a significant overall growth of $8.2 \%$ in the period in analysis compared to the same period of the previous year.

\section{Develop a Global Partnership for Development}

The target is to develop an open trading and financial system, based on rules, predictable and non-discriminatory, including a commitment to good governance, development and poverty reduction.

In the scope of the activities of a bilateral and multilateral nature, the period in analysis was characterized by intense political-diplomatic activities, both at presidential, ministerial and technical level, including the accrediting of new ambassadors and/or high commissioners. We should also emphasize the effective participation of the country at international level, especially: the visit of the President of the Republic to Ghana and Ethiopia, where he participated in the celebrations of the $50^{\text {th }}$ Anniversary of Ghana's Independence and in the VIII Ordinary Conference of the African Union, in the meeting of the NEPAD Implementation Committee and in the Forum of Heads of State and Government of the African Peer Review Mechanism (APRM), respectively; to Tanzania where he participated in the Extraordinary Summit of the SADC Organ for Cooperation in the Areas of Policy, Defence and Security, with the objective to analyse the political and security situation in the region; to France, to participate in the work of the $24^{\text {th }}$ Summit of Heads of State and Government of Africa and France; to Norway, Japan and Vietnam in official visits; and to South Africa to participate in the XVII World Economic Forum; visits in the scope of the PALOP-EC Cooperation, to Bissau, Luanda, Praia and Sao Tome for the alignment and strengthening of the PIR PALOP implementation mechanisms.

We should also emphasize the visit in July of His Excellency the President of the Republic to Washington DC to take part in the Compact signing ceremony, in the scope of the Millennium Challenge Account - MCA, at the value of 506.9 million dollar for the next five years, allotted to the financing of development programmes in the areas of Water and Sanitation, Roads and the Private Sector, in Cabo Delgado, Niassa, Nampula and Zambezia Provinces. 
In the same period the country received in official visits the President of the People's Republic of China and the President of Angola, with positive political and economic results for the implementation of the Government's Five-year Plan and PARPA II, resulting in a strengthening of the bonds of friendship and cooperation, which was expressed in the signing of instruments in several areas and in a working visit. A visit of the President of Zimbabwe to Sofala Province, on the occasion of the signing of the Agreement on the Development of the Beira Corridor, between the two countries, as well as the inauguration of the fuel tanks for Zimbabwe.

Also in the sphere of cooperation and negotiation the Mozambique/Malawi, Mozambique/Cuba, Mozambique/China, Mozambique/ Indonesia and Mozambique/ Brazil Mixed Commissions took place

Following the diplomatic activity aimed at the mobilisation of resources to support poverty reduction and development programmes in Mozambique, we should point out the realization of the Joint Review 2007, which was aligned with the realization of the VI Development Observatory, at central level; Participation in the Seminary of the Eastern and Southern African countries about the implementation of the Paris Declaration and about foreign aid management systems.

The National Cooperation Policy project was concluded and filed with the Secretariat of the Council of Ministers.

Participation in the Workshop on: "The Dimensions of Poverty in the SADC Region" with the objective to share information and experiences between the various sectors of the Member States, about better common ways and strategies to be adopted in the region with a view to the eradication of poverty taking into account the Millennium Development Goals (MDGs) and the implementation of the Regional Indicative Strategic Development Plan of SADC (RISDP) and the creation of a Poverty Observatory in the SADC Region.

We should still mention the launching of the "ODAMOZ" cooperation data bank and the management and coordination process between MPD, MINEC and partners.

\section{2 DEMOGRAPHIC IMPACT OF HIV-AIDS}

According to the latest data about the demographic impact of HIVIAIDS in the country, the national prevalence rate remains high $(16 \%)$ and with a tendency to stabilise. In the Central and Northern regions of the country prevalence tends to stabilise, when compared to the Southern region. The highest prevalence is in the Southern Region (21\%), followed by the Central Region (18\%). The Northern Region of the country continues having the lowest rate of prevalence $(9 \%)$.

The III General Census of Population and Housing was taken, the preliminary results of which show that in 2007 Mozambique had a population of 20,530,714 inhabitants, of which $52.3 \%$ are females. Nampula and Zambezia Provinces continue the most populated ones of the country, with $4,076,642$ and 3,832,339 inhabitants, respectively. Niassa Province, in spite of being one of the largest of the country, continues being the least inhabited. It should be noted that, according to the schedule of activities published by INE, the publication of the final results of the III General Census of Population and Housing is expected to be concluded in November 2009. 
According to more current data to which we have access, the number of new cases of HIVIAIDS has doubled in the country, having increased from 30,332 (2006) to 62,633 HIV positive cases in 2007. The situation tends to be more serious in the Southern Region of the country, the provinces of which occupy top positions in terms of prevalence rates. The notified levels of the evolution of the endemic disease are quite preoccupying, taking into account the preventive activities that were performed during the period in analysis with a view to reduce the number of new cases of infection. (For more details see the HIVIAIDS combat and prevention activities in the chapter on cross-cutting issues).

In the scope of the integration of population factors into the development plans the terms of reference were prepared for the production of modules that will guide the integration of demographic variables into the plans.

In order to offer information, education and communication enabling women, men and adolescents to manage their reproductive and sexual life in conformity with their wishes, individual capacities and sense of civic and social responsibility, a study was prepared entitled: The youth and HIVIAIDS: Gender Differences in Mozambique. The methodology to estimate poverty using the Questionnaire of Basic Well-Being Indicators was also improved.

A study was done on women in the informal sector and the vulnerability to HIVIAIDS infection in the Beira Corridor. The production of the final report is in progress.

Similarly, basic studies were done in selected provinces for the expansion of the experience of the Population Programme in Zambezia. At this moment the selection of the province to benefit from the expansion is ongoing.

Similarly, the Terms of Reference were prepared for doing a study in Gaza Province on the analysis of the population concentration pattern and the location of basic social infrastructures. On the other hand, preparations were made for the celebration of the World Population Day, an act that took place on 11 July, with a motto focussing on safe maternity issues. Likewise, the Government participated in the preparation of the report on the State of the African Population in 2006.

In the scope of the reduction of morbidity caused by water-born diseases, an integrated approach of water supply, sanitation and hygiene promotion programmes, the National Sanitation Campaign was launched.

Regarding nationwide activities for the progressive increase of the population's knowledge through the health and education services, awareness-raising activities aimed at parents and communities are ongoing, with a focus on the districts. Similarly, the national programme "a world without secrets", a programme for HIVIAIDS prevention and combat, was implemented and evaluated in Tete, Zambezia and Cabo Delgado Provinces.

In the sphere of the promotion of sector and interdisciplinary coordination for the formulation and implementation of intervention programmes that correspond to the main national preoccupations regarding the population, the school health programme that is ongoing between the Ministry of Education and Culture and the Ministry of Health was reactivated. In this scope, the nutritional strategy for people living with HIVIAIDS was discussed. 


\section{III.3 MAIN OBJECTIVES OF THE ECONOMIC AND SOCIAL PLAN}

The Economic and Social Plan for 2007 defined the following main objectives:

- Achieve an economic growth of about $7.0 \%$;

- Contain the annual average inflation rate at $5.9 \%$;

- Reach a level of 2,292 million dollar of exports of goods, representing a growth of about $9.0 \%$;

- Reach a level of net international reserves that finance about 4 months of imports of goods and services;

- Continue the creation of conditions that make investment in Mozambique attractive, safeguarding however a correct management of the environment;

- Improve the number and quality of the public education, health, water and sanitation, road and energy services;

- Continue the decentralization of the State Budget to the districts.

The Review of the Economic and Social Plan for 2007 indicates the following:

- Growth of the Gross Domestic Product in the order of 7.3\%;

- An average inflation rate (CPI-Maputo) of $8.16 \%$;

- Exports of goods, reported until September, reached a value of about USD 1,843.6 million;

- The balance of net international reserves amounted to USD 1,492 million, in other words, guaranteeing a coverage of 5 months of imports of goods and non-factor services;

- The entry of Investments, measured by the total of Disbursed Private Loans and Direct Foreign Investment, reached until September a value of USD 677.6 million.

The results of the macroeconomic indicators show a positive performance of the country's economy, in spite of the occurrence of natural disasters.

\section{III.4 OVERALL PRODUCTION}

The year 2007 was characterised by the occurrence of adverse climatic conditions, namely, floods, droughts, inundations, storms, cyclones, and extreme high tides, as well as the explosions of the Ammunition Depot in Maputo, causing the loss of lives of more than a hundred of our fellow-citizens, and the displacement of about half a million people and the destruction of public and private socio-economic infrastructures. This situation demanded additional efforts of the Government and other parties involved, with a view to the normalization of economic and social life.

In spite of these occurrences, economic and social activity was positive. As a matter of fact, in 2007 overall production increased by $7.8 \%$ compared to the levels recorded in 2006, thus exceeding the target of $7.2 \%$ laid down in the plan. 
Large contributions to the overall performance were made by agriculture, livestock breeding and silviculture $(8.6 \%)$, construction $(9.9 \%)$, trade $(9.0 \%)$, and transport and communications (20.4\%).

Table 1: Overall Production

\begin{tabular}{|lll|}
\hline PRODUCTION & 2007 PL & 2007 REV \\
\hline AGRICULTURE, LIVEST. BR. AND FISHING & 11.2 & 8.6 \\
Agriculture & 12.2 & 6.7 \\
Livestock Breeding & 9.7 & 33.5 \\
Silviculture and Forest ExpI. & 2.9 & 2.5 \\
FISHING & 3.5 & -3.3 \\
MINING INDUSTRY & 11.0 & 10.0 \\
TRANSFORMING INDÚSTRY & 3.9 & 2.8 \\
ELECTRICITY AND WATER & 9.0 & 8.4 \\
CONSTRUCTION & 8.0 & 9.9 \\
TRADE & 5.5 & 9.0 \\
REPAIR SERVICES & 0.6 & 0.6 \\
RESTAURANTS AND HOTELS & 8.5 & 12.8 \\
TRANSPORT AND COMMUNICATIONS & 14.2 & 20.4 \\
FINANCIAL SERVICES & 2.4 & 2.7 \\
REAL ESTATE RENTING & 2.4 & 2.4 \\
SERVICES PROVIDED TO COMPANIES & 3.5 & 4.0 \\
GOVERNMENT SERVICES & 9.1 & 4.9 \\
OTHER SERVICES & 0.1 & 0.1 \\
\hline TOTAL PRODUCTION & $\mathbf{7 . 2}$ \\
\hline
\end{tabular}

With the exception of fisheries, performance of all productive sectors was good.

\section{III.5 MONETARY AND FOREIGN EXCHANGE SECTOR}

\section{Monetary and Financial Programme}

The financial programme for 2007 determined as final Government targets a real GDP growth of $7.0 \%$ and an annual inflation rate of $6 \%$. In agreement with these objectives laid down in the PES, on the monetary side the following indicators were attached to these targets: 
Table 2: Monetary and Financial Programme

Initial Monetary Programme - 2007

\begin{tabular}{|l|c|}
\hline Description & Programm \\
\cline { 2 - 2 } & December-07 \\
\hline Performance Criteria & Balance (10^3 Mt) \\
\hline Net International Reserves (NIR) - 10^6 USD & 1,182 \\
Monetary Base (MB) & 15,976 \\
M3 & 60,175 \\
Net Credit to Government (NCG) - Flow & $-1,158$ \\
Credit to the Economy (CE) - System & 29,231 \\
\hline & Annual Change of de \\
\hline M3 & Balance \\
MB & $17.2 \%$ \\
CE - System & $14.2 \%$ \\
\hline
\end{tabular}

In view of the evaluation of the performance of the economy in the first half of 2007, in October a revision of the initial targets of the monetary programme was done. The new figures are the ones given in the following table, which also presents the level of accomplishment, on the basis of existing preliminary data:

Table 3: Monetary Execution

Execution of Monetary Programme (Revised) - 2007

\begin{tabular}{|l|c|c|}
\hline \multirow{2}{*}{ Description } & Exugramime & Executed \\
\cline { 2 - 3 } & December-07 & December-07 \\
\hline Perform ance criteria & \multicolumn{2}{|c|}{ Balance in 10^MT } \\
\hline Net International Reserves (NIR) - 10^6 USD & 1,300 & 1,492 \\
Monetary Base (MB) & 17,404 & 17,838 \\
M3 & 64,786 & 65,330 \\
Net Credit to Government (NCG) - Flow & -1.828 & $-1,324$ \\
Credit to the Economy (CE) System & 33,186 & 31,172 \\
\hline M3 & \multicolumn{2}{|c|}{ Annual Change of Balance } \\
MB & $20.9 \%$ & $27.9 \%$ \\
CE - System & $18.1 \%$ & $21.1 \%$ \\
\hline
\end{tabular}

Of the information presented above we point out the following:

- In December 2007 the balance of the Monetary Base amounted to 17,838 million meticais, corresponding to an expansion of $21.1 \%$, against a target of $18.1 \%$;

- The constitution of Net International Reserves exceeded the target of USD 1,492 million by USD 192 million, guaranteeing about 5 months of coverage of total imports of goods and non-factor services, including the operations of large projects;

- The net position of the State vis-à-vis the banking system (NCG) amounted to 1,324 million meticais (data of November), against 1,828 million meticais planned for December. 


\section{Evolution of the Main Monetary Aggregates}

\section{Monetary Base (MB)}

Provisional information shows that at the end of December 2007, the value of this aggregate amounted to 17,838 million meticais, representing an annual growth of $21.1 \%$, an increase of 434 million compared to the target. The behaviour of notes and coins in circulation explains to a great extent the non-accomplishment observed in the aggregate.

The large withdrawals of cash by the Commercial Banks from the Bank of Mozambique as precautionary measure to anticipate their clients' demand for cash, which accelerates in this part of the year as a result of the Christmas and New Year celebrations, which in 2007 coincided with two four-day long weekends. In spite of the enormous effort and investment being done in the national payment system, mainly its technological infrastructure, electronic payments are still in an incipient phase and most of the public is very much inclined to use cash. This phenomenon had already occurred in June 2007, when the 25 June holiday coincided with a long weekend. The fact that the State did a substantial part of its expenditure towards the end of the year also contributed to the acceleration of notes and coins in circulation.

With a view to control the growth of the Monetary Base, the Bank of Mozambique carried out interventions in the interbank, monetary and foreign exchange markets which allowed the drainage of 10,493.21 million meticais, through the sale of USD 461.1 million in the course of the whole year 2007, of which 5,121.51 million were realized in the $2^{\text {nd }}$ half of the year (USD 114.7 million). On the other hand, and in net terms, 2,711.65 million Treasury Bills were issued, of which 1,297.46 million in the second half of the year. In 2007, the sterilization of total liquidity carried out by the central bank amounted to $13,204.86$ million meticais.

During the second half of the year the Bank of Mozambique did not change its intervention interest rates, namely those of the Standing Lending Facility (FPC), of $15.5 \%$, and of the Standing Deposit Facility (FPD), of $10.5 \%$, after the downward adjustment carried out in June 2007.

\section{Net Credit to Government (CLG)}

Preliminary November data reported show that the accumulated CLG flow in the banking system until November 2007, calculated as the difference between the credits granted to Government by the banking system and the Government deposits into the banking system, excluding the deposits consigned to special projects and those resulting from revenues of the concession of the Moatize charcoal exploitation licence to CVRD, represented a savings of about 1,324 million meticais

\section{Net International Reserves (NIR)}

Provisional information shows that the NIR balance at the end of December 2007 amounted to USD 1,492 million, equivalent to about 5 months of imports of goods and non-factor services by the gross reserves, including the large projects. The balance at the end of December corresponds to a constitution of USD 192 million above the target and USD 261 million higher compared to December 2006. This is basically due to the following factors:

On the receipts side: 
- External grants to support the balance of payments - USD 314.4 million;

- External credits - USD 100.7 million

- Miners' income - USD 60.8 million;

- Revenue of investment abroad - USD 79.8 million;

- Receipts in favour of the State - USD 219.1 million;

- Other receipts - USD 86.6 million.

On the outgoings side:

- Sales made by the BM on the $\mathrm{MCl}$ - USD 423.0 million;

- Payments ordered by the State - USD 90.2 million;

- Payment of the external debt service - USD 49.9 million

- Net bank transfers abroad - USD 24.5 million;

- Net foreign exchange loss - USD 15.8 million.

- Other outgoings - USD 33.8 million.

\section{Total Payment Means (Monetary Mass)}

Information available until November 2007 shows that the balance of the broadest monetary aggregate (M3, composed of notes and coins in circulation and total deposits in local and foreign currency) amounted to 65,330 million meticais, equivalent to an accumulated growth of $11,746.3$ million meticais $(21.9 \%)$ and an annual growth of 14,234 million (27.9\%). Deposits in foreign currency increased by USD 280.2 million in the first 11 months of the year (5,920.3 million meticais), thus dominating the accumulated expansion of the M3 aggregate.

In the M2 aggregate, which includes notes and coins in circulation and the M3 components denominated only in meticais, in its turn, there was an accumulated increase of 5,826.1 million meticais (16.8\%), and an annual expansion of 7,621.5 million meticais $(23.1 \%)$.

The more accentuated increase of the deposits in foreign currency until November 2007 determined the increase of its weight in total deposits, having risen from $40.5 \%$ in December 2006 to $43.3 \%$ in November, representing however a slight reduction compared to the $43.8 \%$ weight observed last June.

\section{Retail Interest Rates}

In the retail market, the nominal average interest rates for a one-year maturity, after during the first half year having remained rather stable, showed a downward tendency in the second half, until November, in line with the movements occurred on the Interbank Money Market.

The average interest rate applied by the commercial banks to their clients for loans in local currency - one-year maturity - decreased to $21.4 \%$, in November 2007, after $23.8 \%$ last June and $23.2 \%$ in December 2006, representing a decrease of 240 base points compared to June and of 180 base points compared to December 2006. 
The evolutionary trend of the interest rates of passive operations is contrary to the active rates, taking into account that the average rate of the system for a one-year maturity increased to $12.8 \%$ in November, corresponding to an increase of 50 base points compared to last June and 40 points compared to the levels of December 2006.

With this movement of the interest rates, the spread between the interest rates of active and passive operations, which amounted to $10.8 \%$ in December 2006, decreased to $8.6 \%$ in November 2007.

\section{Credit to the Economy}

The balance of credit to the economy reported at the end of November 2007 amounted to $31,156.31$ million meticais, which compared to December 2006 represents an increase of $3,758.2$ million meticais $(13.7 \%)$ and, compared to November 2006, an increase of 4,036.1 million meticais (14.9\%).

Regarding the credit components, one observes a bigger change of credit denominated in meticais, since its weight in total credit increased from $68.0 \%$ in December 2006 to $73.1 \%$ in November 2007. Credit in foreign currency suffered an accumulated reduction of $4.2 \%$.

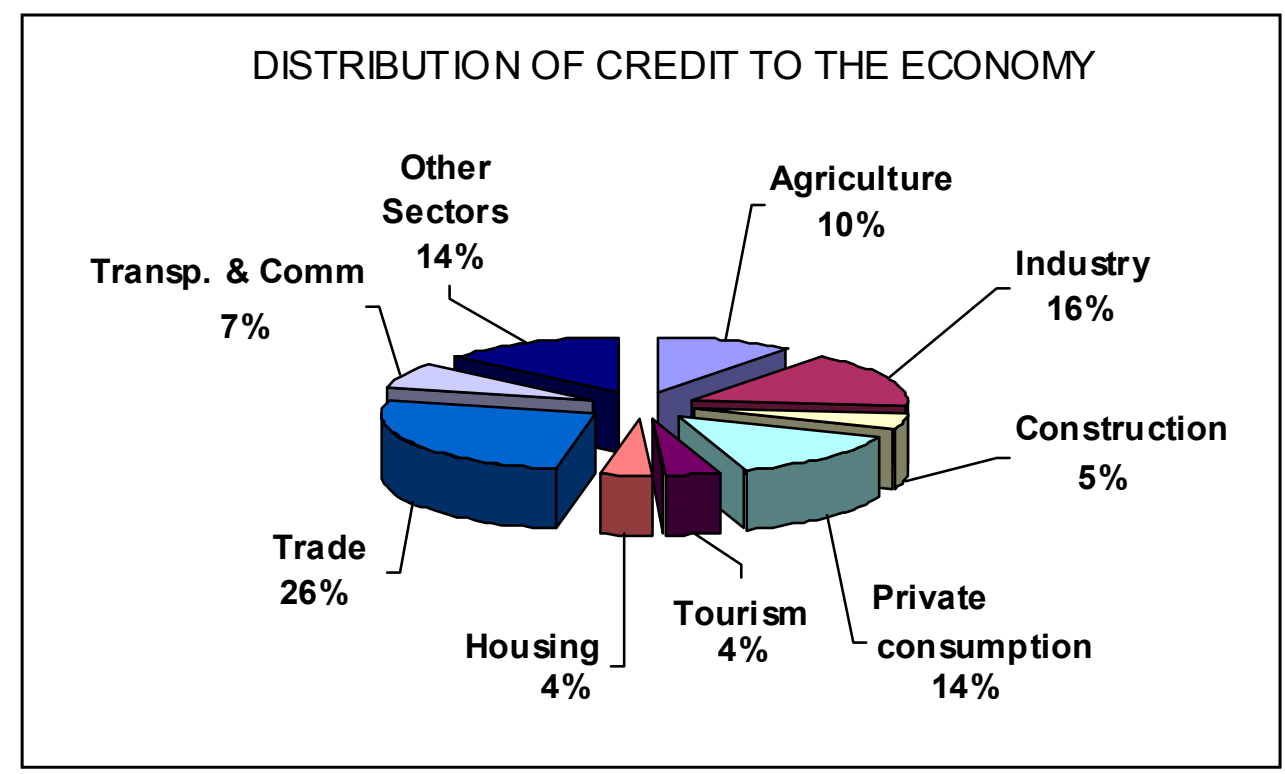

Regarding the distribution of credit by sector, at the end of November 2007 trade benefited from the largest slice, with $26.0 \%$ of the total balance, followed by industry with $16.0 \%$, private consumption with $14 \%$, agriculture with $10.4 \%$, transport and communications with $7.1 \%$ and construction with $4.7 \%$. It should be noted that in the period in analysis the weight of credit to the agricultural sector increased by $2.4 \mathrm{pp}$, compared to June 2007.

\section{Exchange Rate}

In 2007 the Metical enjoyed relative stability with a tendency to appreciate in relation to the American dollar and the South-African rand, compared to December 2006, together with the interventions carried out by the Government on the interbank foreign exchange market, the international tendency of a weakening American dollar. Indeed, on 31 December 2007 the foreign exchange rate in relation to the dollar 
amounted to $23.6 \mathrm{MT} / \mathrm{USD}$, against 25.77 MT/USD on 31 December 2006. In December the average rate of the metical vis-à-vis the American dollar amounted to 24.2 MT/USD, against an average of 26.2 MT/USD in December 2006, as shown by the following table.

Table 4: MT/USD Exchange Rate

FOREX MARKET QUOTATION OF METICAL AGAINST USD

\begin{tabular}{|c|c|c|c|c|c|c|c|c|c|c|c|c|}
\hline ANO & Jan & Fev & Mar & $\mathrm{Abr}$ & Mai & Jun & Jul & Ago & Set & Out & Nov & $\overline{D e z}$ \\
\hline \multicolumn{13}{|c|}{ AV. RATES - MT/USD } \\
\hline 2003 & 23,8 & 23,8 & 23,8 & 23,8 & 23,8 & 23,8 & 23,7 & 23,7 & 23,7 & 23,8 & 23,8 & 23,8 \\
\hline 2004 & 23,7 & 23,8 & 23,8 & 23,8 & 23,7 & 23,4 & 23,0 & 22,7 & 22,2 & 21,0 & 20,3 & 19,3 \\
\hline 2005 & 18,8 & 18,4 & 19,6 & 20,0 & 23,5 & 24,5 & 24,6 & 24,5 & 24,6 & 25,5 & 28,1 & 24,8 \\
\hline 2006 & 23,9 & 24,4 & 25,0 & 25,1 & 25,3 & 25,1 & 25,8 & 25,8 & 26,0 & 26,0 & 26,2 & 26,2 \\
\hline 2007 & 26,1 & 26,2 & 26,2 & 26,3 & 26,3 & 26,1 & 26,0 & 25,8 & 25,9 & 25,8 & 25,2 & 24,2 \\
\hline \multicolumn{13}{|c|}{ ACCUMULATED GROWTH RATE (\%) } \\
\hline 2003 & 0,5 & 0,5 & 0,5 & 0,5 & 0,5 & 0,4 & $-0,1$ & 0,2 & 0,2 & 0,4 & 0,5 & 0,6 \\
\hline 2004 & $-0,6$ & 0,0 & 0,0 & 0,0 & $-0,4$ & $-1,7$ & $-3,3$ & $-4,9$ & $-6,7$ & $-11,9$ & $-14,9$ & $-18,9$ \\
\hline 2005 & $-2,9$ & $-5,0$ & 1,1 & 3,3 & 21,6 & 26,5 & 26,9 & 26,7 & 27,2 & 32,0 & 45,2 & 28,0 \\
\hline 2006 & $-3,4$ & $-1,5$ & 1,1 & 1,4 & 2,1 & 1,5 & 4,1 & 4,3 & 5,0 & 5,2 & 5,8 & 5,7 \\
\hline 2007 & $-0,2$ & 0,3 & 0,3 & 0,6 & 0,5 & $-0,4$ & $-0,8$ & $-1,2$ & $-1,1$ & $-1,2$ & $-3,8$ & $-7,6$ \\
\hline \multicolumn{13}{|c|}{ CORRESP. GROWTH RATE (\%) } \\
\hline 2003 & 2,1 & 1,7 & 1,3 & 0,9 & 0,7 & 0,5 & $-0,2$ & $-0,3$ & $-0,6$ & $-0,7$ & $-0,1$ & 0,6 \\
\hline 2004 & $-0,5$ & 0,1 & 0,1 & 0,1 & $-0,3$ & $-1,4$ & $-2,6$ & $-4,5$ & $-6,3$ & $-11,6$ & $-14,8$ & $-18,9$ \\
\hline 2005 & $-20,7$ & $-22,9$ & $-18,0$ & $-16,2$ & $-0,9$ & 4,4 & 6,5 & 8,1 & 10,6 & 21,6 & 38,6 & 28,0 \\
\hline 2006 & 27,3 & 32,7 & 28,0 & 25,6 & 7,4 & 2,8 & 5,0 & 5,4 & 5,7 & 2,0 & $-6,8$ & 5,7 \\
\hline 2007 & $\overline{9,2}$ & $7 \overline{7,5}$ & 4,9 & 4,8 & 4,1 & 3,7 & $\overline{0,7}$ & $\overline{0,1}$ & $-0,5$ & $-0,8$ & $-3,9$ & $-7,6$ \\
\hline
\end{tabular}

Graphically one can observe that compared to the same period of 2006, the tendency of the dollar was to appreciate, culminating with an accumulated appreciation of $7.6 \%$ in December 2007.

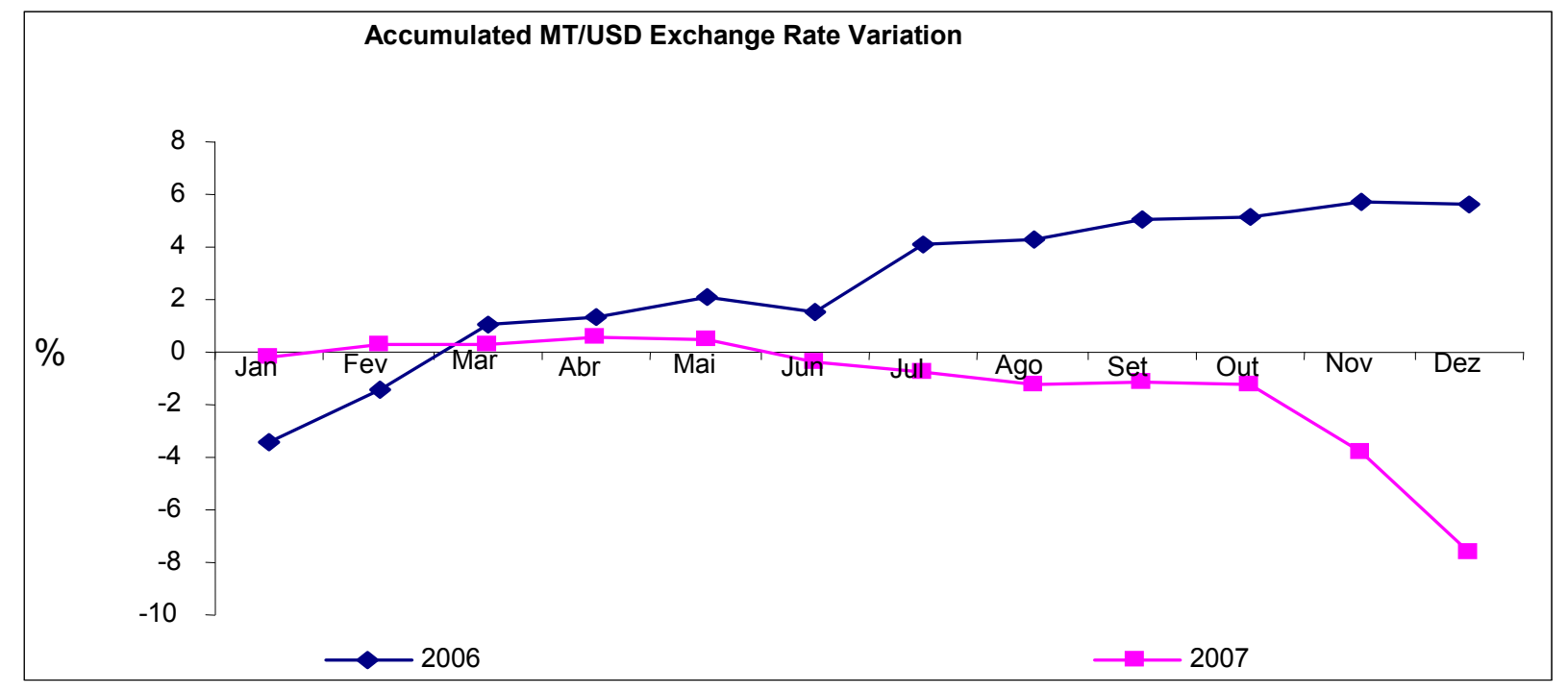

In December the MT/ZAR exchange rate was $3.54 \mathrm{MT} / \mathrm{ZAR}$. Compared to the 3.72 MT/ZAR of December 2006, there was an accumulated appreciation of the metical of $4.9 \%$. 
Table 5: MT/ZAR Exchange Rate

\begin{tabular}{|c|c|c|c|c|c|c|c|c|c|c|c|c|}
\hline YR & Jan & Fev & Mar & $\mathrm{Abr}$ & Mai & Jun & Jul & Ago & Set & Out & Nov & Dez \\
\hline \multicolumn{13}{|c|}{ AVER. RATE - MT/ZAR } \\
\hline 2003 & 2,78 & 2,90 & 3,01 & 3,12 & 3,21 & 3,03 & 3,17 & 3,23 & 3,24 & 3,42 & 3,48 & 3,66 \\
\hline 2004 & 3,51 & 3,53 & 3,61 & 3,67 & 3,52 & 3,61 & 3,72 & 3,61 & 3,45 & 3,36 & 3,38 & 3,39 \\
\hline 2005 & 3,16 & 3,06 & 3,25 & 3,25 & 3,73 & 3,62 & 3,67 & 3,79 & 3,87 & 3,89 & 4,22 & 3,89 \\
\hline 2006 & 3,93 & 3,99 & 4,00 & 4,12 & 4,01 & 3,62 & 3,64 & 3,72 & 3,51 & 3,41 & 3,61 & 3,72 \\
\hline 2007 & 3,64 & 3,67 & 3,57 & 3,70 & 3,75 & 3,64 & 3,73 & 3,58 & 3,64 & 3,83 & 3,75 & 3,54 \\
\hline \multicolumn{13}{|c|}{ ACCUMULATED GROWTH RATE (\%) } \\
\hline 2003 & 3,3 & 8,1 & 11,9 & 16,0 & 19,5 & 12,8 & 18,0 & 20,1 & 20,7 & 27,2 & 29,7 & 36,3 \\
\hline 2004 & $-4,2$ & $-3,6$ & $-1,3$ & 0,3 & $-3,9$ & $-1,5$ & 1,7 & $-1,4$ & $-5,8$ & $-8,3$ & $-7,6$ & $-7,4$ \\
\hline 2005 & $-6,7$ & $-9,8$ & $-4,1$ & $-4,2$ & 9,9 & 6,8 & 8,1 & 11,8 & 14,2 & 14,6 & 24,3 & 14,6 \\
\hline 2006 & 1,0 & 2,7 & 2,9 & 6,0 & 3,1 & $-6,8$ & $-6,4$ & $-4,3$ & $-9,9$ & $-12,3$ & $-7,3$ & $-4,4$ \\
\hline 2007 & $-2,1$ & $-1,4$ & $-4,0$ & $-0,4$ & 0,8 & $-2,0$ & 0,3 & $-3,7$ & $-2,1$ & 2,9 & 0,9 & $-4,9$ \\
\hline \multicolumn{13}{|c|}{ CORRESP. GROWTH RATE (\%) } \\
\hline 2003 & 27,4 & 32,9 & 38,2 & 38,9 & 32,9 & 24,1 & 30,1 & 34,6 & 36,1 & 41,9 & 37,9 & 36,3 \\
\hline 2004 & 26,5 & 21,6 & 20,2 & 17,8 & 9,6 & 19,0 & 17,4 & 11,9 & 6,4 & $-1,8$ & $-2,9$ & $-7,4$ \\
\hline 2005 & $-9,8$ & $-13,3$ & $-10,0$ & $-11,5$ & 5,9 & 0,5 & $-1,5$ & 5,0 & 12,3 & 15,8 & 24,7 & 14,6 \\
\hline 2006 & 24,1 & 30,5 & 23,0 & 26,9 & 7,6 & 0,0 & $-0,7$ & $-1,9$ & $-9,5$ & $-12,2$ & $-14,5$ & $-4,4$ \\
\hline 2007 & $-7,3$ & $-8,2$ & $-10,8$ & $-10,2$ & $-6,5$ & 0,6 & 2,4 & $-3,8$ & 3,8 & 12,1 & 4,1 & $-4,9$ \\
\hline
\end{tabular}

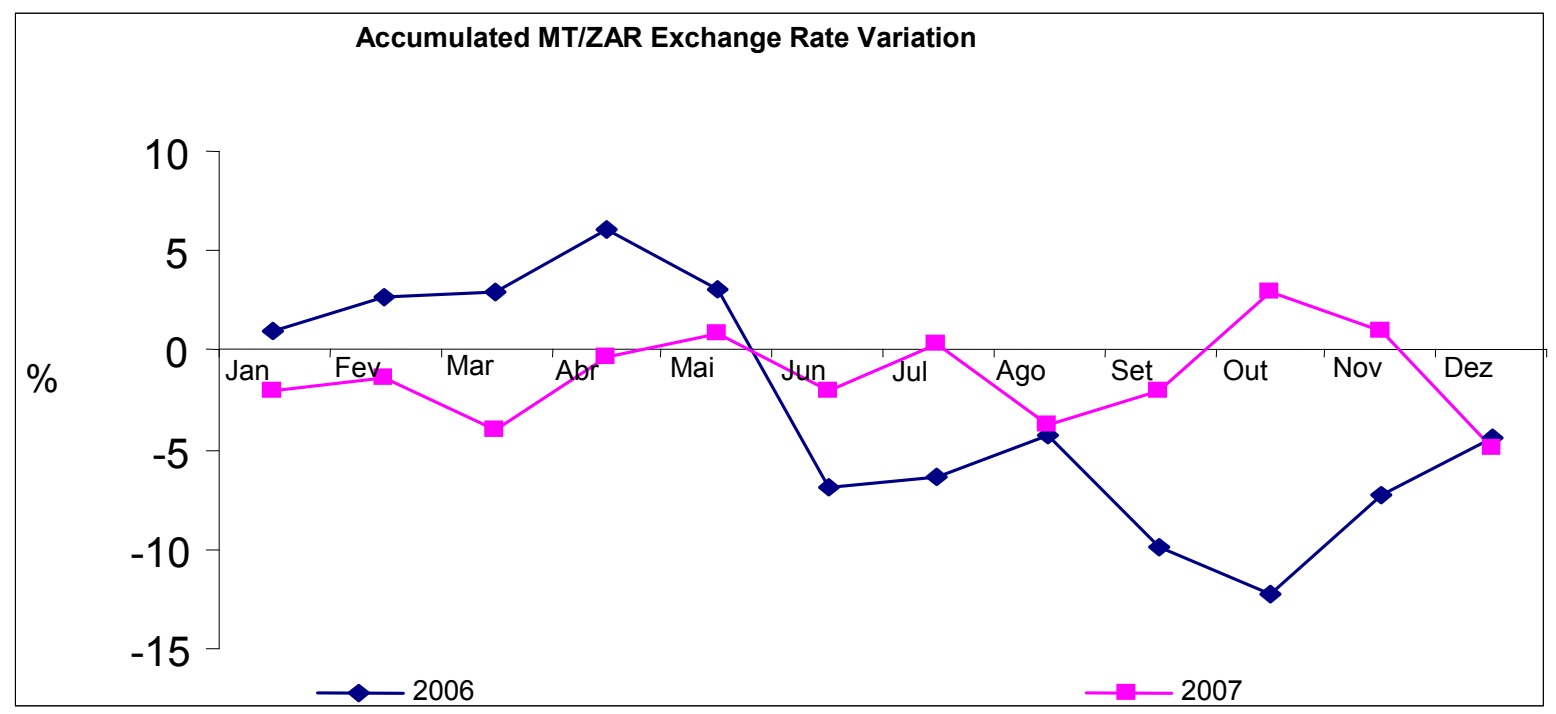

\section{Policy Measures}

With a view to increase transparency in the management of monetary policy in conformity with international practice in this field, the medium and long term Monetary Policy Strategy was launched and made available on the Bank of Mozambique's Website, and in June the Monetary Policy Committee Regulation was amended. The Committee now publishes its deliberations after each session, thus increasing monetary policy's transparency and communication.

In the course of the second half-year, the Monetary Policy Committee recommended that the interventions on the interbank markets should be intensified, with a view to control the Monetary Base to levels in agreement with the defined inflation objectives. This allowed a continued stability of the Metical, in a scenario of fully functioning market conditions and foreign exchange sales satisfying demand, resulting in an appreciation of the metical in relation to the dollar and to the rand of $8.3 \%$ and $5.6 \%$, respectively. This factor allowed the mitigation of the increase of imported goods prices. 
Within the strategy to expand financial services to the rural areas, the Bank of Mozambique published Notice 10/GBM/2007, of 25 May, establishing a special regime applicable to micro-finance banks and institutions intending to expand their activities to the rural areas, through the establishment of branches or other forms of representation, in addition to the approval of Notice 02/GGBM/2007, changing the Compulsory Reserves regime. Important provisions of this last measure are the reduction of the compulsory reserves coefficient from $11.51 \%$ to $10.15 \%$, the inclusion of cash kept in branch offices located in rural areas in assets eligible to compulsory reserves constitution, and the enlargement of the base of incidence to all liabilities held by the credit institutions, excluding those deriving from other institutions' appropriations on the MMI.

The response of the credit institutions and finance companies to the challenge of the enlargement of financial services to rural and peri-urban areas was quite positive. The establishment of 40 new commercial bank counters was authorized, thus enlarging the coverage of the banking network to 32 districts and increasing the network of ATMs, electronic payment posts (POS) and the number of bank accounts.

The Bank of Mozambique opened Branches in Tete, Pemba and Lichinga, thus enlarging its network to eight provinces of the country. Two new credit institutions (Banco terra and Moza Banco) were also authorized to operate on the market

In 2007, the Bank of Mozambique continued with the reforms of the financial system, through the publication of several normative documents, with a view to confer greater effectiveness to the national payment system, turn the interbank markets more operational and improve the companies' financial reporting system through the introduction of the International Financial Reporting Standards (IFRS) for the entire banking system

\section{III.6. INFLATION}

An analysis, based on the aggregate index known as MABENA, of the evolution of inflation during the year 2007, shows an accumulated (annual) inflation of about $12.10 \%$. This behaviour can be explained by the price increase trend in the course of almost all months of the year, particularly January (1.37\%), February $(1.38 \%)$, October (1.32\%), November (1.90\%) and December (3.19\%).

In general, the reasons of inflation in 2007 subdivide into two groups of factors: external and domestic ones.

The external shocks, with impact on the increase of international commodity prices, namely petroleum and its derivatives, cereals and oleaginous products. As a matter of fact:

- The international petroleum price, which at the end of December 2006 amounted to USD 53.8 per barrel, ended the year 2007 at the level of USD 90.84 , representing an increase of about $67 \%$ - when in the assumptions underlying the definition of macroeconomic indicators for the PES 2007 an increase of only $3 \%$ was anticipated - with a very considerable impact on worldwide transport costs and from there on direct costs of production;

- The average price of number 1 wheat, which in December 2006 amounted to USD 242 per ton, ended the year 2007 at the level of USD 435 per ton, representing an increase of $43 \%$, com impact on the domestic prices of bread, 
pasta, animal feed and other derivatives. The price of number 2 wheat increased by $81 \%$, from USD 229 to USD 415;

- In December 2006 the average CIF price of current rice amounted to USD 317 per ton, having increased to USD 400 in December 2007;

- The difficulties in the supply of horse mackerel on the part of Namibia, traditional source of this product for the Maputo City consumers, led to a shift of demand to more distant markets, namely Chile, Peru and New Zealand, which supply more expensive horse mackerel, with implications for domestic prices;

- The escalation of the international prices of cereals and oleaginous products, mainly resulting from the supply crisis, coincided with the reduction of grants in goods on the part of the United States of America (wheat) and Japan (rice), which resulted in an increase of the commercial component of imports by the private sector, with implications for domestic prices;

- The acceleration of the inflation in the Republic of South Africa, one of the main sources of imports of food products with an important weight in the CPI basket. As a matter of fact, in November consumer inflation in South Africa amounted to $8.4 \%$, exceeding the top level of the $3-6 \%$ variation band stipulated as target for that country, while producer inflation amounted to 9.1\%;

- A particular aspect of the relatively high weight of the above-mentioned products in the CPI basket is that it brought about a change in its seasonal behaviour. Indeed, the customary reduction of prices observed between the months of January and March did not occur in 2007. Prices had a systematic upward trend during the whole year.

\section{At domestic level:}

- In December there were a few difficulties in supplying the market with products such as chickens and eggs, due to adverse climatic conditions that affected chicken growth and a heat wave that led to the death of about 23,000 laying hens;

- The lack of storage capacity for frozen products, such as horse mackerel and chickens, has also contributed to the depletion of their stocks at the end of the year, a time of high consumption, in which suppliers give priority to the large consumer markets;

- The concentration of consumers' expenses around the Christmas and New Year season favoured a speculative behaviour on the part of some traders.

- The deficiencies of the trading circuits in Maputo City also played a role, particularly in December, resulting in a fictitious supply deficit, mainly at retail level, and in serious differences between wholesale and retail prices. Only in this way can the sharp increase of the retail price of tomatoes and potatoes be explained, even when supply was regular, resulting in unchanged wholesale prices. 
Table 6: MABENA CPI

PRICE INDEX - MABENA - BASE DEC $2004=100$

\begin{tabular}{|c|c|c|c|c|c|c|c|c|c|c|c|c|}
\hline & JAN & FEV & MAR & $\mathrm{ABR}$ & $\overline{\mathrm{MAI}}$ & JUN & JUL & AGO & SET & OUT & NOV & $\overline{D E}$ \\
\hline \multicolumn{13}{|l|}{ INDEX: } \\
\hline 2004 & 94,23 & 95,06 & 96,03 & 96,78 & 96,99 & 96,69 & 97,01 & 96,95 & 96,98 & 97,56 & 98,09 & 100,00 \\
\hline 2005 & 100,97 & 100,41 & 100,47 & 100,37 & 100,46 & 101,82 & 103,86 & 104,20 & 104,14 & 104,76 & 108,82 & 113,07 \\
\hline 2006 & 115,77 & 118,25 & 118,44 & 117,80 & 116,27 & 116,06 & 115,93 & 6,25 & 117,45 & 118,11 & 119,61 & 112,26 \\
\hline 2007 & 123,94 & 125,65 & 126,16 & 126,94 & 127,52 & 127,10 & 127,39 & 128,24 & 128,63 & 130,33 & 132,81 & 137,05 \\
\hline \multicolumn{13}{|c|}{ CHAIN RATE OF CHANGE (\%): } \\
\hline 2004 & 3,04 & 0,88 & 1,02 & 0,78 & 0,21 & $-0,30$ & 0,33 & $-0,06$ & 0,04 & 0,60 & 0,55 & 1,94 \\
\hline 2005 & 0,97 & $-0,56$ & 0,06 & $-0,11$ & 0,09 & 1,35 & 2,00 & 0,33 & $-0,06$ & 0,60 & 3,87 & 3,90 \\
\hline 2006 & 2,39 & 2,14 & 0,16 & $-0,53$ & $-1,30$ & $-0,20$ & $-0,11$ & 0,28 & 1,03 & 0,56 & 1,27 & 2,21 \\
\hline 2007 & 1,37 & 1,38 & 0,41 & 0,62 & 0,46 & $-0,33$ & 0,22 & 0,67 & 0,30 & 1,32 & 1,90 & 3,19 \\
\hline \multicolumn{13}{|c|}{ CORRESPONDING GROWTH RATE (\%): } \\
\hline 2004 & 13,76 & 12,98 & 12,12 & 11,99 & 11,66 & 11,56 & 11,50 & 11,08 & 10,69 & 10,57 & 10,26 & 9,35 \\
\hline 2005 & 7,15 & 5,63 & 4,62 & 3,71 & 3,58 & 5,30 & 7,06 & 7,49 & 7,38 & 7,38 & 10,93 & 13,07 \\
\hline 2006 & 14,66 & 17,76 & 17,88 & 17,37 & 15,73 & 13,98 & 11,62 & 11,57 & 12,78 & 12,74 & 9,92 & 8,13 \\
\hline 2007 & 7,05 & 6,26 & 6,52 & 7,76 & 9,68 & 9,52 & 9,88 & 10,31 & 9,52 & 10,34 & 11,03 & 12,10 \\
\hline \multicolumn{13}{|c|}{ ACCUMULATED ANNUAL GROWTH RATE (\%): } \\
\hline 2004 & 3,04 & 3,94 & 5,01 & 5,82 & 6,05 & 5,73 & 6,07 & 6,01 & 6,05 & 6,68 & 7,26 & 9,35 \\
\hline 2005 & 0,97 & 0,41 & 0,47 & 0,37 & 0,46 & 1,82 & 3,86 & 4,20 & 4,14 & 4,76 & 8,82 & 13,07 \\
\hline 2006 & 2,39 & 4,58 & 4,75 & 4,18 & 2,83 & 2,64 & 2,64 & 2,82 & 3,87 & 4,46 & 5,79 & 8,13 \\
\hline 2007 & 1,37 & 2,77 & 3,19 & 3,83 & 4,31 & 3,96 & 4,19 & 4,89 & 5,21 & 6,60 & 8,63 & 12,09 \\
\hline
\end{tabular}

Data collected in December 2007 in Maputo, Beira and Nampula City show an increase of the overall price level in the order of $3.19 \%$, compared to the previous month

The division of food and non-alcoholic beverages, with a positive monthly price variation of $5.13 \%$, was the main contributor to the general level of price escalation occurred, by contributing to total monthly inflation with about 2.94 positive percentage points.

Price variations of tomatoes (28.4), horse mackerel (13.0\%), coconuts $(18.5 \%)$, live chickens $(6.3 \%)$, cooking oil $(7.0 \%)$, spaghetti $(17.1 \%)$ and wheat bread $(1.8 \%)$, contributed to the total monthly inflation of 2.17 positive percentage points.

In 2007 the division of food and non-alcoholic beverages imposed the general price escalation during the year, contributing to total accumulated inflation with about 8.99 positive percentage points. 


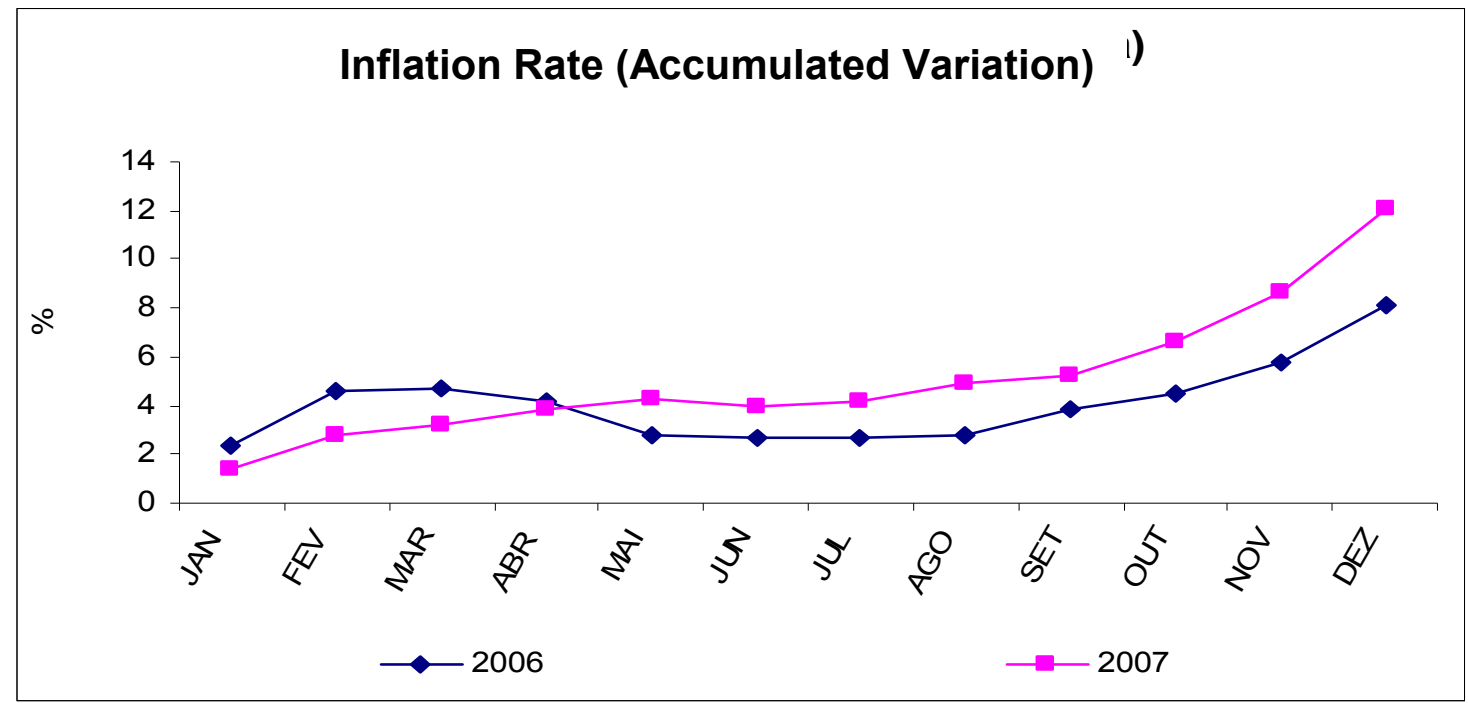

Data collected in Maputo City show the occurrence of an accumulated inflation of $10.26 \%$. In the course of the month of December 2007 there was an increase of the general price level in the order of $2.77 \%$ compared to the previous month

The division of food and non-alcoholic beverages, with a positive monthly price variation of $4.88 \%$, was the main contributor to the general level of price escalation occurred, by contributing to total monthly inflation with about 2.60 positive percentage points.

Table 7: Maputo CPI

PRICE INDEX - MAPUTO - BASE DEC 2004 = 100

\begin{tabular}{|c|c|c|c|c|c|c|c|c|c|c|c|c|}
\hline & JAN & FEV & MAR & ABR & MAI & JUN & JUL & AGO & SET & OUT & NOV & DEZ \\
\hline \multicolumn{13}{|l|}{ INDEX: } \\
\hline 2004 & 94,33 & 94,76 & 95,71 & 96,99 & 97,60 & 97,53 & 97,54 & 97,06 & 96,91 & 97,50 & 98,55 & 100,00 \\
\hline 2005 & 101,46 & 100,64 & 100,90 & 100,66 & 100,73 & 101,40 & 104,24 & 104,49 & 103,48 & 103,76 & 106,45 & 111,15 \\
\hline 2006 & 113,14 & 115,98 & 117,71 & 117,84 & 116,52 & 116,30 & 115,78 & 115,55 & 116,57 & 117,41 & 119,11 & 121,57 \\
\hline 2007 & 122,40 & 122,29 & 123,46 & 124,96 & 126,22 & 126,07 & 126,34 & 126,99 & 126,81 & 128,03 & 130,43 & 134,04 \\
\hline \multicolumn{13}{|c|}{ CHAIN RATE OF CHANGE (\%): } \\
\hline 2004 & 2,88 & 0,46 & 1,00 & 1,34 & 0,63 & $-0,07$ & 0,01 & $-0,49$ & $-0,16$ & 0,61 & 1,07 & 1,48 \\
\hline 2005 & 1,46 & $-0,81$ & 0,26 & $-0,24$ & 0,07 & 0,67 & 2,80 & 0,24 & $-0,96$ & 0,27 & 2,59 & 4,41 \\
\hline 2006 & 1,79 & 2,51 & 1,49 & 0,11 & $-1,12$ & $-0,19$ & $-0,45$ & $-0,20$ & 0,89 & 0,72 & 1,44 & 2,07 \\
\hline 2007 & 0,69 & $-0,09$ & 0,96 & 1,22 & 1,01 & $-0,12$ & 0,21 & 0,52 & $-0,14$ & 0,96 & 1,88 & 2,77 \\
\hline \multicolumn{13}{|c|}{ CORRESPONDING GROWTH RATE (\%): } \\
\hline 2004 & 17,40 & 15,27 & 13,49 & 13,60 & 12,46 & 13,26 & 13,32 & 12,04 & 11,06 & 10,63 & 10,84 & 9,07 \\
\hline 2005 & 7,56 & 6,20 & 5,43 & 3,78 & 3,20 & 3,96 & 6,86 & 7,65 & 6,79 & 6,42 & 8,02 & 11,15 \\
\hline 2006 & 11,51 & 15,25 & 16,66 & 17,07 & 15,69 & 14,70 & 11,08 & 10,58 & 12,65 & 13,16 & 11,89 & 9,37 \\
\hline 2007 & 8,19 & 5,43 & 4,88 & 6,04 & 8,32 & 8,40 & 9,12 & 9,91 & 8,79 & 9,04 & 9,51 & 10,26 \\
\hline \multicolumn{13}{|c|}{ ACCUMULATED ANNAUL GROWTH RATE (\%): } \\
\hline 2004 & 2,88 & 3,36 & 4,39 & 5,79 & 6,45 & 6,37 & 6,39 & 5,86 & 5,69 & 6,34 & 7,48 & 9,07 \\
\hline 2005 & 1,46 & 0,64 & 0,90 & 0,66 & 0,73 & 1,40 & 4,24 & 4,49 & 3,48 & 3,76 & 6,45 & 11,15 \\
\hline 2006 & 1,79 & 4,35 & 5,91 & 6,02 & 4,84 & 4,64 & 4,17 & 3,96 & 4,88 & 5,63 & 7,16 & 9,37 \\
\hline 2007 & 8,19 & 5,43 & 4,88 & 6,04 & 8,32 & 8,40 & 9,12 & 9,91 & 8,79 & 9,04 & 9,51 & 10,26 \\
\hline
\end{tabular}

It should be noted that the price evolution of the division of food and non-alcoholic beverages in the course of the year was identical to the evolution of the general price level, thus showing its relative importance for general price behaviour. 
Price variations of tomatoes (19.8), live chickens (14.0\%), coconuts $(28.6 \%)$, horse mackerel $(8.2 \%)$, spaghetti $23.6 \%)$, bread $(2.3 \%)$ and rice $(1.2 \%)$, contributed to the total monthly inflation of 1.97 positive percentage points.

Data collected in the course of the year 2007 show an accumulated (annual) inflation of about $10.26 \%$. This behaviour is explained by the price escalation trend during almost every month of the year, especially in April (1.22\%), November (1.88\%) and December $(2.77 \%)$.

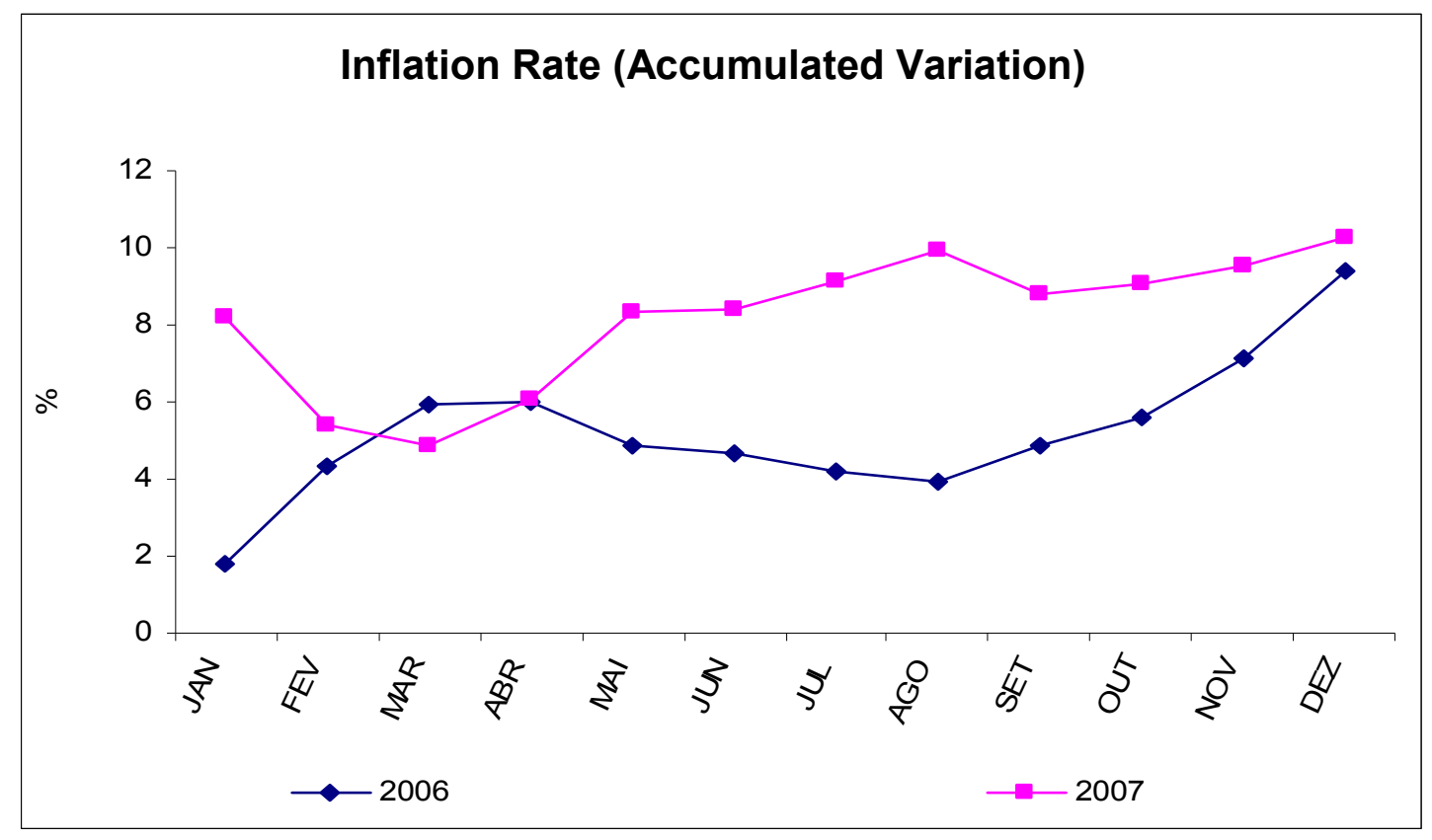

During the year 2007 the division of food and non-alcoholic beverages imposed the general price escalation, contributing to total accumulated inflation with about 7.59 positive percentage points.

The annual price variation of bread $(23.7 \%)$, horse mackerel $(40.5 \%)$, rice $(12.2 \%)$, onions $(39,8 \%)$, fresh, refrigerated or frozen fish $(25.0 \%)$, firewood $(27.1 \%)$ and Irish potatoes $(33.5 \%)$, contributed to total accumulated inflation with 5.20 positive percentage points.

Taking the average 12-month price variation as reference, annual inflation in Maputo City was $8.16 \%$, equivalent to 5.09 percentage points less than in the same period of 2006.

The average variation of the division of food and non-alcoholic beverages was in the order of $9.01 \%$.

In Beira City, accumulated inflation reached $14.78 \%$. In the course of the month of December 2007 there was an increase of the general price level of $4.81 \%$.

The division of food and non-alcoholic beverages, with a positive monthly price variation of $7.66 \%$, was the main contributor to the general price escalation level occurred, contributing to total monthly inflation with about 4.38 positive percentage points. 
It should be noted that the price evolution of the division of food and non-alcoholic beverages in the course of the year was identical to the evolution of the general price level, thus showing its relative importance for general price behaviour.

The price variations of coconuts $(55.8 \%)$, tomatoes $(40.0 \%)$, cooking oil $(6.95 \%)$, fresh, refrigerated or frozen goat's meat $(11.4 \%)$, chicken eggs $(42.4 \%)$, fresh, refrigerated or frozen horse mackerel $(5.2 \%)$, and rice $(3.8 \%)$, contributed to total monthly inflation with 3.20 positive percentage points.

\section{Table 8: Beira CPI}

PRICE INDEX - BEIRA - BASE DEC $2004=100$

\begin{tabular}{|c|c|c|c|c|c|c|c|c|c|c|c|c|}
\hline & JAN & FEV & MAR & $\mathrm{ABR}$ & $\mathrm{MAl}$ & JUN & JUL & AGO & SET & OUT & NOV & DEZ \\
\hline \multicolumn{13}{|l|}{ INDEX: } \\
\hline 2004 & 94,87 & 96,62 & 97,74 & 97,80 & 97,46 & 96,90 & 97,83 & 98,23 & 98,38 & 98,86 & 98,75 & 100,00 \\
\hline 2005 & 100,70 & 100,62 & 100,16 & 99,46 & 99,11 & 99,81 & 100,60 & 100,82 & 101,71 & 102,47 & 106,08 & 109,39 \\
\hline 2006 & 113,42 & 114,49 & 113,35 & 112,08 & 112,15 & 112,48 & 112,55 & 113,21 & 114,01 & 114,34 & 114,84 & 118,85 \\
\hline 2007 & 121,82 & 124,65 & 126,14 & 126,24 & 126,69 & 123,21 & 122,71 & 122,86 & 125,50 & 130,16 & 126,93 & 136,42 \\
\hline \multicolumn{13}{|c|}{ CHAIN RATE OF CHANGE (\%): } \\
\hline 2004 & 2,90 & 1,84 & 1,16 & 0,06 & $-0,35$ & $-0,58$ & 0,96 & 0,41 & 0,14 & 0,49 & $-0,11$ & 1,27 \\
\hline 2005 & 0,70 & $-0,07$ & $-0,46$ & $-0,70$ & $-0,35$ & 0,70 & 0,79 & 0,22 & 0,88 & 0,74 & 3,53 & 3,12 \\
\hline 2006 & 3,68 & 0,94 & $-0,99$ & $-1,13$ & 0,06 & 0,30 & 0,06 & 0,58 & 0,71 & 0,29 & 0,43 & 3,49 \\
\hline 2007 & 2,50 & 2,33 & 1,19 & 0,08 & 0,35 & $-2,75$ & $-0,40$ & 0,12 & 2,14 & 1,14 & 2,55 & 4,81 \\
\hline \multicolumn{13}{|c|}{ CORRESP. GROWTH RATE (\%): } \\
\hline 2004 & 11,62 & 13,60 & 13,20 & 12,31 & 11,01 & 8,95 & 9,14 & 9,84 & 10,13 & 9,93 & 8,96 & 8,46 \\
\hline 2005 & 6,14 & 4,14 & 2,47 & 1,70 & 1,70 & 3,00 & 2,83 & 2,63 & 3,39 & 3,65 & 7,43 & 9,39 \\
\hline 2006 & 12,64 & 13,78 & 13,18 & 12,69 & 13,15 & 12,69 & 11,88 & 12,29 & 12,10 & 11,59 & 8,25 & 8,65 \\
\hline 2007 & 7,40 & 8,88 & 11,28 & 12,64 & 12,97 & 9,54 & 9,03 & 3,53 & 10,07 & 11,00 & 13,34 & 14,78 \\
\hline \multicolumn{13}{|c|}{ ACCUMULATED ANNUAL GROWTH RATE (\%): } \\
\hline 2004 & 2,90 & 4,80 & 6,01 & 6,07 & 5,70 & 5,10 & 6,10 & 6,54 & 6,70 & 7,22 & 7,10 & 8,46 \\
\hline 2005 & 0,70 & 0,62 & 0,16 & $-0,54$ & $-0,89$ & $-0,19$ & 0,60 & 0,82 & 1,71 & 2,47 & 6,08 & 9,39 \\
\hline 2006 & 3,68 & 4,66 & 3,62 & 2,45 & 2,52 & 2,82 & 2,89 & 3,49 & 4,22 & 4,53 & 4,98 & 8,65 \\
\hline 2007 & 2,50 & 4,88 & 6,13 & 6,22 & 6,60 & 3,67 & 3,25 & 3,38 & 5,59 & 6,80 & 9,51 & 14,78 \\
\hline
\end{tabular}

Data collected in the course of the year 2007 show an accumulated (annual) inflation of about $14.78 \%$. This behaviour is explained by the price escalation trend during almost every month of the year, especially in January $(2.50 \%)$, February $(2.33 \%)$, September $(2.14 \%)$, November $(2.55 \%)$ and December $(4.81 \%)$. 


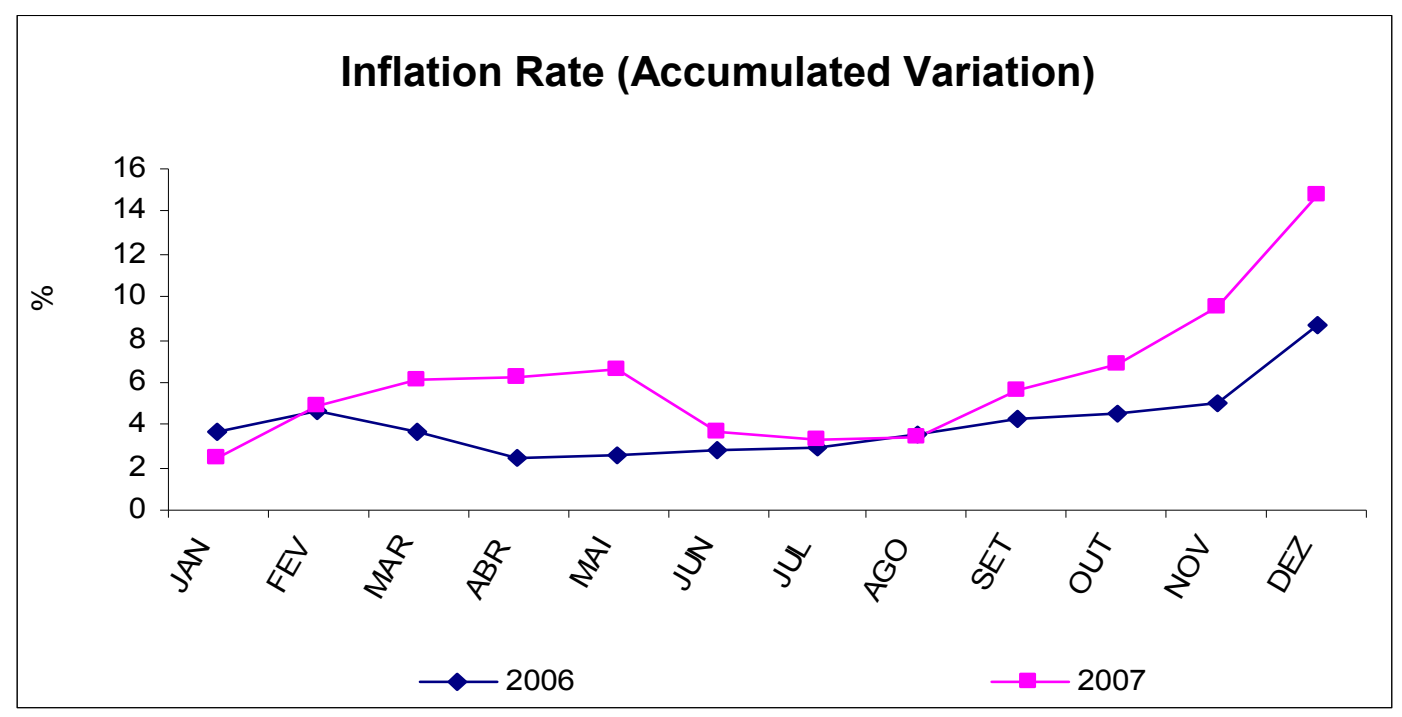

In 2007 the division of food and non-alcoholic beverages imposed the general price escalation during the year, contributing to total accumulated inflation with about 10.51 positive percentage points.

The annual price variations of coconuts $(103.8 \%)$, wheat bread $(50.0 \%)$, cooking oil $(41.7 \%)$, suburban semi-collective passenger transport (Chapa) $(23.8 \%)$, fresh, refrigerated or frozen horse mackerel $(31.3 \%)$, paraffin $(28.4 \%)$, and dried prawns $(69.8 \%)$, contributed to total accumulated inflation with 8.0 positive percentage points.

Taking the average 12-month price variation as reference, annual inflation in Beira City was $10.8 \%$, equivalent to 1.06 percentage points less than in the same period of 2006.

The average variation of the division of food and non-alcoholic beverages was in the order of $11.97 \%$.

In Nampula City accumulated inflation amounted to $13.32 \%$, with a December inflation of $2.65 \%$.

The division of food and non-alcoholic beverages, with a monthly positive price variation of $3.68 \%$, contributed to total monthly inflation with about 2.38 positive percentage points.

The price variations of fresh, refrigerated or frozen horse mackerel $(21.6 \%)$, tomatoes $(37.1 \%)$, onions $(44.3 \%)$, groundnuts $(10.8 \%)$, cooking oil $(11.5 \%)$, wheat bread $(3.2 \%)$ and paraffin $(1.8 \%)$, contributed to the total monthly inflation of 2.69 positive percentage points. 
Table 9: Nampula CPI

PRICE INDEX - NAM PULA - BASE DEC $2004=100$

\begin{tabular}{|c|c|c|c|c|c|c|c|c|c|c|c|c|}
\hline & JAN & FEV & MAR & $\mathrm{ABR}$ & $\overline{M A I}$ & JUN & JUL & AGO & SET & OUT & NOV & $\overline{D E Z}$ \\
\hline \multicolumn{13}{|l|}{ INDEX } \\
\hline 2004 & 92,72 & 93,25 & 93,98 & 94,07 & 93,81 & 93,32 & 93,67 & 94,24 & 94,93 & 95,58 & 95,48 & 100,00 \\
\hline 2005 & 100,26 & 99,79 & 99,92 & 100,60 & 101,12 & 104,40 & 105,98 & 106,60 & 107,53 & 108,71 & 115,80 & 119,98 \\
\hline 2006 & 122,91 & 125,90 & 124,28 & 122,71 & 119,36 & 118,69 & 119,16 & 120,29 & 122,74 & 122,74 & 124,77 & 126,57 \\
\hline 2007 & 128,75 & 133,02 & 131,43 & 131,39 & 130,77 & 132,48 & 133,49 & 135,34 & 134,87 & 137,76 & 139,72 & 143,43 \\
\hline \multicolumn{13}{|c|}{ CHAIN RATE OF CHANGE (\%): } \\
\hline 2004 & 3,78 & 0,57 & 0,79 & 0,09 & $-0,27$ & $-0,53$ & 0,38 & 0,60 & 0,74 & 0,69 & $-0,11$ & 4,73 \\
\hline 2005 & 0,26 & $-0,47$ & 0,13 & 0,68 & 0,52 & 3,24 & 1,51 & 0,59 & 0,87 & 1,10 & 6,52 & 3,62 \\
\hline 2006 & 2,44 & 2,43 & $-1,29$ & $-1,26$ & $-2,73$ & $-0,56$ & 0,39 & 0,95 & 0,49 & 0,49 & 1,65 & 1,44 \\
\hline 2007 & 1,72 & 3,32 & $-1,20$ & $-0,03$ & $-0,48$ & 1,31 & 0,76 & 1,39 & $-0,36$ & 2,14 & 1,43 & 2,65 \\
\hline \multicolumn{13}{|c|}{ CORRESPONDING GROWTH RATE (\%): } \\
\hline 2004 & 4,91 & 3,34 & 4,67 & 5,29 & 9,63 & 10,37 & 9,59 & 10,19 & 10,66 & 11,89 & 10,99 & 11,93 \\
\hline 2005 & 8,13 & 7,01 & 6,32 & 6,94 & 7,79 & 11,88 & 13,14 & 13,12 & 13,27 & 13,73 & 21,27 & 19,98 \\
\hline 2006 & 22,59 & 26,17 & 24,38 & 21,98 & 18,03 & 13,69 & 12,44 & 12,84 & 12,91 & 12,91 & 7,75 & 5,49 \\
\hline 2007 & 4,75 & 5,10 & 5,75 & 7,07 & 9,56 & 11,62 & 12,02 & 12,52 & 10,41 & 12,20 & 11,98 & 13,32 \\
\hline \multicolumn{13}{|c|}{ ACCUMULATED ANNUAL GROWTH RATE (\%): } \\
\hline 2004 & 3,78 & 4,37 & 5,20 & 5,29 & 5,01 & 4,45 & 4,85 & 5,48 & 6,26 & 6,99 & 6,88 & 11,93 \\
\hline 2005 & 0,26 & $-0,21$ & $-0,08$ & 0,60 & 1,12 & 4,40 & 5,98 & 6,60 & 7,53 & 8,71 & 15,80 & 19,98 \\
\hline 2006 & 2,44 & 4,93 & 3,58 & 2,27 & $-0,52$ & $-1,08$ & $-0,69$ & 0,25 & 2,30 & 2,30 & 3,99 & 5,49 \\
\hline 2007 & 1,17 & 5,65 & 3,84 & 3,81 & 3,31 & 4,67 & 5,47 & 6,93 & 6,56 & 8,84 & 10,39 & 13,32 \\
\hline
\end{tabular}

Data collected in the course of the year 2007 show an accumulated (annual) inflation of about $13.32 \%$. The months of February, October and December had the highest levels of price escalation in the course of the year with $3.32 \%, 2.14 \%$ and $2.65 \%$ respectively.

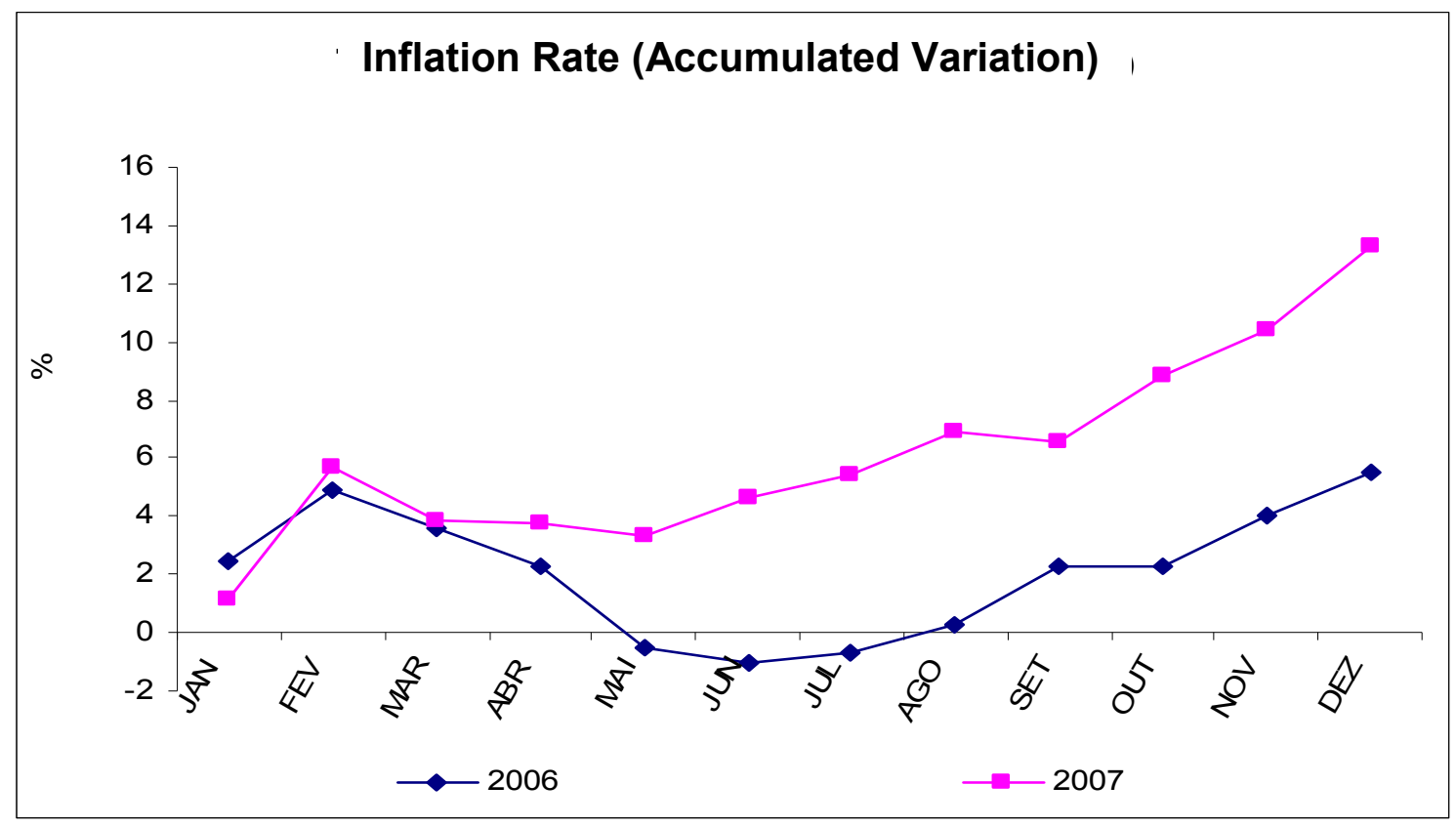

In 2007 the division of food and non-alcoholic beverages imposed the general price escalation during the year, contributing to total accumulated inflation with about 10.34 positive percentage points. 
The annual price variation of horse mackerel $(60.8 \%)$, maize flour $(34.1 \%)$, coconuts $(43.6 \%)$, dried cassava $(42.4 \%)$, paraffin $(28.4 \%)$, wheat bread $(39.1 \%)$, and fresh, refrigerated or frozen prawns $(80.6 \%)$, contributed to total accumulated inflation with 9.71 positive percentage points.

Taking the average 12-month price variation as reference, annual inflation in Nampula City was $9.72 \%$, equivalent to 5.93 percentage points less than in the same period of 2006.

The average variation of the division of food and non-alcoholic beverages was in the order of $11.10 \%$.

\section{III.7. BALANCE OF PAYMENTS}

The information available refers to September 2007.

Following the evolution of the balance of payments in the course of 2007, the PES 2007 targets were adjusted and replaced by those presented in the tables below.

The deficit of the partial goods account, accumulated until September 2007, amounted to about USD 400.9 million, corresponding to $67.2 \%$ of the programme for 2007 (USD 596.7 million), which results in a savings of USD 195.7 million.

Table 10: Trade Balance

\begin{tabular}{lrrrrr}
\multicolumn{7}{c}{ TRADE BALANCE - 10^6USD } \\
\hline \multicolumn{1}{c}{ Trade Balance } & 2004 & 2005 & 2006 & 2007 Progr. & SeP. 2007 \\
\hline \multicolumn{1}{c}{ BALANCE } & $-\mathbf{3 4 5 , 8}$ & $-\mathbf{4 9 7}$ & $\mathbf{- 5 3 3 , 0}$ & $\mathbf{- 5 9 6 , 7}$ & $\mathbf{- 4 0 1 , 0}$ \\
Exports (fob) & 1503,9 & 1745,3 & 2381,1 & 2483,1 & 1843,6 \\
$\quad$ of which Large Projects & 1048,5 & 1262,5 & 1698,8 & 1792,7 & 1411,8 \\
Growth Rate (\%) & 44,1 & 16,1 & 36,4 & 4,3 & \\
Imports (cif) & $-1849,7$ & $-2242,3$ & $-2914,1$ & $-3079,8$ & $-2244,6$ \\
$\quad$ of which Large Projects & $-292,9$ & $-384,3$ & $-701,1$ & $-617,6$ & $-537,2$ \\
\hline
\end{tabular}

The revised programme for 2007 anticipated that Exports of goods until December of that year would attain USD 2,483.1 million as a result of the growth of large project exports of $5.5 \%$ and of exports of the remaining sectors of the economy of $1.2 \%$ compared to 2006. Until September 2007, the value of exports of goods was USD 1,846.6 million, in other words, $74.2 \%$ of what was planned for the whole year 2007 .

Until September 2007, compared to same period of 2006, income from the export of goods increased by $4.1 \%$, particularly the large project exportS which grew by $12.5 \%$, contrary to the remaining sectors of the economy, in which in aggregated terms exports decreased by $16.2 \%$. Consequently, until September 2007, income of goods exported by the large projects and that of the remaining sectors of the economy REACHED $78.7 \%$ and $62.6 \%$, respectively, OF what was planned until December of the same year. 
Table 11: Exports

EXPORTS - 10^6 USD

\begin{tabular}{lrrrr}
\hline & 2004 & 2005 & 2006 & Sep. 2007 \\
\hline \hline Prawns Descript & 91,8 & 70,9 & 102,9 & 54,1 \\
Cashew kernels & 8,0 & 5,5 & 12,6 & 6,3 \\
Cotton & 35,8 & 56,3 & 42,1 & 33,1 \\
Sugar & 38,2 & 37,7 & 71,4 & 49,4 \\
Tobacc & 40,9 & 43,2 & 109,0 & 45,2 \\
Jimber & 30,0 & 32,4 & 46,7 & 27,0 \\
Cashew nuts & 21,2 & 17,6 & 20,5 & 10,8 \\
Electric power & 102,3 & 141,8 & 177,8 & 187,5 \\
Gas \& Condensate & 31,3 & 100,2 & 109,6 & 85,3 \\
Mozal products & 915,0 & 1020,5 & 1401,3 & 1139,0 \\
Non-Monetary gold & 1,3 & 0,5 & 1,7 & 0,8 \\
Other & 180,1 & 206,3 & 295,4 & 205,1 \\
\hline TOTAL & $\mathbf{1 4 9 5 . 9}$ & $\mathbf{1 7 3 2 . 9}$ & $\mathbf{2 3 9 1 . 0}$ & $\mathbf{1 8 4 3 , 6}$ \\
\hline
\end{tabular}

The main factors explaining the increase or reduction of exports per product until September 2007, compared to the same period of 2006, are the following:

- Cashew kernels - a drop of $43.7 \%$, to USD 6.3 million, due to the closure of three cashew nut processing factories in Nampula, occurred at the end of 2006;

- Cotton - a growth of $20.2 \%$, to USD 33.1 million, due to the increase of production in the 2005/2006 agricultural campaign, having attained about 123 thousand tons of cotton, 44 thousand tons more than in the previous campaign, together with the increase of the respective price on the international market by $6.6 \%$;

- Timber - a growth of 53.5\%, to USD 27.0 million, due to the increase of the number of simple licences granted for timber exploitation, as a response to the increase of demand for precious wood of class 2, 3 and 4, which can legally be exported in logs, having China as preferential market;

- Electric power - a growth of $35.5 \%$, to USD 187.5 million, due to the increase of the exported volume by $8.5 \%$. South Africa consumed $79.3 \%$ of total exported power $(7,090.224 .3$ Megawatt in the period in analysis) and the remainder was for Zimbabwe;

- Gas - a growth of $4.9 \%$, to USD 85.3 million. Due to the increase of production to $86,969,427.95$ GJ, $11 \%$ more in relation to the same period of 2006;

- Aluminium ingots - a growth of $10 \%$, to USD 1,139.0 million explained by the price increase of this product on the international market by about $7.3 \%$;

- Prawns - a reduction of $31.8 \%$, to USD 54.1 million, due to the fall of the respective price on the international market.

- Sugar - a reduction of $21 \%$, to USD 49.4 million caused by the decrease of its price on the international free market by $36.7 \%$, combined with the fact that in the same period of 2006 there had been large volumes of sugar in addition to the quotas on the part of USA and European markets. 
- Tobacco - a reduction of $45.7 \%$, to USD 45.2 million due to the reduction of the exported volume of processed tobacco, as the processing company started, from the end of December 2006 onwards, to follow a processing schedule, which foresees an off-season stoppage in the $1^{\text {st }}$ quarter and a restart in April of each year.

- Cashew nuts - a reduction of about $54.6 \%$, to USD 10.8 million resulting from the fall of the average price practiced on the international market and the increase of production in West Africa, the quality of which is considered better than that of Mozambique.

- Re-export of fuels - a reduction of $20.6 \%$, to USD 22.4 million. Zimbabwe, Zambia, Malawi and the Democratic Republic of Congo reduced the volume of purchases of fuels in Mozambique (32,492.7 metric tons until September 2007 , against 41,036 metric tons in the same period of the previous year), as a consequence of the fuel price increase trend on the international market.

Regarding Imports, the revised programme for 2007 anticipated imports at the value of USD 3,079.8 million, until December (see table below). Provisional data of the Balance of Payments until September 2007 show that the value of imports of goods was USD 2,244.6 million, representing a level of execution of $72.9 \%$ in relation to the revised programme.

Table 12: Imports

IMPORTS - $10^{\wedge} 6$ USD

\begin{tabular}{lrrrr}
\hline \multicolumn{1}{c}{ Description } & 2004 & 2005 & 2006 & sep. $\mathbf{2 0 0 7}$ \\
\hline \hline Petroleum derivates & 194,5 & 237,1 & 314,3 & 287,9 \\
Electrical power & 68,6 & 72,5 & 75,5 & 86,4 \\
Cars & 107,3 & 136,6 & 164,3 & 158,0 \\
Cereals & 131,4 & 156,9 & 136,3 & 123,9 \\
Sugar & 17,8 & 9,0 & 3,5 & 0,9 \\
Beer & 1,3 & 1,8 & 1,1 & 0,7 \\
Medicines & 27,3 & 24,3 & 31,1 & 35,4 \\
Capital goods & 277,2 & 313,2 & 278,7 & 303,4 \\
Othert goods (incl. adjustm) & 731,4 & 906,6 & 990,9 & 710,8 \\
\hline Total without large projects & $\mathbf{1 5 5 6 , 8}$ & $\mathbf{1 8 5 8}$ & $\mathbf{1 9 9 5 . 7}$ & $\mathbf{1 7 0 7 0 7 , 4}$ \\
\hline Large projects & 292,9 & 384,3 & 620,6 & 537,2 \\
\hline Total & $\mathbf{1 8 4 9 , 7}$ & $\mathbf{2 2 4 2 , 3}$ & $\mathbf{2 6 1 6 , 3}$ & $\mathbf{2 2 4 4 , 6}$ \\
\hline
\end{tabular}

The main factors explaining the increase or reduction of imports in the period in analysis are:

- Cereals - a reduction of $11.9 \%$, to USD 123.9 million, since the production of cereals in the $2006 / 2007$ campaign increased by $2.4 \%$ to 2.17 million metric tons compared to the previous campaign.

- Cars - an increase of 10 base points, to USD 158.0 million, resulting from the accumulation of stocks occurred until the end of 2006.

- Medicines - a growth of $14.2 \%$, to USD 35.4 million, reflex of the increase of the quantities of the various drugs needed by the National Health System.

- Sugar - a reduction of $70.1 \%$, to about USD 900 thousand, due to the abundance of local sugar on the domestic market, with a stock at the end of the $3^{\text {rd }}$ quarter of 2007 of 91,053 tons. 
- Fuels - an increase of $2.7 \%$, to USD 287.9 million, resulting from the crude price increase trend on the international market, in spite of the reduction of the imported volume of diesel oil by $1.2 \%$. It should be noted that $98 \%$ of the volume of imported fuels until September 2007 was composed of diesel oil $(70 \%)$, petrol $(16 \%)$ and Jet A-1 $(11 \%)$.

- Capital goods - a growth of $10 \mathrm{pb}$, to USD 303.4 million, particularly machinery and equipment for public works, building construction and similar works.

- Large Projects - a growth of about 3\%, to USD 537.2 million, due to the import of materials and equipment for the Pande/Temane Natural Gas Project.

Regarding the balance of services, the deficit of the partial services account until September 2007 amounts to 266.2 million USD, determined by the behaviour of the items of transport, travels, construction and business services, which suffered aggravations.

Table 13: Balance of Services

BALANCE OF SERVICES - 10^6USD

\begin{tabular}{|c|c|c|c|c|}
\hline Balance of Services & 2004 & 2005 & 2006 & \\
\hline BALANCE & $-275,8$ & -306,7 & -358,5 & $\overline{-266,2}$ \\
\hline Revenue & 255,6 & 341,9 & 385,6 & 336,4 \\
\hline Expenditure & $-531,4$ & $-648,6$ & $-744,1$ & $-602,6$ \\
\hline
\end{tabular}

In 2007 the constitution of external assets in the form of direct investment abroad amounted to USD 0.1 million.

In terms of DFI in Mozambique we should mention the net receipt of funds of about USD 227.7 million, representing a turning in the position of the economy with respect to its external responsibilities, because in the same period of 2006 the tendency was a net reduction of liabilities.

Table 14: Private Foreign Loans and Foreign Investment

PRIVATE FOREIGN LOANS AND FOREIGN INVESTMENT - $10^{\wedge} 6$ USD

\begin{tabular}{lrrrr}
\hline & 2004 & 2005 & 2006 & Set. 2007 \\
\hline \hline Private loans (disbursements) & 461,1 & 463,1 & 609,9 & 449,9 \\
Direct foreign investment & 244,7 & 107,9 & 153,7 & 227,7 \\
\hline \hline TOTAL & 705,8 & 571,0 & 763,6 & 677,6 \\
\hline
\end{tabular}

Direct foreign investment originated from 34 countries, particularly the USA, Switzerland, Mauritius, South Africa, United Kingdom, China, Portugal, Tanzania, Spain and Canada as the ten largest investors.

In general, from the table below one can infer that in September 2007 the deficit of the current account including grants amounted to USD 290.9 million (see the table below), representing about half (50.3\%) the plan until December of the same year. This result was due to the fact that until September 2007 and compared to the same period of 2006 reductions occurred in the deficits of the goods $(-4.0 \%)$ and services $(-8.1 \%)$ accounts and an increase of current transfers by $18.3 \%$, in spite of the deterioration of the revenue account by $28.2 \%$. 
Table 15: Balance of Payments

Main Balance of Payments Accounts - 10^6 USD

\begin{tabular}{|c|c|c|c|c|}
\hline \multirow{2}{*}{ Description } & 2006 & 2007 & Until Sep '07 & Level of accompl. \\
\hline & Real (1) & Plan (2) & Real (3) & $(\%)(4)=(3) /(2)$ \\
\hline Current Account, excl. grants & $-1125,2$ & $-1600,4$ & $-775,0$ & 48,4 \\
\hline Current Transfers & 2570,4 & 1022,5 & 484,1 & 47,3 \\
\hline Current Account, incl grants & $-1445,2$ & $-577,9$ & $-290,9$ & 50,3 \\
\hline Capital \& Financial Account & $-1421,9$ & 801,0 & 165,7 & 20,7 \\
\hline Errors \& omissions & 115,2 & 147,8 & 125,2 & 84,7 \\
\hline Overall balance & 138,5 & 370,8 & 24,0 & 6,5 \\
\hline Financing & $-138,5$ & $-370,8$ & $-24,0$ & 6,5 \\
\hline
\end{tabular}

During the first 9 months of 2007 there was a net inflow of resources into the country in the form of current transfers in the order of USD 484.1 million, corresponding to about half $(47.3 \%)$ the plan until December. The distribution was as follows:

- USD 441.5 million for financing central administration activities, through the State Budget, particularly: (i) import support, (ii) emergency programmes, (iii) the import of medicines and (iv) special programmes; and

- USD 42.5 million for other sectors of the economy. The total volume of funds received from abroad for other sectors was determined by the increase of income transfers on the part of Mozambican workers resident abroad and by inputs made into the accounts of a few NGOs operating in the country, in the scope of strengthening their financial positions.

The capital and financial account shows that capital transfers and net financial flows attained in September 2007 a value of USD 165.7 million, representing a level of execution of $20.7 \%$ in relation to the plan for 2007 , as a result of the inflow of capital in the order of USD 385.1 million and a net outflow of financial resources at the value of USD 219.4 million, which can mainly be explained by the deposits done by the commercial banks (USD 163.1 million) and by other sectors (USD 338.0 million).

The overall balance had a surplus of USD 24.0 million, corresponding to $6.5 \%$ of the plan for December, representing a financing capacity of the rest of the world to the same extent. As a result of the overall surplus recorded until September, there was a constitution of reserve assets on the part of the monetary authority of USD 168.8 million, most of which in the form of deposits in foreign currency.

For the financing of the external and budget imbalances, the country resorted once again to external financing sources to be able to materialize part of its investment programmes. In this scope, net loans contracted by the Mozambican economy until September 2007 amounted to USD 269.9 million.

Concerning Investment by sector, 186 projects were approved in 2007, involving a total investment of USD 7,532,175,811 and capable of creating 19,633 jobs.

The largest volumes of approved investment were in the sectors of Mineral Resources, Industry, Tourism and Hotels, Services and Agriculture and Agroindustries. Nampula, Tete, Maputo, Sofala and Gaza Provinces received in decreasing order the largest volumes of approved investment. 
Table 16: Approved investment by Sector

Approved Investment by Sector

\begin{tabular}{|c|c|c|c|c|c|c|c|}
\hline \multirow{2}{*}{ Sector } & \multirow{2}{*}{$\begin{array}{l}\text { No of } \\
\text { Proj. }\end{array}$} & \multicolumn{4}{|c|}{ Value in Million USD } & \multicolumn{2}{|c|}{ Employm. } \\
\hline & & IDE & IDN & Total & $\%$ & No & $\%$ \\
\hline Agriculture \& Agro-Industry & 16 & $\overline{52,87}$ & 9,45 & 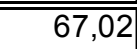 & 0,89 & 2.432 & 12,39 \\
\hline Aquiculture \& fishing & 4 & 9,78 & 1,56 & 13,24 & 0,18 & 210 & 1,07 \\
\hline Banks \& Insurers & 3 & 1,05 & 0,53 & 2,00 & 0,03 & 34 & 0,17 \\
\hline Construction \& Public Works & 13 & 11,49 & 1,08 & 13,60 & 0,18 & 1.293 & 6,59 \\
\hline Industry & 64 & 192,77 & 22,12 & 401,11 & 5,33 & 8.305 & 42,30 \\
\hline Mineral Resources & 5 & $5.177,29$ & 0,25 & $6.582,25$ & 87,39 & 1.268 & 6,46 \\
\hline Transport \& Communications & 13 & 25,64 & 2,60 & 68,19 & 0,91 & 589 & 3,00 \\
\hline Tourism \& Hotels & 46 & 138,10 & 7,17 & 271,57 & 3,61 & 4.844 & 24,67 \\
\hline Other & 22 & 53,69 & 3,38 & 113,20 & 1,50 & 658 & 3,35 \\
\hline$\overline{\text { TOTAL }}$ & 186 & $5.662,68$ & $\overline{48,14}$ & 7532,17 & 100,00 & 19.633 & $\overline{100,00}$ \\
\hline
\end{tabular}

Regarding the provinces, 186 projects were approved, with a total investment of about 7,533 million USD, creating 19.633 new jobs. Provinces with a large number of approved projects were Maputo (77), followed by Inhambane (29), Gaza (17) and Manica (16).

Table 17: Approved investment by Province

\begin{tabular}{|c|c|c|c|c|c|c|c|}
\hline & Approve & ivestme & Pro & & & & \\
\hline \multirow{2}{*}{ Province } & \multirow{2}{*}{$\begin{array}{l}\text { No of } \\
\text { Proj. }\end{array}$} & \multicolumn{3}{|c|}{ Value in Million USD } & \multirow[b]{2}{*}{$\%$} & \multicolumn{2}{|c|}{ Employm. } \\
\hline & & IDE & IDN & Total & & No & $\%$ \\
\hline "Cabo Delgado & 6 & 0,71 & 0,22 & 1,07 & 0,01 & 77 & $\overline{00,39}$ \\
\hline Niassa & 2 & 0,15 & 0,50 & 0,65 & 0,01 & 43 & 0,22 \\
\hline Nampula & 12 & $5.017,08$ & 10,47 & $5.059,91$ & 67,17 & 1.440 & 7,33 \\
\hline Zambézia & 6 & 2,27 & 3,64 & 10,20 & 0,14 & 758 & 3,86 \\
\hline Tete & 7 & 199,42 & 0,36 & $1.600,68$ & 21,25 & 343 & 1,75 \\
\hline Manica & 16 & 8,42 & 1,30 & 15,23 & 0,20 & 1.938 & 9,87 \\
\hline Sofala & 14 & 6,60 & 3,38 & 166,77 & 2,21 & 3.952 & 20,13 \\
\hline Inhambane & 29 & 48,45 & 1,12 & 54,97 & 0,73 & 1.105 & 5,63 \\
\hline Gaza & 17 & 92,95 & 1,74 & 95,51 & 0,80 & 693 & 3,53 \\
\hline Maputo* & 77 & 286,64 & 25,41 & 527,78 & 7,01 & 9.284 & 47,29 \\
\hline TOO T L & 186 & $5.662,68$ & 48,14 & 7.532,78 & 100,00 & 19.633 & $\overline{100,00}$ \\
\hline
\end{tabular}

\section{MAIN LINES OF DEVELOPMENT BY PILLAR}

\section{IV.1 ECONOMIC DEVELOPMENT}

\section{A. AGRICULTURE}

\section{AGRICULTURAL PRODUCTION, LIVESTOCK BREEDING AND FORESTRY}

The 2006/07 agricultural campaign was characterized by late and irregular rains, which resulted in inundations. Large areas with a variety of crops were lost on the margins and affluents of the Zambezi River in Sofala, Zambezia, Tete and Manica Provinces. In the Northern Region, the rains were also excessive causing a few local inundations, mainly in Nampula (Moma and Malema Districts) and Cabo Delgado (Muidumbe, Macomia and Mueda Districts) Provinces.

The Southern Region of the country was characterized by irregular rains during the whole first growing season, resulting in a severe drought that affected above all maize production. The drought occurred in this part of the country assumed alarming proportions in terms of production and was considered the most serious one of the 
last few years, mainly in Maputo Province, where $55 \%$ of the total area sown was lost.

The agricultural campaign was also affected by cyclone Favio, which affected Inhambane, Sofala and Manica Provinces. In Inhambane Province the following districts were seriously affected: Vilanculos, Inhassoro, Govuro and Massinga. Affected districts in Sofala were Machanga and Chibabava, and in Manica Province Gondola and Sussundenga.

The impact of the cyclone on crops was mainly on maize that was already in an advanced stage of its vegetative cycle and was then knocked down, and also resulted in the flooding of fields on the margins of the Buzi and Dombe Rivers.

About 369 thousand ha ( $7 \%$ of the total planted area) with a variety of crops were lost, of which 203 thousand ha due to drought, 93 thousand ha due to inundations and about 73 thousand ha due to the cyclone, affecting about 309 thousand peasant families.

In the campaign in analysis the effect of pests and diseases was not significant. In Gaza Province, however, an area of about 508 ha is estimated to have been lost due to the armyworm.

Following the above-mentioned disastrous effects, which created an emergency situation, the Government, in coordination with its partners, prepared an immediate response plan aimed at boosting the second agricultural growing season, which benefited more than 97,000 families.

In spite of the adversities, agricultural production, livestock breeding and silviculture increased by about $8.6 \%$.

Commercial agricultural production and the commercialisation of family produce, including auto-consumption, increased by $6.7 \%$.

Table 18: Agricultural Production (Growth rates in \%)

\begin{tabular}{|c|c|c|}
\hline & 06/07 PL & 06/07 REV \\
\hline TOTAL & 12.2 & 6.7 \\
\hline COMMERCIAL & 5.1 & 0.7 \\
\hline FAMILY TOTAL & 12.9 & 7.3 \\
\hline COMMERCIALISED & 17.9 & 11.0 \\
\hline SELF-CONSUMPTION & 9.8 & 4.9 \\
\hline
\end{tabular}

The commercialisation of basic food products increased by $27.7 \%$, contrary to the commercialisation of export products which suffered a decrease of $13.3 \%$ and of products for the agro-industry (a decrease of $0.6 \%$ ). 
Table 19: Commercial Production and Family Sector Commercialisation (Growth rates in \%)

\begin{tabular}{|lll|}
\hline DESCRIPTION & $\mathbf{0 6 / 0 7} \mathbf{P L}$ & $\mathbf{0 6 / 0 7} \mathbf{~ R E V}$ \\
\hline EXPORT PRODUCTS & $\mathbf{1 1 . 6}$ & $\mathbf{- 1 3 . 3}$ \\
Cashew nuts & 19.4 & 18.4 \\
Cotton & 10.0 & -40.8 \\
Copra & 0.0 & 0.0 \\
Cane sugar & 10.3 & -1.6 \\
Citrus fruits & 16.7 & 5.5 \\
Tea leaves & 0.0 & 10.4 \\
\hline BASIC FOOD PRODUCTS & $\mathbf{2 7 . 6}$ & $\mathbf{2 7 . 7}$ \\
Maize & 2.8 & 10.6 \\
Husked rice & 10.9 & 15.0 \\
Sorghum & 0.0 & 32.3 \\
Cassava & 5.6 & 13.3 \\
Peeled groundnuts & 5.2 & 66.9 \\
Beans & 6.9 & -16.4 \\
Vegetgables & 96.0 & 87.0 \\
Onions & 11.0 & 88.1 \\
\hline PRODUCTS FOR INDUSTRY & $\mathbf{0 . 6}$ \\
Tobacco & $\mathbf{0 . 2}$ & -1.3 \\
Tomatoes & 0.0 & 0.9 \\
\hline TOTAL & 0.7 & $\mathbf{8 . 1}$ \\
\hline
\end{tabular}

There was a decrease of the commercialisation of cotton, due to climatic conditions. The unfavourable cotton production was related to the significant reduction of the number of cotton producers with a consequent reduction of planted areas, having attained 72,175 tons against 122,000 tons in the previous campaign. The lack of rains occurred in the critical flowering and cotton capsule filling period, which together with the cold made it impossible for the capsules to open, thus contributing to their decay.

For the 2006/2007 campaign, cashew nut sales amounted to 74,397 tons of nuts, representing a growth of $18.4 \%$ compared to the $2005 / 2006$ campaign, which reached 62,821 tons. This product was commercialised at an average producer price of $6.50 \mathrm{MT} / \mathrm{kg}$, having resulted in an income of 491 million MT for the families. It should be noted that the edafoclimatic conditions in the main cashew production area of the country (the northern provinces) and the price increase during the campaign contributed positively to the success of this campaign.

The production of sugar cane suffered a decrease of $1.6 \%$, due to the poor distribution of the rains, a few periods of drought in areas where the sugar refineries are situated. These problems were aggravated by deficient irrigation to complement the rains, as well as by electric power problems, in this case in the Marromeu sugar refinery. These problems affected income.

The tea sector faced big constraints along its value chain, having resulted in low production levels and poor competitiveness at international level. For the 2006/07 campaign the production of tea leaves amounted to 17,671 tons, a growth of $10.4 \%$ compared to the previous campaign (16,000 tons). 
The high levels of commercialisation of basic food products resulted basically from the growth occurred in the commercialisation of vegetables $(87.0 \%)$.

The production of inputs for the agro-industry decreased by $0.6 \%$, with a decrease occurred in the commercialisation of tobacco $(1.3 \%)$. This decrease was due to a few constraints, mainly:

- Weakness of the companies' technical assistance rural extension networks.

- Limited response capacity on the part of the tobacco promotion companies to assist the increasing number of peasants and small farmers.

- Delays in making inputs available.

Data collected by the national early warning system show (see table below) that in the family sector there was a general increase of productivity for food crops, with the exception of beans, as the increase of production was superior to the expansion of cultivated areas. It should be noted that the levels of productivity were negatively influenced by the occurrence of natural disasters, which resulted in the loss of crops.

Table 20: Agricultural Production of the Family Sector

\begin{tabular}{|l|c|l|c|l|c|c|}
\hline \multicolumn{3}{|c|}{ 2005/06 Campaign } & \multicolumn{2}{c|}{ 2006/07 Campaign } & \multicolumn{2}{c|}{ Change } \\
\hline Crops & Area & Production & Area & Production & Area & Prod. \\
\hline & 000 ha & 000 ton & 000 ha & '000 ton & $\%$ & $\%$ \\
\hline Maize & 1,471 & 1,534 & 1,505 & 1,579 & 2.3 & 3.0 \\
\hline Sorghum & 542.3 & 339 & 558 & 348 & 2.9 & 2.7 \\
\hline Millet & 97 & 43 & 101 & 45 & 4.1 & 5.0 \\
\hline Husked rice & 194 & 183 & 204 & 196 & 5.0 & 7.4 \\
\hline Total Cereals & $\mathbf{2 , 3 0 5}$ & $\mathbf{2 , 0 9 8}$ & 2.368 & $\mathbf{2 , 1 6 8}$ & $\mathbf{2 . 8}$ & $\mathbf{3 . 4}$ \\
\hline Beans & 458 & 219 & 471 & 225 & 2.8 & 2.7 \\
\hline Groundnuts & 315 & 146 & 323 & 142 & 2.4 & -2.5 \\
\hline $\begin{array}{l}\text { Total } \\
\text { leguminous }\end{array}$ & $\mathbf{7 7 4}$ & $\mathbf{3 6 5}$ & $\mathbf{7 9 4}$ & $\mathbf{3 6 7}$ & 2.6 & 0.6 \\
\hline Cassa va & 1,126 & 7.552 & 1.150 & 8.161 & 2.2 & 8.1 \\
\hline Total & 4,204 & & 4,312 & & 2.6 & \\
\hline
\end{tabular}

In this campaign a production of 2.2 million tons was achieved. The levels of family production led to an increase of the levels of commercialisation of food products, with the exception of beans, mainly for vegetables (136.9\%) and onions (315.9\%). 
Table 21: Commercialisation of the Family Sector (Growth rates in \%)

\begin{tabular}{|lll|}
\hline DESCRIPTION & $\mathbf{0 6 / 0 7} \mathbf{~ P L}$ & $\mathbf{0 6 / 0 7 ~ R E V ~}$ \\
\hline \hline EXPORT PRODUCTS & $\mathbf{1 3 . 7}$ & $\mathbf{- 1 9 . 8}$ \\
Cashew nuts & 19.4 & 18.4 \\
Cotton & 11.2 & -40.7 \\
Cane sugar & 166.7 & 50.0 \\
Citrus fruits & 0.0 & 0.0 \\
\hline BASIC FOOD PRODUCTS & $\mathbf{3 4 . 4}$ & $\mathbf{3 3 . 3}$ \\
Maize & 3.5 & 13.0 \\
Husked rice & 14.3 & 20.0 \\
Millet & 0.0 & 35.6 \\
Cassava & 7.1 & 16.9 \\
Peeled groundnuts & 5.3 & 68.7 \\
Beans & 7.4 & -17.1 \\
Vegetables & 153.7 & 136.9 \\
Onions & 4.3 & 315.9 \\
\hline PRODUCTS FOR THE INDUSTRY & $\mathbf{- 1 . 1}$ \\
Tobacco & $\mathbf{0 . 1}$ & -1.4 \\
Tomatoes & 0.0 & $\mathbf{2 . 1}$ \\
\hline TOTAL & 2.1 & $\mathbf{1 1 . 0}$ \\
\hline
\end{tabular}

Livestock breeding production increased by $33.5 \%$. The preliminary results of the TIA 2007 (Agricultural Inquiry) show that in 2007 the overall cattle population amounted to $1,425,884$ heads.

In 2007 total beef, pork and chicken production attained a volume of 19,829.5 tons, representing a growth in the order of $41 \%$ compared to the previous campaign $(14,106.2$ tons $)$.

The production of beef in the period in analysis was $6,584.2$ tons, corresponding to a growth of $6.1 \%$, i.e., $97.5 \%$ of the plan.

There was a growth in pork production of 13.5\%. In 2007841 tons were produced, against 747.5 tons in 2006 . The level of PES execution was $97 \%$.

Growth in chicken production, compared to 2006 , was about $73 \%$, with $55.5 \%$ for the commercial sector and $180 \%$ for the family sector. This growth was due to credits made available to the poultry sector by the Government and its partners, the reduction of imports of frozen chickens, partnership agreements signed between the U.G.C. and the DELTA TRADING commercialisation company, and the establishment of new commercial poultry farms (Mozambique Farma) in Namaacha District.

The production of fresh milk in the period in analysis amounted to 1,352,405 litres, representing a decrease of $0.3 \%$ compared to the same period of the previous year. This decrease was caused by the low level of investment in the dairy companies.

The production of consumption eggs amounted to $2,557,515$ dozen $(30,688,980$ units), corresponding to a growth of $34.2 \%$. Main producers contributing to these levels of production of consumption eggs were the Galovos Company in Namaacha District and a few medium-size poultry-farmers who benefited from a credit from the Government and its partners for the poultry sector. 
Growth in the silviculture and forest exploitation subsector was about $2.5 \%$, with an increase of the production of timber logs of $3 \%$. In 2007 the volume of licensed timber logs was higher than in 2006, due to the increase of the number of operators, and the commitment of the concessionaries to explore fully the volumes authorized in previous campaigns. Regarding wood fuels and construction materials, the growth was basically due to the increase of the number of operators, together with the increasing demand for these products on the domestic market.

In the whole country about 50,511 thousand $\mathrm{m}^{3}$ of sawn timber was processed during the 2007 campaign, of which $2,306 \mathrm{~m}^{3}$ of parquet, $1,173 \mathrm{~m}^{3}$ of sleepers, 3,974 $\mathrm{m}^{3}$ of poles. This increase reflects the impact of Government measures concerning the processing of Mondzo, Ironwood, Chanato and Muaga species before their export, which led to an increased production in some provinces, namely Sofala, Manica, Nampula, Niassa and Zambezia.

\section{POLICY MEASURES}

In this sector the activities focussed on the increase of productivity and production to guarantee food security, increase producers' income and competitiveness, ensure the sustainable management of natural resources, promote the development of the private sector and production systems in the perspective of the value chain, the development of technologies that promote the use and sustainable management of natural resources, and the development of an effective and efficient public sector responding to the expectations of citizens and economic agents.

In this context, the following activities were performed:

With regard to the creation of adapted agricultural technologies four new varieties of crops were made available, one of which a hybrid maize for each one of the three agro-ecological zones (high, medium and low altitude) and one of nhemba beans;

In the scope of pre-basic seed production (agricultural research) $83,756 \mathrm{~kg}$ of basic cereal seeds, $5,000 \mathrm{~kg}$ of basic cotton seeds and $28,250 \mathrm{~kg}$ of basic bean seeds were produced.

Regarding the dissemination of agricultural technologies, assistance was given by the public services to about 285,361 families (direct assistance), of which 23,588 in Maputo, 15,867 in Gaza, 20,090 in Inhambane 21,274 in Manica, 41,251 in Sofala, 65,610 in Zambezia, 23,865 in Tete, 29,084 in Nampula, 20,866 in Cabo Delgado and 23,866 in Niassa.

In the scope of the provincial agricultural extension services it was planned to assist 24,075 families with improved planting material, namely cassava stakes and sweet potato stems, particularly in Cabo Delgado, Nampula, Sofala and Maputo Provinces. Two species with a new propagation method were identified, 27.5 ha of vegetative propagation material (cassava) were planted and $130,200 \mathrm{~kg}$ of vegetative propagation material produced benefiting 3,962 families with vegetative material (1736 in Maputo, 53 in Gaza, 398 in Manica and 1775 in Nampula).

In the area of technology dissemination, the following activities were performed:

- Radio programmes for the dissemination of technical messages were broadcast with a total of 191 hours;

- A total of 2,863 demonstration plots were established, mainly for food crops. 
In the area of livestock breeding promotion, the following activities were performed:

- A total of 5,397 heads of cattle were distributed in the provinces of Cabo Delgado (202), Niassa (1,230, Nampula (25), Zambezia (547), Tete (492), Sofala (666), Manica (288) and Maputo (834). A total of 6,574 small ruminants were distributed in the provinces of Cabo Delgado $(2,086)$, Nampula (871), Zambezia (430), Tete (200), Manica (894), Sofala (469), Inhambane $(1,124)$ and Maputo (500).

- A total of 257 pairs of draught oxen and 362 ploughs were distributed, as follows: Cabo Delgado: 25 pairs and 25 ploughs, Niassa: 45 pairs and 37 ploughs, Nampula: 16 pairs, Zambezia: 2 ploughs, Tete: 62 pairs and 50 ploughs, Sofala: 65 pairs and 28 ploughs, Inhambane: 210 ploughs, Maputo: 44 pairs and 10 ploughs; pairs of donkeys: 30 in Sofala; and 133 carts in Cabo Delgado (25), Sofala (31), Inhambane (74) and Maputo (3).

- A total of 2000 birds were distributed in Niassa, 452 ducks in Inhambane and 300 chickens in Maputo, 160 birds to 34 beneficiaries in Sofala and 173 birds in Chimoio town benefiting 71 people.

With regard to the implementation of the agricultural production intensification and diversification programme,

- A total of 474 tons were produced in Cabo Delgado: maize (148), sorghum (14.4), Nhemba beans (61.6), sesame (18) and rice (232.2) on an area of 407 hectares. In Niassa 146.8 ton were distributed (maize, rice, sorghum, beans, Irish potatoes and vegetables) and about 3,433 peasant families were assisted;

- In Inhambane 111,30 tons of maize, beans and vegetables were made available; and in Zambezia 123,400 tons of various seeds; in Tete 406 tons of cereals, beans and vegetables were distributed; in Nampula 10 tons of various seeds were distributed; and in Maputo 90 tons of maize, rice, and nhemba beans were made available.

Regarding the animal and plant health campaign against the large woodworm, the following activities were performed:

- Monitoring and control of the groundnut caterpillar in Maputo, Gaza and Inhambane Provinces. In Inhambane the service providers' network was extended to cover groundnut producers in all districts, while 5 to 10 providers were formed in each district.

- Pesticide tests were done by UEM students for caterpillar control. A meeting in Inhambane is planned for the dissemination of the research results in the scope of pest control.

With regard to the public livestock vaccination and extension campaign:

- In the whole country 798,595 doses of vaccine against anthrax were produced and 4,202,500 doses of vaccine against Newcastle disease, while 683 community vaccinators were trained (Cabo Delgado 298, Niassa 63, Nampula 66, Zambezia 90, Manica 86, and Maputo 80). In the whole country 4,159,595 heads of cattle received a tick bath and 3488 heads were iron-marked "Made in Mozambique", mainly in Nampula Province; 
- In the whole country 2,663,957 vaccinations against Newcastle disease wee given, 787,846 against anthrax, 314,070 against symptomatic anthrax, 333,200 against foot-and-mouth disease, 190,000 against nodular dermatosis, and 85,837 against rabies.

The detailed vaccination plan of the provincial and district services is presented in the following table:

Table 22: Vaccinations

\begin{tabular}{|l|l|l|l|}
\hline Vaccines & $\mathbf{2 0 0 6}$ Real & 2007 Plan & $\mathbf{2 0 0 7 ~ R e a l ~}$ \\
\hline Anthrax & 738,192 & $\mathbf{8 0 2 , 9 8 6}$ & $\mathbf{7 8 7 , 8 4 6}$ \\
\hline $\begin{array}{l}\text { Symptomatic } \\
\text { Anthrax }\end{array}$ & 293,267 & $\mathbf{3 1 9 , 6 0 4}$ & $\mathbf{3 1 4 , 0 7 0}$ \\
\hline Brucellosis & 73,100 & $\mathbf{7 4 , 3 8 0}$ & \\
\hline $\begin{array}{l}\text { Foot-and-mouth } \\
\text { disease }\end{array}$ & 327,826 & $\mathbf{4 6 5 , 0 1 6}$ & $\mathbf{3 3 3 , 2 0 0}$ \\
\hline $\begin{array}{l}\text { Nodular } \\
\text { Dermatosis }\end{array}$ & 128,676 & $\mathbf{3 5 2 , 0 2 3}$ & $\mathbf{1 9 0 , 0 0 0}$ \\
\hline $\begin{array}{l}\text { Newcastle } \\
\text { Family Sector }\end{array}$ & $2,300,384$ & $\mathbf{2 , 7 0 0 , 4 4 5}$ & $\mathbf{2 , 6 6 3 , 9 5 7}$ \\
\hline Rabies & 115,384 & $\mathbf{1 2 0 , 7 4 4}$ & $\mathbf{8 5 , 8 3 7}$ \\
\hline Tuberculin & 12,150 & $\mathbf{1 3 1 , 3 9 2}$ & \\
\hline
\end{tabular}

In the scope of the promotion of cashew production:

- A total of 3,388,710 cashew-trees were treated, benefiting 113,652 families;

- In Nampula 2,471,496 cashew-trees were cleaned, benefiting 106,671 families of which 95,427 headed by men and 11,244 by women, and 145,000 cashew-trees were pruned. In Zambezia 274,410 cashew-trees were cleaned, 205,489 trees were pruned and 805 producers were trained. In Inhambane 23,878 cashew-trees were pruned and 337,506 trees were cleaned;

- A total of 1,446,369 grafted seedlings were produced (Cabo Delgado 92,688, Nampula 1643,589, Zambezia 214,069, Sofala 400, Manica 6,675, Inhambane 216,143, Gaza 1,193,470 and Maputo 79,335) benefiting 13,238 families, of which 2,082 are headed by women;

- A total of 574,119 seedlings were distributed over the producers (Cabo Delgado 61,272, Nampula 141,861, Zambezia 131,814, Inhambane 64,82, Gaza 139,474 and Maputo 34,474) benefiting 13,238 families, of which 2,082 are headed by women.

Regarding the improvement of the availability of agricultural inputs:

- A total of 26 agricultural input markets were organised in Nampula, Manica Gaza and Maputo Provinces, benefiting 97,000 people;

- A total of 124,337 fruit trees of various species were distributed (Niassa 8,611 fruit trees of which 7,793 exotic and 818 native trees, Zambezia 3,881 fruit trees of various kinds, benefiting 78 schools, Tete 92,231 fruit trees of various kinds, Sofala 900 mango trees, 3,573 orange trees and 1,500 avocado trees to plant in the resettlement centres and in Maputo 5,030 fruit trees of various kinds were distributed); 
- Local seed was produced on 718 ha of maize, 227.5 ha of rice and 1,479 ha of beans.

- About 8,000 tons of various seeds of the following crops were produced and certified: maize, rice, millet, beans, nhemba beans and groundnuts.

In the scope of the promotion of jatropha production a bed of jatropha was established in the nursery to monitor its germination power and about 2,030 ha of jatropha were grown;

Regarding the promotion of agricultural infrastructure construction and rehabilitation:

- 8 rural pharmacies were established (4 in Inhambane, 1 in Cabo Delgado, 2 in Niassa, and 1 in Nampula).

- A total of 3,520 ha of irrigation schemes were rehabilitated (Niassa 94, Nampula 70, Tete 20, Zambezia 45, Sofala 110, Inhambane 821, Gaza 2,300 and Maputo 60).

- 10 elevated water tank systems were set up in Sofala Province in the districts of Caia (2), Cheringoma (2), Machanga (1), Maríngue (1), Chemba (1), Marromeu (1), Chibabava (1), and Búzi (1).

- The Licuári irrigation scheme was rehabilitated, the Namacurra irrigation scheme was measured out, the rehabilitation of the Thewe-II irrigation scheme and the construction of the Mugonhane irrigation scheme were started;

- The rehabilitation of the Ninthulo irrigation scheme was concluded, the construction of a dam in Namarroi started, the construction of a dam in Morrumbala concluded and the dimensioning of the Batmziva irrigation scheme in Nicoadala was concluded;

- A total of 187 pedal pumps were distributed in Tete, 190 pedestal pumps in Niassa and 4 in Sofala; 65 mechanical pumps were distributed in Sofala and Inhambane, 2 in Niassa, 4 in Zambezia, 1 in Tete, 4 in Gaza, 36 in Maputo.

Regarding the improvement of access to information about agricultural markets, continuity was given to the collection, processing and dissemination of information about domestic agricultural markets, including the availability, flows and prices of agricultural products, as well as the cost of transport of the products, and the transmission of 173 hours of radio programmes in local languages with market information; 134 hours of information about agricultural markets were broadcast (Nampula 26, Manica 6, Maputo 10 and Cabo Delgado 92).

With regard to the promotion of private sector development and of production systems in the perspective of the value chain, 3000 licences and phytosanitary certificates were issued, of which 1200 in Maputo Port, 1000 in Beira Port and 800 in Nacala Port;

- A total of 371 inspections of various products were carried out, 2124 licences and 3671 phytosanitary certificates issued at the Maputo PIF; 237 inspections of various products, 111 licences and 341 phytosanitary certificates at the Beira PIF and 359 inspections to various products, 36 licences and 766 certificates in Nacala. 
With respect to the creation of incentives and the promotion of producer organisations, 2450 associations were assisted.

In relation to the improvement of communities' equitable access to natural resources for sustainable use and management,

- 9400 DUAT processes were digitalized;

- 18 community delimitations were carried out, corresponding to an area of 496,289 ha;

- 92 awareness-raising talks for the dissemination of the Land Law were given, for a universe of 2193 people, of which 1229 women and 964 men.

In the scope of support to the establishment of local and national private initiatives for rational and sustainable forest exploitation,

- 12 forest concessions were approved: 4 in Tete, 3 in Inhambane, 1 in Sofala, 1 in Nampula, 1 in Zambezia, 1 in Cabo Delgado and 1 in Gaza;

- 18 management plans were approved (3 in Zambezia, 3 in Inhambane, 5 in Tete, 4 in Nampula, 1 in Cabo Delgado, 1 in Sofala and 1 in Gaza), corresponding to an area of about 721,622 ha;

- 4,366 ha were reforested for industrial production in Niassa and Manica.

In the field of the provision of information about existing natural resources, particularly the development of an integrated, multifunctional and digitalized Single National Land Cadastre System, and also the identification of potential areas for wildlife management, and taking a wildlife census,

- The first phase of the design of the LIMS (Land Information and Management System) was concluded, 10 crocodile exploitation areas (collection of eggs and catching crocodiles) along the Zambezi River were identified: 1 in Tete, 1 in Zambezia, 3 in Niassa (Nipepe, Maúa and Metarica), 1 in Cabo Delgado (Macomia), 2 in Sofala (Caia and Chemba), and 2 in Gaza (Mabalane and Massingir), and areas for wildlife management were identified in Inhambane, Zambezia and Cabo Delgado.

With regard to land use and benefit aspects, 389,040.82 ha in several coastal districts were inventoried and mapped.

Regarding the improvement of the inspection of natural resources exploitation, 426 land lots with a DUAT were inspected in the whole country, with the exception of Maputo and Gaza, new inspectors were recruited in almost all provinces and 13 awareness-raising campaigns were launched in the whole country about the importance of wildlife; 4 warning signs against crocodiles were placed in Mopeia and Chinde Districts (Luabo), in Zambezia Province, and 115 wild animals were killed, in defence of people and property.

With regard to forest fire control, the implementation of the national forest fire programme was monitored in Nampula and Maputo Provinces and database information was produced about the occurrence of forest fires in the country. 


\section{B. INFRASTRUCTURES}

\section{CONSTRUCTION}

Overall growth of construction was $9.9 \%$. This reflects the performance of company construction, which increased by $19 \%$ with the execution of public investment projects, namely in the areas of roads, bridges and social infrastructures.

The occurrence of floods and cyclones, and the explosions of the Malhazine Ammunition Depot turned part of the attentions of the activities planned in the PES 2007 to the reconstruction and resettlement of the affected population's lives. Thus, the construction works did not attain the targets planned in the main components of the Third Roads Programme for the year 2007.

Table 23: Road Rehabilitation

\begin{tabular}{|c|c|c|c|}
\hline Type of activity & $\begin{array}{c}\text { Annual Plan } \\
2007\end{array}$ & $\begin{array}{l}\text { Real } \\
2007\end{array}$ & \% Exec. \\
\hline Rehabilitation of national roads* & 317 & 164 & $52 \%$ \\
\hline Rehabilitation of regional roads & 610 & 654 & $107 \%$ \\
\hline Periodic road maintenance & 1,197 & 1,106 & $92 \%$ \\
\hline Routine road maintenance & 17,200 & 15,431 & $90 \%$ \\
\hline Bridge rehabilitation and building & 21 & & \\
\hline
\end{tabular}

*Primary and secondary roads

\section{POLICY MEASURES}

\section{Roads and Bridges}

The main objective of PES 2007 in the area of Roads and Bridges consisted of the continuation of the works defined in the Third Roads Programme. During the year 2007, performance of the Roads and Bridges was as presented in the following table:

Table 24: Roads Rehabilitation and Maintenance (km)

\begin{tabular}{|l|l|l|l|l|l|}
\hline & $\mathbf{2 0 0 3}$ & $\mathbf{2 0 0 4}$ & $\mathbf{2 0 0 5}$ & $\mathbf{2 0 0 6}$ & $\mathbf{2 0 0 7}$ \\
\hline Roads Rehabilitation & 827 & 819 & 1,375 & 822 & 817 \\
$\quad$ National roads & 235 & 314 & 574 & 556.5 & 163 \\
Regional Roads & 592 & 507 & 801 & 265.5 & 654 \\
Periodic Maintenance & 396 & 514 & 1,004 & 527.9 & 1,106 \\
Routine Maintenance & 10,592 & 9,653 & 10,705 & $7,783.9$ & 15,431 \\
Bridge Rehabilitation and Construction & 15 & 7 & 5 & 7 & 1 \\
& & & & & \\
\hline
\end{tabular}

Source: Ministry of Public Works and Housing, BPES 2007

During the period in analysis $817 \mathrm{~km}$ of roads were rehabilitated, of which $163 \mathrm{~km}$ national roads and $654 \mathrm{~km}$ regional roads.

Concerning national roads, $163 \mathrm{~km}$ were rehabilitated of the $317 \mathrm{~km}$ initially planned, with prominence for the conclusion of the rehabilitation works of the sections: EN1 Maputo-Marracuene, EN 104 Nametil - Angoche, EN 6 Mutua - Inchope. The rehabilitation works of the EN1 Namacurra - River Ligonha section is in progress. Performance details are presented in the table below: 
Table 25: Rehabilitation of National Roads

\begin{tabular}{|l|l|l|}
\hline Section & Length in $\mathbf{~ k m}$ & Real in $\mathbf{~ k m}$ \\
\hline EN1 Maputo - Marracuene & 2.0 & 8.0 \\
EN7 Vanduzi - Changara & 12.0 & 0.0 \\
EN1 Namacurra - R. Ligónha & 237.0 & 129.7 \\
EN6 Mutua - Inchope & 12.0 & 12.0 \\
EN 104 Nametil - Angoche & 3.0 & 13.3 \\
EN1 Jardim - Benfica & 2.0 & 0.0 \\
EN1 Xai- Xai - Chissibuca & 13.0 & 0.0 \\
EN1 Massinga - Nhanchengue & 16.0 & 0.0 \\
EN361 Maniamba - Metangula & 20.0 & 0.0 \\
& & \\
\hline TOTAL & 317.0 & 163.0 \\
\hline
\end{tabular}

Source: Ministry of Public works and Housing, BPES 2007

Regarding the rehabilitation of regional roads, the activities comprised the rehabilitation of $654 \mathrm{~km}$ of the $610 \mathrm{~km}$ foreseen in the PES 2007. This activity is managed at provincial level in the scope of the decentralization. However, 3 rural roads rehabilitation projects were selected at central level: R445 Macarretane Massingir, R1005 Maríngue - Gombalançai - Sena (the works were concluded in May 2007) and R452/859 Mapapa - Maniquenique (rehabilitation works in progress, with its conclusion foreseen for April 2008).

With regard to the rehabilitation of secondary roads, which comprised the EN 361 , Maniamba - Metamgula $(20 \mathrm{~km})$, the works contracts were concluded and the contractors have started works in the last quarter of 2007.

In relation to periodic maintenance works, about 1,106 km of the 1,197 km initially planned were accomplished and the maintenance works of the Chissibuca - Maxixe section of the EN1 were concluded.

In relation to the construction of bridges, the construction of the Guija bridge (Limpopo River) was concluded, while works are in progress on the Lugela bridge (Lugela River), Rovuma (Rovuma River), Moamba (Incomati River) and Zambezi (Zambezi River). The conclusion of these works is foreseen for 2008 with the exception of the Zambezi bridge, which is foreseen for 2009. Concerning bridge rehabilitation, works are in progress on the Meluli bridge (Meluli River) while its conclusion is foreseen for 2008 , while 21 drainage structures were also concluded in the scope of bridge rehabilitations in Zambezia.

In the scope of bridge construction in Zambezia Province, 14 new bridges were built.

In the scope of the national roads network maintenance programme, passableness was ensured on $70 \%$ of the roads, against $76 \%$ initially foreseen for the classified roads network. This situation was due to the fact that the PARPA II indicators were set according to the old classified roads network, which was $25,339 \mathrm{~km}$ while the current one is $29,341 \mathrm{~km}$.

\section{Water Supply and Sanitation}

\section{Water and Sanitation}

In the water area the activities focussed on the improvement of the level of coverage and the level of service provision, together with institutional measures with a view to achieve self-sustainability of water supply to rural, urban and peri-urban populations. 
With regard to rural water supply, during the year 2007 the construction and rehabilitation of 2,442 dispersed water points was concluded, of which 1,369 boreholes, 160 wells and 913 rehabilitations, additionally benefiting about 1,221,000 people in the whole country. With this execution it was possible to achieve a coverage of $48.5 \%$.

Table 26: Water Point Rehabilitation and Construction

\begin{tabular}{|l|l|l|l|l|l|l|l|l|l|}
\hline \multirow{2}{*}{ Province } & \multicolumn{2}{|c}{ Wells } & \multicolumn{2}{c|}{ Boreholes } & \multicolumn{2}{c|}{ Rehabilitation } & \multicolumn{2}{c|}{ Total } & $\begin{array}{l}\text { Population } \\
\text { served }\end{array}$ \\
\cline { 2 - 11 } & Plan & Real & Plan & Real & Plan & Real & Plan & Real & (11) \\
\hline Niassa & 0 & 11 & 183 & 186 & 40 & 57 & 223 & 254 & 127,000 \\
\hline Cabo Delgado & 0 & 28 & 48 & 79 & 117 & 68 & 165 & 175 & 87,500 \\
\hline Nampula & 12 & 35 & 468 & 367 & 200 & 84 & 680 & 486 & 243,000 \\
\hline Zambezia & 36 & 64 & 235 & 444 & 48 & 101 & 319 & 609 & 304,500 \\
\hline Tete & 0 & 8 & 0 & 33 & 65 & 124 & 65 & 165 & 82,500 \\
\hline Manica & 0 & 0 & 10 & 61 & 20 & 112 & 30 & 173 & 86,500 \\
\hline Sofala & 0 & 4 & 10 & 99 & 40 & 104 & 50 & 207 & 103,500 \\
\hline Inhambane & 0 & 0 & 43 & 66 & 150 & 153 & 193 & 219 & 109,500 \\
\hline Gaza & 0 & 0 & 10 & 16 & 60 & 53 & 70 & 69 & 34,500 \\
\hline Maputo & 0 & 10 & 10 & 18 & 65 & 57 & 75 & 85 & 42,500 \\
\hline Total & $\mathbf{4 8}$ & $\mathbf{1 6 0}$ & $\mathbf{1 0 1 7}$ & $\mathbf{1 , 3 6 9}$ & $\mathbf{8 0 5}$ & $\mathbf{9 1 3}$ & $\mathbf{1 8 7 0}$ & $\mathbf{2 , 4 4 2}$ & $\mathbf{1 , 2 2 1 , 0 0 0}$ \\
\hline
\end{tabular}

Source: Ministry of Public Works and Housing, BPES 2007

In relation to the Small Water Supply Systems (PSAA):

- Emergency works of the Moma Capital system in Nampula Province were carried out, rehabilitation works of the Nametil systems in the same province were concluded and rehabilitation works of the Sussundenga system in Manica Province started.

- Interventions are in progress for the repair/reposition of the systems which together will serve 12,720 people.

In the scope of urban water supply, for the Delegated Management Framework (DMF) projects during the year 2007 8,502 new domiciliary connections were made and 216 standpipes were constructed and rehabilitated. With this execution it was possible to achieve a coverage of $40.0 \%$ against $38 \%$ planned. Details are presented in the table below. 
Table 27: Urban Water Supply

\begin{tabular}{|c|c|c|c|c|c|c|c|c|}
\hline \multirow[t]{2}{*}{ Group } & \multirow[t]{2}{*}{ City } & \multirow[t]{2}{*}{ Project } & \multicolumn{2}{|c|}{$\begin{array}{l}\text { New } \\
\text { connections } \\
2007\end{array}$} & \multicolumn{2}{|c|}{$\begin{array}{ll}\text { New } & \text { standpipes } \\
2007 & \end{array}$} & \multicolumn{2}{|c|}{$\begin{array}{l}\text { Rehabilitated } \\
\text { standpipes } \\
2007\end{array}$} \\
\hline & & & Plan & Real & Plan & Real & Plan & Real \\
\hline \multirow{10}{*}{ DMF } & Maputo & $\begin{array}{l}\text { Capacity increase and expansion project of } \\
\text { the Maputo Water Supply System }\end{array}$ & 1200 & 2912 & 25 & 0 & 15 & 10 \\
\hline & Xai-Xai & $\begin{array}{l}\text { Construction works and expansion of the Xai- } \\
\text { Xai System }\end{array}$ & 150 & 470 & 10 & 30 & 15 & 0 \\
\hline & Chókwè & $\begin{array}{l}\text { Construction works and expansion of the } \\
\text { Chókwè System }\end{array}$ & 100 & 338 & 3 & 7 & - & 30 \\
\hline & $\begin{array}{l}\text { Inhamban } \\
\text { e }\end{array}$ & $\begin{array}{l}\text { Construction works and expansion of the } \\
\text { Inhambane System }\end{array}$ & 150 & 422 & 4 & 7 & - & 0 \\
\hline & Maxixe & $\begin{array}{l}\text { Construction works and expansion of the } \\
\text { Inhambane and Maxixe System }\end{array}$ & 100 & 517 & 3 & 25 & - & 0 \\
\hline & Beira & $\begin{array}{l}\text { Expansion of the Supply Network of Dondo } \\
\text { Town }\end{array}$ & 200 & 1131 & 11 & 2 & 3 & 0 \\
\hline & $\begin{array}{l}\text { Queliman } \\
\mathrm{e}\end{array}$ & Network expansion "phase 1" & 150 & 322 & 20 & 22 & 5 & 0 \\
\hline & Nampula & Network expansion "phase 1" & 200 & 1825 & 3 & 59 & 2 & 5 \\
\hline & Pemba & Network expansion "phase 1" & 100 & 274 & 15 & 13 & 5 & 0 \\
\hline & Moatize & System rehabilitation and improvement & - & 30 & 6 & 4 & - & 0 \\
\hline $\begin{array}{l}\text { Outsid } \\
\text { e DMF }\end{array}$ & Gurué & $\begin{array}{l}\text { Expansion of the Gurué water supply system } \\
\text { distribution network }\end{array}$ & 150 & 0 & 5 & 0 & - & 0 \\
\hline \multicolumn{3}{|l|}{ TOTAL } & 2500 & 8502 & 105 & \begin{tabular}{|l|}
169 \\
\end{tabular} & 45 & 47 \\
\hline
\end{tabular}

Source: Ministry of Public Works and Housing, BPES 2007

Regarding urban, peri-urban and rural sanitation, the following activities were performed:

Water Supply, Sanitation and Institutional Capacity Building Project in 4 towns of the Southern Region (Inhambane, Maxixe, Xai-Xai and Chókwè):

- The consultancy for the reform study was started;

- The contracting of consultants for the preparation of sanitation master plans in the four towns is ongoing.

Maputo water supply system rehabilitation project - sanitation component:

- Start of the implementation of the low-cost sanitation programme, health education for communities and schools in Laulane, Mahotas and Hulene A and B neighbourhoods and construction and inspection works of the " $T$ " basin drainage channel are in progress.

At peri-urban sanitation level:

- A total of 9,645 improved latrines were constructed of the 10,200 planned, together with health education programmes, which benefited about 48,225 additional people. 
- Institutional capacity building in the towns covered by the Water Supply, Sanitation and Institutional Capacity Building Project of the four towns (Inhambane, Maxixe, Xai-Xai and Chókwè).

- The urban sanitation coverage rate is $47 \%$.

At rural sanitation level:

- 11,352 improved latrines were built of the 2,000 planned, which will benefit about 56,760 people. Thus, coverage of sanitation services for rural areas is $39 \%$ against $37 \%$ planned and total coverage of population with access to sanitation services was $42.2 \%$.

In the scope of water resource management the following activities were performed:

- Two seminars were conducted to present the report about the ARA Norte establishment in Lichinga;

- The rehabilitation and premises expansion works of the Lichinga hydrometry sector for housing the Rovuma Basin Management Unit were concluded;

- The former Montepuez hydrometry sector was partially rehabilitated, including the acquisition of office equipment;

- The Rovuma Basin Committee was created and the respective bylaws were discussed;

- The ARA Centro-Norte installation commission was created and its respective competences defined;

- Meetings were held with consumers for the dissemination of ARA CentroNorte's role;

- Several training courses for ARA Centro's technical staff were administered;

- The implementation of the ARA Zambezi - HCB protocol was started, including the allocation of the respective budget item for 2006 and 2007;

- The construction works of a shelter for the flood warning systems in the scope of SADC-HYCOS were concluded;

- The office and housing construction works in Guijá in Lionde were concluded for the transfer of the UGBL from Xai-Xai to Massingir and the construction was started of permanent UGBL premises in Chókwè;

- The basic urbanization of the Lionde and Guijá settlement was concluded;

- The construction projects of the ARA - Sul headquarters in Malhampsuene were prepared.

\section{Water Resources}

- A total of 62 hydroclimatological stations were rehabilitated (24 hydrometric stations and 38 pluviometric stations) of the 42 stations planned (21 hydrometric and 21 pluviometric stations). 
Regarding hydrographic basin studies and planning the following activities were performed:

- The development strategy of the Púngoè River Basin was approved;

- The draft monograph of the Melema River Basin was concluded;

- The pre-conditions for the implementation of the credit agreement were met and a preliminary proposal was presented for the inventory and priorities for the development of shared water basins (Save, Búzi and Rovuma) at ARA - Norte and ARA - Centro level;

Regarding shared rivers the following activities were carried out:

- A tender was launched for the submission of technical and financial proposals for doing the study, in the scope of the joint Limpopo Basin study - inventory and diagnosis phase;

- The basic conditions for the establishment of the secretariat were concluded, i.e., the financial agreement between GTZ and the DNA in representation of the LIMCOM states;

- A study was done for the establishment of the Rovuma Basin Committee;

- Studies were done in the water resource component in the Maputo Basin;

- A data bank for the whole Zambezi basin was designed - the Zambezi Water Information System (ZAMWIS);

- A plan was prepared for the operationalization of the Zambezi Basin Commission - ZAMCOM;

- The Terms of Reference were prepared for the working group for the implementation of the results of studies to start the negotiation process for the revision of the 1976 agreement on Umbeluzi River water sharing.

\section{In the Scope of Institutional Development}

\section{Roads Sector}

- About 57 ANE technicians were trained to strengthen their response capacity;

- A seminar was conducted about social and environmental issues for ANE technicians, including delegates, MICOA and CMM technicians and consultants;

- The current edition of the environmental handbook for roads works in Mozambique was revised; the resettlement plan of the Lichinga Montepuez road was implemented, in coordination with the Montepuez, Balama, Chimbunila and Madjune District Administrations as well as the Montepuez town council.

\section{Water Sector}

- The activities of the Water and Sanitation Group (GAS) were consolidated; 
- At the level of the water and sanitation sector activities were performed with a view to the establishment of the SWAP, the first phase of which focussing on the rural water component;

- Survey and mapping activities of the existing information systems were carried out, and the strategy document for the Water Information Sector System (SINAS) was prepared;

In the scope of integrated sector planning and evaluation the PESA-ASR was concluded, discussed, approved and disseminated.

\section{ENERGY SECTOR}

During the period in analysis the production of electricity and water increased by $8.4 \%$ compared to 2006 .

Total energy production was 16,079,937 MWh, of which 16,062,987 MWh hydroelectric power and the remaining $16,950 \mathrm{MWh}$ thermal, corresponding to a growth in the order of $9.1 \%$, compared to the production volume reached in 2006.

EDM's hydroelectric power production decreased by $0.1 \%$, i.e., it amounted to 216,407 MWh against 216,635 MWh in 2006, which happened because there was greater availability of HCB power and a synchronization of the EDM and HCB systems, which made it possible to plan the Chicamba, Mavuzi and Coromana production as well as to improve power management and optimise our hydroelectric power stations.

Total consumption recorded in 2007 exceeded the 2006 level of consumption of by $0.4 \%$. MOZAL is the largest electric power consumer, with 7,849,236 MWh of the total volume of $9,460,450 \mathrm{MWh}$, thus representing $83 \%$ of total final consumption. In 2007 EDM acquired 38\% more power from HCB than in 2006.

In terms of performance, in 2007 EDM established 92,145 new domestic and industrial connections, corresponding to $11 \%$ compared to 2006 .

In 2007 the value of electric power exports attained USD 244.8 million against USD 184.2 million in 2006, representing an increase of $32.9 \%$ of the volume of sales on the international market, with prominence for the value of HCB exports, which exceeded the 2006 volume by $31.4 \%$, thanks to sales to the Zimbabwean market.

\section{POLICY MEASURES}

In this sector, the activities planned were basically concentrated on the promotion of growth of the production, export and domestic market sales of electric power, petroleum products, natural gas and its derivatives, so as to increase the contribution of the sector to Gross Domestic Product, the inspection of sector activities, as well as the expansion of the national power grid to the district capitals and administrative posts.

Regarding the national power grid expansion programme, the following activities were carried out:

\section{Cabo Delgado}

With regard to the conclusion of the Substation construction works in Metoro Administrative Post and of the electrification of the Metoro District Capital and the 
Ancuabe Graphite Mine, the Chiúre and Montepuez District Capitals, as well as of Salawe Locality in Metoro and Nanjua and Namanhumbir Localities in Montepuez,

- Civil construction work on the Metoro Substation was resumed to interconnect to Namapa (Eráti), as well as the poles erection works of the Montepuez line after a project work stoppage on the part of the contractor. Due to the contractor's poor performance, the electrification works of the Ancuabe and Chiúre District Capitals were interrupted and postponed to 2008.

Regarding the continuation of the clearing, perforation and others activities with a view to the electrification of Mueda, Muidumbe, Macomia, Meluco, Nangade, Palma, Quissanga and Ibo Districts, in the scope of Phase II of the Cabo Delgado Project, to be concluded in 2009:

- The preparation of the specifications for the electrification of Nangade, Palma, Mueda and Mocímboa da Praia (project lot 1 and 2) is in progress;

- Also in this scope the electrification of Murrébwè Administrative Post in Mecufi District was concluded, the network extended by $3 \mathrm{~km}$ for the electrification of the Alto-Gingone neighbourhood in Pemba Town, the medium tension network extended by $7 \mathrm{~km}$ for the electrification of Muxara, in Pemba Town, and 14,235 consumers connected.

Niassa

With regard to the continuation of the topographical survey, project execution and other activities for the electrification of the capital towns of Mecanhelas, Maúa, Marrupa and Metarica Districts and Entre Lagos Locality, in Mecanhelas, a tender was launched for the construction of the Cuamba-Marrupa section and the evaluation report was prepared.

Continuation of the consultancy, project design, topographical survey and other activities for the electrification of Mepica Locality in Cuamba District, Mecunica Village in Metarica District, Namicundi Administrative Post in Metarica District, Vahiua Village in Maúa District and Matucuta Locality in Majune District; the tender evaluation report was also prepared.

\section{Nampula}

With regard to the conclusion of the electrification of Namapa, Capital of Eráti District; Muecate, Murrupula, Moma, and Nacarôa District Capitals; Chalaua Administrative Post in Moma, Netia Administrative Post in Monapo, Geba Administrative Post in Memba and Mutivaze Administrative Post in Nampula-Rapale and Namaíta Locality in Nampula-Rapale District:

- The electrification of Murrupula and of Geba Administrative Post in Memba was concluded;

- The construction of the high-tension line to Topuito in Moma District was concluded and the electrification of the Moma District Capital was started in the scope of the Moma Heavy Sands Project, and the electrification works in Muecate, Nacarôa, Chalaua, Netia and Namaíta were interrupted, due to the contractor's poor performance. 
Regarding the start of the execution of the network extension works to Nampula Capital, Nacala Porto Capital, Memba Capital and Mecuburi Capital, Namina Locality and the Marratana Refugee Centre in Nampula-Rapale District, the works contract was approved and the updating of the delimitation of zones to be connected to the grid is in progress.

With regard to the electrification of Mutivaze Administrative Post in Nampula-Rapale, the construction of the medium-tension line to Murrupula Capital was resumed.

Regarding the conclusion of the Viability Study for the construction of the Hydroelectric Dam on the Lúrio River, the evaluation of the study report is ongoing; the electrification of Itoculo Village and Muelege Locality in Monapo District was concluded and the installation of pre-paid meters (CREDELEC) in llha de Moçambique District was started, having been installed 900 of the 2,600 allocated meters.

\section{Zambezia}

With regard to the conclusion of the Pebane Capital electrification works, in the scope of the Namacurra Electrification Project - Extension to Pebane, including Mocuba Administrative Post; conclusion of the electrification works of the Gilé District Capital, of the Uapé Substation, the extension of the Alto Molócuè Substation, high and medium tension lines for the electrification of Uapé, Naquissupa and Muiane Localities in Gilé District, and of Morrua and Marropino in Ile District:

- The construction of the medium-tension network was concluded, resulting in the electrification of Pebane District, including Mocubela Administrative Post and Nante and Mocubela Villages, having been connected 250 new consumers;

- 148 tower foundations were made and 86 towers (75\%) erected, as works civil construction works of the Uapé Substation were concluded and the adjustment of the $110 \mathrm{KV}$ line cables is in progress;

- All equipment for the works was acquired and compensations paid to the population living in the demarcated area, and the Maganja da Costa Uapé line was concluded, remaining its operationalization.

With regard to the start of the electrification works of Magiga, Ratata and Nante Localities in Maganja da Costa, in the scope of the Namacurra Rural Electrification Project - Extension to Pebane, the supply lines were concluded to previously identified consumers in Ratata, Magiga and Impaca Localities - Pebane District, and the acquisition of more transformers for the remaining planned localities is in progress.

Also in the scope of the electrification in Zambezia Province,

- Mijalane, Recamba and Marunda Localities in Inhassunge District were electrified;

- Santagua (Quelimane Town), Mucelo Novo and Magodone (Nicoadala) and Malinguine (Namacurra) neighbourhoods were electrified; 
- A 6-km section of the $11 \mathrm{kV}$ network in Quelimane was rehabilitated, in Sangariveira, Coalane II, Catequistado and Chuabo Dembe neighbourhoods;

- A $17-\mathrm{km}$ section of the low-tension network in Quelimane was rehabilitated, in Kansa $(3 \mathrm{~km})$, Santagua $(2.5 \mathrm{~km})$ and Torrone Velho $(3.5$ $\mathrm{km})$, Vila Pita $(1.5 \mathrm{~km})$, Saguar $(4.5 \mathrm{~km})$ and Chirangano $(2 \mathrm{~km})$ neighbourhoods;

- 135 new public lighting points were erected in Kansa, Torrone Velho, Chirangano, Saguar Piloto and Airport neighbourhoods;

- A public lighting network with $16250 \mathrm{~W}$ points built in the Benfica Camp in Quelimane, in the scope of the School Sports Competitions Festival;

- The viability study for the implementation of the Majawa Hydroelectric Power Station Project was concluded and the preparation of the Development Plan by the consortium, aimed at the implementation of the Project, is ongoing.

$\underline{\text { Tete }}$

Regarding the start of the power distribution network expansion and improvement works in Tete Town and in Moatize Town, Moatize District, the replacement of the concrete poles, which are in very bad state, is in progress and civil construction works have started for building a transformer post.

With regard to the continuation of the electrification works of Luenha (the capital of Changara District), Missawa and Mazoe Localities in Changara District, Chicoa and Chipalapala Localities in Cahora Bassa District, the electrification of Luenha (Changara) was concluded, as well as the evaluation of the tender bids for the electrification of the remaining localities.

Concerning the start of the electrification works of the District Capitals of Zumbo, Tsangano, Chifunde, Mágoè (Mphende), Chiúta (Manje), Marávia (Fíngoè) and Macanga (Furancungo), the works contract was approved by the Government, as well as between EDM and the contractors for the execution of electrification works of the Mágoè (Mphende) and Tsangano District Capitals, and the remaining five District Capitals (Zumbo, Chifunde, Manje, Fíngoè and Furancungo).

With regard to the contracting of contractors for the Mozambique - Malawi Interconnection project, the preliminary design of the line by the project consultant was concluded and a contractor pre-qualification tender launched, the evaluation report of which is almost concluded.

Regarding the conclusion of the Viability Study for the implementation of the Moatize Thermal Power Station, on 15 November 2007 a Memorandum of Understanding was signed between the Ministry of Energy and a consortium comprising the AES Southern Africa, EDM-E.P. and Rio Doce Mozambique (RDMZ) companies.

With regard to the start of the establishment of the executor company for the implementation of the Mphanda Nkuwa Hydroelectric Power Project,

- In December 2007 a Memorandum of Understanding was signed between the Ministry of Energy and the consortium created (EDM, Camargo Correa 
and Energia Capital) aimed at giving continuity to the necessary activities with a view to the development of the Project.

Also in this scope and with respect to the Cahora Bassa Hydroelectric Power Station,

- On 27 November 2007 the reversal process of the of the Cahora Bassa Hydroelectric Power Station control and management to the Mozambican State was concluded, with the payment of USD 750 million to the Portuguese Government, thus turning the Government of Mozambique into the largest shareholder holding $85 \%$ of capital stock.

\section{Manica}

Concerning the conclusion of the electrification works of the Guro District Capital, Cruzamento de Macossa, Inhazónia, Nhassacara and Nhampassa Localities in Báruè;

- The Catandica Substation rehabilitation and extension works to supply the above-mentioned places are being concluded, including the installation of the transformers in all places, and the erection of medium-tension poles in the Catandica - Guro section was started.

With regard to the start of the network extension works to Chimoio Town, Gondola Town, Sussundenga Town, Manica- Town and Messica Administrative Post in Manica, the undertaking was approved and the preparation of the specifications is in progress.

Regarding the start of the electrification works of Macossa District Capital, Mandie Administrative Post in Guro, Sussundenga Farmas in Sussundenga District, Chigondore 300 ha-irrigation scheme in Gondola District and Catandica irrigation scheme for 24 farms in Báruè District, medium-tension poles were erected for the electrification of the farms in Catandica.

With regard to the preparation of the specifications for the rehabilitation of the Mavúzi and Chicamba Hydroelectric Power Stations;

- A Memorandum of Understanding was signed between EDM-E.P. and SNPower of Norway for the establishment of a partnership for the rehabilitation and exploitation of the Mavúzi and Chicamba Power Stations, pursuing the activities for the implementation of the rehabilitation and optimisation works.

$\underline{\text { Sofala }}$

Regarding the conclusion of the electrification works of the Marromeu District Capital and the - "Companhia de Sena" sugar Factory,

- The civil construction works of the Marromeu Substation were concluded, 9 foundations were constructed, adding up to 242 foundations of a total of 259 , and 69 towers were erected, adding up to 241 towers of a total of 259.

- 17 timber posts were erected for the provisional line until the arrival of 4 tubular poles, the foundations for the Zambezi River crossing were 
concluded, and the installation of the metal profiles of the 3 foundations in the Chimuara (Caia) Substation was concluded.

With regard to the conclusion of the electrification works of the Caia and Cheringoma District Capitals, as well as the electrification of the Administrative Posts of Murraça in Caia, Inhamitanga in Cheringoma and the Localities of Micane in Cheringoma and Missana in Marromeu, the electrification of the Caia Capital was concluded on 30 December 2007 and the acquisition of 7 transformer posts is in progress.

Regarding the preparation of the specifications for the electrification of the capitals of Chibabava, Machanga, Marínguè, Chembae and Muanza, the Administrative Posts of Muxúnguè in Chibabava, Estaquinha in Búzi, Chupanga, Nensa and Cónduè in Marromeu District and the Localities of Samanda and Goonda in Chibabava, Nhamapaza in Marínguè, Bândua, Nhango, Chironda, Casa Nova, Cherimone and Nova Sofala, as well as Missão São António and Missão São José, Internato and Hospital in Búzi District, Missão Mangunde and Internato in Chibabava, a tender was launched for the electrification of Chibabava-Búzi and additional financing guaranteed by DANIDA and NORAD.

Concerning the contracting of contractors for the execution of the rehabilitation works of the distribution networks of Beira City and Dondo Town, the preparation of the specifications for launching the tender is being concluded, and the contractor prequalification for the selection of companies with sufficient execution capacity was concluded.

\section{Inhambane}

With regard to the conclusion of the electrification project in the district capitals of Morrumbene and Massinga, Morrungulo in Massinga and Cambine Administrative Post in Morrumbene, Mavila, Zandamela, Chissibuca and Banguza Localities in Zavala;

- The following works contracts were signed (Lot 1 and Lots 2 and 3):

- Lot 1: Construction of an 80-km section of the Maxixe Murrumbene - Massinga 33-kV line, including a $10-\mathrm{km}$ branch to Cambine;

- Lot 2: Construction of a 20-km section of the SWER line from Massinga to Murrungulo, construction of a $24-\mathrm{km}$ section of the Quissico - Mavila - Banguza SWER line;

- Lot 3: Installation of 23 three-phase 33/0.4 kV transformers and 100 monophase $33 / 0.23 \mathrm{kV}$ transformers

- Works were late and the contract with the contractor was cancelled for not complying with the stipulations.

With regard to the start of the network extension works in Inhambane Town, Massinga Town and Morrumbene Town, about $10 \mathrm{~km}$ of the Inhambane City lowtension network were extended and the works were suspended due to the poor performance of the contractor.

Regarding the start of the electrification works of Panda Town and the Localities of Helene in Zavala, Urrene and Inhassune in Panda, Nhacoongo and Chacane in 
Inharrime, the works were suspended due to the poor performance of the contractor and the respective contract was rescinded.

Regarding the execution of the viability study for the construction of the Temane Natural Gas Thermal Power Station, the creation was authorized of a consortium comprising the EDM-E.P., INTELEC, Holdings, Lda companies, which selected SUEZ International as strategic partner; the viability study for the construction of a Power Station was done.

\section{Gaza}

With regard to the conclusion of the electrification works of Massingir Town, Chibuto Town, Zongoene Administrative Post in Xai-Xai District, Chalala Administrative Post in Manjacaze District, Canhane, Banga Comercial, Banga Novo, Banga Velho, Chitar, Makhatine, Tchaúque, Vila Mapai, Aldeia 25 de September, Mashoe, Djodjo and Mahanguene Localities in the Limpopo Valley, Chivonguene in Guijá, Chinhacanine and Mavoze in Chókwè, Madendere, Macúacuà, Aldeia das Laranjeiras, Nwadjahane, Coolela in Manjacaze District;

- Aldeia 25 de September, Djodjo, Machinhe, Mahanguene, Zollo, Banga and Massingir in Chokwé District - Massingir and Neighbourhoods 2 and 3 of Julius Nyerere Village and Macamwine Neighbourhood in Xai-Xai were electrified.

- The electrification of Zongoene Administrative Post and of the Localities of Macúacuà and Nwadjahaneis in progress, and

- Specifications were prepared, a study done, manufacturers approved, materials acquired and transported to the works site for the construction of the Chókwè Massingir line. However, 572 poles were already erected.

Concerning the execution of a topographical survey for the extension of the power distribution networks in Manjacaze Town, Chibuto Town, Chókwè Town, Guijá Town, Macia Town, Bilene Town and Xai-Xai and in Chicumbane Locality in Xai-Xai, the contract was approved by the Government and the mobilisation of the contractor to start the works is in progress.

With regard to the creation of the consortium for the implementation of the Massingir Hydroelectric Dam construction project,

- The Hidroeléctrica de Massingir, Lda company was authorized, a consortium comprising ARA Sul, Bruno \& Lopes Moçambique Bruno Lopes/ARA SUL, integrating local private companies, to pursue the necessary activities for the development of the project.

The negotiations of the gas price for the Thermal Power Station in Chókwè District were concluded.

\section{Maputo Province}

With regard to the start of the power distribution network extension works for the electrification of the Manhiça District Capital, the Administrative Posts of Xinavane and Maluana in Manhiça, Mapulanguene and Motaze in Magude, Catuane in Matutuíne, Mumemo, Cumbeza-Zona Eucaliptos and Gwava in Marracuene, Changalane Administrative Post and Mahelane Locality in Namaacha, Sikwama, 
Tsalala, Machava, Bunhiça, Machava-Baião, Singatela, São-Dâmaso, Ndlavela, $1^{\circ}$ de Maio, Khongolote and Tchumene Neighbourhoods in Matola Town, Mahangane, Rádio Técnica, Faixa Quartel and Mahau in Matutuíne District,

- The works contract was signed and the works started, the delimitation of the zones to be electrified was updated, a detailed survey was done and the preparation of the project design is in progress.

Regarding the conclusion of the construction works of the National Clearance Centre,

- The civil construction works of the National Clearance Centre were concluded and the connections to the Remote Terminal Units started (Remote Telecontrol Units in the substations).

With regard to the execution of the viability study for the Natural Gas Thermal Power Station of Moamba District,

- The viability study is being concluded; the station's capacity is estimated at a maximum of $22 \mathrm{MW}$.

\section{Maputo City}

Concerning the start of the power distribution network extension works for the electrification of the CMC/Grande Maputo, G. Dimitrov (Engraxador and Z. Springer), Zimpeto Q1, Malhazine, Inhagoia, Bagamoio, FPLM, Chamanculo, Costa do Sol, Polana Caniço, Hulene, Mavalane Faixa 1, Ferroviário-estaçao and Pescadores Neighbourhoods, the topographical survey and the design of the medium and lowtension networks is in progress. New Substations were built and new equipment was installed to improve the power quality in Laulane, Mahotas and Triunfo.

With regard to the execution of the viability study for the Maputo City Natural Gas Thermal Power Station, the preparation of the terms of reference for contracting consultancy services for the preparation of the technical-economic viability study was started; the station's estimated capacity is $22 \mathrm{MW}$.

\section{Electrification on the basis of generator sets:}

Niassa

Regarding the construction of the electricity network for the electrification of Matchedge Locality in Sanga District, the contractor who will execute the electrification works in the Locality was selected.

\section{Cabo Delgado}

- The electrification of Mucojo Administrative Post in Macomia and Murrébuè Administrative Post in Mecufi was concluded;

With regard to the installation of generator sets and the respective distribution networks in Mazeze and Chiúre Velho Administrative Posts in Chiúre District and Muaguide Administrative Post in Meluco District, the contractor who will execute the electrification works of Mazeze, Chiúre Velho and Muaguide was selected and has started the execution.

Nampula 
The Namaponda Administrative Post Capital in Angoche District was electrified;

\section{Zambezia}

With regard to the rehabilitation of the electricity system for the electrification of Chire administrative Post in Morrumbala District and Chinde Town, the respective works contract was signed and the Administrative Tribunal's Approval was obtained.

With regard to the construction of power stations and low-tension power distribution networks in the Derre Administrative Post Capital in Morrumbala District and the Tacuane Administrative Post Capital in Lugela District, the contractor who will execute the Derre, Chire and Tacuane electrification works was selected and has started the execution.

$\underline{\text { Tete }}$

The electrification works of N'tengo wa Mbalame Administrative Post in Tsangano District were concluded.

The contract with the contractor to execute the Inhangoma electricity network construction works ( $2^{\text {nd }}$ phase) in Mutarara District was rescinded due to poor performance.

\section{Manica}

Concerning the conclusion of the electrification works of Dacata Administrative Post in Mossurize District, the contractor who will execute the works was selected and has started the execution of the works.

\section{Electrification based on Alternative Sources}

\section{Photovoltaic Systems (Solar Panels)}

\section{$\underline{\text { Tete }}$}

Muze Administrative Post in Zumbo District was electrified.

\section{Zambezia}

With regard to the electrification of 50 rural schools in Alto Molócuè, Chinde, Gilé, Gurué, lle, Morrumbala, Manganja da Costa, Inhassunge, Lugela, Namarrói, Mopeia, Pebane and Milange Districts, the contract with the contractor who will execute the works was signed.

With regard to the electrification of 50 rural health centres in Alto Molócuè, Chinde, Gilé, Gurué, Manganja da Costa, Ile, Inhassunge, Lugela, Morrumbala, Milange, Mocuba, Nicoadala, Namacurra, Namarrói, Mopeia and Pebane Districts and the DSC Quelimane, the contract with the contractor who will execute the works was signed.

\section{Nampula}

Regarding the electrification of 50 rural schools in Angoche, Nacarôa, Malema, Meconta, Mecuburi, Memba, Mongicual, Mogovolas, Moma, Monapo, Mossuril, Muecate, Murrupula, Nacala Velha, Nampula, Ribáuè, Lalaua, Eráti and Ilha de Moçambique Districts, the tender was launched and the works contractor was selected. 
Regarding the electrification of 50 rural health centres in Angoche, Erati, Lalaua, Malema, Meconha, Meconta, Mecuburi, Memba, Mongicual, Mogovolas, Moma, Monapo, Mossuril, Muecate, Murrupula, Nacala-velha, Ribáuè, Nacarôa and Nampula-Sede Districts, the tender was launched and the works contractor was selected.

\section{Sofala}

With regard to the electrification of Muxúnguè Administrative Post in Chibabava District,

- The Muxúngue rural hospital in Muxúngue - Chibabava District was electrified on the basis of solar panels; and

- Chupanga Administrative Post in Marromeu District was electrified on the basis of photovoltaic systems, including the water supply system covering 3,500 beneficiaries.

Niassa

Concerning the electrification of Lissete Administrative Post in Mandimba District, Ngaúma Velha Administrative Post in Ngaúma District and Nacúmua Administrative Post in Metarica District, the tender was launched and the works contractor was selected.

\section{Mini-Hydroelectric Power Stations}

Tete

The electrification of Kazula Administrative Post in Chiúta District is in progress.

Manica

With regard to the electrification of Rotanda and Sembézia Administrative Posts in Sussundenga District, Mavonde Administrative Post in Manica District, and Honde Locality in Báruè District,

- The tender was launched for the selection of the consultant to do the socioeconomic study for the construction of a new mini-hydroelectric power station in Mavonde and the rehabilitation of a water mill and the commercialisation of EBAF equipment in Rotanda Administrative Post;

- A comparative study is in progress between the installation of a new minihydroelectric power station or the connection to the National Power Grid;

- The TORs are being concluded for the contracting of a contractor who will execute the construction of a mini-hydroelectric power station in Mavonde; and

- Repair of the damage caused by the heavy rains occurred in Honde during the night between 31 December and 1 January 2007 was concluded.

\section{Zambezia and Niassa}

The electrification project of the Majaua Administrative Post community in Milange District in Zambezia was submitted to and approved by the European Commission in the scope of the European Union's Energy Facility Initiative. 
With regard to the conclusion and dissemination of the results of the survey of potential small-scale hydroelectric power plants, so as to create a database of potential mini-hydroelectric power stations, in Zambezia and Niassa, data collection was concluded and the conclusion was drawn that the data should be improved to produce reliable information based on the GIS (Geographic International System).

\section{Promotion of the Sustainable Use of Energy Resources through the Diversification of Energy Sources based on Biomass}

\section{Zambezia}

The implementation of the electric power generation project on the basis of coco shells in the Chinde District Capital, in Micaúne Administrative Post and in Bajone Locality in Maganja da Costa District became unviable due to the fatal yellowing of the coconut palms, which reduced the availability of coco shells.

\section{Sofala and Maputo}

Regarding the implementation of the improved ovens and stoves project:

- 800 portable stoves were produced in Beira City and 16 institutional stoves built in health centres, educational establishments, prisons and barracks in Beira City and in Dondo District.

- 1,000 portable stoves were produced in Magude and Marracuene Districts and 19 fixed institutional stoves were built in health centres, educational establishments, barracks and prisons, as well as 16 fixed domestic stoves in houses in Magude, Moamba and Boane Districts.

\section{Remaining Provinces}

With regard to the dissemination of improved ovens and stoves in the various provinces of the country,

- A training course on the production of portable and fixed improved stoves was conducted in Sofala, involving all provinces of the country. The course resulted in the training of 19 potters and 10 technicians, 1 from each Provincial Directorate of Mineral Resources and Energy;

- Training courses were held in all provinces of the country about the production of improved ovens, having resulted in the training of 28 charcoal burners in each province;

- Trainers were trained at national level and the dissemination of the stove project at level provincial was started;

- In all provinces infrastructures were built, such as: 1 ceramic oven, which has also been used for the production of vases, bowls, pots, etc, 2 potter's wheels, 1 to 2 tanks for the conservation of water, and a house to store pieces of ceramic work.

Niassa

- 10 stoves were installed in 10 institutions: 1 simple stove in the Provincial Hospital, 1 triple stove in the Civil Prison, 1 simple stove in the Boardinghouse of the Utuculo Training Centre, 1 stove in the Josina Machel Girls' 
Boarding-house, 1 double stove in the Dom Luís Gonzaga Child Centre and 1 double stove in the Boarding-house of the Basic-Level Agricultural School;

\section{Cabo-Delgado and Nampula}

- Potters were trained in the production of pieces of ceramic work and bricks.

\section{Zambezia}

- 350 pieces of ceramic work and bricks were produced and burnt for the installation of stoves; stoves were installed in the following establishments: Boarding-house 25 de September, IMAP, Boarding-house dos Continuadores in Cualane, Boarding-house $1^{\circ}$ de Julho in Coalane, Boarding-house 17 de September, Sangariveira Female prison and $5^{\mathrm{a}}$ Girassol Prison.

Tete

- 350 pieces of ceramic work and bricks were produced and burnt for the installation of fixed stoves; 11 stoves were installed (1 double stove for each, in the Moatize Hospital, in the Moatize Medium-Level Geology and Mines Institute, Moatize District Prison, São José Orphanage and Elderly Support Centre, Navy Barracks and Hotel Kaswende and 2 stoves for each in the Tete Provincial Hospital and the Tete Provincial Prison).

Sofala

- The project was officially launched and 16 stoves were installed in 12 institutions:

- Beneficiary institutions were: 1 simple stove in the $3^{\text {rd }}$ Special School, 1 double stove for each in the Chingussura Health Centre and Elderly Support Centre; 2 double stoves in the Rocket Brigade, 2 quadruple stoves in the Military Training Centre; 3 double stoves in the Beira Airforce Base and 7 triple stoves for each in the Adult Education Institute, the Inhamizua Teacher Training Institute, the Dondo Boarding School, the Beira Health Science Institute, the Military Administration and Commandos Unit.

Inhambane

- About 800 pieces of ceramic work were produced and burnt for the installation of fixed stoves, and 5 families received fixed domestic stoves:

- Beneficiary institutions were: 9 double stoves for each in the Chicuque Rural Hospital, the Chambone Boarding-house, the Emília Daússe Boarding-house, the Emília Daússe Teacher Training Centre in Chicuque, 3 de Fevereiro, the FIR Command, the Cumbana Rural Hospital, the Jangamo Rural Hospital, the Eduardo Mondlane Boarding-house, 2 double stoves and 1 simple stove in the barracks, 2 triple stoves in the Inhambane Hospital and the Inhambane Provincial Prison.

Gaza

- 500 pieces of ceramic work and about 2500 size-10 bricks and 1000 bricks and 30 pieces of ceramic work were produced and burnt for the installation of fixed stoves; a total of 11 fixed stoves were installed in social institutions, and 4 families benefited also of fixed stoves: 
- Beneficiary institutions were: 2 double stoves for each in the Manjacaze Hospital and the Provincial Hospital; 1 double stove for each in the FIR, the Xai-Xai Arts and Crafts School, the Provincial Nursery School and IMAP; 1 triple stove in the Joaquim Chissano Secondary School and 2 triple stoves in the Provincial Prison.

- The project was officially launched.

\section{Fuels}

With regard to the dissemination and implementation of the Decree governing the production, distribution and commercialisation of petroleum products,

- The Decree was published in June 2007, 3 regional seminars were held, covering the Northern, Central and Southern Region, for the dissemination of the Decree and the implementation at national level of the provisions of Decree 63/06 of 26 December is ongoing.

The preparation and adoption of technical regulations with standards for the construction of storage infrastructures, the distribution, the commercialisation and transport safety of petroleum products and natural gas is being concluded.

The preparation of the viability study for the production of LPG from natural gas components is being concluded.

With regard to the continuation of the implementation of the Illuminating Paraffin Use Expansion Project in the rural areas:

- The sites for the expansion of the project in Niassa Province were identified (Mecula, Mavago, Nipepe and Mecanhelas) and local operators to benefit from financing for the implementation of the project are being identified;

- Ten paraffin sellers received FUNAE loans in the scope of the expansion of the fuel distribution network in the remote zones Chiúre, Montepuez, Namuno, Meluco, Muidumbe, Palma and Mecufi. Districts.

With regard to the increase of access to fuel for the Marrupa and Lago District Capitals in Niassa Province, an agreement was signed to finance fuel commercialisation in the supply point situated in Luambalo Locality in Majune District.

Concerning the conclusion of the natural gas market study:

- The technical and economic viability study for the construction of the natural gas distribution network in Maputo City and in Marracuene District is in its final phase and activities are being carried out with a view to the construction of the second fuel storage project in Beira Port.

\section{FISHERIES}

Fish production decreased by about $3.3 \%$, due to a decrease of commercial production and of aquaculture.

The negative performance of industrial and semi-industrial fishing is largely explained by the fact that about $20 \%$ of the fishing units did not sail. The escalation 
of the fuel price on the international market, decapitalization of a large part of the operators and market problems stand out among the factors behind this.

Table 28: Overall Fish Production (Growth rates in \%)

2007 PL

\begin{tabular}{|l|}
\hline 3.5 \\
\hline 5.4 \\
0.0 \\
0.0 \\
0.0 \\
\hline
\end{tabular}

2007 REV

\begin{tabular}{|r|}
\hline-3.3 \\
\hline-6.2 \\
0.8 \\
-1.7 \\
2.4 \\
\hline
\end{tabular}

The decreases occurred in the catch of kapenta, the production of which suffered a large decrease of $44.5 \%$, and of shrimp, the capture of which decreased by $24 \%$, contributed to this fall.

Table 29: Commercial Fish Production

\begin{tabular}{|c|c|c|c|}
\hline Type & $2007 \mathrm{PL}$ & 2007 REV & \\
\hline & (Tons) & (Tons) & (Real growth rate) \\
\hline Lobster & 2 & 8 & $0.0 \%$ \\
\hline Crab & 160 & 125 & $16.8 \%$ \\
\hline Shrimp & 1,850 & 1,366 & $-24.2 \%$ \\
\hline Fish & 600 & 658 & $-1.1 \%$ \\
\hline Prawns* & 9,200 & 7,701 & $4.2 \%$ \\
\hline Crayfish & 100 & 153 & $62.8 \%$ \\
\hline Squids \& octopus & 160 & 138 & $21.1 \%$ \\
\hline Kapenta & 13,500 & 8,882 & $-44.5 \%$ \\
\hline Accomn fish & 1,500 & 873 & $-49.4 \%$ \\
\hline Total & $\overline{27,072}$ & 19,904 & \\
\hline
\end{tabular}

The unfavourable climatic conditions are behind the decrease of kapenta catch, while for shrimp it apparently is the voluntary reduction of the production capacity on the part of the ship owners due to the difficult conditions of access to international market. Of the 20 fishing boats allocated to the shrimp fishing campaign, only 15 sailed during the year.

The commercial prawn catch, excluding aquaculture production, attained about 7,008 tons, representing $88 \%$ of the about 8,000 tons planned in the 2007 PES.

The overall volume of catch (excluding aquaculture) attained 19,211 tons.

Table 30: Aquaculture Production

Aquaculture
\begin{tabular}{|lc|cc|}
\hline Pescaria & 2007 PL & & 2007 Rev \\
\hline & (Tons) & (Tons) & (Real growth rate) \\
Marine prawns & 1,200 & 693 & $-30.4 \%$ \\
Marine algae & 30 & 69 & $360.0 \%$ \\
Fish & 70 & 145 & $173.6 \%$ \\
\hline Total & 1,300 & 907 & \\
\hline
\end{tabular}


Aquaculture prawns production amounted to 693 tons, representing $58 \%$ of the about 1,200 tons planned in the 2007 PES. The fall basically results from the closure in May 2007 of one of the three important aquaculture units.

Table 31: Traditional Fish Production

\begin{tabular}{|lc|cc|}
\hline Type & 2007 PL & \multicolumn{2}{c|}{ 2007 REV } \\
\hline Lobster & (Tons) & (Tons) & (Real growth rate) \\
Crab & 5 & 33 & $560.0 \%$ \\
Fish & 170 & 105 & $-40.0 \%$ \\
Inland water fish ${ }^{*}$ & 50,000 & 41,537 & $-27.7 \%$ \\
Prawns & 7,000 & 14,425 & \\
Acetes & 2,000 & 781 & $-42.9 \%$ \\
Cephalopodas & - & 1,946 & $-3.6 \%$ \\
Sharks & 200 & 540 & $118.6 \%$ \\
Other & 600 & 720 & $-7.2 \%$ \\
Accomp. f & 1,500 & 2,176 & $12.9 \%$ \\
\hline Total & & 5,522 & \\
\hline
\end{tabular}

Traditional fishing attained a production of 67,785 tons against 61,475 tons in 2006 . It should be noted that a large part of the information of the traditional fishing review excludes the month of December 2007.

There was a high level of catch in inland waters, 14,425 tons against 7,000 tons planned. This level of catch was due to the enlargement of the sampling area, having also been included Massingir and Niassa data.

\section{POLICY MEASURES}

In this sector the activities carried out were basically a continuation of the pursuance of its central objective, which is to contribute to economic growth and to the sustainable development of fisheries, with prominence for the improvement of the fishing communities' living conditions. Thus, during the year 2007 the following activities were performed:

In the scope of traditional fishing,

- The II National Traditional Fishing Census was taken covering seawater and inland waters, and data processing was concluded;

- Fishing extension activities were carried out, consisting of experimental fishing and the dissemination of fishing techniques and skills, the experimental introduction of low-cost engines, training in improved fishing techniques, catch handling, processing and conservation and the organisation of fishing communities;

- Training was given in improved fishing techniques, catch processing and handling, involving a total of 831 traditional fishermen and processors in the Provinces of Cabo Delgado (173), Niassa (56), Nampula (115), Tete (114), Zambezia (174) and Inhambane (178);

- A total of 3,310 beneficiaries, of which $44 \%$ women, received training in the field of savings and rotational credit in the Provinces of Cabo Delgado (36), Nampula (148), Zambezia (234). 
Regarding aquaculture, the Aquaculture Development Strategy was prepared and approved by the Council of Ministers.

In commercial aquaculture, the following activities were worthy of note:

- Monitoring of the activities of the three commercial aquaculture companies in Cabo Delgado, Zambezia and Sofala Provinces.

- Start of industry consultations to discuss and enrich the Code of Conduct, aimed at a sustainable prawns production.

- Updating of the inventory of the potential development of marine aquaculture in the coastal zones of Maputo, Gaza, Inhambane, Sofala, Zambezia, Nampula and Cabo Delgado Provinces.

In the domain of pisciculture,

- The practice of pisciculture in inland areas was promoted, consisting of the implementation of improved aquaculture techniques, support to pisciculture development initiatives, training was given to fish breeders and extensionists, and the potential development of freshwater aquaculture was evaluated;

- Technical assistance was provided, consisting of an evaluation of the tank construction methodology and conservation, of the level of fish development through fishing trials, and of fish feeding techniques;

- Fish breeders and extensionists were trained in the methodologies of savings and rotational credit and activities were carried out to guarantee access to micro-credit for the fishing communities in the areas of intervention.

Regarding fisheries research,

- The situation of fish resource exploitation was monitored and evaluated. A significant growth was observed due to a comprehensive research cruise carried out in the last quarter along the whole Mozambican seacoast, until a depth of $800 \mathrm{~m}$. Data on the main resources of commercial value and on the environment were collected;

- Continuity was given to the evaluation of the situation of prawn fishing on the Sofala Bank, of shrimp and of line fishing;

- The situation of the resource was monitored and evaluated and an evaluation cruise was carried out of the source of the kapenta;

- A one-month research cruise was carried out regarding shrimp fishing, with the Spanish research ship, and a report was prepared and disseminated within and outside the sector;

- 15 specific studies were done, including about white prawns, grouper, rock-bass, tilapia, magumba and other small marine animals, with a few study reports already concluded.

The activities performed in the area of aquaculture research include the preservation, renewal and cleanup of the micro algae culture and the conclusion of 
the fieldwork of the aquicolous and hydrobiological study of the Pemba Bay, as well as the establishment of the Tilapia Fry Production Laboratory in Marracuene.

With regard to sport fishing, a Sport and Recreational Fishing Census was taken in all 4 provinces of the Southern Region (Maputo Province, Maputo City, Gaza and Inhambane) and the respective data processing is in progress.

Concerning catch inspection and quality control,

The activities carried out in this scope were focussed on the institutional establishment and autonomization of the National Catch Inspection Institute (INIP) at provincial level. To this end,

- The Sofala Branch was created and the premises of the INIP Branch in Maputo Province were rehabilitated,

- The preparation was started of the creation of an INIP Branch and an Agency in Angoche and Nacala Districts in Nampula Province respectively, which is in an advanced stage. The offices that will house the Branch have been rehabilitated and a residence for the Delegate was acquired in the same town.

- A revision was carried out of the Licensing and Health Certification Procedures, which were published in the Bulletin of the Republic (the Government Gazette) and in pamphlets disseminated in the industry.

So as to render the licensing and health certification process more effective,

- The licensing database was consolidated and a health certification and laboratories database was created.

- Divers laboratory equipment was acquired for doing analyses of heavy metals, representing added value for the sector, considering that these analyses will no longer be done in South Africa, as was previous practice.

With a view to ensure the quality of fishing and aquaculture products and their compliance with the demands of the international market,

- A new version of the National Residue and Heavy Meta Control Plan was produced and approved;

- Contacts with the industry were intensified and training was given in product contamination risk analysis as a measure to ensure the desired quality of the fishing products they handle.

So as to reduce the dependence of the Mozambican fishing products on the European Union market, the INIP, in collaboration with the Eduardo Mondlane University, organised courses aimed at providing the industry and fisheries inspectors with knowledge about the necessary health requirements for fishing products exports to the United States of America.

In the scope of hygiene and health it was possible to ensure the development of production and processing conditions, as well as of inspection capacity comparable to international standards, allowing access to the export markets for fishing and aquaculture products.

In the scope of fisheries management and administration, 
- The first version of the draft of the Inland Water Fishing Regulation was concluded and internal consultations are currently in progress;

- The structure of the draft of the new Fishing Law was designed and the text is currently being drawn up;

- Through a Ministerial Diploma the fishing breaches process regime was approved and through another Ministerial Diploma the fishing licence request form was amended;

- The preparation of the National Plan for the Combat of Unreported and Unregulated Illegal Fishing was concluded, a beginning was made of the preparation of the Sofala Bank prawn fishing management plans and for line fishing south of the $21^{\circ} \mathrm{S}$ parallel, as well as a demonstration in Beira City of the use of TEDs and the supervision of VMS equipment aboard the fishing boats.

Regarding the strengthening of inspection capacity, an important activity was the freight for a two-year period of an inspection boat and the acquisition of two inflatable semi-rigid boats for carrying out the offshore fishing inspection activities. Inspection equipment was also acquired, namely: 3 long-range SSB HF radios, and a GPS for the inland provinces, namely Niassa, Tete and Manica.

In the scope of infrastructures and fishing equipment,

- The Angoche Fishing Port Quay was rehabilitated;

- The first phase (studies) of the Beira Fishing Port Rehabilitation Project was concluded and the works tender was launched;

- The new Catch Inspection Laboratory and offices of the Provincial Fisheries Directorate in Quelimane were officially inaugurated.

In the scope of the integrated community development projects, involving the beneficiary communities themselves, we point out that,

- The construction works of four markets in Nampula, Zambezia, Sofala and Cabo Delgado were concluded;

- The construction works of three schools in Sofala were concluded; in Nampula Province 24 water sources were built/rehabilitated; 2 water captation systems in the Angoche (1) and Mogincual (1) Health Centres were constructed;

- Maintenance was done of access roads to fishing centres in Nampula: $92.5 \mathrm{~km}$ of main roads $(52.5 \mathrm{~km}$ in Mogincual, $35 \mathrm{~km}$ in Angoche, $5 \mathrm{~km}$ in Moma). Additionally, a total length of $8.5 \mathrm{~km}$ of community sections was opened in Moma $(3.5 \mathrm{~km})$ and Angoche $(5 \mathrm{~km})$; in Zambezia: a total length of $166 \mathrm{~km}$ of roads in Pebane $(136 \mathrm{~km})$, Maganja da Costa $(14 \mathrm{~km})$ and Nicoadala $(16 \mathrm{~km})$ Districts.

In the scope of fishing promotion,

- Credits were granted to traditional fishermen on the basis of rotational credit funds at the total value of 1.96 million meticais to 239 beneficiaries in the provinces of Niassa (13), Nampula (13), Tete (65), Sofala (1), Manica (102), Inhambane (34), Gaza (10) and Maputo (1); 
- Loans were granted to 3 microfinance institutions regarding the integrated project credit line, namely: the Small Industry Promotion Fund, AMODER and GAPI, which play a retail role for the beneficiary communities;

- The construction of 4 buildings for the Chicôa Park in Tete Province was concluded;

- An ice production factory was established in Machanga District;

- The activities of the Mbuna Mozambique company, specialised in the exploitation of ornamental fish in Lake Niassa for export, were revitalized;

- The Inhambane fishing scheme was made operational and its productive capacity of 2,000 kg/day re-established.

Regarding international cooperation,

- The integration of Mozambique in the international arena was maintained through participation, at technical and political level, in specialized meetings of FAO, the SWIOFC Commission, the African Union and SADC, which are dialogue platforms for reaching agreement about the fishing and aquaculture development agenda at global and regional level.

- Bilateral collaboration was enlarged through the signing of three new Fishing and Aquaculture Cooperation Protocols with Angola, Spain and Vietnam.

- New relationship terms with the EU were adopted, through the signing of the Partnership Agreement in the field of fishing, and consultations started with a view to the adoption of cooperation instruments with Brazil and Chile.

Grants were received from 13 partners and loans from 4 international finance institutions, resulting in the execution of 13 national and 3 regional projects.

\section{MINERAL RESOURCES}

Mineral production increased by $10.0 \%$ compared to the year 2006 . This growth is due to the increase of the production of limestone, tantalite, beryl, garnet, cracked stone, marble, seawater matter and natural gas. 
Table 32: Mineral Production

MINERAL RESOURCES - Growth rates in (\%)

\begin{tabular}{|lll|}
\hline TYPE & $\mathbf{2 0 0 7} \mathbf{P L}$ & $\mathbf{2 0 0 7}$ REV \\
\hline Pitcoal & 76.2 & -42.4 \\
Bauxite & 10.2 & -21.9 \\
Graphite & 0.0 & 0.0 \\
Raw bentonite & 80.5 & 0.0 \\
Treated bentonite & 16.7 & 10.2 \\
Sorted bentonite & 66.7 & 176.1 \\
Activated bentonite & 0.0 & 0.0 \\
Marble in sheets & 20.2 & 29.8 \\
Marble in blocks & 4.9 & 13.3 \\
Polishable garnet & 26.1 & 55.1 \\
Plished stones & 0.0 & 0.0 \\
Gold & 19.4 & 11.6 \\
Scrap seawater & 16.2 & 29.6 \\
Tourmaline & 26.4 & -99.4 \\
Tantalite & 20.8 & 145.1 \\
Beryl & 28.3 & 86.6 \\
Sand & 9.1 & 4.7 \\
Limestone & 58.3 & 766.1 \\
Rhylites & 33.3 & -1.6 \\
Granites & 0.0 & 0.0 \\
Dumortierite & 10.0 & -90.5 \\
Natural gas & 1.9 & 2.3 \\
\hline TOTAL & $\mathbf{1 1 . 0}$ & $\mathbf{1 0 . 0}$ \\
\hline
\end{tabular}

Limestone production increased significantly, having attained $1,350,000.0$ tons against $155,870.0$ tons produced in 2006 , representing a growth of $766.1 \%$.

The production of tantalite has been quite positive in the last few years. As a matter of fact, production increased by $145 \%$ compared to 2006 , so above the forecasts. Tantalite production increased as a result of the improvement of the processing plant in Marropino, which will lead to an increased exploitation of the mineral resources.

Pitcoal production was planned to increase by about $76.2 \%$. However, only $23,601.5$ tons were produced, against 40,952.6 tons produced in 2006, representing a decrease of $42.4 \%$, due to the temporary closure of the Chipanga XI underground pit in Moatize for security reasons.

The negative growth (-21.9\%) of bauxite production in Penha Longa, Manica District, was due to the constant interruptions of power supply and to access problems.

Argil production was not satisfactory, as the constraints occurred in the first half of the year seriously affected the annual production level. Production amounted to 22,000.0 tons against 22,051.9 tons produced in 2006.

Natural gas production increased by $2.3 \%$ and it continues having the greatest weight in the overall structure of the sector. Its contribution is decisive of the overall production level.

In May 2007 the production of heavy sands in Moma started. During the year 175,644 tons of concentrate were produced. The concentrate separation process is carried out in phases. In 2007 only the first phase occurred, in which the concentrate 
is extracted and kept in stock for subsequent extraction of zircon and rutile. Thus production amounted to 141 thousand tons of ilmenite against 350 thousand tons planned, 26 thousand tons of zircon against 30 thousand tons planned and 8.8 thousand tons of rutile against 9 thousand tons planned.

\section{POLICY MEASURES}

In this sector the planned policies aimed at the promotion of the prospecting and exploration of heavy minerals, base metals, precious metals, gold and diamonds, the preparation and publication of geological maps, the rehabilitation and expansion of the country's seismographic stations, small-scale and traditional mineral exploitation and the promotion of the establishment of mineral processing and primary transformation industries in the country. For this purpose, the following activities were performed during 2007:

Geological area:

Regarding the heavy sand minerals prospecting and exploration promotion programmes in areas stretching from Quelimane to Quinga in Zambezia and Nampula Province, respectively, the following is worthy of note:

- The heavy mineral prospecting and exploration activities in the licensed areas along the coastal strip were continued. These areas include the above planned, allowing the identification of additional reserves in the Moma heavy sands deposit;

- Start of the production of heavy mineral concentrate.

With regard to heavy sand minerals prospecting and exploration, namely in Xai-Xai, Chongoene until Inhambane, Micaúne, Deia, Pebane and the development of the Chibuto and Moebase heavy sands projects:

- The aerial-photographic studies and digital field studies were concluded in Xai-Xai and Chongoene in Gaza Province and in Jangamo in Inhambane Province.

- The geological mapping was carried out for soil classification with a view to the selection of mechanical sounding sites.

- Studies were done on the social environment of the communities living in the exploration areas.

- The prospecting and exploration activities in the licensed areas in Micaúne, Deia and Pebane in Zambezia Province continued;

- In the Moebasse heavy sands project additional mineralogical tests were carried out for the design of the processing plant;

- The Technical-Economic Viability Study of the Chibuto Heavy Sands Project was submitted and validated. Laboratory tests are being carried out for the characterization of the heavy minerals.

Regarding the inventorying of non-metallic minerals in Maputo, Gaza and Inhambane Provinces and of mineral and thermal water in the whole country, 
- The collection of argil samples for laboratory analyses is in progress, with the aim to determine their suitability for the production of ceramic materials by the local population, and

- Fieldwork was done in Mutamba, Jangamo District; in Inharrime; in Jofane, in Govuro District; in Nova Mambone; in Vilanculos and Panda, in Inhambane Province, and the mineral and thermal water inventorying project was prepared. Fieldwork is expected to start in the second quarter of 2008.

Concerning the preparation and publication of geological maps on the basis of geological base mapping,

- Modern geological maps were produced and published, according to international standards, at a 1:250,000 scale, covering the whole country, as well as 1:50,000 geological maps of a few potential mineral resource regions in Niassa, Tete and Manica Provinces,

- New geophysical data were prepared, covering the western part of Mozambique, namely Manica and Maputo Provinces and part of Tete, Inhambane and Gaza Provinces.

With regard to guaranteeing the continuation of prospecting and exploration in selected areas of Mocuba and in areas indicated as "mining ticket" areas in Namunonono in Zambezia, Cuamba in Niassa, Moma, Monapo, Nacarôa, Mecubúri and Murrupula in Nampula,

- Exploration activities were carried out in Moma, Monapo, Nacarôa, Mecubúri and Murrupula Districts in Nampula Province, and recommendations were made for areas to be indicated. Fieldwork was also done in Namunonono in Zambezia Province;

- The preparation of the prospecting and exploration project was concluded for selected areas of Mocuba and areas indicated as mining ticket areas in Namunonono in Zambezia, Cuamba in Niassa, Moma, Monapo, Nacarôa, Mecuburi and Murrupula in Nampula;

In the scope of updating the 1:1,000,00 geological map of Mozambique,

- Work was done on the compilation (preparation of base maps and topographical maps with rivers, roads, localities) and edition of the map (joining and uniformization of the 1:250,000 geological maps symbology); the correction and integration of geological units, as well as the preparation of the Explanatory Note are in progress.

- Work was done on the compilation and edition of the 1:250,000 geological map so as to guarantee the updating of the $1: 1,000,000$ geological map of Mozambique.

Regarding the environmental geological mapping of the coastal zone of Mozambique on a scale of 1:50,000 and the preparation of the 1:50,000 Engineering Geology Map of Maputo,

- Work was done on the correction of the eastern part of the $1: 50,000$ Geological Map of Catembe, as well as on the preparation of the Explanatory Note; 
- Work is in progress on the production of the preliminary version of the 1:50,000 Geological Map of the Greater Beira Area and on the correction and preparation of the Explanatory Note of the 1:25,000 Geological Map of Bazaruto Island;

- Information was collected on soil maps, water boreholes, wells and geotechnical data in several institutions that produce geoscientific information;

- Work was done on information collection, inventorying and surveys for the production of the 1:50,000 Geo-Environmental Map of the Maputo Metropolitan Area.

With regard to the rehabilitation and expansion of the country's seismographic stations in Mueda, Mocuba and Massingir,

- New equipment was installed in the Lichinga and Manica stations, which allows the continuous despatch of data to the Seismic Data Processing and Analysis Centre in Maputo;

- Inspections were carried out in Massingir, Mocuba and Mueda, in Gaza, Zambezia and Cabo Delgado Provinces respectively, for the construction of seismographic stations.

Concerning the promotion of geological studies for the evaluation of the carboniferous potential of areas adjacent to the Moatize deposit and of other areas situated in Tete, Niassa, Cabo Delgado and Manica Provinces:

- Mapping activities started in the areas adjacent to the Moatize deposit, in Benga (1) and the north of Rovubué (3), on the basis of aerogeophysical data and samples collected on-site (Mutarara, Cahora Bassa, Mucanha Vuzi and the north of Revubúe);

- Samples were collected in the coal outcrops in Mandimba District in Niassa Province and in the Lugenda River Basin in Cabo Delgado Province and sent for laboratory analyses to determine the quality of the coal. The sounding programme to determine the reserves and conditions of the Espungabera deposit in Mossurize District in Manica Province is being prepared.

With regard to the promotion of the dissemination of geological base information of the country for the identification of new deposits with exploitation potential,

- The geological database was improved through the production of 1:250,000 geological maps covering the whole country; as a result, existing aerogeophysical data cover about $75 \%$ of the country;

- Pamphlets were produced containing a summary of the country's geological information, available at the various MIREM institutions and on its Website http://www.dng.gov.mz.

Regarding preparations to guarantee that the XXVII Meeting of the of SEAMIC (Southern and Eastern African Mineral Centre) Governmental Council will take place in May.

- From 29 to 31 May the $27^{\text {th }}$ Meeting of the of the Southern and Eastern African Mineral Centre (SEAMIC) Governmental Council was held in Maputo 
with the presence of delegates from Angola, Ethiopia, Kenya, Mozambique, Tanzania and Uganda.

With regard to the continuation of the implementation of the project to create the National Geological Museum,

- The rehabilitation and modification works of the National Geology Museum were concluded, a new permanent exhibition of geology and mineral resources was opened to the public and the Mozambican ACT/UIS Laboratories were inaugurated in Tete, to support the geological and mining activities, particularly those carried out in the Central Region.

Mining Area:

With regard to small-scale and traditional mining and support to small national mining operators trough technical assistance, investment facilitation and environmental education and training in Manica, Zambezia and Nampula Provinces,

- Training activities were carried out in Munhena, Sussundenga and Bandire, in Manica Province with the participation of local traditional miners associations, as well as in Muva and Jagoma in Mogovolas and Moma Districts, respectively, about gold extraction and processing techniques.

- The construction of the gold processing plant of the Munhena pilot project in Manica was concluded; pumps, hoses, shovels and pickaxes were acquired for the associations of Mimosa in Manica, Namunonono in Zambezia and Muva in Nampula; and activities were carried out in Niassa, Nampula, Zambezia and Maputo Provinces with a view to mitigate the negative environmental effects resulting from traditional mining;

- Production equipment was acquired and hired out to two small-scale mining companies, one in Zambezia Province and the other one in Nampula, engaged in the production of construction stones; computer equipment was also acquired to support the Association of Mozambican Operators (Amomine);

- Following the placing of technicians in the Districts, technical assistance activities are ongoing in Manica, Zambezia and Nampula Provinces, as well as the monitoring of mining activities and environmental management;

- Four houses for the employed technicians were built in Lalaua (1), Nacala (1) and Moma (2) Districts.

Regarding the continuation of the promotion of ornamental rock exploitation in Tete, Manica, Sofala and Cabo Delgado, ornamental rock prospecting and exploration activities were carried out in the licensed areas in Tete and Manica Provinces, and the promotion of ornamental rock exploitation is ongoing.

With regard to the continuation of the promotion of the exploration and prospecting of base metals, precious metals, gold and diamonds in Cabo Delgado, Niassa, Tete, Manica and Zambezia Provinces,

- Prospecting and exploration activities of base metals, precious metals, gold and diamonds in Cabo Delgado, Niassa, Tete, Manica and Zambezia 
Provinces are in progress, as well as the evaluation of copper reserves in the Mundonguara mine in Manica;

- Gold and base metal prospecting and exploration were carried out in Manica, Tete, Niassa, Cabo Delgado and Zambezia Provinces.

- The alluvium gold mine in the Mutambarico region in Manica District was inaugurated.

With regard to the promotion of the establishment of minerals processing and primary transformation industries in the country, premises in Nampula were identified and rehabilitated with a view to the establishment of a Gemmology and Gem Cutting Centre, while the identification of the respective equipment for subsequent acquisition is in progress; in addition, the $1^{\text {st }}$ International Mozambican Mineral and Gem Trade Fair was held from 25 to 28 October, with the participation of 14 local exhibitors, and the presence of about 15 international operators.

Concerning the promotion of the exploitation of industrial mineral deposits, with a view to the establishment of fertilizer industries in the country,

- Guano prospecting and exploration activities were carried out in Búzi and Cheringoma in Sofala Province, Inhassoro and Mabote in Inhambane Province; the same was done for diatomite in Manhiça, Maputo Province and for apatite in Monapo in Nampula Province;

- A beginning was made with the diatomite promotion project with a view to its use in agriculture and livestock breeding in Maputo Province, and the use of limestone in agriculture in Nampula Province, in coordination with the Ministries of Agriculture and Science and Technology and the Eduardo Mondlane University;

- Field tests were started in Mafuiane, Boane District, Maputo Province for the use of diatomite in agriculture, involving 13 peasant members of the Mafuiane Irrigators Association; cucumber, green beans, nhemba beans and okra were selected for the tests.

- The design of the project for the use of diatomite in livestock breeding was concluded;

- A beginning was made with the collection of test soil samples in Nampula, Zambezia and Niassa Provinces for the use of limestone in agriculture.

Regarding the strengthening of the mining inspection and control capacity and the dissemination of mining legislation,

- A study was prepared on gold mining and commercialisation in the country, and inspections were carried out in Maputo, Sofala, Manica, Tete, Zambezia and Nampula Provinces, covering most of the licensed areas.

- $6,300 \mathrm{~kg}$ of corundum were confiscated in Changara District, Tete Province; $113 \mathrm{~kg}$ of diamond stones in Machipanda, Manica Province; $8.5 \mathrm{~kg}$ of tourmaline in Báruè District, Manica Province; $24 \mathrm{~kg}$ of tourmaline in Vandúzi, Manica Province; and $1 \mathrm{~kg}$ of smoked quartz in Manica, in coordination with the Mozambican Police; 
- Last June a meeting was held in Nampula with inspectors attached to the various Provinces, for the study and dissemination of the Mining Legislation, with emphasis on the Mining Law and its Regulations (Regulation of the Mining Law and the Technical Safety and Health Regulation for GeologicalMining Activities);

- The attachment of inspectors in Murrupula, Nacala, Lalaua, Mecuburi and Nacaroa Districts in Nampula Province proceeded;

- Meetings were held with mining title holders, the Mining Legislation was disseminated and there was an exchange of experience between the various participants about healthier ways to develop the activity as well as to allow greater interaction between the title holders;

- 65 mining licences were cancelled due to the non-accomplishment of legal provisions;

In the scope of the dissemination of mineral resources to attract investment and educate the new generations,

- Dissemination activities were carried out of the measures to be taken before, during and after the occurrence of earthquakes. A mobile exhibition was organised in schools in Maputo City about the main mineral resources of the country, covering more than 4 thousand secondary and technical school students;

With regard to the promotion of the creation of associations, cooperatives, unions or other forms of organisation in the scope of precious and semiprecious stone extraction and processing in the country, as a way to ensure a sustainable exploitation of resources,

- Traditional miners associations were created in Jagoma (Nampula), Namunonono (Zambezia) and training was offered to associations in Mulevala (Zambezia), Marilongue and Madzanidzani (Tete); and support was given to the formalization of eight traditional miners associations, four in Manica Province and another four in Niassa Province;

With regard to the organisation of the Gem Fair in Nampula and the Gold Fair in Nampula, the preparation of the $5^{\text {th }} \mathrm{Gem}$ and Gold Fair in Nampula is in progress, as well as the preparation and dissemination of the $1^{\text {st }}$ International Minerals and Gem Fair of Mozambique.

In the hydrocarbon area,

Concerning the guaranteed continuation of the systematic hydrocarbon exploration in the Mozambique and Rovuma Basins, including the seismic acquisition and drilling boreholes in the Zambezi onshore/offshore Blocks, Blocks 16 and 19,

\section{A. Rovuma Basin}

- The Environmental Impact Studies (EIA) in the 1, 4 and onshore area were approved and the respective Environmental Licences were issued, and on the onshore area the EIA is still ongoing for the collection of bidimensional seismic data and the drilling of exploration wells. 
- A total of $3000 \mathrm{~km}$ of bidimensional seismic data (2D) were collected, while their processing is still ongoing, as well as two old data lines for a qualitative comparison in areas 2, 5 .

- Negotiations with the winning company for the Hydrocarbon Exploration Concession Contract for areas $3 \& 6$ were concluded.

Mozambique Basin:

- Well evaluation studies of the results in offshore Zambezi for the definition of the subsequent exploration strategy are ongoing.

- A beginning was made with the Environmental Impact Studies for the collection of seismic data and the drilling of exploration wells in the Sofala, M10 and Zambezi Blocks.

- Geochemical sampling activities were carried out in the Inhaminga Block and $200 \mathrm{~km}$ of bidimensional seismic (2D) data collected, which are currently being processed and interpreted.

- In Blocks 16 \& 19, situated in the proximity of Pande and Temane, the first $2040 \mathrm{~km}^{2}$ of 3D seismic data of the country were collected, which are currently being processed and interpreted.

With regard to the monitoring of the conclusion of the evaluation studies of the Inhassoro Deposit, allowing its commercial exploitation; the reserves of all gas deposits in the Pande-Temane Blocks. i.e, Pande, Temane, Temane-Este and Inhassoro Gas Fields, were updated.

Regarding a conclusion of the natural gas use and distribution studies in the five tapping points with a view to the implementation of projects related to the industrial and domestic sector;

- Several gas consumption studies are ongoing, from the existing tapping points for the production of electricity and for industrial and domestic consumption, while various projects are being considered, such as the power station to be established in Temane, the electricity production projects in Chókwè and Ressano Garcia, the cement factories project in Salamanga and other natural gas-based projects.

- The production systems of several industrial units of the Matola industrial area were converted and switched to the use of natural gas.

Regarding the conclusion of studies for the expansion of the Gas Processing Centre and the gas pipeline,

With regard to additional exploration in the Pande-Temane Block, including the drilling of exploration and production wells so as to increase reserves and maximize the exploitation of gas resources of this Block;

- A campaign is in progress for drilling production wells in the Pande and Temane development areas, where a total of 11 wells were already drilled; sealing and abandonment activities of 5 old wells were carried out and pressure control equipment was installed in selected wells. 6 evaluation wells were drilled, of which 5 in Inhassoro and 1 in Temane. 
- The drilling of natural gas exploration wells in the area adjacent to the Pande/Temane fields is in progress with a view to gaining better knowledge of potential natural gas and condensate reserves, both in the Inhassoro gas field and in the areas that are object of exploration wells.

Concerning the conclusion of the study of the Pande-Temane condensate exploitation options, including the possibility of processing within the country, studies for the exploitation and processing of condensate are being evaluated with a view to the creation of surplus value and maximize the benefits for the country, since the product will be sold on the international market after production/stabilization.

Regarding the expansion of the Data Centre, so as to turn it into a national and international reference centre, rendering assistance to companies interested in investing in the petroleum sector;

- Data transcription to larger-capacity tapes is in progress and operations are being adjusted in order to meet international standards.

- SMT Kingdom Suite interactive software was acquired to be used for setting up hydrocarbon potential evaluation projects in the sedimentary basins of Mozambique and the installation of a Petroleum Data Management System.

Concerning the consolidation of the sector's legal framework and the creation of a National Petroleum Institute;

- The tax regime applicable to the petroleum sector was approved, a defining instrument for investor behaviour and for the captation of taxes generated by the sector; the preparation of the Petroleum Plant Licensing Regulation was concluded and the draft of a specific environmental regulation is being prepared.

With regard to the inspection and monitoring of gas and condensate transport and sales to domestic and industrial consumers, the management of natural gas transport operations is in progress with a view to the monitoring of environmental, health and security issues, as well as the volumes transported/distributed by the operating company.

With regard to the monitoring of gas production and transport activities, taking into account environmental and security issues, including making technical audits,

- The control and management of the whole petroleum business was carried out, especially safety issues; technical audits were made to the natural gas business, including audits to the gas and condensate measuring system and the reception and analysis of production reports, their integration with a view to a better definition of potential current and surplus reserves.

In relation to the promotion of licensing new hydrocarbon exploration areas, the sector participated in several promotional events organised at regional and international level, particularly the Eastern Africa Hydrocarbon Conference, Arusha Tanzania, the Conference on Deep-Water Petroleum in Angola, the Petroleum and Gas Conference, organised by UNCTAD in Kenya, the Africa Upstream Conference, Cape Town - RSA, the India Africa Hydrocarbon Conference, New Delhi - India. 
The $3^{\text {rd }}$ tender for issuing a licence for exploration areas in the central part of the Mozambique Basin was launched.

\section{E. INDUSTRY AND TRADE}

\section{INDUSTRIAL PRODUCTION}

In 2007 industrial production increased by $3.0 \%$. A large contribution to this increase came from the food and beverage division companies, with an accumulated production of $7,911.9$ million MT, representing a weight of $15.8 \%$ in the industrial production structure.

\section{Table 33: Evolution of Industrial Production by Division}

Unit/Meas: $10^{\wedge} 6 \mathrm{MT}$

\begin{tabular}{|l|l|l|l|l|}
\hline Description of Divisions & 2006 & 2007 & $\%$ Incr. & $\%$ Str. \\
\hline Other Extractive Industries & 16.1 & 11.2 & -30.3 & 0.0 \\
\hline Food and Beverage Industries & $7,047.9$ & $7,911.9$ & 12.3 & 15.8 \\
\hline Tobacco Industry & $2,291.2$ & $2,215.0$ & -3.3 & 4.4 \\
\hline Textile Industry & 84.1 & 86.3 & 2.7 & 0.2 \\
\hline Clothing Industry & 57.4 & 55.2 & -3.8 & 0.1 \\
\hline Tanning and Shoe Industries & 30.4 & 25.0 & -18.0 & 0.0 \\
\hline Paper, Cardboard, etc. Industries & 247.2 & 244.9 & -1.0 & 0.5 \\
\hline Edition, Printing and Reproduction & 344.8 & 509.9 & 47.9 & 1.0 \\
\hline Chemical Industries & 456.1 & 497.5 & 9.1 & 1.0 \\
\hline Rubber and Plastics Industry & 402.6 & 382.8 & -4.9 & 0.8 \\
\hline Base Metal Industries & $37,054.0$ & $37,360.5$ & 0.8 & 74.5 \\
Metal/Machinery and Equipment Industry & 163.1 & 162.9 & -0.1 & 0.3 \\
\hline N.E. Machinery and Equipment & 72.9 & 80.8 & 10.9 & 0.2 \\
\hline Electrical Machinery and Appliances & 224.8 & 377.8 & 68.0 & 0.8 \\
\hline Manuf. of Automobile and Trailers & 5.3 & 3.7 & -30.1 & 0.0 \\
\hline Manuf. of other Means of Transport & 19.9 & 10.1 & -49.3 & 0.0 \\
\hline Manuf. of Furniture; Other Transforming Ind. & 202.5 & 235.9 & 16.5 & 0.5 \\
\hline Total & $48,720.5$ & $50,171.4$ & 3.0 & 100.0 \\
\hline
\end{tabular}

In 2007 performance of the Food and Beverage Industries was positive with a production of 7,911.9 million MT, against 7,047.9 million MT in 2006, corresponding to a growth of $12.3 \%$.

The growth of this group was influenced positively by the "Made in Mozambique" promotion campaign of domestic products and by the implementation of the Ministerial Diploma 99/2003 on the customs regime of the transforming industry. A positive contribution were given by the Fasorel companies with the installation of a new refinery for oil production. Concerning mineral water, worthy of note are the contributions of Vumba and Alvor, CDM-Maputo and the Chimoio and Nampula Coca-Cola factories, which did investments to increase their production capacity.

In 2007 the production of the printing and reproduction of recorded information division amounted to 509.9 million MT, corresponding to a growth of $47.9 \%$ compared to 2006, when its production volume was 344.8 million MT. The ongoing activities in the scope of the promotion and consumption of domestic products "Made in Mozambique" and the monitoring of the Memoranda of Understanding signed with 
the various public sectors that demand products of this division (printing material, forms, files, school books) introduced a new dynamic in the performance of this industry.

The production of the base metal industries increase by $0.8 \%$, in which the Mozal production increased by $0.3 \%$ and thanks to the positive participation of the Onda Lagoa Industry with the increase of orders and production of corrugated iron sheets, as well as the impact of the benefit of Diploma 99/2003 of 13 August, which exempts the transforming industry from custom duties.

The production of the clothing industry has been increasing gradually and amounted to 86.3 million MT, against 84.1 million MT in 2006, corresponding to an increase of $2.7 \%$. Contributions to this increase were given by the involvement of domestic companies in the supply of clothing orders in the health, education, defence, interior and other public sectors. Performance of this sector is expected to improve.

Production in the other extractive industries category (salt extraction and refinement) decreased by $30.3 \%$, which was due to the fact that the company faced problems of machinery breakdowns, in addition to the rains that affected harvests, as well as a change of management, which culminated in a redimensioning of the work force, which has greater weight in this division as well as the poor quality of the salt produced by the company. This last fact was a factor limiting exports to Malawi.

The production of the tobacco industry decreased by $3.3 \%$. This poor production was due to the fact that a few constraints prevailed, related to the supply of raw materials by the Mozambique Leaf Company, which worked for a period of 5 months.

\section{TRADE}

The results achieved indicate an increase of the commercial activity by $9.0 \%$, resulting from the positive behaviour of the real sector, namely the agricultural sector, the transforming industry and the extractive industry, as well as the net increase of the international trade flow, reported in the balance of payments.

\section{POLICY MEASURES}

In this sector the activities carried out in 2007 aimed at the creation of a regulatory environment favourable to the development of the domestic industry; the reactivation of the textile and clothing sector, the chemical industry, the printing industry, the metal industry; the sustainable development of small and medium-sized enterprises (SMEs); the monitoring and supervision of the privatised companies; the promotion of agricultural commercialisation; the effective participation in bilateral and multilateral systems and in similar international bodies, and also to discipline the execution of the economic activities of the sector. In this scope, the following activities were carried out:

In the scope of the creation of a favourable regulatory environment for the development of the domestic industry, the Industrial Policy and Strategy, the SME Strategy and the Competition Policy were harmonized;

In the scope of the reactivation of the textile and clothing, chemical, printing and metal sector, the following activities were carried out in the period in analysis:

- The Competition Policy was approved and published in the Government Gazette, the preparation of the Competition Law was started and a 
preliminary draft was produced, which was distributed to several institutions and Ministries for the collection of contributions and comments;

- The Industrial Policy and Strategy was approved and its implementation started; and the SME Strategy was approved;

- The Metal Sector Strategy was approved and the preparation of the Textile and Clothing Sector Strategy is in progress;

- The preparation of the Chemical Sector Strategy is in progress and the Terms of Reference (ToRs) for the preparation of the Printing Sector Strategy was prepared.

In the scope of post-privatisation monitoring, visits were paid to 49 companies in Maputo, Zambezia, Nampula, Cabo Delgado, Sofala and Tete Provinces and in Maputo City.

With regard to the continuation of technical assistance activities for salt producers, to guarantee iodate salt consumption in the whole country,

- Supervision activities were performed consisting of the collection of iodized salt samples on the formal and informal markets for analysis, with the objective to evaluate the salt iodization procedures at the Nampula salt pans;

- A new Technical Assistance Programme was introduced by the Micronutrient Initiative Organisation (from Canada), which consisted of the distribution of 5 salt iodization machines. Their technical assistance will duration of 2 years;

- $2000 \mathrm{~kg}$ of potassium iodate were imported as well as 10 portable salt analysis laboratories, to be distributed to salt producer associations;

- 5 rapid test kits were distributed to the producer association in Nampula, MISAU, the Customs and MIC's General Inspectorate;

- Provincial action plans were prepared in the whole country, which take the specific situation into consideration, in the scope of monitoring the implementation of the Agricultural Commercialisation Strategy (ECA) at national level.

Regarding the dissemination of markets access mechanisms and the promotion of the organisation and participation in national and international Fairs:

- The dissemination and monitoring of preferential market access mechanisms was carried out in Nampula (Nacala), Manica, Tete and Cabo Delgado (Pemba) Provinces, especially for the SADC Trade Protocol and the Bilateral Agreements with Zimbabwe and Malawi;

- Several national-level companies were contacted and Premier Group volunteered to organise mobile fairs in all provinces, in a first phase in the Southern Region.

In the scope of rendering support to the organisation of maize, beans and groundnut producers in Niassa, Tete and Zambezia Provinces, with capacity for export to Malawi, the following activities are worthy of note:

- Market and price information was disseminated, by radio and in local languages so as to reach the producers in Niassa; 
- Continuity was given to the purchase of beans and groundnuts for export by the Export Marketing, V\&M and DECA companies;

- Producers in Niassa and Zambezia were supported by Clusa in several areas, especially commercialisation;

- The implementation of the Market-Oriented Producers Support Project was started in Tete (Mutarara) and Zambezia (Morrumbala) Provinces.

Promotion of Agro-Processing.

- Activities were carried out with special emphasis on the promotion of rural industrialization through the establishment of processing units suitable for rural areas (in size, easy handling and maintenance, and without requiring a specialized work force) with the involvement of government bodies at central, provincial and district level, in partnership with the local private sector with a view to guarantee maintenance and the availability of spares for the installed equipment.

- The installation of various sets of equipment for agro-processing was guaranteed for all provinces.

Regarding the monitoring of the implementation of the Agricultural Commercialisation Strategy (ECA) at national level,

- Provincial action plans were prepared in the whole country, taking into consideration the specific reality of each Province;

- The 2006/07 agricultural commercialisation campaign, was ensured successfully with the involvement of several operators at national level;

- VAT exemption for maize and oleaginous products for the agro-industry was extended. The objective of this measure is to contribute to the reduction of the production costs and attract domestic industries for the consumption of local raw materials, thus reducing imports;

- Domestic and international market and price information was disseminated (through the trade weekly bulletin, Sima, newspapers and the radio) to producers and other participants of the value chain at national level;

- The rural fairs and markets guide, an important instrument defining the methodology for organizing and holding fairs, was prepared and distributed at national level;

- The technical maize commercialisation guide was prepared and distributed to serve as a work instrument for rural extension workers, NGOs and economic associations, the private sector, etc;

- The preparation of the Cassava Development Strategy, covering its full value chain (production, commercialisation, processing and consumption), was started;

- A favourable environment was created, leading to the creation of new agricultural commercialisation companies (DECA in Manica, Cereais do Zambeze in Tete, Chikira in Nampula), in addition to other informal sector participants; 
- ICM warehouses were made available to the private sector (e.g., Consórcio Malonda in Niassa, Export Marketing in Cabo Delgado, Nampula and Zambezia, V\&M in Manica and Tete, DECA in Sofala and Manica, and Higest in Manica);

- Border trade monitoring was carried out;

- Maize (17,394 tons) and beans (345 tons) were acquired by the World Food Programme in Sofala, Tete, Manica and Nampula Provinces at the value of USD $3,836,043$, corresponding to $99,737,118.00 \mathrm{MT}$, in the scope of the promotion of local purchases of consumption goods for the emergency area;

- FARE and other micro-credit institutions (AMODER, GAPI, Projecto Malonda), continued to support the financing of commercial operators in the rural areas, in addition to the commercial banks for interested and eligible economic agents;

In the scope of efforts aimed at the preparation of the Strategic Export Plan and the monitoring of the implementation of the timber products export development strategy, the dissemination of market access mechanisms, and the promotion of the organisation and participation in national and international fairs, the following activities were performed:

- The business opportunities in the wood and timber area were monitored and in partnership with the Studies and Development Centre (Cedarte) and Aid to Artisans, an initiative was launched for holding the first partnership meeting for the promotion of arts and crafts in Nampula Province.

With regard to the improvement of the country's participation in the regional and multilateral trade system, through participation in economic SADC and WTO negotiations, the following activities were performed:

Regional Integration Process:

- The Mozambican Regional SADC Integration Strategy was prepared and approved;

- The dissemination of the decisions of the Heads of State and Government Summit about the Creation of the Free Trade Zone is ongoing in the whole country;

- Public debates were held about the regional integration process at public, private and civil society sector level.

Regarding the negotiation of the Economic Partnership Agreements between the SADC and the EU (EPAs) and the improvement of the country's participation in the multilateral trade system - WTO:

- Public debates were held about the Economic Partnership Agreements;

- The negotiation of the Economic Partnership Agreement (EPA) with the European Union in the SADC/EPA group is ongoing. This agreement includes, among other issues, access to the goods and services market and development assistance funds; 
- A provisional Agreement was signed to turn the trade relations between these two blocks compatible with the WTO rules and to guarantee access to the European market in preferential conditions, with the exception of South Africa.

- Mozambique's participation and representation in meetings in the scope of the WTO was ensured.

Regarding preferential access of producers to the markets of Mozambique's main partners, through the negotiation of bilateral trade agreements, favouring the African countries of the region, the following was accomplished:

- The final text of the Bilateral Trade Agreement with Zambia, relative to Rules of Origin, was prepared. Zambia proposes the application of the COMESA Rules of Origin;

- A session of the Mixed Commission between Mozambique and Malawi was held, in which the implementation of the preferential agreement between the two countries was analysed;

- A technical evaluation was carried out with Swaziland about the level of implementation of the decisions taken in the second session of the Mixed Commission between the two countries;

- A bilateral economic summit between Mozambique and South Africa was held, in which the following aspects were analysed relative to the area of industry and trade: (i) the evaluation of the Economic Cooperation Memorandum; (ii) a discussion about Mozambique joining the SACU, and (iii) the project to establish a Metal Plant in Matola.

Dissemination of the Market Access Mechanisms:

- In coordination with the Mozambican Customs, the preferential market access mechanisms were disseminated in Nampula and Sofala Provinces and in Maputo City, with the objective to provide local economic agents as well as customs agents with the necessary knowledge that will above all allow local exporters to take advantage of the opportunities given by these mechanisms;

- A meeting was held with businessmen for the economic cooperation between China and the CPLP countries;

- An open week was held about the Open Door's Week multilateral trade system, in the scope pf the JITAP (Joint Integrated Technical Assistance Programme);

- Activities were carried out allowing the creation of mechanisms for access to the Malawian market, for the export of salt. The visit of a delegation of that country to Ilha de Moçambique, Mossuril and Nacala Districts was also accompanies with the objective to disseminate the Malawian legislation about salt imports;

- A Memorandum of Understanding was signed regarding joint monitoring of iodized salt export/import;

- An ordinary meeting of the Timber Sector Executive Group (GES-Madeiras) was held to analyse the level of accomplishment of the Strategy for the Development of Mozambican Processed Timber Products Exports; 
- Information about the arts and crafts fairs, which were held in Milan and Portugal, was disseminated to operators of this area;

- An International Maputo Fair, in which the Provinces were represented, was organised with the motto "Made in Mozambique". The Fair enjoyed the participation of 15 countries (RSA, Germany, Angola, Botswana, Brazil, Canada, Spain, Macau, Portugal, Kenya, Swaziland, Tanzania, Zambia, Zimbabwe, and Vietnam) and 192 local exhibitors, with the following distribution: (20) Cabo Delgado, (6) Niassa, (13) Nampula, (17) Zambezia, (15) Tete, (51) Manica, (24) Sofala, (10) Inhambane, (14) Gaza, (8) MaputoProvince and (14) in Maputo-City;

- Participation in the International Fairs of Zimbabwe, Malawi, Dar-es-Salaam, Lisbon (arts and crafts), INTERZUM (wood) in Germany and in the buyers and sellers meeting in Johannesburg, in the scope of the Trade Africa programme;

- Cooperation with several national and international institutions with a view to guarantee the integrated development of exports.

Standardisation and Quality:

- The preparation of new statutes and of the Metrology Bill is ongoing in the context of the creation of a legal and transparent basis for the development of standardisation, metrology, accreditation and test systems in the country.

- Training and awareness-raising seminars were held for economic agents and civil society about the importance of the certification of products and services for the development of the national economy.

- 36 standards were approved with a view to improve quality and standardisation for the following sectors: food: fruit, rice, tea, cashew nuts, bananas, mangoes, cassava flour and cooking oil; construction (blocks and soils); energy (graphic symbols for electrical diagrams); the environment (environmental management systems - requirements and guidelines); labour (work health and safety management systems - specifications, types of current and distribution systems).

Improvement of the Business Environment

- At ministerial level those activities were identified that will come to be licensed in a simplified way by the one-stop shops (BAUs) and the Decree institutionalising the BAUs was approved.

- Activities were carried out in favour of the improvement of the business environment in the sphere of the removal of administrative barriers obstructive to business and investment, resulting in the improvement of the country's position in the Doing Business ranking $\left(140^{\text {th }}\right.$ and $\left.134^{\text {th }}\right)$ and in the official recognition by the World Bank that Mozambique is one of the five most reforming countries in Africa.

- The analysis was concluded of the suggestions resulting from the harmonization of the first version of the Business Environment Improvement Strategy with various institutions, and the Strategy Action Matrix and Plan was prepared. 
- Information was gathered and crossed about licensing requirements and procedures regarding economic activities, in which large parts of this activity were decentralized to the Town Councils, which will execute this under municipal bylaws.

- The permanent dialogue with the private sector was consolidated, culminating in the successful $10^{\text {th }}$ Annual Private Sector Conference, the main theme of which "The Challenge to Mozambique of Regional SADC Integration".

In the scope of the promotion and incentives in the use of the Industrial Property System several provincial seminars were held for the dissemination of the new Code of Industrial Property and the registration of trademarks.

\section{F. TOURISM}

\section{RESTAURANTS AND HOTELS}

In the last few years growth in the Tourism sector has been significant. It is estimated that in 2007 about $1,259,000$ visitors entered the country and that the largest number of entries was for purposes, which increased from 664,300 in 2006 to 771,000 in 2007.

The occupation rate of tourism establishments reported in the first half of 2007 shows that Maputo, Sofala and Cabo Delgado Provinces had the largest contribution. Likewise, the number of licensed beds increased from 15,740 in 2006 to 17,035 in 2007.

Indeed, the production of restaurants, hotels and similar establishments increased by $12.8 \%$, measured by the tourism income indicators of the balance of payments, the number of night's lodgings and the movement of airline passengers.

There was also an increase of the volume of investment and of the number of approved projects. In 2007 the value of investment was 972 million American dollars of 133 approved projects and in 2006 investment amounted to 607 million American dollars of 113 approved projects, which shows the continuous growth trend of this sector.

\section{POLICY MEASURES}

In this sector, the activities for 2007 focussed on the consolidation of the legal framework, the requalification of lodgings and similar establishments, the implementation of the marketing and human resource strategy, the improvement of the management of protected areas, the preparation of the conservation policy, the implementation and continuation strategy of the development of conservation areas, and the intensification of financial support for domestic entrepreneurs and local communities. Thus, the following activities were performed:

In the institutional and Human Resources sphere:

- Dissemination activities were carried out regarding the Tourism Sector's Human Resource Development Strategy and the Conservation Areas in the Northern Region, Niassa, Cabo Delgado and Nampula;

- The revision of MITUR's professional careers was concluded, including the conservation areas; 
- Two (2) seminars were held, one in the Northern Region and the other one in the Southern Region, about the tourism sector's statistics system;

- Workshops were held about hotel and tourism management, conservation management, tourist guide courses and basic hotel business courses in Cabo Delgado, in Vilanculos Town, in Manica Province; in Sofala, in Maputo City and Province, in Quelimane and in Tete.

- The results were disseminated of the inquiry of tourist expenses in January, April and October 2007, covering 8 border posts, namely Mavalane, Vilanculos, Pemba, Ponta de Ouro, Ressano Garcia, Machipanda, Giryondo and Goba.

In the sphere of regulation and intersector coordination:

- In the scope of the classification of tourist lodging establishments, catering and beverage, according to the new system in Maputo, Gaza and Inhambane Provinces:

- The draft Organic Statute of the Tourism Regulatory Council was prepared and discussed in a technical commission, and

- The pilot project was implemented in Inhambane and Gaza Provinces and in Maputo City, with the objective to test the classification system;

- The software was concluded and installed for the cadastre of tourist and similar establishments and technical staff was trained for its use;

- Giving continuity to the regulation of the Tourism Law, namely the activities regarding car hire for tourism and eco-tourism purposes,

- Regulations were prepared, approved and published for tourist lodging, catering and beverage, dance halls, periodic dwelling rights, tourist transport and tourist entertainment;

- Draft decrees were prepared for the regulation of eco-tourism and of hunting tourism;

- Regarding the zoning of the priority tourist investment areas of Sussundenga and of Vilanculos the Terms of Reference were prepared and a pre-selection of consultants carried out;

- In the scope of giving continuity to the simplification of the approval procedures of tourist projects, a deconcentration and decentralization was carried out through the transfer of approval and licensing powers to the provincial level and the municipal councils respectively;

- To consolidate the dialogue forum with the private sector at regional level (South, Centre and North), through the establishment of a Code of Conduct,

- The installation commission for the creation of the National Federation of Hotel Business Associations of Mozambique was established, and

- The Code of Conduct was approved and will be disseminated and implemented in 2008.

In the sphere of conservation areas: 
- The Preliminary Inception Report of the Conservation Policy and its Implementation Strategy were presented and the Diagnosis of the Current Conservation Situation in Mozambique was prepared.

- Concerning the improvement of the management of protected areas, through the rehabilitation of infrastructures, the supply of the necessary equipment for the functioning of the national parks and reserves (Maputo Special Reserve, Chimanimani Reserve, Banhine National Park, Zinave National Park), the following activities were carried out:

- The rehabilitation of a house and office in the Maputo Special Reserve was concluded;

- An extension of about $1 \mathrm{~km}$ of the airstrip in Banhine National Park was rehabilitated and periodic maintenance of the airstrip carried out;

- Rehabilitation and maintenance of $30 \mathrm{~km}$ of roads and of 2 bridges in the Chimanimani National Reserve and $37 \mathrm{~km}$ of roads in the Zinave National Park;

- Rehabilitation of $4 \mathrm{~m}$ of bridge in the Chimanimani Reserve.

- With regard to preparation and implementation of the management plans for the Chimanimani Reserve and the Bazaruto Archipelago National Park, of the Tourism Development Plan of the Quirimbas National Park, and the updating and implementation of the management plan for the Maputo Special Reserve,

- The Terms of Reference were prepared and a tender was launched for a consultancy for the preparation of the management plans of the Chimanimani National Reserve;

- The 2008-2012 management plan of the Bazaruto Arquipelago National Park was updated;

- The Tourism Development Plan of the Quirimbas National Park is in preparation, and

- The Management Plan for the Maputo Reserve Special is being implemented.

- Regarding the improvement of the communication system, installing radios and repeaters in all Parks and National Reserves;

- Means of transport, a VSAT system and computers were acquired for Banhine and Zinave National Parks;

- The radio system in the ACTF parks and reserves was designed and the first work phase was concluded;

- The implementation of mitigation measures for the man-animal conflict in the country's conservation areas was concluded, and inspection was strengthened through the recruitment, training and equipment of 20 inspectors for the Marromeu and Gilé Reserves and for the Pomene Reserve. In coordination with MINAG, MDN and MICOA, the action plan for the mitigation of the man-wildlife conflicts was prepared and implemented; 
- A more adequate management, monitoring and evaluation system of sport hunting activities was implemented with a view to the quarterly collection of relevant information about the activity.

- Concerning the establishment of a community lodge near the Massingir Dam, next to the Limpopo National Park, a conceptual document and plan was prepared for granting tourist concessions, which will make greater involvement of the private sector viable;

- The Giriyondo border post was made operational in coordination with the Customs and Migration.

In the sphere of tourism promotion:

- The marketing strategy was disseminated in the country, in Cabo Delgado, Niassa, Nampula and Inhambane Provinces;

- Regarding the creation of a marketing and promotion database, a database was created with images and text about a few points of tourist interest in the country;

- Giving continuity to the marketing campaign, especially aimed at the domestic market:

- Pamphlets and DVDs about Mozambique and tourist guides containing information about the supply of tourist products existing in the provinces were produced and the VI Edition of the Maputo Tourism Trade Fair was organised, with the participation of 143 exhibitors, 33 exhibitors more than in the previous year.

- A variety of promotional material was produced and its respective distribution carried out;

- Participation in the following fairs: Matka (Finland), ITB - Berlin (Germany), Indaba (Durban), BIT (Milan), BTL (Lisbon), VAKANTIEBEURS (the Netherlands), BTM (Maputo), Expo-ZIT (Zimbabwe), CITM (China) and WTM (London).

- In the scope of the establishment of tourism agencies in the main supply markets for the country,

- A Mozambican Agency was established in Germany for the Germanspeaking countries (Germany, Austria and Switzerland), and

- A company was selected for the promotion of the tourism sector in China.

In the sphere of tourism inspection:

- Inspections were carried out of tourist activities in Ponta de Ouro, Malongane, Mamóli, Dobela, Milibangalala and Bilene, with the aim to control land occupation. Additionally, a total of 952 tourist lodging and catering and beverage establishments were inspected in the whole country, against 491 inspections in the same period of the previous year, corresponding to a growth in the order of $194 \%$. 
- The Provincial Directorates of Tourism of Sofala and Manica were audited, including Chimanimani Reserve.

In the sphere of investment:

- In the scope of the project to construct a tourist lodging establishment in Mandimba in Niassa Province and in Tsangano in Tete Province, a tender was launched for the construction of the first establishments in Mandimba, Alto Molócuè, Guijá and Moamba and the DUAT procedure was started;

- The project for the construction of the MITUR and FUTUR building is ongoing, the construction site has been identified and the preliminary draft indicating the type of undertaking to be materialized was designed.

\section{G. TRANSPORT AND COMMUNICATIONS}

During the economic year 2007 overall production of the transport and communications sector increased by about $20.7 \%$. Main contributors to this growth were road transport, air transport and communication services.

Table 34: Transport and Communications - Growth rates (\%)

\begin{tabular}{|lll|}
\hline Type & 2007 PL & 2007 REV \\
\hline Rail transport & 7.1 & -3.0 \\
Road tran sport & 18.2 & 14.8 \\
Pipeline transport & 0.0 & 35.1 \\
Sea and coastal transport & 8.0 & 19.7 \\
Air tran sport & 10.7 & 28.0 \\
Transport-related services & 6.4 & 2.6 \\
Communication services & 13.1 & 28.4 \\
\hline TOTAL & $\mathbf{1 4 . 2}$ & $\mathbf{2 0 . 7}$ \\
\hline
\end{tabular}

In rail traffic there was a decrease of about $3 \%$, basically due to the fact that demand for this service on the market is shared with the road sector, which increased its fleet and started to exploit a few routes on which public users also had rail transport as an alternative.

We should note, however, that on the North Line the frequency of trains increased, particularly on the Cuamba/Lichinga section in which the number of trains increased from 12 in the previous year to 30 .

Regarding pipeline transport, its growth of about $35.1 \%$ is a reflex of the application of the contractual tariff of USD 1,808,000.00 for a volume of transport of 58,000 tons or less. The payment of this agreed tariff is compulsory, whether there is transport or not.

In spite of traffic having increased significantly, if one takes into account that the Zimbabwean economy continues to fall, one can conclude that it would be difficult to reach the installed PIPELINE capacity, a situation which is aggravated by the use of lorries for fuel transport from Beira to Zimbabwe, although the company enjoys exclusive rights for this activity in the Beira Corridor.

Performance of the air transport sector has been positive, which is motivated by new operators entering the market and by the public's positive response to lower tariffs practised by the air companies. 
Most of the positive contributions occurred in air passenger transport were caused by the growth of the domestic segment, in which the number of transported passengers attained 1,102,338 against 982,287 attained in the previous year. A similar situation occurred in the regional segment in which the number of transported passengers attained 333,219 against 304,339 achieved in the previous year.

Overall growth of communications was about $28.4 \%$, resulting from a positive performance of fixed and mobile telephony.

The number of fixed telephony subscribers increased from 2,362.0 subscribers in 2006 to $3,595.0$ in 2007. Similarly, the number of mobile telephony subscribers increased from 5,412.9 subscribers in 2006 to 7,307.4 in 2007.

We should note that the fixed network covered 116 places (provincial and district capitals) and the mobile network 85 . Also important is the conclusion of the no BeiraCaia-Quelimane section of the telecommunications backbone, which entered into commercial exploitation on 7 May 2007.

\section{POLICY MEASURES}

For the year 2007, the sector defined the following main objectives: continuation of the gradual improvement of the reliability, security, convenience and expansion of the transport services offered to the population in urban and rural areas; a more efficient participation of domestic entrepreneurs in the control, operation and investment in subsectors; a rapid development of the sector, through the updating of legislation, adapting it to the changes/demands taking place, and making it more comprehensive and dynamic. In this scope, the following activities were carried out during the year 2007:

In the sphere of maritime, river and lake transport:

- With regard to the start of the emergency dredging in Beira Port, a hydrographic survey was carried out of the channel and of Beira International Port, in June the tender for emergency dredging was relaunched and negotiations with the awarded companies are in progress for carrying out the activities in phases;

- Regarding the construction and rehabilitation of the ferry bridge infrastructures for local traffic of the Maputo/Catembe and Inhambane/Maxixe crossings:

- The proposal to award the contract for the Maputo/Catembe crossing to the Teixeira Duarte company was approved;

- The establishment of the building yard at the Inhambane/Maxixe crossing is in advanced progress, and the construction of the new bridge slab on the Maxixe side was concluded.

- Regarding the acquisition of ferryboats for the Maputo/Catembe, Inhambane/Maxixe, Beira/Búzi, Beira/Machanga and Quelimane/Recamba crossings, construction of the boats has started.

In the sphere of road transport:

- Concerning the acquisition of 70 buses for public transport in Maputo, Beira and Nampula, 65 buses were distributed in the following way: Maputo (34), Beira (15), Nampula (06), Quelimane (04), Inhambane (03) and Pemba (03). 
In the sphere of road safety:

- With regard to the campaign to exchange the current driving licences for SADC licences, the exchange process started on 1 November and its conclusion is foreseen for December 2010;

- So as to intensify road security measures, prioritising the periodic inspection of semi-collective passenger transport, road signalling and the reverification of criteria for awarding and issuing public service driving licences, the following activities were carried out:

- Periodic inspections were carried out semi-collectives passenger transport, in order to verify the technical state of the vehicles, thus guaranteeing that only vehicles in good condition are licensed;

- Preparation of the road signalling revision and harmonization project, in the scope of SADC.

- Approval of the Driving School Regulation and the Driving Test Regulation.

In the sphere of civil aviation:

- In the scope of the Certification and Licensing of the Maputo, Beira, Nampula, Pemba and Vilankulo Airports, the Specific Regulation for Airport Certification and Licensing was prepared.

In the sphere of communications:

- Regarding the expansion of fixed telephony services, the backbone to Chimoio, Tete, Quelimane, Mocuba, Gurué, Nampula, Pemba, Cuamba, Lichinga and Caia, the following activities were carried out:

- The expansion of the fixed telephony services in the Beira-CaiaQuelimane (backbone), Quelimane-Nampula and Nampula-CuambaMocuba sections was concluded and activated.

- Infrastructure construction works on the sites and the installation of power and transmission equipment are in progress;

- The mobilisation of resources for the Cuamba-Lichinga and NampulaPemba sections is in progress;

- The VSAT system was implemented in lle, Mopeia (Zambezia), Chemba, Chibabava, Maríngue (Sofala) and in Machaze in Manica;

- The installation of the CDMA system in all provincial capitals as well as in the districts and municipalities was concluded.

- The installation of rural telecommunications systems in Massangena, Mabalane and Chicualacuala Districts was concluded.

- With regard to the expansion of the mobile cellular telephony services in Maputo (Catuane), Gaza (Mabalane and Maqueze), Sofala (Maríngue), Zambezia (Chinde), Tete (Ulongué) and Nampula (Mogincual) Provinces, the following activities were carried out:

- The expansion of the mobile telephony network in Maputo (Cutuane), Sofala (Maríngue), Tete (Ulongué) and Nampula (Mogincual) 
Provinces was concluded and the expansion of its coverage in Gaza (Mabalane and Maqueze) and Zambezia (Chinde) Provinces is in progress.

In the sphere of ports and railways:

- Regarding the monitoring of the reconstruction of the Sena Line and the rehabilitation of the Machipanda Line,

- A section of about $161.2 \mathrm{~km}$ was constructed between Dondo and Inhamitanga and a section of $45 \mathrm{~km}$ was installed between Inhamitanga and Marromeu;

- Rehabilitation works of the Dona Ana Bridge are in progress;

- The following activities were carried out for the rehabilitation of the Machipanda Line.

$\checkmark$ Replacement of $16 \mathrm{~km}$ of rail;

$\checkmark$ Replacement of 23,500 timber sleepers;

$\checkmark$ Replacement of 24,000 units fastening elements;

$\checkmark$ Realignment of the line was carried out over a length of $150 \mathrm{~km}$;

$\checkmark$ The ballast was completely redone over a length of $159 \mathrm{~km}$.

- Regarding the reactivation of the Ressano Garcia and Goba Lines, the following activities were carried out:

On the Ressano Garcia Line

$\checkmark$ Replacement of 26,553 sleepers;

$\checkmark$ Welding of 350 long bars;

$\checkmark$ Replacement of 450 timber sleepers;

$\checkmark$ Mechanised realignment;

$\checkmark$ Replacement of 5 sets of sleepers;

$\checkmark$ Placing of ballast over $44,310 \mathrm{~km}$;

On the Goba Line

$\checkmark$ Acquisition of 1,100 tons of rails;

$\checkmark$ Emergency rehabilitation for the improvement of the line condition;

$\checkmark$ Preparation of other materials needed for the start of rehabilitation.

In the sphere of meteorology

- With a view to the replacement of the communication systems in the synoptic meteorological stations by GSM-based communication (mobile telephony), the communication systems were replaced by a GSM system (mobile telephony), at the meteorological stations in Cabo Delgado (Pemba), Zambezia (Quelimane and Pebane), Tete (Tete), Niassa (Lichinga) and Manica (Chimoio). 
Supplementary activities:

- The acquisition of 65 buses for public transport was concluded with the reception of the last 20 buses, which were distributed to Maputo (34), Beira (15), Nampula (06), Quelimane (04), Inhambane (03) and Pemba (03).

- Three projects were identified for the creation of roads passenger terminals, namely one for Maputo and two for Beira. The mobilisation of financing for the Maputo project is ongoing, while the two terminals in Beira City are under construction;

- The installation of transmission equipment in Funhalouro (Inhambane), Machaze (Manica), Chemba and Chibabava (Sofala), Ile and Mopeia (Zambezia) and Moma (Nampula) was concluded;

- The installation of the CDMA network in the Central Region (Beira) was concluded, civil construction works are in progress as well as the analysis of the proposal submitted by the contractor to TDM in the Central and Southern Region, respectively;

- With regard to the installation of rural telecommunications systems, activities carried out were:

- Conclusion of equipment installation in Chókwè, Macarretane, Chiambeze, Mabalane and Caniçado in the north of Gaza Province;

- Conclusion of the construction of slabs and anchors in Chibuto, Camessua, Alto Changane, Nalazi, Valente Dindiza and Macuchene, while the construction of anchor slabs in Chicualacuala and Pafúri is in progress;

The rehabilitation of Quelimane Port and of the Ressano Garcia Line is in its final phase, while preventive maintenance of the Goba Line is in progress.

\section{H. SUPPORT TO LOCAL ENTREPRENEURS}

With regard to the creation of a favourable environment for the improvement of competitiveness, 70 businessmen were trained in the field of the Promotion of Small Industries.

The second phase of the PoDE Project is being negotiated. It will be based on activities related to "Competitiveness and Private Sector Development" and will benefit from World Bank financing.

The Small Industry Promotion Fund (FFPI) approved 342 projects, which are expected to create 599 new jobs.

The Economic Rehabilitation Support Fund (FARE):

In the scope of the Economic Rehabilitation Support Fund (FARE) activities are ongoing with a view to the rehabilitation of the rural trade network, through direct financing to economic agents and/or the issue of letters of indemnity.

In this context, 61 projects were financed, namely (11) in Niassa, (6) Cabo Delgado, (4) Nampula, (8) Zambezia, (5) Tete, (16) Sofala, (5) Inhambane, (4) Gaza and (2) in Maputo. 
In the scope of the new FARE philosophy, 12 rural financial institution projects were financed.

In the scope of cashew nut production promotion, the IV Security Fund agreement was established, defining the maximum credit limit to be granted by $\mathrm{BCl}-$ Fomento SARL to each beneficiary company and the maximum volume of cashew nuts expected to be acquired at an estimated price by each one of them through the respective credit for the 2006/2007 campaign.

The implementation of the $2^{\text {nd }}$ phase of the Italian Commodity Aid programme is being negotiated with the Italian cooperation.

In the scope of the implementation of the Private Sector Revitalization Programme, in 2007 a total of 23 new Generic and/or Agricultural Credit Transactions in 4 Provinces were approved in the scope of this Programme: (2) Maputo, (18) Gaza, (2) Inhambane and (1) in Zambezia.

Promotion of domestic production:

Regarding the increase of the supply of domestic products and the improvement of their quality, and the pursue of the strategic activities of Production, Consumption and Export Promotion of Mozambican products and services, the following activities were carried out:

- The regulation about the rights concession criteria for the use of the "Orgulho Moçambicano. Made in Mozambique" mark was published in the national press;

- Two memoranda of understanding were made and signed with the TGV group (a media company) and Profilmes in the scope of the promotion and dissemination of the "Made in Mozambique" project;

- A DVD with the respective clip about the "Made in Mozambique" project was produced and disseminated;

- Two instruction manuals with procedures for acquiring the right to use the "Orgulho Moçambicano. Made in Mozambique" mark were prepared and implemented;

- 200 booklets and 100 pamphlets about the ".... Made in Mozambique" mark and project were prepared and disseminated;

- Participation in seven fairs (the Nyau commemorations, the $\mathrm{VI}$ edition of the Tourism Trade Fair / 2007, the Gastronomic Fair, FACIM, the Agroprocessing Fair in the SADC Day commemorations, the Gastronomic Fair in Lisbon in the Mozambique and Portugal Week commemorations, the Matola Traditional Music Festival and the International Minerals Fair) and in the commemorations of national anniversaries (7 April, 1 May and 25 June);

- The right to use the "Orgulho Moçambicano. Made in Mozambique" mark was granted to a total of 82 entities;

- The Gala of the first 50 entities holders of the "Made in Mozambique" mark was held successfully;

- Six memoranda of understanding were celebrated in the scope of promotion and dissemination among the private sector and the youth, namely for the 
organisation of the $1^{\text {st }}$ Gala for the first 57 entities holders of the right to use the mark, for the production of the television programme called "TV Made in Mozambique", the preparation and display of a multimedia portal about the "Made in Mozambique" project, the production of a live programme about the "Made in Mozambique" project, the organisation of an event called "Clube do Artista Made in Mozambique" and the Mozambique Trade Chamber.

With regard to direct support to local entrepreneurs by FUTUR, through the concession of financial incentives to 20 tourist undertakings,

- The construction of a Tourist Camp in Matchedge in Niassa Province was financed by FUTUR;

- The direct and temporary management of the Andalucia Hotel School was guaranteed by FUTUR, following the cancellation of the contract with Watershed, as well as of the Ponta de Ouro Tourist Camp, following the suspension of the effectiveness of the Prime Minister's Ratification Dispatch by the Administrative Tribunal;

- Tenders were launched for the alienation of the Pomene Hotel, the Zalala Beach Lodges and a restaurant and house in Chocas Mar in Inhambane, Zambezia and Nampula Provinces, respectively; and

- The construction of a motel in Caia District, Sofala Province is in progress.

Regarding the micro-credit decentralization programmes for the financing of 60 projects through FUTUR,

- 36 projects were approved, to the total amount of 10,986,500 MT, of which 25 for micro-credits and 11 for post-floods and post-Favio cyclone. A total amount of 5,077,250 MT was disbursed for these approved projects, corresponding to about $60 \%$ of the approved capital, which was $8,586,500$ MT. For the post-floods and post-Favio cyclone projects of 2007 an amount of $2,050,000$ MT was disbursed, corresponding to $85 \%$ of the approved amount of 2,400,000 MT;

- 30 projects were approved at the value of $750,000.00 \mathrm{MT}$ in the scope of the Decentralized Micro Credit Project.

With regard to the financing of local authorities for the construction of fruit markets in Cumnana, Pambara, Muxúnguè, Tica, Nicoadala and Angónia, and public toilets in Maputo, Sofala, Nampula and Cabo Delgado,

- 1 fruit market for 40 stallholders was constructed in Macia (Gaza) and another one of the same capacity in Manhiça (Maputo), to be handed over to the management of the municipal and district authorities, respectively;

- A socio-economic survey was conducted and the compensation package per family for 144 families was defined (package consisting of 1 house, a machamba and orchard area, a graveyard and a sum of money, as compensation for resettlement damages);

- The resettlement cost per family were defined, including the construction of a house (240 to 350 thousand MT) and a contract was signed with the winning company (Huss construtora Lda); 
- Two model houses were constructed and approved;

- The creation of a joint structure between Park and Procana for the implementation of the resettlement project is in progress;

- 5 public toilets were rehabilitated in llha de Moçambique (Nampula), 2 in Mentangula (Niassa), 1 in Manhiça (Maputo) and 1 in Macia (Gaza).

With regard to support in the area of training and the production of promotional materials for the whole country, among other things for the establishment of tourist information desks in Vilanculos and Machipanda,

- A national inspection seminar was held in Manica and 46 inspectors were trained in the Gorongosa National Park, of which 12 for REM, 10 for Banhine National Park, 17 for Zinave National Park and 7 for Marromeu National Reserve.

\section{IV.2. HUMAN CAPITAL}

\section{A. EDUCATION}

In the area of education, in 2007 priority was given to the expansion of access, through the enrolment of children, youth and adults in several educational and training institutions and the recruitment of teaching staff; the improvement of the quality of education, particularly the development and consolidation of basic education curricula, the introduction of new primary and secondary teacher training models, in-service teacher training and institutional development.

\section{General Education}

In general education, the number of students increased by $10.4 \%$ compared to 2006 , thus continuing the growth trend in relation to the previous years. This achievement represents $98.1 \%$ of what was planned for 2007 . By level of education, there was a more pronounced growth in $2^{\text {nd }}$ level Secondary Education - ESG2 $(33.7 \%)$ and in $2^{\text {nd }}$ level Primary Education - EP2 (24.2\%).

Table 36: Evolution of the Number of Students

\begin{tabular}{|c|c|c|c|c|c|c|c|c|}
\hline \multicolumn{9}{|c|}{ Ev olution of number of students $2003-2007$} \\
\hline \multirow[t]{2}{*}{ Level } & 2003 & 2004 & 2005 & 2006 & \multicolumn{2}{|c|}{2007} & \multirow{2}{*}{$\begin{array}{l}\% \text { accom } \\
\text { Plan }\end{array}$} & \multirow{2}{*}{$\begin{array}{l}\text { \% growth } \\
\text { R07/R06 }\end{array}$} \\
\hline & Real & Real & Real & Real & Plan & Real & & \\
\hline EP1 & $2,825,971$ & $3,071,564$ & $3,393,677$ & $3,597,392$ & $3,945,622$ & $3,866,906$ & 98.0 & 7.5 \\
\hline EP2 & 355,618 & 409,279 & 452,888 & 496,031 & 639,454 & 616,091 & 96.3 & 24.2 \\
\hline ESG1 & 141,795 & 168,798 & 210,128 & 257,729 & 307,806 & 313,692 & 101.9 & 21.7 \\
\hline ESG2 & 18,291 & 21,350 & 25,737 & 35,450 & 43,210 & 47,388 & 109.7 & 33.7 \\
\hline Total & $3,341,675$ & $3,670,991$ & $4,082,430$ & $4,386,602$ & $4,936,092$ & $4,844,077$ & 98.1 & 10.4 \\
\hline
\end{tabular}

The school network increased by $6.7 \%(+722$ schools) compared to 2006, representing $99.7 \%$ of what was planned. 
Table 37: Evolution of the School Network

\begin{tabular}{|c|c|c|c|c|c|c|c|c|}
\hline \multicolumn{9}{|c|}{ Evolution of the school network $2003-2007$} \\
\hline \multirow[t]{2}{*}{ Level } & 2003 & 2004 & 2005 & 2006 & \multicolumn{2}{|c|}{2007} & \multirow{2}{*}{$\begin{array}{c}\% \text { accom } \\
\text { Plan }\end{array}$} & \multirow{2}{*}{$\begin{array}{l}\% \text { growt } \\
\text { R07/R06 }\end{array}$} \\
\hline & Real & Real & Real & Real & Plao & Real & & \\
\hline$\overline{E P 1}$ & 8,07 & 8,37 & 8,69 & 8,95 & 9,33 & 9,303 & 99. & 3.9 \\
\hline EP2 & 195 & १,11 & $\uparrow, 32$ & 1,51 & 1,84 & 1,842 & 69. & 21.7 \\
\hline ESG1 & 92 & a 14 & $n_{15}$ & ${ }^{\wedge} 21$ & ${ }^{\circ} 25$ & 252 & 100. & 16.7 \\
\hline ESG2 & 529 & $n_{30}$ & $a_{35}$ & ${ }^{a} 49$ & ${ }^{3} 56$ & 58 & 903. & 18.4 \\
\hline Total & 9,175 & 9,659 & 10,207 & 10,733 & 11,494 & 11,455 & म्ब9. & 6.7 \\
\hline
\end{tabular}

The distribution per province of the increase of the number of general education schools by 722 new units is presented in the following table.

Table 38: Number of schools that opened and/or introduced levels of education

\begin{tabular}{|c|c|c|c|c|c|c|c|c|c|c|}
\hline \multicolumn{11}{|c|}{ Number of schools that opened and/or introduced levels of schooling in 2007} \\
\hline \multirow[b]{2}{*}{ Provínce } & \multicolumn{2}{|c|}{ EP } & \multicolumn{2}{|c|}{ EP } & \multicolumn{2}{|c|}{ ESG } & \multicolumn{2}{|c|}{ ESG } & \multicolumn{2}{|c|}{ Total } \\
\hline & Plañ & Rea & Plañ & Rea & Plan & Rea & Plan & Rea & Plan & $\operatorname{Rec}$ \\
\hline Cabo Delg & 15 & 14 & 21 & 26 & & 2 & & 0 & 39 & 42 \\
\hline Niassa & 30 & 23 & 22 & 23 & & 3 & & & 59 & 49 \\
\hline Nam & 99 & 97 & 47 & 44 & I & 7 & & & $15 \oint$ & 152 \\
\hline Zambézia & 99 & 96 & $7 q$ & 78 & 5 & 7 & & & $17 \oint$ & 18 \\
\hline Tete & 41 & 32 & 21 & 21 & & 0 & & & 63 & 5 \\
\hline $\begin{array}{l}\text { Manica } \\
\text { Sofala }\end{array}$ & 39 & $\begin{array}{l}24 \\
32\end{array}$ & $\begin{array}{l}34 \\
22\end{array}$ & $\begin{array}{l}31 \\
23\end{array}$ & 1 & 1 & & & $\begin{array}{l}73 \\
58\end{array}$ & 58 \\
\hline Inhambane & 19 & 18 & 22 & 21 & 3 & 3 & & & 44 & 4 \\
\hline Gaza & 8 & 2 & 30 & 19 & 6 & 6 & & & 44 & 4 \\
\hline Maputo $\mathrm{Pr}$ & 7 & 7 & 34 & 33 & إ & & & & 42 & 17 \\
\hline $\begin{array}{l}\text { Maputo C } \\
\text { Tota }\end{array}$ & $\frac{1}{387}$ & 5 & 4 & $\frac{8}{327}$ & 2 & $\frac{2}{36}$ & & 0 & $\begin{array}{r}8 \\
761\end{array}$ & \\
\hline Tota & 383 & $35 d$ & 335 & $32 \pi$ & 36 & 36 & & 9 & 761 & 72 \\
\hline
\end{tabular}

\section{Special Education}

The instruments to collect information about children with special educational needs were prepared and their testing started in 11 schools (one in each province). The effective application of these instruments is foreseen for the $1^{\text {st }}$ quarter of 2008.

In relation to the inclusion of children with special educational needs, we should point out the inclusion of 62,357 children in the whole country, of which 9,874 visually handicapped, 13,157 with hearing disabilities, 6,440 with physical-motor disabilities, 11,859 with learning disabilities, 6,007 with mental retardation problems, 4,426 with behavioural problems, 7,421 with speech problems and 3,173 with multiple disabilities.

Inclusive education strategies and approaches were integrated into the new initial teacher training models for primary education (Form 10+1) and secondary education (Form 12+1), through the subject of psychopedagogy. For in-service teacher training the approach was integrated through the CRESCER Programme (School Strengthening Courses: Systematic, Continuous, Experimental and Reflexive).

A begin was made with the rehabilitation of 2 special schools in Maputo City, namely for deaf and mentally disabled children.

A tender was launched for the construction of 3 Regional Resource Centres in Tete, Nampula and Gaza for disabled people. Works will start in 2008. 


\section{Primary Education}

A total of $3,866,906$ students were enrolled in EP1, corresponding to a growth of $7.5 \%$ compared to 2006 . These students were enrolled in 9,303 schools, representing a growth of $3.9 \%$.

In terms of educational coverage indicators, the net schooling rate in Primary Education (EP1+EP2) was $94.1 \%$, and $90.9 \%$ for girls. In 2007 the schooling rate of 6 -year old girls in grade 1 was $70.0 \%$, having exceeded the target by $3.0 \%$. In 2006 the EP2 pass rate for girls was $28.8 \%$.

In $2^{\text {nd }}$ level Primary Education, the number of students increased by $24.2 \%$ compared to 2006, i.e., 120 thousand additional students in relation to the number in 2006. In 2007 the number of schools teaching EP2 increased by 327 units, from 1,514 schools in 2006 to 1,842 schools.

With regard to new enrolments, 349,248 students attended grade 6 for the first time, representing a growth of $32.6 \%$ in relation to the 2006 enrolment. The gross enrolment rate increased from $52.5 \%$ in 2006 to $70.7 \%$ in 2007 , exceeding the plan $(67.3 \%)$ by $3.4 \%$.

In terms of basic education infrastructures, the construction of a total of 1,600 classrooms was concluded, while it is it is expected that about 900 will be concluded until the first quarter of 2008.

\section{Secondary Education}

In 2007 a total of 313,692 students were enrolled in the $1^{\text {st }}$ level of secondary (ESG1). This number represents a growth of $21.7 \%$ in relation to 2006.

These students were enrolled in 52 schools, representing an increase of 36 schools compared to the 216 schools teaching this level in 2006.

The $2^{\text {nd }}$ level of secondary education (ESG2) was attended by a total of 47,388 students, representing a growth of $33.7 \%$ compared to 2006 (35,450 students). This level was taught in 58 educational institutions, representing an increase of 9 schools compared to 2006.

In 2007 the following secondary education institutions were rehabilitated and extended: Xai-Xai Secondary School in Gaza Province, Ilha de Moçambique Secondary School in Nampula Province and Massinga Secondary School in Inhambane Province. The construction of Espungabera Secondary School was also concluded.

The rehabilitation and extension works of Ulóngue Secondary School in Tete Province are in progress.

The projects for the construction of Macia Secondary School in Gaza and Chidzolomondo Secondary School in Tete Province were concluded and the respective tenders were launched.

Also in 2007 a beginning was made with the contracting of consultants for the design and preparation of tender documents for the construction of Tsangano Secondary School in Tete and of Lichinga and Macalodje Secondary Schools in Niassa Province, as well as the requalification and conclusion of Salamanga Secondary School in Maputo Province. 
Also in the scope of the infrastructure building, tender documents were prepared for the construction of 2 secondary schools, one in Chiúre in Cabo Delgado and another one in Marrupa in Niassa, as well as for the rehabilitation of 3 secondary schools in Nacala in Nampula Province, Dondo in Sofala Province and Maxixe in Inhambane Province.

Contracts were signed for the construction of Secondary School Ribáuè Secondary School in Nampula, Mocuba Secondary School in Zambezia and Montepuez Secondary School in Cabo Delgado, as well as the rehabilitation of Cuamba and P.S. Kankhomba Secondary Schools in Niassa, of Angoche Secondary School in Nampula and Pemba Secondary School in Cabo Delgado. Works will start in January 2008.

\section{Distance Learning}

In the scope of the extension of the Secondary Distance Learning Project (PESD), ongoing in Nampula Province, the preparation, reproduction and distribution of selfteaching materials and the redefinition of the programme's implementation strategy is ongoing, with a view to its extension in 2008 to the whole country. In this context, the following activities were carried out:

- Preparation of the PESD-ESG1 implementation manual;

- Preparation of the form 8 modules;

- Training of 165 tutors, 22 coordinators and 11 supervisors;

- Collection op statistical data about the Form 8 candidates to be enrolled in the PESD;

- Awareness-raising at provincial level regarding the expansion of the PESD in 2008;

- Carrying out a diagnosis for the establishment of 6 Support and Learning Centres (CAAs) in each province;

- Reproduction and distribution of 7,200 pamphlets of the first three modules of all Form 8 subjects for the 3,300 students to be enrolled in all provinces of the country.

For the introduction of Form 9 the following activities were performed:

- Preparation of PESD-ESG1's modules for Form 9;

- Reproduction and distribution to Nampula of 6,300 pamphlets of 21 Form 9 modules for 300 students;

- Equipping of 22 CAAs with computer equipment and 10 CAAs with reproduction equipment (photocopiers and duplicators).

Premises for the functioning of the Open and Distance Learning Institute (IEDA) were constructed in Marracuene in Maputo Province, as well as 6 staff houses in order to strengthen the management of distance learning.

For the Medium-level Distance Teacher Training Course, covering all provinces of the country, the following activities were carried out: 
- An accumulated total of 6,395 teachers were enrolled in initial teacher training, attending the medium-level course in 161 pedagogical nuclei. Planned teacher enrolment for 2007 was 3,875.

- A total of 275 tutors, 22 coordinators and 11 supervisors were trained in educational management and supervised teaching practice;

- A total of 66,000 pamphlets of the 65 modules were reproduced and distributed for the enrolment of 300 teachers in each province;

- 22 CD-ROMs were produced, containing 65 self-teaching modules and three course orientation handbooks;

- 11 NUFORPEs were equipped with computer equipment and material for their functioning.

\section{Teaching Staff Training}

In 2007 new courses were introduced based on the new primary school (Form 10+1) and secondary school (Form 12+1) teacher training models. A total of 2,869 trainees attended the Form 10+1 course, while 1,086 trainees were enrolled in the Form 12+1 course. With the introduction of the Form $10+1$ model for primary school teacher training, the previous $7+3$ and Form $10+2$ models were phased out.

Regarding curriculum development for the initial primary school teacher training courses, important activities carried out were the training of teachers for the Teacher Training Institutes in several subjects of the new curriculum and syllabi, as well as the creation of a secondary school teacher-training course in some campuses of the Pedagogical University.

A total of 4,019 students attended the final courses of the Form $7+3$ Primary School Teacher Training Course (CFPPs), corresponding to a decrease of $34.6 \%$ compared to 2006. A total of 2,530 students were enrolled in the Form 10+2 Course, representing a decrease of 56.8\% compared to the 5,852 students enrolled in 2006.

A total of 68 and 69 teachers were enrolled in the medium-level Form 10+1 and Form 10+2 English teacher training courses, respectively.

All Provinces implemented the Medium-level Distance Teacher Training Course. The first 71 and 106 medium-level students graduated in Sofala Province and Maputo City, respectively.

A total of 9,186 new basic education teachers were employed, adding up to a sum total of 82,037 teachers of a universe of 108,750 education employees.

The percentage of teachers teaching two shifts in EP1 was $41.5 \%$ and of contracted female teachers it was $44.98 \%$.

A total of 760 school managers were trained.

Regarding teacher training infrastructures, the following should be mentioned:

- The construction works of the Teacher Training Institutes (IFPs) of Alto Molócuè, Morrumbala, Xai-Xai and Chimoio were concluded; the rehabilitation and extension works of the Namaacha and Inhaminga IFPs were concluded; 
the rehabilitation and extension works of Homoine IFP are in progress and their conclusion is foreseen for May 2008.

- A beginning was made with the rehabilitation of the Maputo Language Institute.

\section{Technical-Professional Education (ETP)}

In the scope of strengthening their formative and administrative component, continuity was given to the laboratory and office equipment programme for the technical education schools covered by the PIREP.

The functioning of the Marrupa Fauna and EcoTourism School in Niassa Province was strengthened and a medium-level course is being introduced in the Lhanguene Trade School.

Regarding ETP infrastructures, the construction works of the Moamba Professional School Boarding-house were concluded; the Dom Bosco Higher Institute (ISDB) started functioning with distance courses for 113 students; the rehabilitation of the Basic-level Chókwè Agricultural School is in progress; the rehabilitation works of the Xai-Xai Industrial and Commercial School are in their final stages.

Regarding school enrolment, a total of 2,213 students were enrolled at elementary level in the 13 existing public schools, corresponding to $113 \%$ of the plan and to a growth of $38 \%$ in relation to the previous year.

A total of 24,197 students were enrolled in basic-level day schools, corresponding to $98 \%$ of the plan and to a growth of $1.0 \%$ compared to 2006 .

A total of 4,797 students were enrolled in medium-level day schools, corresponding to $97.2 \%$ of the plan and to a growth of $8 \%$ compared to the previous year.

\section{Literacy and Adult Education}

The expansion of the functional literacy, adult education and non-formal education programmes was accomplished, with emphasis on women and girls in favour of the gender balance, through the implementation of programmes involving young students in an initiative called "The Family Without Illiteracy", a regular literacy programme with a current duration of 2 years. All programmes give priority to women, whose participation rate is $70 \%$.

The implementation and consolidation of the literacy programme by radio and television, aimed at 500 thousand people becoming literate by radio and 50 thousand by television reached about 140.000 participants.

With regard to the pilot implementation of the new literacy curriculum in Maputo, Manica and Cabo Delgado Provinces, the preparation of the necessary conditions, namely the production of materials and staff training, is still ongoing and expected to end in 2008.

In 2007 a total of 3,352 literacy and adult education units were functioning, representing an increase of 115 units compared to 2006. The level of execution of the target was $89 \%$. 
In literacy classes a total of 599,114 students $\left(1^{\text {st }}\right.$ and $2^{\text {nd }}$ year) were enrolled, of which 345,941 are women. In adult education classes 142,433 students were enrolled, corresponding to an increase of $2.6 \%$ compared to 2006 .

In the Alfa-Radio modality (literacy by radio) 3,200 literacy teachers, 320 supervisors and 30 literacy teacher trainers of the Southern Region were trained.

In the National Adult Education Institute in Sofala 2 dormitory wards were rehabilitated and a dining hall, a porch and an administrative block were built.

The Literacy and Adult Education Staff Training Centre construction project of Cabo Delgado, Gaza and Manica was revised and the phased construction of the 3 Centres was rescheduled.

\section{Improvement of Teaching Quality}

In the course of 2007 the constant innovations of the basic education curriculum were disseminated, especially promotion by learning cycles. The materials produced and ways to implement local curricula in the Teachers Training Institutions were disseminated, and as technicians were monitored and trained in the production of instruments.

A total of 12,104,036 schoolbooks were distributed free of charge.

Concerning bilingual and multiple class teaching in primary education, the protobook, the student's book and the teacher's manual for Form 6 were produced. Teacher Training Institute (IFP) teachers, pedagogical technicians and schoolteachers were trained in bilingual education methodologies. Also worthy of note in this scope are the monitoring and supervision activities carried out in 48 primary schools of Maputo, Sofala, Manica, Zambezia, Inhambane, Tete and Nampula Provinces, and the production of complementary literature booklets.

Regarding General Secondary Education reform, a new curriculum was produced, as well as syllabuses for all subjects. These documents were submitted for consultation and validation through national fora that were organised. Trainers were trained who will, in their turn, conduct teacher seminars about the philosophy of the new ESG curriculum. A draft of a new evaluation regulation was produced and is still in a consultation phase.

Regarding the revision of the Secondary Education Strategy, important activities were the execution of a diagnosis and the start of the definition of immediate impact actions to be considered in 2008. These actions include the schoolbook, school materials and laboratory equipment.

Regarding the implementation of the Non-Formal Education Programme (ENF), in 2007 the organic gardening, small enterprise management and low-cost construction courses in Inhambane, Manica and Sofala Provinces were extended to Maputo, Tete and Niassa.

The Base Pedagogical Nuclei (NPBs) were revitalized at provincial level. The centres were reorganized in groups of 4 or 5 centres per district led by a coordinator.

\section{School Sports}

School infrastructure construction and rehabilitation works were executed to receive the VIII Festival of the School Sports Competitions that were held in Quelimane. This 
Festival involved about 2,000 people, among athletes coming from all provinces, organizers and escorts.

In Quelimane 132 sport agents were trained in training subjects and 60 in arbitrage and judgement in the modalities of handball, volleyball, chess and athletics.

As a complement to the teaching and learning system and in coordination with partners, several sports and cultural activities were carried out in primary schools, with prominence for a basketball show, a mini-basket championship and a CocaCola football cup.

\section{School Health}

The reactivation of the School Health Programme is ongoing, in coordination with MISAU and communities. There is a teacher manual about school health, serving as a guide in 'Teachers Training Institutions (IFPs).

The Strategy for the Prevention of Abusive Alcohol and Drug Consumption in the School Communities was prepared.

The Basic School Health Package Programme was implemented in 2,172 EP1 schools and in 659 EP2 schools. Also in this scope, 100 primary school teachers in Maputo City were trained in oral health topics, and 240 teachers in Maputo, Cabo Delgado, Tete, Manica and Inhambane Provinces in all components of the Basic School Health Package.

A total of 2,200 copies of the School Health Programme Implementation Guide and of the School-age Population Health Promotion Strategy were distributed per province.

Students of all Maputo City primary schools were desparasited and the deparasitation of Maputo Province students was interrupted due to a deficient circulation of information to the parents. The deparasitation of primary school students in Tete Province continued.

\section{Production and School Nourishment}

A begin was made with the survey of existing school production infrastructures in educational establishments in the whole country. We should also note that school area demarcations and acquisition of the respective titles are in progress, in collaboration with MINAG at provincial and district level. School administrator training activities were carried out in the field of school production, food planning, nutrition, food management and hygiene.

\section{HIGHER EDUCATION}

Main activities carried out in this scope were the following:

- Conclusion and evaluation of the pilot phase of the National Quality Guarantee and Accreditation System (SINAQUES) and of the National Academic Credits Accumulation and Transfer System (SNATCA);

- Production of 2006 higher education statistics and indicators;

- Approval of the document creating the National Scholarship Fund; 
- Start of the preparatory activities for the construction three new Polytechnic Institutes (Gaza, Manica and Tete);

- Start of the academic year at the Lúrio University, a new higher education institution created in the scope of the ongoing efforts aimed at the extension of the supply capacity of higher education institutions in the country;

- Activities for the creation of a National Distance Teaching Institute in Lichinga are ongoing.

\section{CULTURE}

In the field of culture, efforts continued concentrated on the promotion of culture, the preservation and dissemination of the national cultural heritage and on the development and strengthening of cultural capacity and infrastructures. Thus, with a view to the accomplishment of these priorities, the following activities were, among others, performed:

\section{Preservation and Appreciation of the Cultural Heritage}

The list of immovable cultural heritage objects was updated and two of them were selected to be proposed for the World Heritage List. The selected sites are Ilha do Ibo and the Serra Vumba Rock Paintings in Manica.

The preparation of the Museums and Monuments Policy was concluded.

In the scope of the preservation of immaterial heritage, the timbila preservation programme was started to be implemented through documental research activities with a view to the creation of a timbila data bank and directory. Regarding the Nyau, activities focused on research and data collection, making an inventory of existing groups in Chifunde and holding a Nyau exhibition in Angónia.

Awareness-raising campaigns were launched for the preservation of cultural heritage. Thus, the Cultural Heritage Protection Law was explained to municipal bodies, the municipal police and users of cultural heritage erected in Maputo City. A guiding instrument (a circular) about the use of cultural resources in teaching was distributed to the schools of the country, and the use of legislation for the protection of archaeological stations was explained (Massingir District), as well as for the preparation of protection plaques of immovable goods (Niassa and Maputo Provinces).

Regarding the preparation of the National Book Policy implementation strategy, a base proposal was prepared for the implementation strategy that will serve as support for the consultancy work to take place in 2008.

As a way to offer a large contribution to the rationalisation of the book market and ease of information exchange at sector level, the introduction of the feasibility of an international book numbering system was planned, a useful instrument for their acquisition, processing and bibliographic verification by the libraries and for the rationalisation of the publishers' and book retail market's orders and accounts.

The preparation of the Mozambican Cinema Policy was started in 2007. 
The cultural heritage was disseminated through the production of didactic materials for schools and for the media, in the scope of the promotion of community participation in the conservation of the cultural heritage.

In llha de Moçambique the rehabilitation of Casa Girassol, a monumental building and example of restoration, was concluded.

\section{Development and strengthening of the cultural capacity and infrastructures}

The rehabilitation of the National Library of Mozambique and of the National Ethnological Museum of Nampula was started, and the rehabilitation of the Casa da Cultura in Nampula was concluded and the institution is functioning.

\section{Strengthening of the partnership with various participants}

The Regulation for the $1^{\text {st }}$ edition of the Scientific-Cultural Days was prepared and they are expected to take place from May 2008.

With a view to the participation of Mozambique in the $3^{\text {rd }}$ edition of the CPLP Cinema Festival, fund-raising activities are ongoing. The organisation of the $1^{\text {st }}$ CPLP Cinema and Audiovisual Show was prepared for the same purpose objective to take place in 2008.

Knowledge about the cultural reality was promoted through research and the dissemination of ethnological, linguistic, sociological and historical studies.

Preparatory activities are ongoing for holding the II National Conference on Culture, to take place in September 2008.

In the scope of socio-cultural events, worthy of mention are the organisation of local arts and crafts fairs at provincial level, with the involvement of craftsmen and the community in general.

Interprovincial cultural exchanges/digressions were promoted for the dissemination of the Timbila and the Nyau, as immaterial world heritage proclaimed by UNESCO:

- The Nyau travelled through Niassa, Zambezia, Manica, Sofala, Inhambane, Gaza and Maputo Provinces, and Maputo City, and

- The Timbila was exhibited in Gaza and Maputo Provinces and in Maputo City.

The Office of the Conservation and Restoration of Ilha de Moçambique (GACIM) was established. Two GACIM technicians benefited from a 30-day course about the preservation of Cultural World Heritage in the People's Republic of China.

The preparation of the plan for the protection of the subaquatic heritage of llha de Moçambique was concluded.

The dissemination of the cultural heritage of protected areas and historical sites and places was done through the media, manuals, pamphlets, talks, (local and provincial) festivals, commemoration of historical-cultural dates and through other means enabling their public knowledge. Also in this scope, holiday camp on llha de Moçambique was organised, with the participation of 100 students from Niassa, Cabo Delgado and Nampula Provinces.

\section{Institutional Development}


In the scope of institutional development, worthy of note are the start of the revision of the National Education System Law and the continuation of the preparation of the School Map, of which the collection of data about existing educational institutions in all provinces of the country was concluded.

\section{B. HEALTH}

In the area of health, efforts continued concentrated on the improvement of the Mozambican population's state of health through interventions contributing to the reduction of morbi-mortality and to the increase of the population's access to the health network and services.

\section{State of health of the population}

In general, the period in analysis was characterized by a decrease of the number of cases of compulsory notification diseases (with the exception of rabies and dysentery), compared to the same period of 2006. The decrease of cases of cholera was the largest, from 5,431 cases in 2006 to 1,454 cases in 2007. In spite of the reduction of the notified number of cases of cholera, the mortality rate increase slightly, from $0.41 \%$ to $0.64 \%$.

In the period in analysis 254 suspected cases of measles were notified, with one obit, against 184 cases notified in the same period of 2006. Although these data show an increase of the number of cases, this increase is apparent, because 183 of the total number of notified cases were investigated and only 1 was positive for measles.

The nutritional surveillance indicators from 2003 to 2007 show that the nutritional state of the Mozambican population continues preoccupying and deserving special attention, mainly the Low Weight at Birth, which, with an average national rate of $11.1 \%$ places the country in a state of emergency, because it exceeded the limit fixed at $7 \%$.

Regarding the Insufficient Growth indicator, all provinces present acceptable rates, amounting to a national average of $4.6 \%$, which is within the acceptable parameters.

The Provinces presenting the highest Insufficient Growth and Low Weight at Birth rates are Niassa $(5.6 \%)$ and Nampula (15.8\%), respectively.

\section{Population Health Care}

The volume and consumption of services measured by outpatient visits and attendance units increased by $6.9 \%$ and $15.9 \%$, respectively, compared to 2006 . The increase of the volume and consumption of services reflects the increase of access to health services, due to the expansion, extension and/or refunctionalization of the health network and equipping of health units, as well as to the improvement of the quality of the services provided. As was the case in 2006, the lowest number of visits per inhabitant $(0.70)$ occurred in Zambezia Province. This is two times lower than in Maputo Province (1.38). 
Table 39: Evolution of Overall Health Care

Ev olution of Overall Heatlh Care
\begin{tabular}{|l|c|c|c|r|}
\hline & 2006 & \multicolumn{2}{|c|}{2007} & Ev ol.(\%) \\
Indicators & Real & Plan & Real & R07/R06 \\
\hline Outpatient visits & $18,907,920$ & $19,385,000$ & $20,211,763$ & 6.9 \\
Outpatien visits/inhab. & 0.95 & 0.95 & 0.99 & \\
Attendance units & $72,908,863$ & $85,752,940$ & $84,535,901$ & 15.9 \\
\hline
\end{tabular}

\section{Maternal and Child Health Programme}

With a view to the reduction of maternal mortality, the efforts focused on the expansion of Basic Essential Obstetric Care (BEOC) and on the integrated VTP services. Regarding the expansion of BEOC, there was a decrease of the number of health units (HUs) offering this service, $55 \mathrm{HUs}$ (June 2007) to $46 \mathrm{HUs}$ (at the end of 2007). As a result, BEOC coverage decreased from $1.35 \mathrm{HU} / 500,000$ inhab to 1.13 $\mathrm{HU} / 500,000$ inhab, remaining at $60 \%$ of the 2007 target $(1.9 \mathrm{HU} / 500,000$ inhab) and being even further away from the 2009 target. Financial constraints, not allowing the training of more Maternal and Child Health Nurses (MCHNs) for BEOC contributed to this situation, together with the transfer of trained MCHNs from the accredited HUs to cover other HUs. In some HUs these female nurses are replaced by male nurses or by staff without BEOC training, affecting the performance of these activities.

With regard to Comprehensive Essential Obstetric Care (CEOC), which are only provided in HUs with surgical capacity, no HUs were opened in 2007 with surgery, thus maintaining previous year's coverage. The lack of qualified staff was behind the lack of CEOC expansion, considering that for a $\mathrm{HU}$ to be accredited for CEOC, it should meet, among others, the following requirements: (i) differentiated equipment; and (ii) qualified staff, at least a surgery technician and an anaesthetist.

National coverage in the period in analysis was $0.91 \mathrm{HU} / 500,000$ inhab CEOC.

Current coverage of waiting homes for pregnant women is $64 \%$ in the district capitals with waiting homes for pregnant women, exceeding the 2007 target of $60 \%$. The target for 2009 is $71 \%$. It should be noted that this coverage is only in relation to the district capitals. There are districts with more than one waiting home, which means greater access of pregnant women to safe maternity services. Regarding this strategy the improvement of the management of these homes, rendering them more functional, is a major challenge to the sector.

With a view to protect pregnant women against malaria, the Intermittent Preventive Treatment (IPT) of malaria during pregnancy is included in the pre-natal visits. In 2007 the percentage of pregnant women who took at least 2 doses of IPT was $37.2 \%$, a coverage that is inferior to the 2007 target of $60 \%$. From the start of the IPT programme (a $9 \%$ coverage) there has been a significant evolution of the number of pregnant women benefiting from this treatment.

Furthermore, the following documents were prepared in the period in analysis: (i) VTP guides; (ii) the Sexual and Reproductive Health Policy; (iii) Base lines for quality control of SSRNI services, the implementation of quality improvement standards was started; (iv) proposal for abortion legislation amendments; (v) proposal for an international partnership activities plan for maternal and neonatal health; (vi) Strategy for early diagnosis of uterine carcinoma. 
Also worthy of note is the start of the Maternal and Neonatal Health Needs Assessment study, involving 450 health units. This study is an important tool for the identification of the main constraints and the best way to respond to the population's real needs.

Analysing the sexual and reproductive health indicators, one observes that all of them increased compared to the same period of the previous year. The coverage of institutional deliveries increased, having attained the planned target, as shown in the following table:

Table 40: Evolution of Maternal and Neonatal Health Coverage Rates

\begin{tabular}{|l|c|c|c|}
\hline \multicolumn{4}{|c|}{ Ev olution of $\mathrm{MCH}$ cov erage rate } \\
\hline & 2006 & \multicolumn{2}{|c|}{2007} \\
\cline { 3 - 4 } Indicators & Real & Plan & \multicolumn{1}{|c|}{ Real } \\
\hline Pre-natal visits & $99.4 \%$ & $98.0 \%$ & $100.0 \%$ \\
Institutional deliv eries & $48.9 \%$ & $52.0 \%$ & $51.9 \%$ \\
Post-deliv ery visits & $59.0 \%$ & $64.0 \%$ & $69.9 \%$ \\
\hline
\end{tabular}

In the last few years the maternal intra-hospital mortality rate tends to increase. From January to December 2007 the rate was 198/100,000 live births, against $191 / 100,000$ live births in 2006. As in 2006, the highest rates occurred in Cabo Delgado, Inhambane and Nampula Provinces (figures above the national average) and the lowest in Maputo Province and Maputo City. The upward trend of the intrahospital maternal mortality rate is related to the arrival of more women to the HUs, due to the improvement of the services provided (BEOC) and the improvement of the registration system.

In the scope of the reduction of the child mortality rate, important activities performed were the preparation of policy documents about sexual and reproductive health $(\mathrm{SRH})$ and neonatal and child health $(\mathrm{NCH})$, the guide-book for the reduction of maternal and neonatal mortality (road map), the Global Partnership Plan for Maternal Neonatal and Child Health (PMNCH), the Strategic Neonatal and Child Health Plan (2008-2010), and the definition of criteria and standards for the improvement of the quality of reproductive, neonatal and child health services, the Training Manual about Community Health Care for Newborns (AIDI-C) for Elementary Polyvalent Agents (APEs) training, and the health information and education materials for Newborns in the Community.

Also in the scope of service quality improvement, an orientation meeting about paediatric care was held in the reference hospitals, followed by an evaluation in the José Macamo Hospital, the Manhiça Health Centre, the Xinavane Rural Hospital and the Xai Xai Provincial Hospital.

The Integrated Attention to Child Diseases strategy (AIDI) is being implemented in all HUs of the primary and reference network by trained staff. During the period in analysis AIDI courses were given in Maputo City and in Sofala, Zambezia, Niassa, Cabo Delgado, Tete and Inhambane Provinces. A total of 301 health professionals were trained. Community AIDI courses were also given in Gaza and Inhambane, with a total of 56 participants.

The rate of visits by $0-11$ months old children did not change compared to 2006, while the rate for $0-4$ years old children decreased from $69.1 \%$ in 2006 to about $59.2 \%$ in 2007 . The poor influx of mothers or escorts to the growth control visits after the 9-months vaccination contributed negatively to this situation. 
Table 41: Evolution of the Coverage Rate of Visits of 0-11 month and 0-4 year old children

\begin{tabular}{|l|c|l|c|}
\hline \multicolumn{4}{|c|}{ Evolution of the MCH coverage rate } \\
\hline \multirow{3}{*}{ Indicators } & 2006 & \multicolumn{2}{|c|}{2007} \\
\cline { 3 - 4 } & Real & Plan & Real \\
\hline $1^{\text {st }}$ visits children (0-11 months) & $100.0 \%$ & $98.0 \%$ & $100.0 \%$ \\
$1^{\text {st }}$ visits children 0-4 years) & $69.1 \%$ & $74.0 \%$ & $59.6 \%$
\end{tabular}

In the scope of the reduction of the malnutrition prevalence rate and impact, contrary to the plan the implementation of the Nutrition Surveillance Observatories did not start due to the need to revise the proposed methodology.

In the area of micronutrient supplementation, Vitamin A capsules were sent to all provinces for 6-59 month old children and for post-natal women and iodine capsules for 0-14 year old children, for women of childbearing age (15 - 49 years) and pregnant women.

The coverage of Vitamin A supplementation, both for post-natal women and for 6-59 month old children decreased from $45 \%$ in 2006 to $43 \%$ in 2007 (post-natal women) and from $62 \%$ in 2006 to $32 \%$ in 2007 (6-59 month old children). For both target groups, Vitamin A supplementing coverage is below the $60 \%$ target set for 2007 .

Regarding post-natal women supplementation, only Inhambane Province attained and exceeded the planned target. In relation to 0-59 month old children, no Province managed to attain the proposed target.

In the scope of iodine deficiency control, the implementation of the lodised Oil Supplementation Programme was started in the 4 target provinces (Nampula, Tete, Zambezia and Niassa). In the same scope, of a total of 57,930 tons of salt produced, 53,724 tons were iodised (93\%), representing an increase compared to 2006, when $74 \%$ was iodised.

The supplementation of pregnant women and babies with iron and folic acid was intensified through the implementation of the Basic Nutrition Package in the Health Units.

It should be noted that the above described nutrition activities have been carried out through the implementation of the Basic Nutrition Package (PNB) at primary health care level. Also in the scope of the implementation of the BNP, 1,150 health workers were trained, amounting to a total of 2,813 trained workers in all provinces of the country.

In the scope of the Nutrition Rehabilitation Programme (NRP), training was offered at national level to 110 health workers about the implementation of Nutrition Rehabilitation Centres.

In relation to training activities about Severe Acute Malnutrition Management, 426 health workers were covered in 2007, adding up to a present total of 1,483 trained workers. Also in the scope of Community-Based Management of Severe Acute Malnutrition (Supplementation with plumpy'nut), 850 health workers were trained in 2007 , adding up to a present total of 878 trained workers.

Regarding the Treatment of Severe Acute Malnutrition, the country's mortality rate, which is $11.5 \%$, is above the limits considered acceptable (<10\%). Cabo Delgado, Nampula and Zambezia Provinces and Maputo City present acceptable mortality rates, while Niassa, Inhambane and Gaza Provinces present mortality rates above 
$15 \%$, indicating an emergency situation. These data show a grave and preoccupying situation, in relation to the intra-institutional management of Severe Acute Malnutrition.

Also in the scope of the Nutrition Rehabilitation Programme in the provinces, in relation to Community-based Malnutrition Treatment, the 2007 data show that 110 Health Units in a total of 87 Districts in all provinces of the country already implement the current protocol defined for the treatment of Severe Acute Malnutrition without complications (supplementation with plumpy'nut).

\section{Extended Vaccination Programme}

In the period in analysis, 1,051 HUs had functioning fixed vaccination posts, corresponding to $87 \%$ of the number planned $(1,205 \mathrm{HUs}$ with fixed posts). The planned targets were exceeded in terms of vaccination coverage, in spite of the decrease of vaccination coverage for VAS and DPT/Anti-polio and HB $\left(3^{\text {rd }}\right)$, compared to the same period of the previous year.

In relation to BCG coverage, there were no big changes in the last two years, which means that although the rate of institutional deliveries is not very high, a bigger part of the children are vaccinated.

Concerning VAS, there was a decrease in 2007 in the order of $7.6 \%$, though the target was exceeded. The same trend occurred in relation to DPT/Anti-Polio and HB $\left(3^{\text {rd }}\right)$, where coverage decreased from $100 \%$ in 2006 to $95 \%$ in 2007 .

The decrease of vaccination coverage compared to 2006 , is related to planning and management problems, financial constraints and lack of human resources.

Table 42: Evolution of the PAV Coverage Rates

\begin{tabular}{|l|c|c|c|}
\hline \multicolumn{3}{|c|}{ Ev olution of PAV cov erage rates } \\
\hline & 2006 & \multicolumn{2}{|c|}{2007} \\
\cline { 3 - 4 } Indicators & Real & Plan & Real \\
\hline BCG [0-11 months] & $100.0 \%$ & $90.0 \%$ & $100.0 \%$ \\
VAS [9-23 months] & $100.0 \%$ & $75.0 \%$ & $93.4 \%$ \\
DPT/Anti-polio and HB (3 ${ }^{\text {rd }}$ dose) & $100.0 \%$ & $75.0 \%$ & $95.0 \%$ \\
\hline
\end{tabular}

\section{School and Adolescent Health Programme}

The activities of the school health component were concentrated on the expansion of the implementation of the Basic Health Package to the district capitals.

A total of 502 teachers were trained in school health topics, against 2,340 teachers planned. The objective of the training of teachers in school health topics is to boost the performance of Basic Package-related activities so as to improve monitoring and guidance of school-age children in the schools.

VAT was administered in schools to 554,604 children ( $1^{\text {st }}$ dose) and to 287,507 children $\left(2^{\text {nd }}\right.$ dose $)$.

In the scope of the deparasitation of school students, Maputo City started the training of 335 teachers and desparasited 25,391 children of a total of 206,641, corresponding to $12.2 \%$. The non-accomplishment of the target is due to articulation problems with a few schools in Maputo Province and Maputo City. 
In relation to Vitamin A supplementation, a test was done in EP1 and EP2 schools in Gaza Province and a plan drawn up for 2008. On the other hand, 66 First Aid Kits were bought for teachers in Mossurize District in Manica Province.

\section{Mental Health}

In this scope, important activities were the contracting of 2 psychologists for the opening of the Child and Juvenile Psychological Rehabilitation Centre (CERPIJ) of Beira Central Hospital and the child attendance in Infulene Psychiatric Hospital, and 4 psychologists for the Applied Psychology and Psychotecnical Exams Centre (CEPAEP), in addition to the administration of training courses for existing staff.

\section{Major endemic diseases}

In this scope priority was given to the prevention, control and treatment of the main endemic diseases with greater influence on the population's morbi-mortality.

\section{Malaria}

In 2007 the number of malaria cases decreased slightly. A total of $6,318,764$ "malaria cases" and 3,360 obits were notified, against 6,335,757 cases and 5,042 obits notified in 2006. The largest proportions of cases were in Nampula, Sofala and Zambezia Provinces (20, 11 and 10\%, respectively). In Maputo Province and Maputo City the number of notified cases went down.

With a view to reduce the weight and impact of malaria, continued priority was given to the implementation of the vector control programme through intra-domiciliary spraying (PIDOM), larvae control and the distribution of mosquito nets. Special attention was given to cases diagnosis, medicine supply and case management, strengthening institutional capacity, collaboration and coordination with implementation partners with a view to the expansion of interventions.

The new standards for handling cases of malaria (change of the $1^{\text {st }}$ and $2^{\text {nd }}$ lines of treatment) were prepared and approved. The Rapid Diagnosis Tests (TDRs) were introduced and 2,000,000 tests were distributed. Provincial laboratory supervisors and 1 laboratory technician for each one of the provincial hospitals were also trained in the scope of the introduction of the use of malaria TDRs and a refresher course was given to laboratory technicians at national level.

Trainer training was equally conducted for Community Health Agents (ACSs) for the correct and timely treatment of malaria in the community, namely provincial health coordinators and those in charge of the provincial pharmacy stores in the whole country. It should be noted that these trainers are responsible for the training of all ACSs at provincial level.

In the scope of vector control, PIDOM was extended to Milange (Zambezia), Caia (Sofala), Guijá and Massingir (Gaza) Districts and DDT was introduced in the Southern Region of the country (in Inhambane and Gaza Provinces).

Domiciliary spraying was carried out in 45 districts, covering 1,537,825 houses. As a result of this effort the protection of $35 \%$ of the population was ensured.

From January to December 2007 about 938,950 long-duration mosquito nets were distributed in all provinces of the country.

Tuberculosis and leprosy 
In the scope of the reduction of the weight and impact of tuberculosis (TB), between January and September 2007 the cure rate was $82.0 \%$ against $78.9 \%$ in the same period of 2005 , which shows a positive evolution in the order of $3.1 \%$, attributed to the improvement of the implementation of direct observation of treatment (DOT), which guarantees the regular taking of drugs and greater adherence to the treatment. The abandonment rate was $4.6 \%$ against $5.4 \%$ in the same period of 2005 , which also shows an improvement of the awareness-raising activities with a view to avoid treatment abandonment. It should be recalled that for this rate, the maximum figure accepted by the $\mathrm{WHO}$ is $5 \%$.

The obit rate was $10.2 \%$ against $11.7 \%$ in the same period of 2005 . The unfavourable results rate (the sum of abandonment's, obits and transfers), which evaluates the overall performance of the programme, was $6.6 \%$ against $8.2 \%$ in the same period of 2005, which shows an improvement, in spite of the various constraints in the performance of the programme.

In the scope of the implementation of the tuberculosis control strategy, the DOTs continue being extended at all levels. In the course of 2007 many provinces extended the DOTs to more peripheral health units, i.e., to the peripheral health centres, amounting to a total of 261 peripheral health units that started to implement DOTs, basically the treatment of patients under direct observation by a health professional - DOT in the initial phase as well as the follow-up of patients, which increases the coverage of institutional DOTs (real access to these services) to $76.6 \%$.

During the period in analysis $92 \%$ of TB/HIV patients in the whole country started the preventive treatment with cotrimoxazol with the objective to reduce the appearance of other opportunistic infections, as well as patients' mortality.

In order to reduce the weight and impact of leprosy, continued priority was given to community involvement. A review and updating was also done of the leprosy cases being treated in the more endemic districts of the country. All districts of Sofala Province were covered.

In Nampula City 12 professionals from Nampula, Cabo-Delgado, Manica and Zambezia Provinces were trained for doing operational research related to leprosy in their respective provinces.

\section{Expansion of the health network}

In the scope of the increase of access to health services through the expansion of the health network, expansion works and the improvement of the health network's working conditions, of the support systems and of the training institutions were carried out during the period in analysis. Thus, 19 type II CSRs were concluded, the operating block and the $1^{\text {st }}$ rehabilitation phase of the Cuamba Rural Hospital were concluded, and the Massinga Rural Hospital was extended. In terms of training institutions, the construction works of the Mocímboa da Praia and Quelimane Training Centres were started.

\section{Human Resource Development}

A total of 48 bachelors in surgery were graduated in the ISCISA. In the same period, 1,667 health professionals of other levels were graduated, of which 150 in promotion courses, 353 in medium-level initial courses and 1,164 in basic-level courses, adding 
up to 1,715 graduates, corresponding to $99 \%$ of the number of graduations planned until the end of 2007. Compared to 2006, the number of graduates increased by $28.9 \%$.

\section{Pharmaceutical area}

In the scope of the public sector reforms and the acceleration of changes in the sector in general and particularly in the Central Store of Medicines and Medical Goods (CMAM), from January 2007 the implementation of the Operational Transition Plan (POT) is ongoing, aimed at the transfer of the activities carried out by Medimoc to the CMAM with a view to improve the flow of medicines in the SNS.

Concerning stock and furniture management and the distribution of medicines and medical goods to the SNS, classical medicines and PME kits were distributed, according to criteria and standards in force.

With a view to the improvement of the flow of medicines, lists of medicines and/or medical goods were prepared for various programmes and specific MISAU sectors (Tuberculosis, Malaria, HIV, Laboratory, Blood Bank) and the specialists were regularly consulted for the definition of the list of priorities through the application of the respective acquisition priority criteria.

In relation to the pharmaceutical inspection services, inspections were carried out in two districts, two companies and eight private pharmacies in Maputo City. The Chamanculo, José Macamo and Mavalane General Hospitals also received inspection visits. In the same period the opening of another 6 pharmacies was authorized in Maputo, Gaza, Inhambane and Nampula Provinces.

\section{LABOUR}

In the area of labour continued priority was given to the development of programmes ensuring the increase of employment opportunities, to the prevention of labour conflicts in companies and the expansion of the social security system services.

Thus, among other activities carried out for the accomplishment of the defined objectives, the following should be highlighted:

\section{Legislative action}

- The Labour Law and the Social Security Law were approved;

- The Compulsory Security Regulations, the Domestic Labour Regulations and the Minimum Wage Definition Criteria were approved;

- Premises for the establishment of the Matola Labour Mediation and Arbitrage Centre (Maputo Province) were acquired;

- A commission was created for the regulation of the mediation centres;

- International labour standards were disseminated in the country and the ratified and not ratified conventions are already available on the Sector's Website.

\section{Labour, Employment and Professional Training}

In the scope of the progressive and sustained expansion of the supply of employment and professional training infrastructures in the country, the first phase of 
the workshop buildings of the Professional Training Centres in Pemba and Quelimane was concluded and a begin was made with their equipping.

Regarding professional training for unemployed workers and first-time job seekers, the following main activities were carried out:

- A total of 11,258 job seekers were trained in various specialities in the Public and Private Professional Training Centres, of which 39 handicapped persons, thus exceeding the defined target by about $445.9 \%$. This increase is related to the improvement of the collection of data, which came to include other Training Centres in addition to those belonging to the INEFP. Compared to 2006 (when 7,980 job-seekers were trained), the number of trained workers increased by $41.7 \%$. The following table shows the distribution of unemployed workers trained by province:

Table 43: Professional Training of Unemployed Workers

\begin{tabular}{|l|r|r|r|}
\multicolumn{4}{|c|}{ Professional training of job-seekers } \\
\hline & Planned & Exec. & \% exec. \\
\hline Niass & 200 & 524 & 262 \\
Cabo Delg & 304 & 948 & 311.8 \\
Namp & 328 & 1,511 & 460.7 \\
Zamb. & - & 115 & - \\
Tete & - & 992 & - \\
Manic & 104 & 239 & 229.8 \\
Sof. & 672 & 1,400 & 208.3 \\
Inhamb. & 188 & 1,165 & 619.7 \\
Gaza & 80 & 339 & 423.8 \\
Maputo C & 433 & 3,802 & 878.1 \\
Maputo P & 216 & 223 & 103.2 \\
\hline Tot & 2,525 & 11.258 & 445.9 \\
\hline
\end{tabular}

- A total of 139 job-seekers were trained through mobile units, of which 32 waiters (16 in Xai-Xai and 16 in Inhambane), 65 cooks (36 in Xai-Xai and 29 in Inhambane), 42 in the mixed course (25 in Xai-Xai and 17 in Inhambane);

- A total of 1,283 job-seekers were trained in small business management, of which 344 in Maputo City, 212 in Sofala, 65 in Nampula, 150 in Niassa, 37 in Cabo Delgado, 39 in Inhambane, 20 in Gaza and 316 in Maputo Province, representing $72 \%$ of the plan (1,790 job-seekers). In comparison, in 2006161 job-seekers had been trained;

- Professional training posts were organised for 1,894 job-seekers and selfemployment candidates, of which 735 in Niassa, 40 in Nampula, 25 in Zambezia, 305 in Sofala, 251 in Maputo Province and 538 in Maputo City, against 1,000 planned;

- 62 people were trained in the cook's, waiter's and mixed course at the Inhambane Higher Hotels and Tourism School (UEM).

In the scope of the employment of job-seekers:

In the whole country 163,594 unemployed job seekers were registered, of which 32,910 are women. Compared to 2006 this represents a growth of $4.8 \%$. Of the above-mentioned total number of job seekers, 81,065 do so for the first time and 82,529 are seeking new employment. The largest numbers of unemployed workers 
are registered in Nampula, Sofala and Maputo Provinces. The following table shows the distribution of registered unemployed workers by province:

Table 44: Unemployed workers by province

\begin{tabular}{|l|r|r|r|}
\hline \multicolumn{4}{|c|}{ Registered unemploy ed workers } \\
\hline Provinces & $1^{\text {st }}$ job & New job & Total \\
\hline Niassa & 2,162 & 2,804 & 4,966 \\
Cabo Delgado & 5,839 & 6,558 & 12,397 \\
Nampula & 26,715 & 21,612 & 48,327 \\
Zambézia & 7,482 & 2,727 & 10,209 \\
Tete & 5,133 & 3,361 & 8,494 \\
Manica & 3,294 & 8,627 & 11,921 \\
Sofala & 11,657 & 16,975 & 28,632 \\
Inhambane & 3,615 & 6,188 & 9,803 \\
Gaza & 2,979 & 519 & 3,498 \\
Maputo Prov. & 4,268 & 10,518 & 14,786 \\
Maputo City & 7,921 & 2,640 & 10,561 \\
\hline Total & 81,065 & 82,529 & 163,594 \\
\hline
\end{tabular}

The employment centres registered 12,957 unemployed workers, of which 2,115 are women, against 16,118 unemployed workers registered in the same period of 2006. The practise of seeking employment opportunities through employment centres decreased by about $20 \%$ in relation to 2006 . This happened because the employers can hire workers directly.

Until the end of 2007 a total of 5,626 employment offers were communicated to the employment centres, of which 741 jobs were for women. In the same period of 2006 6,477 job offers were communicated, of which 899 were for women. Through the employment centres 5,653 unemployed workers were employed by several companies, against 4,867 unemployed workers employed in 2006.

Table 45: Employment of unemployed job seekers

\begin{tabular}{|l|r|r|r|}
\hline Province & $\begin{array}{l}\text { Registered } \\
\text { job-seekers }\end{array}$ & $\begin{array}{c}\text { Offers } \\
\text { received }\end{array}$ & $\begin{array}{l}\text { Number } \\
\text { employed }\end{array}$ \\
\hline Niassa & 56 & 34 & 39 \\
Cabo Delg. & 393 & 71 & 107 \\
Nampula & 4,499 & 507 & 375 \\
Zambézia & 1,665 & 68 & 116 \\
Tete & 478 & 134 & 280 \\
Manica & 620 & 283 & 263 \\
Sofala & 2,870 & 2,193 & 1,610 \\
Inhambane & 1,053 & 88 & 537 \\
Gaza & 196 & 10 & 88 \\
Maputo P. & 625 & 2,066 & 2,066 \\
Maputo C. & 502 & 172 & 172 \\
\hline Total & 12,957 & 5,626 & 5,653 \\
\hline
\end{tabular}

A total of 16,592 job-seekers managed to find employment through direct admissions, thus distributed by province: Niassa (1,743); Cabo Delgado (359); Nampula (4,454); Zambezia (51); Tete (1,393); Manica (817); Sofala (871); Inhambane (931); Gaza (140); Maputo Province (621) and Maputo City $(5,212)$. In relation to the year 2006, in which 9,611 job seekers were employed, there was an increase of $73 \%$.

About 23,121 citizens found self-employment activities through associations at district level and individual initiatives, thus distributed by province: Niassa (130); Cabo Delgado (2,376); Nampula (40); Zambezia (461); Tete (2716); Manica (1,733); 
Sofala (11,386); Inhambane (2,044); Gaza (64); Maputo Province $(2,032)$; MaputoCity (139).

In the scope of migratory labour:

A total of 45,036 Mozambican workers were recruited for the mines in South Africa, against 47,748 in the previous year. Similarly, the contracts of 6,714 Mozambican workers in the agricultural sector were legalised and renewed. Compared to the year 2006, in which the contracts of 6,954 Mozambican workers were renewed and legalised, there was a decrease in the order of $3.4 \%$.

\section{Labour Inspection}

In the scope of labour inspection and relations the following main activities were carried out:

- A total of 78 labour inspection agents were trained in the whole country, against 45 planned;

- A total of 124 inspection agents were trained against 98 planned. In the Southern Region 64 agents were covered, in the Central Region 30 agents and in the Northern Region also 30;

- A total of 4,998 establishments of various branches were inspected against 4,378 planned. Compared to 2006, in which 3,529 establishments were inspected, there was a growth in the order of $41.6 \%$.

- During the inspections 4,946 transgressions of various labour standards were detected, of which 1,691 resulted in fines and the remaining 3,255 cases received a written warning;

- The parties were made aware of the importance and opportunity of celebrating the Collective Labour Regulation Instruments (IRCT), as a means of stabilising labour relations and creating and preserving social tranquillity;

- Labour legislation was disseminated in the fields of: rights and obligations, collective negotiations, salaries, work health and safety, work of women, minors and disabled persons;

- Monitoring of the collective negotiation processes at company level;

- A total of 383 conflicts were mediated and conciliated, of which 168 collective and 214 individual conflicts, covering a total of 13,631 workers. In the same period of 2006 a total of 199 labour conflicts were mediated;

- Information material was produced about collective negotiations, the role of the Labour Administration in the prevention of labour conflicts and the profile of the mediator.

\section{Social Security}

In the scope of social security, a total of 1,860 contributors and 42,752 beneficiaries were registered, representing an accomplishment of the planned targets in the order of $132.8 \%$ and $106.8 \%$, respectively. Compared to the year 2006, in which 1,788 contributors and 33,995 beneficiaries were registered, there was an increase in the order of $4.02 \%$ and $25.7 \%$, respectively. 


\section{Consultative Labour Commission}

In the scope of the tripartite social dialogue, involving the Government, the employers and the trade unions, two ordinary sessions and one extraordinary session were held in which, among other points, the following issues were dealt with: the proposal of the criterion to be used, from 2008, for fixing national minimum wages; the Regulation of the Social Security Law; the Regulation of the Domestic Labour Law.

\section{WOMEN AND SOCIAL WELFARE}

In the area of women and social welfare priority continued to be given to the execution of activities aimed at the protection and social assistance to people living in a state of extreme poverty, particularly women heads of households, children, the elderly and handicapped persons, guaranteeing them access to development opportunities, the expression of their capacities and the exercise of their civic rights.

Thus, with a view to the achievement of the defined objectives, the following activities among others were carried out:

\section{In the scope of the development of women}

- 29 women associations, of which 3 in Niassa Province, 16 in Cabo Delgado and 10 in Maputo Province, were trained in the field of Project Management, Women's Rights, the Law of the Family, Gender and HIVIAIDS;

- Sewing material and mills were distributed to 5 women associations, benefiting about 66 members, of which 45 in Niassa Province and 21 in Cabo Delgado;

- A total of 30 women were trained in Lichinga Town in the field of Project Management and Marketing;

- A total of 32 District Counsellors of the Legal Offices were trained in the field of the applicability of the Law of the Family, matrimonial conflict resolution and associative ways of organisation;

- A total of 390 women were trained in Inhambane Province in the field of needlework, embroidery, typing, informatics, painting and weaving;

- A total of 73 women heads of households were integrated into the cassavagrowing project in Maputo Province.

\section{In the scope of the protection of children}

In the scope of the Family Location and Reunification Programme 10,335 children were documented and 3,121 children were reunited, corresponding to $861 \%$ and $1,248 \%$ of planned, respectively.

Table 46 Family Location and Reunification Programme

\begin{tabular}{|l|r|r|r|r|r|}
\hline \multicolumn{7}{|c|}{ Family location and reunification programme } \\
\cline { 3 - 4 } Indicators & 2006 & \multicolumn{2}{|c|}{2007} & \% accom. & $\begin{array}{c}\text { \% growth } \\
\text { P07/R06 }\end{array}$ \\
\hline Documented children & Real & Plan & \multicolumn{1}{c|}{ Real } & Rlan \\
Reunited children & 4,053 & 1,200 & 10,335 & 861 & 155 \\
& 1,111 & 250 & 3,121 & 1,248 & 181
\end{tabular}




\section{In the scope of the Preschool Education Programme}

A total of 56,017 children attended the three types of preschool education establishments, corresponding to more than $100 \%$ of planned. Of the total number of children attended, 1,608 children were in public infant centres, 11,962 in centres private infant centres and 42,447 in community infant schools.

With a view to the revision and harmonization of the didactic materials in use in the infant centres, the collection of materials used in the preschool syllabuses was started and visits were paid to a few infant centres in Sofala, Zambezia, Inhambane, Gaza and Maputo Provinces and in Maputo City.

Table 47: Preschool Education

Preschool education

\begin{tabular}{|c|c|c|c|c|c|}
\hline \multirow[b]{2}{*}{ Indicators } & \multirow{2}{*}{$\begin{array}{l}2006 \\
\text { Real }\end{array}$} & \multicolumn{2}{|c|}{2007} & \multirow{2}{*}{$\begin{array}{l}\% \text { accom. } \\
\text { Plan }\end{array}$} & \multirow{2}{*}{$\begin{array}{l}\text { \% growth } \\
\text { R07/R06 }\end{array}$} \\
\hline & & Plan & Real & & \\
\hline State infant centres & 15 & 15 & 15 & 100.0 & - \\
\hline Enrolled children & 1,823 & 1,500 & 1,608 & 107.2 & -11.8 \\
\hline Private Infant Centres & 147 & 120 & 157 & 130.8 & 6.8 \\
\hline Enrolled children & 12,722 & 7,500 & 11,962 & 159.5 & -6.0 \\
\hline Community infant schools & 611 & 550 & 629 & 114.4 & 2.9 \\
\hline Enrolled children & 42,151 & 30,000 & 42,447 & 141.5 & 0.7 \\
\hline
\end{tabular}

\section{In the scope of deprived children}

The attendance of deprived children is basically done through the reception centres and the kindergarten. The majority of these establishments are managed by private institutions, among which religious denominations are prominent.

Thus, during the period in analysis the reception centres attended 23,875 street children. A total of 1,29 children were also attended in the 25 kindergarten functioning in the whole country, of which 683 in the 7 public kindergarten and 1,046 in the 18 private kindergarten.

Table 48: Attendance of deprived children

\begin{tabular}{|c|c|c|c|c|c|}
\hline \multirow[b]{2}{*}{ Indicators } & \multirow{2}{*}{$\begin{array}{l}2006 \\
\text { Real }\end{array}$} & \multicolumn{2}{|c|}{2007} & \multirow{2}{*}{$\begin{array}{c}\% \text { accom } \\
\text { Plan }\end{array}$} & \multirow{2}{*}{$\begin{array}{l}\% \text { growth } \\
\text { R07/R06 }\end{array}$} \\
\hline & & Plan & Real & & \\
\hline Street child centres & 131 & 72 & 171 & 237.5 & 30.5 \\
\hline Enrolled children & 20,895 & 8,000 & 23,875 & 298.4 & 14.3 \\
\hline State kindergarten & & & 7 & 87.5 & -12.5 \\
\hline $\begin{array}{l}\text { Enrolled children } \\
\text { Private kindergarten }\end{array}$ & $\begin{array}{r}446 \\
17\end{array}$ & $\begin{array}{r}400 \\
25\end{array}$ & $\begin{array}{r}683 \\
18\end{array}$ & $\begin{array}{l}170.8 \\
720\end{array}$ & $\begin{array}{c}53.1 \\
59\end{array}$ \\
\hline Enrolled children & 734 & 1,400 & 1,046 & 74.7 & 42.5 \\
\hline
\end{tabular}

Also in the scope of child protection and assistance, in coordination with partners that support the child area, the following activities were carried out:

- Training in the field of violence, sexual abuse and trafficking in minors was offered to 120 trainers and 15 technicians of several Government institutions working with orphan and vulnerable children in Maganja da Costa District in Zambezia Province;

- Training in the field of the prevention and fight against violence and sexual abuse of minors was offered to 38 Government and Civil Society representatives in Manica Province; 
- Dissemination about the Rights of the Child was done through the public media;

- The Law regulating the access of minors to nocturnal public recreation spaces and about the consumption of alcohol and tobacco (Law 6/99) was disseminated in Sofala Province, involving members of Government and representatives of the institutions responsible for the nocturnal public recreation spaces.

\section{In the scope of the elderly}

In the period in analysis 624 elderly were attended in the 24 Elderly Support Centres (CAVs) functioning in the country. On the other hand, 2,721 elderly were attended in the 19 existing Open Community Centres in the whole country.

Three houses for the same number of elderly were constructed, two of which in Marracuene District and one in Matola District.

Table 49: Attendance of elderly

Attendance of the elderly

\begin{tabular}{|l|r|r|r|c|c|}
\hline & 2006 & \multicolumn{2}{|c|}{2007} & \% accom & \% growth \\
\cline { 3 - 4 } Indicators & Real & Plan & Real & Plan & R07/R06 \\
\hline State support centres & 9 & 9 & 10 & 111.1 & 11.1 \\
Elderly attended to & 200 & 250 & 312 & 124.8 & 56.0 \\
Private support centres & 13 & 15 & 14 & 93.3 & 7.7 \\
Elderly attended to & 310 & 350 & 312 & 89.1 & 0.6 \\
\hline
\end{tabular}

\section{In the scope of handicapped persons (PPDs)}

During the period in analysis 10,386 handicapped persons were identified, 4,911 were looked after, 45,200 integrated into schools, 257 attended in the transit centres, 350 in the special schools, and 56 in the Institute for Visually handicapped Persons.

Table 50: Attendance of handicapped persons

\begin{tabular}{|c|c|c|c|c|c|}
\hline \multirow[b]{2}{*}{ Indicators } & \multirow{2}{*}{$\begin{array}{l}2006 \\
\text { Real } \\
\end{array}$} & \multicolumn{2}{|c|}{2007} & \multirow{2}{*}{$\begin{array}{l}\% \text { accom } \\
\text { Plan }\end{array}$} & \multirow{2}{*}{$\begin{array}{l}\text { \% growth } \\
\text { R07/R06 }\end{array}$} \\
\hline & & Plan & Real & & \\
\hline Identified h. persons & & 7,000 & 10,386 & 148.4 & - \\
\hline Accompanied $h$. persons & 9,339 & 2,500 & 4,911 & 196.4 & -47.4 \\
\hline Handicapped children & 2,472 & 2,000 & 45,200 & $2,260.0$ & 1728.5 \\
\hline 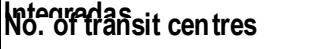 & & & 6 & 100.0 & 0.0 \\
\hline H. persons attended & 28 & 380 & 257 & 67.6 & -8.5 \\
\hline Special schools & & & 3 & 100.0 & 0.0 \\
\hline No. of students & 326 & 330 & 350 & 106.1 & 7.4 \\
\hline Institute for visually h. p. & & & 1 & 100.0 & 0.0 \\
\hline No of students & 150 & 140 & 56 & 40.0 & -62.7 \\
\hline
\end{tabular}

We should also mention that the National Action Plan for the Handicapped Persons Area was disseminated in Sofala, Inhambane and Maputo Provinces, with the involvement of public and civil society institutions, and 964 compensatory devices were distributed, benefiting an equal number of handicapped persons, distributed in the following way: 226 in Niassa, 130 in Cabo Delgado, 110 in Nampula, 195 in Zambezia, 48 in Tete, 27 in Manica, 140 in Gaza, 63 in Maputo Province and 25 in Maputo City. 
Training was offered to 24 sign language interpreters and publicity spots in sign language were translated, in the scope of the dissemination of information about the general population and housing census.

In Cabo Delgado 71 teachers were trained in the field of teaching children with special educational needs.

In Maputo Province 31 sector employees were trained in the use of signs languages.

A total of 101 people were trained in signs languages, of which 76 hearing impaired persons and 25 social mothers of the SOS Children Village in Pemba Town.

In the scope of attendance to drug addicts awareness-raising talks against the consumption and illicit sale of drugs.

Similarly, 34 community activists, 29 teachers and 10 social educators were trained in the field of psychosocial support to children, following the Malhazine Ammunition Depot explosions.

\section{Programmes and Social Assistance Projects}

In this scope, priority continued to be given to social and direct economic assistance to persons unable to work and to the promotion of the socio-economic development of persons or groups of people trained for work.

Thus, through these programmes assistance was given to 143,305 people against 120,437 planned. Compared to 2006, the Food Subsidy Programme increased by $20 \%$, the Social Benefits through Work Programme by $44 \%$, the Income Generation Programme by $43 \%$ and the Direct Social Support Programme by $11 \%$.

In relation to the Community Development Programme, 280 projects were implemented benefiting 561,335 people.

Table 51: Social Assistance Programme - Distribution by Province

\begin{tabular}{|c|c|c|c|c|c|c|c|c|}
\hline \multicolumn{9}{|c|}{ Social Assis tance Programmes } \\
\hline \multicolumn{9}{|c|}{ Distribution of beneficiaries by province } \\
\hline \multirow[t]{2}{*}{ Province } & \multicolumn{2}{|c|}{$\begin{array}{c}\text { Food } \\
\text { Subsidy Pro- } \\
\text { gramme }\end{array}$} & \multicolumn{2}{|c|}{$\begin{array}{l}\text { Social Benefits } \\
\text { through Work } \\
\text { Programme }\end{array}$} & \multicolumn{2}{|c|}{$\begin{array}{c}\text { Income } \\
\text { Generation } \\
\text { Programme }\end{array}$} & \multicolumn{2}{|c|}{$\begin{array}{l}\text { Direct Social } \\
\text { Support } \\
\text { Programme }\end{array}$} \\
\hline & Plan & Real & Plan & Real & Plan & Real & Plan & Real \\
\hline Niassa & 5,800 & 6,669 & 757 & 1,762 & 330 & 989 & 1,757 & 2,366 \\
\hline C.Delgado & 6,500 & 7,842 & 220 & 203 & 358 & 149 & 710 & 1,958 \\
\hline Nampula & 20,900 & 23,298 & 523 & 627 & 955 & 761 & 1,708 & 2,678 \\
\hline Zambézia & 10,300 & 11,907 & 490 & 580 & 958 & 761 & 1,655 & 3,665 \\
\hline Tete & 4,800 & 6,640 & 220 & 258 & 458 & 346 & 1,000 & 619 \\
\hline Manica & 10,200 & 11,192 & 343 & 470 & 278 & 188 & 793 & 697 \\
\hline Sofala & 7,770 & 8,459 & 389 & 425 & 1,025 & 1,010 & 1,200 & 2,186 \\
\hline Inhambane & 7,900 & 10,979 & 239 & 291 & 458 & 138 & 793 & 715 \\
\hline Gaza & 13,900 & 16,933 & 644 & 863 & 1,178 & 439 & 1,093 & 1,550 \\
\hline Maputo P. & 4,730 & 5,091 & 120 & 193 & 158 & 182 & 672 & 1,008 \\
\hline Maputo C. & 4,200 & 3,967 & 435 & 387 & 568 & 321 & 952 & 1,543 \\
\hline Total & 97,000 & 112,977 & 4,380 & 6,059 & 6,724 & 5,284 & 12,333 & 18,985 \\
\hline
\end{tabular}

\section{E. YOUTH AND SPORTS}

In the area of youth and sports, priority continued to be given to the integration of youth in the country's development process, strengthening youth and sports 
associative movements, the consolidation of the practice of physical exercise and sports and the development of top-class sport.

\section{Youth area}

With the objective to strengthen the National Youth Council (CNJ) to ensure the effective performance of its role as intermediary between the youth and the State, the following activities were carried out:

- Technical, methodological and financial assistance was given to the CNJ;

- The Youth Associative Movement Regulation was approved;

- Technical assistance was provided for the legalization of 96 youth associations against 110 planned;

- The Intersector Adolescent and Youth Support Committee - CIADAJ was approved in general;

- The Manga Youth Centre was partially rehabilitated.

With the objective to guarantee the participation of the youth in the creation of employment and self-employment opportunities, the following main activities were performed:

- A total of 103 income-generating youth micro-projects were financed, against 110 projects planned, and 266 youths were trained in the field of small business management;

- A total of 416 youths were trained in the field of leadership, associative management, income-generating project preparation and entrepreneurship;

- A total of 108 national trainers were trained in the field of leadership, project management and life skills, against 165 trainers planned.

In the scope of the development of programmes about life skills aimed at the youth, the following activities were carried out:

- The Geração Biz Programme was launched in Nampula and Manica Provinces and extended to 19 new districts in Zambezia (4 districts), Inhambane (3 districts), Sofala (3 districts), Nampula (3 districts), Tete (2 districts), Cabo Delgado (2 districts), Maputo City (1 district) and Maputo Province (1 district);

- A total of 126 community leaders and 97 parents and educational tutors were trained in the field of HIVIAIDS prevention and combat;

- 8 nuclei were created and 108 activists were trained to work in the field of drug consumption and trafficking prevention;

- The I National Youth Meeting about HIVIAIDS was held, which approved the Youth Commitment to the Fight against AIDS. A total of 580 youths from the whole country, including representatives from Angola and Cabo Verde, participated in the meeting.

With a view to promote among the youth the interest for sports, tourism and art and culture as a way to occupy their spare time, the following activities were carried out: 
- The Provincial and Regional Camp was organised in Boane District, with the participation of 352 youths;

- The infrastructures situated on Tofo Beach in Inhambane were partially rehabilitated and will serve as youth lodging house;

- Regional Music Crossroads Festivals were held in the Northern, Central and Southern Regions, and Mobile Festivals in Gaza and Cabo Delgado, having participated 60 music groups and 374 youth artists.

Aimed at guaranteeing access opportunities to new information and communication technologies for the youth, the following activities were carried out:

- A Youth Centre was created in Chiúre (Cabo Delgado);

- A total of 30 youths were trained in Gaza in basic computer applications.

\section{Sports area}

In the scope of the consolidation of sports and of the "Mozambique in Movement" programme, the following activities were carried out:

- A total of 105 community sports promoter trainers were trained;

- School holiday sports tournaments were held involving 64,198 participant children;

- Long-distance runs were organised involving 6,675 participants;

- Various sports tournaments were held involving 18,510 athletes and more than 134 teams in the scope of the National Sports Week commemorations;

- Women sports tournaments were held involving 3,263 participants in football, 631 in handball, and 189 in athletics.

In the scope of sports agents training, the following activities were carried out:

- A total of 119 sports agents (managers, trainers) were trained for working with handicapped persons, against 18 agents planned;

- Training was offered to basic and $1^{\text {st }}$ level sports agents in the modalities of athletics, handball, basketball, football, volleyball and gymnastics with the participation of 779 sports agents against 705 agents planned.

In the scope of top-class sports:

- Sports tournaments were held involving 25,360 athletes and 33 nuclei were created in the scope of the Fut-21 Project;

- Conditions were created for the construction of the National Stadium;

- Construction works of the Pemba Municipal Stadium were started;

- The foundation was built in the Costa do Sol and Machava Stadium football pitches in Maputo for placing a synthetic grass cover;

- Support was given for the participation of Mozambican Teams in the afro-cups in the modalities of football (Desportivo de Maputo and Têxtil de Púnguè) and women's basketball (Desportivo de Maputo and ISPU), men's basketball (Ferroviário da Beira and Ferroviário de Maputo); 
- The Safe Sports Regulation and the Anti-Doping Control Regulation were approved;

- Support was given to the participation of Mozambique in the XI edition of the Pan-African Games. The country was represented by a delegation of 69 people, among which athletes, federation and top officials and guests. One gold medal was won by athlete Leonor Piúza in the women's $800 \mathrm{~m}$.

\section{IV.3. GOVERNING}

Good governance is one of the fundamental conditions for the success of the fight against poverty strategy. PARPA includes policies for the promotion of good governance, such as decentralization and deconcentration, public administration reform to give a better response to citizens' needs, strengthening the capacity and efficiency of the legal and judicial system, improvement of public security and the development of a programme focussed on the reduction of corruption at all levels.

\section{A. PUBLIC SECTOR REFORM, DECENTRALIZATION AND DECONCENTRATION}

Public sector reform comprises the components of decentralization and deconcentration; rationalisation of structures and service provision processes, improvement of public policies formulation and monitoring processes, professionalization of public sector employees, improvement of financial management and accountability and fight against corruption.

The activities of this sub-component are subdivided into three main areas, namely: decentralization and deconcentration; rationalisation of structures and service provision process. In general and taking into account these areas, the following activities were performed in 2007:

In the area of decentralization and deconcentration, PARPA establishes as main objective conferring greater dynamism and capacity to local state bodies at district and provincial level. To this effect, the following activities, among others, were performed during 2007:

- A total of 512 Directors of District Services were appointed in the 128 Districts, in the scope of District Government restructuring and decentralization and the organisational structures and respective staff lists of each one of the District Services were prepared;

- Regarding the definition of the State and Municipal Bodies' competences:

- The proposal for the decentralization of roads, water, agriculture, education and health sector funds to Local Governments was prepared and approved;

- The proposals from the Ministries about the competences to be decentralized to the local State bodies were systematized.

- In relation to Local State Administration training:

- All District Administrators and State representatives in the Autarchies were trained, 
- The directors of District Services in the Southern Region (83) and heads of department of the Provincial General Offices (28) were trained;

- Technical assistance was provided to Local State Bodies;

- A total of 162 medium and higher-level technicians of the Environmental Planning and Local Planning and Development areas were contracted and will be placed in 54 selected districts.

- A total of $4,9982^{\text {nd }}$ level community authorities were recognised and allowance payments ensured for already recognised $1^{\text {st }}$ and $2^{\text {nd }}$ level community authorities (5,087 and 4,998 respectively) and legitimated $(7,509)$;

- Purchases were done of 1,500 pairs of uniforms for the community authorities, 1,500 long-sleeved shirts, 200 long-sleeved blouses, 1,500 berets, 1,500 pairs of socks, 4,542 badges, 4,463 emblems, 6,791 ribbons, 6,661 flags, 1,453 pairs of shoes and 2.475 waist-belts;

- A proposal was prepared for the organisational structure of Provincial Governments;

- A proposal was prepared for District Administrator performance evaluation criteria and parameters.

- With the aim of consolidating the functioning of the Local Consultative Councils, in the scope of the deconcentration process, covering Local State Bodies at provincial, district, administrative post, locality and village level, the Local Council (CL) Organisation and Functioning Regulation was revised;

- A proposal for a modular training curriculum for members of Local Councils and Community Authorities was prepared;

- A national District Administrator meeting was held as well as a National Town Council meeting;

- A study was done and the conditions of some district capitals and administrative posts evaluated for extending the introduction of autarchies to new territorial units;

- The Law of the Provincial Assemblies (Law 5/2007) and the respective Electoral Law were approved; the identification and/or rehabilitation of premises for the functioning of the Provincial Assemblies (APs) was started and the guide for their establishment was prepared;

- Information was collected for the restructuring of administrative posts and localities and the structuring of State representation in the Autarchies;

- A diagnosis was prepared of the delimitation of 14 towns not integrated in a District territory, including the provincial capitals and Nacala-Porto, Ilha de Moçambique and Maxixe;

- A revision was carried out of the Finance and Autarchic Heritage Law, while the study for the revision of the Autarchic Tax Code is ongoing;

- The Municipal Staff Lists of Angoche and Matola were ratified and the organic statutes of the Municipal Councils of Nampula, Nacala, Milange, Maxixe and Matola were revised; 
- The legislation about Municipal Environmental Planning was revised;

- The study for the revision of the Autarchic Compensation Funds (FCA) allocation and Local Initiative Investment criteria was started.

\section{Other Activities carried out:}

- The preparation of the proposal for the adjustment of the PoliticalAdministrative Division of the country was concluded;

- The Regulation about the Municipal Police Uniform in the light of Decree $35 / 2006$ of 6 September was prepared and other legislation in the scope of the revision of the Autarchic Package approved and complementary legislation prepared.

- Assistance was given to the working visits of His Excellency the President of the Republic to the provinces in the scope of Open Governance;

- Inspection missions were carried out to MAE's organisational units, to Inhambane and Gaza Provinces; to the Support and Reconstruction Office (GAR), to the INGC and to Chemba District,

In the scope of Decentralized Planning and Finance:

- A total of 175 technicians were trained in the scope of the PES and OE preparation in Nampula Province;

- Technical assistance was provided for the preparation of 20 PESODs for the year 2008;

- Training in Financial Management (SF) and in the Revenue Registration and Control System (SISRECORE) was given in the following districts: Mogovolas, Moma, Angoche, Mogincual, Monapo, Nampula-Rapale and Mecuburi;

- A total of 20 public works technicians, who are part of the ETDs, were trained in the preparation of administrative competition processes, including the design of an executive project;

- The preparation of 1116 PEDDs was concluded and the respective confirmation on the part of the local authorities is awaited;

- A total of 11 territorial plan plans were prepared namely: in Nhamatanda, Sofala; 3 in Tete Province: Manje and Mavuzi ponte, Chiuta, Mocumbura and Magoe Districts; 7 in Zambezia Province, in Namacurra, Mocuba, lle, Mopeia, Gilé, Gurué and Morrumbala Districts;

- Training on PEDD preparation methodologies was given to members of the EPAPs and ETDs in Tete, Zambezia, Manica and Sofala Provinces;

- The preparation of training manuals for the preparation of District Development Plans was concluded, consisting of a set of two manuals per training module.

\section{Public Service}

In the scope of public servant training, 719 civil servants were graduated in the Lichinga, Beira and Maputo IFAPAs, of which 409 women and 310 men; 95 modular 
course trainers for the Southern Region were trained; 33 medium-level courses started with a total of 985 trainees; Modules were prepared and revised in the common and specialized areas of Human Resources $(\mathrm{RH})$, Budget and Property Management (GOP) and Autarchic Management (GA); 412 students (215 men and 197 women) were graduated by the IFAPAs in the regular classes regime;

In the scope of the decentralization and deconcentration process and of the implementation of Decree 5/2006 of 12 April, human resource managers at central and local level were trained and the Staff Lists and Organic Statutes of several institutions were prepared and approved;

In the scope of top-level authorities training, four training actions were conducted for Ministers, Deputy Ministers and Permanent Secretaries of the Ministries, Provincial Governors and Permanent Secretaries and Heads of Administrative Posts, and managers and executive staff were also trained (Ministry of Youth and Sports managers and Ministerial Assistants);

State Administration Sector inspectors were trained and technical assistance provided to all Municipal Councils, in the field of public attendance and administrative procedures;

- In the area of Public Service Human Resource Management, the following activities should be highlighted:

- A group of 46 civil servants, integrating the first group of public service managers, were graduated;

- The Human Resource Manager Forum was institutionalised at central, provincial and district level (districts of Niassa, Nampula, Zambezia, Tete, Sofala, and Maputo Provinces), thus allowing the permanent training of about 1,410 human resource managers;

- The Interministerial Public Administration Training Group (GIFAP) was reactivated, integrating 12 institutions;

- The Training Department Heads of all Provincial General Offices were trained and integrated;

- The Statistics Manuals of the basic-level General Area and of the basic-level Common and Specialization Areas of training courses for District civil servants in a Distance Learning Regime were concluded and 5 vehicles for distance learning were acquired;

- The District Administrators and Permanent Secretaries of all Districts of Cabo Delgado and Manica Provinces were trained in the field of Leadership and Relationships Management;

- In the scope of infrastructure construction and rehabilitation:

- The Works Contract for the first lot of the Beira IFAPA infrastructure rehabilitation and extension works was awarded to the ECOB Company;

- The construction of the Lichinga IFAPA's female dormitory was concluded, resulting in a capacity for 50 women, also benefiting about 85 students from Cabo Delgado and Nampula Provinces and from a few Districts of Niassa Province; 
- The $1^{\text {st }}$ training seminar for General Inspectors of the Ministries was held with the participation of the Administrative Tribunal;

- The Draft IGAE Organic Statute was concluded, as well as the Inspection Manual and Guide;

- The census of all State Employees and Agents was taken;

- The Electronic Staff Information Sub-system (e-SIP) was created;

- The Salaries Policy Parameters were prepared;

- The Results-based Conceptual Performance Management System Model in the Public Service was prepared;

- The EGFE Bill was filed with the Assembly of the Republic (AR), for approval;

- The Action Plan of the State Documents and Archives Management Strategy was prepared and harmonized;

- The National State Archives System (SNAE) and its respective operationalisation instruments were prepared and disseminated (in the central and local State bodies);

- A total of 46 State Documents and Archives Management trainers were trained as well as 591 State Documents and Archives Managers;

- A total of 2,201 State employees and agents were trained, among which toplevel leaders, managers and technicians.

\section{Other activities carried out:}

- The construction was started of the Public Administration Excellency Centre of the Community of Portuguese Speaking Countries (CPLP), on the Maputo IFAPA premises;

- A total of 16 civil servants were trained at international level, through their participation in the following training fields: Human Resource Management Course (4); Law Creation Course (6); e-Learning Course (1); Human Resource Management Policies Conception and Implementation (2); Information and Computer Management (2); Effective Project Cycle Management Course (1);

- The ISAP website was created;

- Modules were produced for the Professional Bachelor courses in Public Administration (BPAP) and for the Professional Licentiate courses in Public Administration (LPAP);

- The Public Service Charter is being prepared;

- The Code of Conduct for Holders of Government Positions and Top State Authorities was approved by Government;

- The Decree and the role of the Interministerial Public Sector Reform Commission was revised, resulted in the approval of Presidential Decree 2/2007 of 8 March.

- Dissemination activities were carried out of Decree 14/2007 of 10 April. 
- The following draft legislation was prepared:

- The revision of Decree 4/81 of 10 June was started;

- The Code of Administrative Procedures (Terms of Reference prepared);

- General Principles for the Creation, Composition and Functioning of the Interministerial Commissions of the Council of Ministers;

- The Memorandum of Understanding for the financing of the $2^{\text {nd }}$ RSP phase was signed between the Government and the Partners of the Public Sector Reform Common Fund.

Monitoring visits were paid to all provinces.

\section{B. JUSTICE}

In the scope of Justice, the following activities, among others, were carried out in 2007:

- A total of 103,287 processes were tried in the Judicial Courts in 2007. The proportion of the detained population awaiting trial is of the order of $39 \%$ against $42 \%$ in 2006 ;

- In relation to the Registry, $1,626,411$ citizens were registered against $1,530,109$ in the previous year;

- Dissemination of the Law of the Family continued in all provinces, with special emphasis on the spouses' rights and obligations;

- A total of 1,646 Community Courts were revitalized, thus contributing to the resolution of conflicts in the communities;

- The Provincial Branches of the Institute of Judicial Sponsorship and Assistance (IPAJ) were institutionalised. In this scope, 38 IPAJ district branches were established.

- Legal clinics were created in the Maputo City and Province prisons, to render assistance to prisoners; a total of 165 prisoners have received assistance;

- A dissemination programme of the material about fundamental citizens' rights was prepared and partnerships with other organisations established for the production of information programmes about women's rights;

- Regarding prison system reform, productive activities in all prison establishments were reactivated as part of the prisoners' re-education: agricultural activities in Mabalane, Hanhane, Bela-Vista, Tete and Manica; workshop activities in Machava and Mabalane; livestock breeding in Mabalane, Ndlavela and Mieze and pisciculture in Mabalane, Tete, Manica, Zambezia and Niassa. For the same purpose bakeries were created in the prisons of Beira, Dondo, Nhamatanda, Quelimane, Nampula and Niassa;

- A technical-professional graphic art training programme was implemented in the Maputo Central Prison, a carpentry in Maputo and Nampula and a blacksmith's workshop in Maputo.

In the scope of training and human resources: 
- A total of 23 administrators for the Provincial Courts and Attorney's Offices were trained;

- A total of 75 Judicial Magistrates of the Public Ministry and Fiscal Courts were trained;

- A total of 350 prison agents were trained;

- A total of 53 employees were trained, among whom Judicial and Public Ministry Magistrates, District Administrators, Chiefs of Police at district level and Directors of District Services of Economic Activities, in legislation about Natural Resources and Development;

- A course was held for 26 Justice Officials and Assistant Officials for the commercial sections of Nampula and Sofala Provinces;

- Community leaders were trained in Human Rights, involving 44 leaders in Nampula, 19 in Sofala and 25 in Inhambane.

In the scope of Legal Reform:

- Concerning the Law of the Family the Terms of Reference for the regulation of the de facto union were prepared;

- A draft Statute of the Corps of Prison Guards was prepared;

- The Regulation of the National Prison Service Inspection was prepared;

- Legislation was prepared about conflicts of interests and the preparation of specific legislation about conflicts of interests is ongoing;

- The Bills of the Revision of Law 5/92, the Organic Law of the Administrative Tribunal, of Laws 13/97 and 14/97 of 10 July, and of the Law of the Higher Council of the Administrative Magistrature were prepared;

- The drafting of the Bill on Exclusive Measures of Liberty was started;

- The reformulation of the Bill of the Defence of the Consumer was concluded;

- The Council of Ministers approved the Bills about Trafficking in Persons, particularly Women and Children, the Rights of the Child and the Law about the Tutelary Organisation of Minors;

In the scope of the construction and rehabilitation infrastructures and equipment:

- Regarding the construction and equipping of the courthouses in Maputo, Inhambane, Sofala, Zambezia Nampula and Niassa Provinces:

- The executive projects for the construction of the provincial courthouses in Maputo and Inhambane Provinces were concluded and checked by the Administrative Tribunal;

- The conclusion of the executive projects of the courthouses for Niassa Province and Maputo City was started;

- Construction was started of the district courthouses and residences for the judicial and Public Ministry Magistrates in Moma, Cheringoma, Morrumbene and Massinga Districts; 
- Construction works were started of the Xai-Xai Prison, in a combined contracting regime, with direct involvement of the prisoners;

\section{In the scope of the control of legality:}

- the rehabilitation project of the PGR building and of the official residence of the General Attorney of the Republic was prepared;

- The construction and rehabilitation of the following prison units was started:

- Moma Prison was rehabilitated;

- The rehabilitation of the police-controlled prison establishment in Cheringoma is in progress;

- The rehabilitation of the Marromeu District Prison is in progress as well as the rehabilitation of the police station and the construction of the courthouse;

- The rehabilitation and adaptation of the Nampula Industrial Prison is in a conclusive phase, including the creation of a youth section;

- The rehabilitation of the Savane Prison was concluded;

- The rehabilitation of Beira Central Prison was started;

- The Attorney's Offices and residences in Nacala, Monapo, Angoche, Meconta and Ilha de Moçambique Districts were equipped;

- A document management system for the PGR was acquired so as to improve the internal control and document access system;

- Several Codes for the library of the High Court were acquired.

In the scope the control of legality:

- Activities were carried out aimed at the Court procedures framework reform with the recruitment and training of Judicial Administrators;

In the scope of modernization and computerization:

- The connection of the services through Gov-net in all provincial capitals was concluded, including the criminal and commercial records services;

- The development of software for process management was started in the scope of the Integrated Justice Monitoring and Evaluation System, and its conclusion is foreseen for the middle of 2008;

- The connection of the High Court to the e-government network was concluded;

- A variety of computer and reproduction equipment for the PGR was acquired;

- The establishment of the intranet network in the Courts and a connection to the e-government network was started;

\section{SECURITY AND PUBLIC ORDER}

In the sphere of public order, civil identification, migration and the fire brigade, one of the priority objectives is raising the level of performance of the police in the 
prevention and fight against criminality. In 2007 the following main activities were carried out:

- The protection of people and property was strengthened and guaranteed; police operationality was about $69 \%$ against $70 \%$ planned, representing a reduction of $2 \%$ compared to 2006.

- Police operationality in crimes "against property" increased by $5 \%$ in relation to the $62 \%$ of the previous period; in crimes "against persons" and "against public order and tranquillity", operationality was $86 \%$ and $98 \%$, corresponding to an increase of $1 \%$ and $3 \%$ respectively;

- A total of 218 of the 582 officers planned were trained in the field of criminal research and special and reserve forces;

- A total of 7 mixed and specialized police stations were created, against 22 planned, corresponding to an accomplishment of $32 \%$;

- The training of 1,162 PRM trainees is in progress; 350 as prison guards and 475 as border guards;

- The continuation of the higher-level police science courses at the ACIPOL was guaranteed (licentiate, baccalaureate and executive), and 203 police officers concluded their training;

- The Organic Bill of the Mozambican Police and its related Regulations were prepared and filed with the Council of Ministers;

- The Bill on the Public Order and Tranquillity Strategy was prepared;

- A total of 534,054 identity cards were issued against 600,000 cards planned, representing an accomplishment in the order of $89 \%$;

\section{Other Accomplishments}

- The construction of the Nicoadala District Command building in Zambezia Province was concluded;

- The construction of the Muembe District Command building in Niassa Province was concluded;

- The construction of the Mossuril District Command building in Nampula Province was concluded;

- The construction works of the Provincial Civil Identification Services of Inhambane were concluded.

\section{THE MEDIA}

The media contributed to socio-economic and cultural development through the promotion and consolidation of national unity and in strengthening the defence of democracy and the Constitutional State.

In this sense, in 2007 the capacity of the press sector bodies and their regulation was strengthened, through the performance of the following activities:

- The TVM tower in Nampula was erected; 
- The expansion of the national broadcasts to Chicualacuala, Vilankulo and Chumuara is in progress;

- The installation of a kilowatt Televisão de Moçambique (TVM) transmitter in Maxixe Town and the increase of its coverage to $80 \mathrm{~km}$ is in progress;

\section{Other Achievements}

- Video documentaries were produced: Moamba on the march (agriculture); Mapai today (socio-economic aspects) and Waking up (rice production in Chókwè);

- 12 issues of the "O CAMPO" magazine were produced;

- The replacement of the medium wave transmitter in Inhambane was concluded;

\section{E. FOREIGN RELATIONS}

In the area of foreign relations and international cooperation the Government continued to strengthen a privileged relationship with all development partners of Mozambique with a view to the operationalisation of its plans and programmes, for the eradication of absolute poverty, a strengthening of the prestige and reputation of Mozambique in the international arena.

Thus, in the scope of the strengthening of the bilateral and multilateral cooperation, the following achievements are worthy of mention:

- His Excellency the President paid visits to several countries, and participated as well in various kinds of events, in which important cooperation agreements were signed and bilateral and multilateral relations strengthened. We highlight the following:

- Visits to Germany, Brazil, Norway, Italy, Japan, Vietnam, Zambia and Tanzania, and

- Participation in the $62^{\text {nd }}$ Session of the General Assembly of the United Nations (New York), in the Africa-Europe Summit (Portugal), in the $24^{\text {th }}$ Summit of Heads of State and Government of Africa and France, in the XVII World Economic Forum (South Africa) and in the Summit of Heads of State and Government of the Commonwealth (Uganda).

- Ministerial visits were paid to Algeria, Denmark, Egypt, Sweden, Russia and Norway) during which relations of friendship and cooperation were strengthened;

- Participation in the Ordinary Meeting of the SADC Council of Ministers, in the $8^{\text {th }}$ Africa Partnership Forum (APF) (Berlin), in the SADC Integrated Committee of Ministers Meeting (Namibia), in the $34^{\text {th }}$ Islamic Conference of Ministers of Foreign Affairs (Pakistan);

- Visits were paid in the scope of PALOP-EC Cooperation, for agreeing about and strengthening the PIR PALOP implementation mechanisms;

- Visits were received of Foreign Affairs Ministers, Deputy Ministers and State Secretaries (Angola, Austria, Cuba, the Czech Republic, Ethiopia, Italy and Portugal), a visit of the Prime Minister of Flanders, and 2 Deputy Ministers of China (Health and Construction); 
- 29 new Ambassadors and/or High Commissioners were accredited in the context of strengthening political-diplomatic and cooperation relations.

With a view to the continuation of diplomatic initiatives aimed at the mobilisation of material and financial resources to support the implementation of poverty eradication programmes and projects and to ensure economic growth in the scope of the implementation of PARPA (II) the following main activities were carried out:

- Official visits of His Excellency the President of the Republic to Germany, Brazil, Norway, Italy, Japan and Vietnam, with a view to strengthening the already existing cooperation with those countries;

- Visit of His Excellency the President of the Republican to Washington DC, to take part in the Compact signing ceremony in the scope of the Millennium Challenge Account - MCA, at the value of 506.9 million dollar for the next five (5) years, for the financing of development programmes in the areas of water and sanitation, roads and the private sector, in Cabo Delgado, Niassa, Nampula and Zambezia Provinces;

- Participation in the $12^{\text {th }}$ Bilateral Economic Summit with South Africa (Pretoria);

- Visit of the President of the People's Republican of China, resulting in a credit for various activities;

- Visit of the President of the Republic of Angola, resulting in the signing of 9 agreements and the establishment of economic-business partnerships;

- Visit of His Highness the Aga Khan, resulting in His Highness' preparedness to continue the development of his Network's activities in Mozambique;

- Visit, in November, of the Minister of Foreign Investment and Cooperation of the Republic of Cuba, aimed at the evaluation of the cooperation and proceeding with the activities agreed upon in terms of the commitments assumed on the occasion of the XVI Session of the Mixed Commission, held in Maputo;

- Realization of two (2) Tripartite Meetings for the Assessment of UNDPfinanced Programmes or Projects, resulting in the approval of the annual report of the decentralized finance project and the definition of activities for the preparation of the national decentralized planning and finance programme;

- Realization of the Mozambique/Malawi, Mozambique/Cuba, Mozambique/ China, Mozambique/Indonesia and Mozambique/Brazil mixed commissions;

- Realization of Bilateral Consultations between Mozambique and Germany, resulting in the signing of the bilateral programme 2007-2008, with an allocation of 92.5 million euros and a contribution to the State Budget at the value of 20 million euros;

- Contacts were established with the Republican of Angola, Algeria, China and India for the cancellation of the Mozambican debt;

- The debt with China, of about 11 million American dollar, was cancelled. 
- The country participated in the "African festa 2007" in Tokyo and the IV Meeting of the Macau Forum countries' businessmen was held, aimed at investment promotion.

With a view to the establishment of a foreign aid management system, reflecting the defined priorities, in a coherent and comprehensive partnership with the various development partners, the following activities stand out:

- The analysis of the cooperation partners' individual strategies in the context of the Paris Declaration about the effectiveness of the aid was concluded, in a process involving the Government and the Programmatic Aid Partners;

- Participation in a seminar of the Eastern and Southern African countries about the implementation of the Paris Declaration and the foreign aid management systems.

To promote and ensure the implementation of national, sub-regional and regional development priority programmes and projects in the scope of NEPAD, SADC and other bodies of which Mozambique is part, the following activities were performed:

- Participation of the President of the Republic in the $27^{\text {th }}$ Ordinary Summit of SADC Heads of State and Government under the theme: "Regional Integration through Infrastructure Development".

- Participation of the Prime Minister in the Reflection Summit in Algiers about the Implementation of the NEPAD Programme, in which the integration of NEPAD into the African Union processes and structures was treated, resulting in recommendations subsequently endorsed by the NEPAD Implementation Committee;

- Participation of His Excellency the Minister of Foreign Affairs and Cooperation in the Ordinary SADC Council of Ministers Meeting in Zambia;

- Participation in the $8^{\text {th }}$ Africa Partnership Forum (APF) in Berlin, during which political, strategic and socio-economic issues were discussed, related to the development of Africa and to the implementation of NEPAD programmes;

- In the scope of the $10^{\text {th }}$ FED (European Development Fund) the sum of $€ 135$ million for the SADC Regional Indicative Programme (PIR) for the period 2008-2013 was approved;

- Participation in the TICAD Conference about the Environment, in the scope of the preparation of TICAD IV, with a view to the promotion of regional cooperation and strengthening cooperation between the public and private sector;

- Evaluation and monitoring visits were paid to Zambezia Province to the Namacurra-Ligonha River road rehabilitation projects, the health unit rehabilitation works financed in the scope of the rural health system rehabilitation project and the health assistance programme and the bridges component of the Rural Development Programme (PRD);

- An evaluation was carried out of the level of execution of the rural telecommunications system installation works in Inhambane and of the Integrated Water Resource and Water Supply Development Project in the 
Zambezi Valley (ZAMWAT), in Tete; it was concluded that the projects are being executed normally and within the schedule laid down;

- Conclusion of the Final Evaluation of the Cooperation Programme between Mozambique and the European Union financed by the $9^{\text {th }}$ European Development Fund (FED) and the concession of an additional sum of $€ 50$ million for State Budget Support for the year 2008;

- Participation in South Africa in the $37^{\text {th }}$ Meeting of the NEPAD Steering Committee, in which aspects related to the functioning of the NEPAD Secretariat were discussed, as well ways for improvement;

- Start of the self-assessment process in the framework of the African Peer Review Mechanism (APRM), with the contracting of three (3) research institutions.

With regard to the participation in trade negotiations, in the scope of the World Trade Organisation (WTO), the Indian Ocean Rim Association, the African Growth Opportunity Act (AGOA), Everything But Arms (EBA), among other trade opportunities put at Mozambique's disposal, the following activities were relevant:

- Participation in the proceedings of the $85^{\text {th }}$ Session of the ACP Council of Ministers and of the $32^{\text {nd }}$ Session of the Joint ACP-EU Council of Ministers, with a view to evaluate the implementation of the decisions of the $84^{\text {th }} \mathrm{CM}$ ACP and to adopt mechanisms for strengthening the ACP-EU partnership, respectively;

- Participation of the country in several negotiation meetings and in the Regional Preparatory Task Force (RPTF). This negotiation process resulted in the signing of the Interim SADC-EPA/EU Economic Partnership Agreement (EPA);

- Participation in the $54^{\text {th }}$ Session of the United Nations Conference on Trade and Development (UNCTAD), in which the PrepCom of the 2008 Accra Conference (UNCTAD-XII) was established; the 2007 UNCTAD reports on the Lest Developed Countries and on Economic Development in Africa were adopted.

Concerning active participation in the efforts to strengthen the United Nations system in the scope of strengthening multilateralism and international law, to promote a political culture of peace, ensure the defence and preservation of stability and national security, the following achievements are worthy of note:

- Visit of the Deputy Secretary-General of the United Nations and Administrator of the United Nations Development Programme (UNDP), during which the Government's commitment to the implementation of the "Delivering as One UN" Initiative in Mozambique was reaffirmed as well as the United Nations' commitment to continue providing aid to Mozambique;

- Participation in the $38^{\text {th }}$ Session of the United Nations Committee on the Elimination of discrimination against Women;

- Participation in the $15^{\text {th }}$ Session of the United Nations Commission on Sustainable Development; at the occasion, Mozambique informed about the vast energy potential of which it disposes, capable to produce clean energy to 
respond to intern demand and reduce the energy deficit Southern Africa is facing;

- Participation in the $4^{\text {th }}$ Session of the Human Rights Council, during which 9 resolutions and 2 decisions were adopted;

- Participation in the Annual Session of the UNICEF Executive Board, during which Mozambique's support to UNICEF initiatives was reaffirmed in the context of the Medium-Term Strategic Plan and the Education Strategy in the framework of this Plan was approved; UNICEF's participation in the End Child Hunger and Undernutrition Initiative was approved;

- Participation in the African Regional Meeting on Armed Violence and Development;

- Participation in the $62^{\text {nd }}$ Session of the United Nations General Assembly (UNGA);

- Participation in the SADC Meeting on International Terrorism in the scope of Resolution 1373;

- Participation in the $2^{\text {nd }}$ Regular Session of the United Nations Children's Fund, during which aid to countries, particularly in the field of education, was reaffirmed.

With a view to the promotion of the admission of Mozambican officials to subregional, regional and international organisations, of which Mozambique is part, officials were re-appointed and installed to occupy the posts of:

- Commissioner in the African Human and Peoples' Rights Commission, and

- Senior Scientific Officer for the Prevention and Mitigation of Disasters, in the World Meteorological Organisation.

With a view to the implementation of activities in the areas of negotiations, decisionmaking, the ratification of international conventions and treaties and bilateral agreements of national interest, guaranteeing their effective implementation and proper follow-up, we should highlight the following:

- Participation of the country in the negotiations in New York of the United Nations Comprehensive Convention on International Terrorism.

With a view to general, technical and professional staff training, taking into account recent scientific and technological innovations and international cooperation opportunities, worthy of mention are the following achievements:

- Submission of several technicians to various training courses, namely (5) in the French language, (14) Executive Secretaries; (4) in Human Resource Management; (2) in International Relations and Diplomacy (Pakistan), (1) in a United Nations staff course (Sweden), (1) in a training course on the inclusion of HIVIAIDS issues into sectors and programmes, (1) in a training course for lawyers on Legislation about Petroleum and International Hydrocarbon Concession and Exploration Contracts and (1) in an advanced course for Portuguese speaking countries;

- Participation of technicians in seminars, namely (1) in a seminar about the management of Chinese projects and credits in developing countries, (1) in a 
national seminar on the debt strategy and new financings in Mozambique, (1) in a regional seminar on International Humanitarian Law, (2) in a seminar on Conference Diplomacy and Multilateral Negotiations.

With regard to the continuation of the negotiation of visa suppression agreements with the remaining countries of the Southern Africa region and with others of interest for Mozambique so as to facilitate the movement of people with those countries, the following was achieved:

- Conclusion, in October, of the Visa Suppression Agreement with Zimbabwe;

- Conclusion of the negotiation of the draft Agreement between the Government of the Republic of Mozambique and the Government of the Russian Federation about the exemption of visa in diplomatic and service passports, and waiting for its signing;

- Signing of the Agreement for the Concession of Visa to Students of CPLP Member States.

With a view to strengthen the partnership and articulation with foreign nongovernmental organisations in the scope of the implementation of the Five-Year Government Programme's programmes and priorities, the following activities were carried out:

- A total of 41 authorisations were renewed; the activities of 2 NGOs were ended and 13 new NGOs were authorized to operate in Mozambique, adding up to a total of 295 NGOs operating in Mozambique;

- A meeting was held between NGOs and the National Statistics Institute in the scope of the III General Population Census, in which the foreign NGOs' support to the population census was requested and to make foreign staff aware of the need to participate in the census.

\section{In the scope of support to refugees}

In the scope of health, the attendance services were improved with the extension of the Health Centre premises. With the objective of improving the Maternal and Child Health $(\mathrm{MCH})$ services the rehabilitation and extension works of the Maratane Health Centre's Maternity were concluded.

In the scope of the repatriation of refugees from the Great Lakes Region, the repatriation of the first numerous groups of refugees was started; on the other hand, 329 refugees were repatriated to the Democratic Republic of the Congo (DRC);

- A total of 993 cases were submitted to the Consultative Commission for Refugees (CCR); 618 of these cases were rejected, 87 remained hanging and 288 were considered eligible;

In the scope of strengthening the relationship with the Office of the United Nations High Commissioner for Refugees (ACNUR) and with the African Union (AU), the following stands out:

- Participation in the $38^{\text {th }}$ Session of ACNUR's Permanent Committee; at the occasion Mozambique submitted the refugee issues to be included in the ACNUR's 2008-2009 budget;

In the scope of ongoing relations with ACNUR, the country received visits of: 
- The High Commissioner of the United Nations for Refugees, who visited the Maratane Refugee Centre;

- The Director of ACNUR's Bureau for Africa, who discussed with the Mozambican authorities aspects inherent in the implementation of Mozambique's 2006-2009 Strategic Plan;

- The Regional ACNUR Representative, who had the opportunity to get to know the living conditions of the refugees received by Mozambique and to evaluate the aid to be given to this population group, and

- Participation in the $8^{\text {th }}$ Session of the Executive Committee of the High Commissioner of the United Nations for Refugees (EXCOM), during which the Government's commitment regarding the issue of refugees was reaffirmed; the opinion of the country on ACNUR's regionalization was presented; Mozambique's support to the implementation of ACNUR's Strategic Plan for 2007-2009 was ensured and contacts were started with a view to the mobilisation of external funds.

In the scope of the Mozambican Communities abroad:

- Working visits were paid to the Mozambican communities in Malawi, Swaziland and Botswana. In the three countries visited the communities were informed about the provincial elections and about ways of participating in the country's development;

- A meeting was held with Mozambican students abroad, which served for the exchange of experiences and interaction between students in the country and those abroad;

- The dissemination of INACE's Organic Statute in some countries, such as Italy, Botswana and Swaziland.

In the scope of the sea and borders:

- Activities are ongoing to conclude the delimitation of the maritime border with the Republic of South Africa, for the reassertion of the continental border between the Republic of Mozambique, the Republic of Zimbabwe, Malawi, Tanzania, Zambia and Swaziland.

\section{F. DEFENCE}

In the sphere of defence the following activities were carried out in 2007:

- In the scope of the establishment of legal bases defining the guiding principles of the functioning of defence, the following activities were carried out:

- A Decree about the integration and destination of the extinct Military Tribunals' human and material resources was prepared and harmonized with the Ministry of Justice; it is meanwhile in a final phase;

- The Bill on Civic Service was analysed by the Government;

- The preparation of the Code of Military Justice and of the Regulation of Military Discipline was started;

- The Policy on Weapons and Equipment of the Defence and Security Forces was approved by the Government; 
- The preparation of the draft Strategic Military Concept, System of Forces and respective Mechanism and the Military Planning Bill is ongoing;

- The Regulation of the Ministry of National Defence Representations in the country's Diplomatic Missions was approved.

- In the scope of military training and retraining:

- The training of 285 cadets at the Samora Machel Military Academy was continued. This number represents the training of the cadets taken on in 2005 and in 2006, as well as the inclusion of 103 cadets, taken on in 2007;

- Military training and retraining at the Nampula Military School was continued, involving 277 soldiers;

- A total of 140 soldiers were trained at the Logistic Training Centre;

- A total of 233 soldiers learned how to read and write, of which 23 in grade 6 , 78 in grade 7, 38 in grade 5; 58 in the $3^{\text {rd }}$ year and 36 in the $2^{\text {nd }}$ year;

- The basic military training of 1,957 youths of both sexes was concluded;

- The training of 87 soldiers in the sappers speciality was concluded;

- A total of 12 soldiers were trained in the humanitarian demining speciality.

- A total of 87 students were trained abroad in several speciality areas, namely Portugal 44, China 15, South Africa 3, Spain 2, USA 5, Ghana 1, Cuba 3, Greece 7 and Russia 7;

- Military observers were trained in the USA (3), Ukraine (1) and Mali (1);

- The training of 40 parachute troops in Nacala is ongoing.

In the scope of Military Service

- A total of 266,693 youths of both sexes were registered, of which 173,379 men and 93,314 women;

- Classification and selection tests were administered to 30,000 recruits;

- A total of 1,975 recruits were incorporated in two shifts;

- A total of 2,302 military were demobilised, of which 2,251 men and 51 women.

In the scope of the strengthening of FADM's organizational and operational military capacity:

- Structured cabling was installed for the revitalization of FADM's Cartography, while the installation of a few accessories is still lacking;

- The conversion of the Sergeants Training Centre (Boane) into the FADM Boane Sergeants Training School was started;

- Studies were done and projects prepared for the operationalisation of the branches' specialities' practical schools;

- The Coastal Observation Post on Xefina Island was established;

- MDN's Staff Management Computerization Project was concluded;

- The Organic Structure of the Paratroops Battalion with an effective of 510 men was approved; 
- The Organic Structure of the Coastal Artillery Battalion was prepared and approved.

In the scope of the infrastructure rehabilitation and equipment acquisition, repair and/or maintenance programme:

- In the scope of nominalized works:

- The physical rehabilitation of the central command and service building was concluded;

- The rehabilitation of the Manica Provincial Recruitment and Mobilization Centre was concluded;

- The Sofala Provincial Recruitment and Mobilization Centre works are in progress;

- The barracks of the $1^{\text {st }}, 2^{\text {nd }}, 3^{\text {rd }}$ and $4^{\text {th }}$ Companies, shower rooms, toilets, general and emergency kitchen, food stores and dining hall in the Boane Battalion were rehabilitated;

- Barracks 1 and 2 were rehabilitated and rehabilitation works of the fusiliers and marines barracks at the Metangula Naval Base are in progress;

- The preparation of a works contract for the rehabilitation of 4 barracks, 2 shower rooms, health post, dining hall and water supply system at the Cuamba Brigade is in progress;

- The preparation of a works contract for the rehabilitation of the Maputo Military Hospital is in progress;

- The rehabilitation works of the Machava Naval Fusiliers Battalion is in progress;

- The rehabilitation of the command building, administrative building, general kitchen, barracks, dining hall and the drilling of a water borehole of the Technical Radio Battalion was concluded;

- The rehabilitation works of the Montepuez Basic Military Training Centre were concluded;

- The construction of a dining hall in the Manhiça Basic Military Training Centre is in progress.

In the scope of self-executed works:

- The pig pens of the Chókwè agricultural and livestock rearing project were rehabilitated;

- The rehabilitation works of the command building and recruits barracks of the Nampula Military School are in progress;

- The $1^{\text {st }}$ phase of the rehabilitation of the Boane Sergeants School was concluded;

- The $1^{\text {st }}$ phase of the rehabilitation of 5 ablution blocks at the Manhiça Basic Military Training Centre was concluded;

- The rehabilitation works of the soldier barracks, shower rooms and the water supply system of the Machava-Maputo Communications Training Centre is in progress; 
○ The $1^{\text {st }}$ phase of the rehabilitation works of the Army command building was concluded;

o Three pavilions of the Matola Livestock Breeding Project were rehabilitated;

- General painting was done of the three-storied building of the Marine Schools.

In the scope of the creation of conditions for greater involvement of the national defence sector in the country's economic, social and human development efforts:

- Participation in the rescue and resettlement of floods victims in the Zambezi River Valley and in the mitigation of the effects of cyclone Favio. A total of 5,803 people were rescued and 13 tons of various goods belonging to the population and more than 20 tons of INGC food supplies were transported to the affected people;

- Also worthy of mention are the participation in the transport and erection of tents in the reception centres, the construction of latrines as well as in cutting and transporting firewood, among other activities to give support to the populations victims of the disasters.

- Participation in demining activities:

- A total area of $1,025,361 \mathrm{~m}^{2}$ was demined by military of the Mozambican Armed Defence Forces;

- A total of 6,289 mines of various types were destroyed all over the country.

- In the scope of productive logistics:

- Continuity is given to agricultural production and livestock rearing in Chókwè, livestock breeding in Chitima/Tete, agricultural production in Angónia, Niassa/Unango and poultry farming in Hanhane/Matola;

- In the scope of the ongoing development of bilateral and multilateral cooperation, in the context of SADC, NEPAD, AU, CPLP and the UN and of the promotion of national, regional and international stability, the following activities were carried out:

- Participation in peace-keeping missions, both under the aegis of the United Nations and of the African Union and SADC;

- The FADM participated in the FELINO/2007 exercise, in the Republic of São Tomé and Principe;

- A platoon comprising 32 men was created and participated in the launching ceremonies of the SADC Brigade, in Zambia;

- Mapping was done in the country and a report prepared on the participation in the activities of the Interministerial Committee for the Prevention, Combat and Eradication of Illicit Trafficking in Small Arms Light Weapons (COPRECAL).

Concerning the continuation of activities regarding defence diplomacy and bilateral and multilateral cooperation:

- At bilateral and multilateral cooperation level:

- Strengthening and consolidation of the already established relations with the main cooperation partners as well as the identification of new cooperation 
partners, having in view their contribution to the mitigation of current problems of the military regarding logistics, equipment and training;

- Participation in a Workshop on the implementation of the Indicative Strategic Plan for the Organ (SIPO), held in Dar-es-Salaam, United Republic of Tanzania, from 23 to 27 February 2007;

- Participation in the $28^{\text {th }}$ Session of the CIEDS, held in Dar-es-Salaam, Tanzania, from 9 to 12 July 2007;

- Participation in the IX Meeting of the Ministerial Committee of the SADC Organ for Politics, Defence and Security Issues, held in July 2007 in Dar-esSalaam, Tanzania;

- Participation in the $9^{\text {th }}$ Meeting of Heads of the General Staffs of the Armed Forces of CPLP countries, held in Luanda, from 10 to 12 April 2007.

\section{OTHER ACTIVITIES CARRIED OUT}

- The creation of the Monte Binga S.A company was approved by the Government.

- A census of MDN employees was taken in an operation involving 2,991 employees of a total effective of 3,096;

- A joint exercise, called "XENON-MERCURY/2007", was carried out in Moamba District, involving the FADM and members of the British Armed Forces;

- Activities were carried out in the scope of the Emergency Programme determined by the Government, after the tragic explosions occurred in the Mahlazine Ammunition Depot.

\section{G. NATIONAL LIBERATION, THE DEFENCE OF SOVEREIGNTY AND DEMOCRACY AND DISABLED VETERANS}

In this area, in the course of 2007 priority continued to be given to assistance for and the social integration of the National Liberation Struggle combatants, and to the study and dissemination of the history of national liberation.

Thus, for the accomplishment of the defined objectives the following activities were carried out:

- A total of 15,000 national liberation struggle combatant cards were issued, corresponding to a $100 \%$ achievement of the plan;

- A total of 10,530 new requests for fixing pensions were processed and 8,277 new National Liberation Struggle combatant pensions were fixed;

- A total of 42 higher education scholarships were awarded to children of veterans;

- The National Scholarship Fund for Combatants was created and 85 of their children were benefited;

- A total of 84 projects were financed in the areas of trade, agriculture, livestock breeding, fishing, carpentry and small industry, exceeding the target by 14 new projects; 
- The construction of the Veterans Training Centre-school in Manica is in progress.

In the scope of the history and heritage of the National Liberation Struggle, the following activities were carried out during the year 2007:

- Bibliographic material was acquired for the National Liberation Struggle History Research and Documentation Centre;

- Research on the history of the National Liberation Struggle was done, and:

- The preparation of the History Book called "History of the Mozambican Liberation Struggle 1960-1975" was continued;

- A total of 3,375 testimonies and biographical data of combatants were collected.

- Dissemination activities of the History of the National Liberation Struggle were carried out (talks, television and radio debates);

- Signalling and demarcation of sites of historical importance was done, in the scope of the of the National Liberation Struggle bases Mapping Programme, and:

- Identification of 167 sites of historical importance was concluded in Tete Province;

- Work was done on the preservation of the monuments of the following bases: Mandue, Matiguimu, Chivunguevungue, Nhamindimu and Inhamita in Sofala and Chicondomoio and Kassuende in Tete;

- Identification of 67 sites of historical importance in Nangade, Palma, Mueda, Mocimboa da Praia, Muidumbe, Meluco, Ancuabe, Ibo and Montepuez Districts in Cabo Delgado Province;

Work was started on the preservation of the Ngungunhana Base in Niassa.

\section{IV.4. CROSS-CUTTING ISSUES}

\section{A. GENDER}

In this area the Government continued efforts aimed at the promotion of gender equality and equity at all levels and the strengthening of women's power, increasing their participation in the decision-making bodies with recourse to positive discrimination whenever it was deemed necessary. For the accomplishment of these objectives the following activities were carried out.

\section{In the scope of gender policies}

- Gender Units were created in 5 Ministries, namely Women and Social Welfare, Youth and Sports, Science and Technology, Fisheries and Foreign Affairs and Cooperation;

- The Gender Policy and its Implementation Strategy were disseminated to members of the National Council for the Advancement of Women, of CNAM's Technical Council and of the Gender Coordination Group, benefiting 100 people, of whom 75 women and 25 men; 
- The Gender Policy and its Implementation Strategy were disseminated to members of the Provincial Councils for the Advancement of Women, civil society and religious denominations in Niassa, Sofala, Zambezia, Inhambane and Gaza Provinces, benefiting 50 people in each province;

- The functioning of the Provincial Councils for the Advancement of Women in Niassa, Tete, Inhambane, Gaza and Maputo Provinces was consolidated;

- District Councils for the Advancement of Women were created in Angoche, Erati and Murrupula Districts in Nampula Province and in Changara and Chiuta Districts in Tete Province, and

- A seminar was held in Maputo for the presentation of the draft National Action Plan for the Advancement of Women (PNAM 2007-2009).

\section{Society's awareness-raising about women's rights}

- Participation of Mozambique in the New York meeting, in the session in which the Report on the Implementation of the Convention for the Elimination of All Forms of Discrimination Against Women was defended;

- The Network of Women Ministers and Parliamentarians was launched

- Participation of Mozambique in the Commonwealth Meeting of Ministers of Women and Gender in the Republic of Uganda, in which the country presented its experiences and progress achieved in the promotion of women development;

- The national, regional and international instruments regarding gender and women's human rights were disseminated in Niassa, Zambezia, Sofala, Inhambane and Gaza Provinces, benefiting 175 people (35 in each Province), of whom 120 women and 55 men.

\section{Training}

- A total of 25 members of the Provincial Council for the Advancement of Women, of whom 11 women and 14 men, were trained in Cabo Delgado Province in the field of Gender, Development and HIVIAIDS;

- A total of 175 people ( 35 in each Province), of whom 120 women and 55 men, were trained in the field of gender planning and budgeting in Niassa, Zambezia, Inhambane and Gaza Provinces;

- A total of 29 women associations, of which 3 in Niassa Province, 16 in Cabo Delgado and 10 in Maputo Province, were trained in the field of Project Management, Women's Rights, Law of the Family, Gender and HIVIAIDS;

- A total of 30 women were trained in the field of Project Management and Marketing, in Lichinga Town in Niassa Province;

- A total of 32 Legal Office District Counsellors were trained in the field of the applicability of the Law of the Family in matrimonial conflict resolution and in associative organisations;

- A total of 390 Women in Inhambane Province were trained in the field of needlework, embroidery, typing, informatics, painting and weaving. 


\section{Promotion of gender equality and the empowerment of women}

- A total of 73 women heads of households were integrated into the cassava growing project in Maputo Province;

- Sewing material and mills were distributed to 5 women associations, benefiting about 66 members, of which 45 in Niassa Province and 21 in Cabo Delgado.

\section{Multisector response}

In the area of Education the number of students enrolled in adult education and literacy classes increased by $2.6 \%$, reaching a number of 599,114 students $\left(1^{\text {st }}\right.$ and $2^{\text {nd }}$ year), of which $345.941(58 \%)$ are women.

- In Primary Education (EP1+EP2) a net girls' schooling rate of $90.9 \%$ was attained, against an overall rate of $94.1 \%$.

- In 2007 the schooling rate of 6-year old girls in grade 1 was $70.0 \%$, exceeding the target by $3.0 \%$.

- School Councils and final year students in grade 7 and 10 in the boarding schools were made aware of the need for girls to apply for teacher training courses.

- In the 51 Districts presenting a percentage of girls enrolled in basic education below $45 \%$, Schools Councils, community leaders and influential people in the communities were made aware of the need for girls to have greater access to school and complete schooling.

- Teacher Training Institutes were instructed to accomplish rigorously the quota of $60 \%$ for places for women.

- A total of 1,985 members of the School Councils and 102 members of the Gender Units were trained in the field of gender; and

- A variety of materials were prepared for the training of Gender Unit members.

In the area of Security and Public Order 10 attendance sections for victims of domestic violence were opened in the whole country and 120 police officers were trained in Tete, Manica, Sofala and Zambezia in the field of the attendance of victims of domestic violence.

- In the Health area, the Sector Strategy for Gender Equality Inclusion was prepared, paying attention to the areas of service management and health care provision, stressing the need for integration men as clients of the sexual and reproductive health services and for full assistance to victims of violence, and

- Draft gender violence victim attendance and operational research protocols were prepared with a view to the involvement of men as clients of the sexual and reproductive health services.

In Public Service a competition was launched for showing interest in the preparation of a Public Sector Gender Strategy, and the analysis of candidates was started. 
In Justice a study was done on the gender balance in justice institutions and another study was started aimed at the promotion of women in having access to justice institutions.

In the area of Youth and Sports, women sports tournaments were held in several modalities, involving 51 football teams and 3,263 girls; 631 girls in handball and 189 in athletics.

In the area of Labour 139 job seekers, of whom 95 women, were trained in tourism and hotels in Gaza and Inhambane Provinces.

By the Foreign Affairs area a meeting of SADC Ministers in charge of Women and Gender Issues was held in Maputo, aimed at the adoption of the draft SADC Protocol on Gender and Development.

\section{B. HIVIAIDS}

The issue of HIVIAIDS was one of the biggest priorities of the Government in its efforts to fight poverty.

- The $5^{\text {th }}$ Round of the HIVIAIDS Epidemiological Surveillance, held in 2007, verified a decrease of national prevalence to $16 \%$, against $16.2 \%$ observed in 2004 , which shows that the situation continues preoccupying.

- In regional terms there was an inversion of prevalence between the Central and the Southern Region, so that the last one became the most infected region, with a seroprevalence of $21 \%$, followed by the Central Region (the most infected one in 2004), with 18\%. The Northern Region maintains the same levels of prevalence observed in 2004, around 9\%.

- The fight against this epidemic is of a cross-cutting and multisector nature and continued concentrated in the 7 areas of the National Strategic HIVIAIDS Combat Plan (PEN II), namely prevention, advocacy, stigma and discrimination, treatment, mitigation, research and coordination of the national response.

\section{Prevention}

Prevention, combined with treatment and mitigation, continues being the central activity of the HIVIAIDS combat strategy, with greater focus on the following activities:

- Dissemination through interactive activities of messages with emphasis on the protection of children and the realization of child tournaments, in the scope of the dissemination of Law 6/99;

- An additional 86 counselling corners were opened by Geração BIZ for youths and adolescents, increasing the number of counselling corners to 411, covering 68 priority districts and 676,017 adolescents and youths at and outside school.

- A total of 183 SAAJs are functioning, offering sexual and reproductive health services to adolescents and youths, covering $66.6 \%$ of national territory. 
- A total of 42 ATSs integrated in the SAAJs were opened in the Provinces of Manica (7), Maputo (7), Cabo Delgado (6), Tete (5), Inhambane (5), Gaza (4), Niassa (1), Sofala (1) and Zambezia (1) and in Maputo City (5).

- Programmes in local languages dealing with themes related to HIV and AIDS were produced and disseminated by radio and local papers with a reference to socio-cultural aspects of each region, in the scope of turning the messages more Mozambican;

- Programmes dealing with HIV and AIDS were produced and disseminated by papers and television channels;

- The realization of the National Youth Conference and the Subregional Sex Workers Conference was supported, with a view to increase their impact and achieve greater involvement of these more vulnerable groups in HIV and AIDS combat activities;

- About 55,404,388 condoms distributed in the whole country.

- A total of 1610 sessions were held, pamphlets and the CNCS journal distributed, films and videos about HIV and AIDS in work places.

- Health counselling and testing sessions were held, reaching about 6682 workers.

- A total of 242 of peer educator training sessions were held, resulting in the training of 1610 company peer educators, and 586,000 male and 4,830 female condoms were distributed.

\section{Advocacy}

- In the whole country, a message was disseminated to appeal to everybody's responsibility regarding the fight against the epidemic, in the scope of giving continuity to the Presidential Initiative, with the community leaders as main vehicles of communication.

- A total of 250 focal points of the planning sectors were trained, with a view to the inclusion of HIVIAIDS into the sector cycle planning.

- HIVIAIDS policies at the workplace were prepared by 150 companies, most of them large ones.

- Law 5/2000 was disseminated in 120 companies in the whole country.

\section{Stigma and discrimination}

- Twelve regional meetings were held between the various PVHS organisation networks, with a main emphasis on exchange of experiences.

\section{Treatment}

- A total of 86,000 patients received Antiretroviral Treatment (ARVT), representing a growth of $51 \%$ compared to 44000 patients assisted in 2006 .

- As presented in the table below, 6,320 children received ARVT against 3,416 in 2006 , representing a growth of $54 \%$. 
Table 52: ARVT Indicators

\begin{tabular}{|l|c|c|c|c|c|}
\hline ndicator & 2005 & 2006 & 2007 & 2007 targ et $^{*}$ & 2009 targ et \\
\hline $\begin{array}{l}\text { No. ARTV } \\
\text { B6ints }\end{array}$ & 40 & 150 & 210 & & \\
\hline $\begin{array}{l}\text { Patien ts in } \\
\text { Treaament }\end{array}$ & 19,095 & 44,100 & 86,000 & 96,000 & 132 \\
\hline $\begin{array}{l}\text { Children } \\
\text { years }\end{array}$ & 1,668 & 3,416 & 6,320 & 11,820 & \\
\hline
\end{tabular}

Source: MISAU

- The number of Health Units (HUs) offering Vertical Transmission Prevention (VTP) increased to 386 against 222 HUs existing in 2006, representing a growth of $74 \%$.

- A total of 44,795 pregnant women and 26,708 newborns received antiretroviral prophylaxis and 3,647 women started ARVT, as indicated by the following table.

Table 53: VTP Indicators

Table: VTP Indicators for 2005-2007

\begin{tabular}{|c|c|c|c|c|}
\hline Indicators & 2005 & 2006 & 2007 & 2007 target \\
\hline HUs with VTP & 82 & 222 & 350 & 250 \\
\hline HIV+ women & 14.193 & 28.516 & 43968 & 164.971 \\
\hline $\begin{array}{l}\text { HIV+ women who received } \\
\text { ARV prophylaxis }\end{array}$ & 7.69 & 12.15 & & 57.74 \\
\hline Ŵ'Nomen who started ARVT & 554 & 950 & 3647 & 5.774 \\
\hline Children with ARV prophylaxis & 5.439 & 12.042 & 26708 & 49.656 \\
\hline Children tested at 18 months & 581 & 1.026 & & - \\
\hline $\begin{array}{l}\text { Children } \\
\text { result }\end{array}$ & 86 & 211 & & - \\
\hline
\end{tabular}

Source: MISAU

- A total of 113,000 HIVIAIDS infected and affected people received food aid.

- A total of 1,180 nutritional education sessions were held and 295 subprojects were approved, directly benefiting 24,000 and 142,000 people.

- A total of 52,000 domiciliary care beneficiaries in the whole country received assistance.

\section{Mitigation}

- A total of 12,000 seropositive people were covered by the support initiatives, namely in strengthening their capacity for social integration, vocational training in self-employment and housing support;

- A total of 1,200 voluntaries were available in the whole country to offer domiciliary care and aid to AIDS patients;

- There was involvement of religious organisations and associations headed by women for the reception of persons living with HIVIAIDS and orphans and 
vulnerable children (OVCs) so as to reduce their vulnerability, offering basic health care, food preparation and moral support.

\section{Research}

- A methodological review was done and technical partnerships were mobilised for the study on "Prevalence, Behavioural Risks regarding HIVIAIDS";

- Support was given to the bibliographic survey of all studies done by the various actors in the area of HIVIAIDS; and

- The preparation of the protocol of the study on "Alcohol and HIVIAIDS", to be done in Nampula Province, was concluded.

\section{Coordination of the National Response}

- A total of 569 projects were financed in the whole country, of which $528(93 \%)$ in the provinces and the remaining $7 \%$ at central level. Of the total number of financed projects, $89 \%$ belong to civil society and $11 \%$ to the public sector, as presented in the table below.

Table 54: Financing of HIVIAIDS projects

\begin{tabular}{|c|c|c|c|}
\hline \multirow[b]{2}{*}{ Province } & \multicolumn{2}{|c|}{ Financed Projects } & \multirow[b]{2}{*}{ Total } \\
\hline & Civil Society & Public Sector & \\
\hline $\begin{array}{l}\text { Niass a } \\
\text { Cabo-De lgado }\end{array}$ & $\begin{array}{l}42 \\
24\end{array}$ & & $\begin{array}{l}42 \\
24\end{array}$ \\
\hline Nam pula & 29 & & 29 \\
\hline Zambézia & 113 & 1 & 114 \\
\hline Tete & 25 & & 25 \\
\hline Manica & 46 & 1 & 47 \\
\hline Sofala & 31 & 10 & 41 \\
\hline Inhambane & 36 & 6 & 42 \\
\hline Gaza & 82 & 6 & 88 \\
\hline Maputo Province & 28 & & 28 \\
\hline Maputo City & 42 & 6 & 48 \\
\hline Total Provinces & 498 & 30 & 528 \\
\hline Central level & 9 & 32 & 41 \\
\hline Total & 507 & 62 & 569 \\
\hline
\end{tabular}

- Training about concepts and operational monitoring and evaluation mechanisms was given to 78 representatives of the public sector (36), the private sector and higher education institutions (23) and civil society organisations (19);

- Training was given to all technicians of the Provincial Nuclei for the Fight against AIDS (NPCSs), members of the project analysis commissions, about the requirements for the preparation of proposals according to the real needs of the implementation field and the use of resources;

- Communication Strategy kits were distributed to the District Administrators and provincial nuclei, comprising journalists, youths and women and responsible for the operationalisation of the strategy at provincial level were created. 


\section{Multisector response}

In the area of Health 69,003 seropositive cases were notified in the routine data collection system, against 30,332 cases registered in 2006, representing a duplication $(127 \%)$ of the number of cases, with a higher percentage of infected women (56\%).

- An additional 91 new services were opened, adding up to 211 units, exceeding the PEN/AIDS target for 2007.

- A total of 158 doctors and more than 100 medical technicians were trained and the supply of anti retroviral medicines (ARVs) was ensured.

- Two specific training courses were given in Beira, Nampula and Maputo Cities for doctors and medical technicians for the attendance of newborns and for paediatric HIV.

The Agricultural extension workers assisted communities in 80 districts involved in agricultural production and livestock rearing and families involved in commercial stockbreeding, and also assisted the development of school gardens as a learning mechanism and to occupy the students' leisure; and

- In 80 districts the income-generating capacity and food security were strengthened, through the production of high nutritional value crops for PVHS, vulnerable orphans, affected families and communities.

In the area of Women and Social Welfare 3 regional training seminars were held in the field of domiciliary care and visits, benefiting 105 representatives of the Provincial Directorates for Women and Social Welfare and the District Services for Health, Women and Social Welfare;

- A National Seminar was held of the Multisector Nucleus of Orphaned and Vulnerable Children, benefiting 100 representatives of Government Institutions and partners;

- 18 Community Committees for the Protection of Orphaned and Vulnerable Children were created in Palma, Nangade, Muidumbe and Macomia Districts in Cabo Delgado;

- In Matola District in Maputo Province 120 people living with HIV/AIDS, of whom 30 women and 90 men, were aided with a basic monthly food basket;

- In Chiúre District in Cabo Delgado Province 25 activists were trained in the field of domiciliary care for people living with HIVIAIDS;

- In Zambezia Province 43 members of the Provincial Multisector Nucleus for Orphaned and Vulnerable Children were trained in the field of providing psychosocial support.

In the Veterans sector 25 peer educator activists were trained in Gaza, 10 talks were given in Inhambane, 15 in Zambezia and 1 seminar was held in Maputo City;

- A total of 10,500 condoms, 1,650 pamphlets and 1000 booklets about Law $5 / 2002$ were distributed in Gaza, Zambezia and Niassa Provinces and in Maputo City; 
- Two income-generating projects were financed in Marávia and in Maputo City.

In the area of Education HIVIAIDS aspects were integrated into the National Education Policy and the basic education curricula;

- The national prevention radio programme "A world without secrets" and the Basic Package "Abilities for Life" were implemented, evaluated and extended to the provinces, starting with Manica, Sofala and Maputo Provinces;

- The implementation of the national prevention programme "Geração Biz" was extended to Sofala, and was launched in Nampula and Manica covering 343 schools in 64 districts in Niassa, Cabo Delgado, Zambezia, Tete, Inhambane, Gaza and Maputo Provinces and in Maputo City;

- A total of 135,000 orphaned and vulnerable children in EP1 were assisted in 4 districts through the Direct Support to Schools Programme.

The Foreign Affairs area represented the country in a Regional Public Institution Trainers Training Workshop held in Swaziland about the integration of HIVIAIDS into Development Policies and Programmes, and

- The HIVIAIDS Prevention and Combat Sector Plan (2006-2007) was audited with a view to the evaluation of the level of accomplishment of the financial regulations for the management of funds allocated to the sector.

In Public Service the consultancy contract for the design of the respective HIVIAIDS Combat Strategy was concluded.

In the area of Industry and Trade male condoms and IEC material and informative and educational pamphlets were distributed to all organisation units, including the subordinate institutions;

- Food aid was made available to 14 families, corresponding to 50 people, of whom 31 adults and 19 children.

In the Justice area the HIVIAIDS combat plan for the judicial courts was prepared and the treatment and food assistance for infected prisoners is ongoing.

In the Youth and Sports area the $1^{\text {st }}$ National Youth Meeting on HIV/AIDS was held with the participation of 575 youths from all provinces, as well as representatives of Angola and Cape Verde. The meeting approved the Youth Commitment to the Fight Against AIDS;

- A total of 108 national trainers were trained in the field of leadership, project management and Abilities for Living with HIV/AIDS;

- A total of 474 activists working in community awareness-raising in the field of sexual and reproductive Health and HIVIAIDS were trained;

- A total of 126 community leaders and 97 parents and educational tutors were trained in the field of HIVIAIDS prevention and combat;

- A total of 1,401 awareness-raising sessions were held, among which talks, video and theatre sessions and face-to-face counselling, covering a total of 112,917 people. 
In the scope of fighting HIVIAIDS in the workplace, 30 peer educators from 27 Maputo City markets were trained by the Labour sector;

- A total of 107 peer educators were trained in cooperatives, SMEs and OBC in Maputo and Sofala;

- A total of 20 peer educators, of whom 10 belonging to the Mothers of Mavalane Centre and 10 to the MUKHERO Association, were trained in Social Exclusion Combat Strategies and HIVIAIDS;

- Technical and financial support was made available to 70 organisations for the implementation of HIVIAIDS-related activities in cooperatives, SMEs and $\mathrm{OBC}$, in Maputo and Sofala;

- A total of 181 peer educators were trained in the Caminhos de Ferro and Linhas Aéreas de Moçambique companies.

In the Transport and Communications area, the Sector Strategy for the Fight Against HIVIAIDS was prepared. Training seminars were also held on project preparation and HIV/AIDS prevention and combat; and

- The provision of domiciliary care to 25 employees and their families living with HIVIAIDS was followed.

In the Fisheries area the distribution of condoms and the dissemination of information was continued with a view to impact prevention and mitigation, having resulted in greater acceptance on the part of sector employees to do a HIVIAIDS test;

- Awareness-raising sessions against the stigmatisation and discrimination of people living with HIVIAIDS were held, through talks and video projections for 273 sector employees;

- The documentary about HIVIAIDS was disseminated to 15 coastal fishing communities in Nampula (7), Zambezia (7) and Sofala (3) Provinces, including 2 in Beira City; and

- In the scope of the mitigation of HIV/AIDS effects, 33 sector employees and/or their dependants were assisted, by offering them positive life rules, food aid, hospital assistance and counselling and directing them to the health services.

In National Defence, 6 ATS, in the Northern (2), Central (3) and Southern (1) Regions, were opened in the military health units, and

- Three Day Hospitals were opened in each one of the three regions of the country, in which $80 \%$ of the patients are civilians.

In the Energy area the sector strategy to fight HIVIAIDS was disseminated;

- A competition was launched for the preparation of the Sector Study of Knowledge, Attitudes and Practices (CAPs)

- Awareness-raising seminars for the prevention of HIVIAIDS were held in Maputo, Gaza, Inhambane, Sofala, Manica, Tete, Nampula and Niassa; and a national seminar with the participation of focal points at central and provincial level. 


\section{THE ENVIRONMENT}

In the area of the Environment, priority continued to be given to the country's sustainable development, based on a continuous intersector coordination, environmental management and education and territorial planning. Thus, with a view to the realization of the defined objective, the following activities were, among others, carried out:

\section{Intersector Coordination}

In the sphere of intersector coordination the diagnosis of the functioning of the 5 existing environmental units was started, as well as the opportunities for the creation of more units.

The Environmental Strategy for the Sustainable Development of Mozambique was approved.

With respect to the dissemination of environmental statistics, 50 copies of the compendium of environmental statistics were printed for distribution.

\section{Environmental Management}

With the objective of contributing to the prevention of environmental degradation the following activities were carried out:

- With respect to the dissemination and implementation of the Uncontrolled Forest Fire Combat Strategy, manuals for the prevention and control of soil erosion and uncontrolled forest fires were prepared;

- With regard to the dissemination of the National Soil Erosion Control and Combat Strategy, the Action Plan for the Prevention and Control of Soil Erosion was approved;

- Regarding the continuation of the implementation of the erosion combat pilot project in Changara, 1,600 trees (pine-trees, eucalyptus and casuarinas) were planted;

- The integrated environmental plans of the Coastal Zones of Sofala and Zambezia were prepared;

- The draft technical guidelines for the implementation and operationalisation of sanitary landfills in Mozambique were prepared;

- Dissemination was done of good practice of urban environment management, through the training of municipal technicians and leaders and the implementation of demonstration projects in the field of green zones and the management of solid waste.

\section{Assessment of the Environmental Impact}

In this scope, more than 200 projects were pre-evaluated, against 160 projects foreseen in the plan. On the other hand, the removal of obsolete pesticides was concluded in Nampula (130 tons), Cabo Delgado (53 tons), Niassa (20 tons), Zambezia (120 tons) and Manica (90 tons), while the preparation of the $3^{\text {rd }}$ Phase, comprising their destruction and export, is in progress. Similarly, the strategic environmental evaluation of Govuro was concluded. 
In terms of environmental audits in industries in Maputo, Gaza, Inhambane, Sofala, Manica and Nampula, 11 audits were taken, against 15 foreseen in the plan.

\section{Environmental Planning}

Environmental Planning is one of the main environmental priorities in the country. Thus, the following activities are worthy of note:

- The town planning of Mecuburi in Nampula was carried out;

- Current situation and thematic maps were concluded and delivered for the land use plans of the following districts: Chifunde, Macanga, Mutarara and Changara in Tete, Namacurra, Nicoadala, Chinde and Gilé in Zambezia, Machanga, Maríngue and Chemba in Sofala, Manica and Macossa in Manica, Cahora Bassa, Moatize, Chiúta, Marávia and Zumbo in Tete Province; and thematic maps were concluded for Manica, Sussundenga and Gondola (Manica Province) and Chemba (Sofala), Gilé, Namacurra, Nicoadala and Chinde (Zambezia);

- A training course in Environmental Planning and Natural Resources Management was given to 20 District Administrators and 22 Administrative Post Heads in Nampula Province;

- Training in territorial planning and natural resources management was given to 20 district technicians of Cabo Delgado Province, 21 technicians of Maputo province and 55 community leaders of Manica Province and 78 of Manhiça (Maputo);

- Training in territorial planning and natural resources management was given to 24 community leaders of Nipepe District (Niassa) and 27 district technicians of Manica Province;

- In the scope of emergencies, safe areas were identified for the resettlement of 26,000 affected families, of which 11,150 in Mutarara (Tete), 1,351 in Tambara (Manica), 4,000 in Caia, Marromeu, Chemba and Buzi (Sofala) and 10,000 in Mopeia, Nicoadala, Morrumbala and Chinde Districts (Zambezia).

\section{Promotion of the Environment}

In this scope, priority continued to be given to the realization of activities aimed at educating and raising the awareness of society about environmental issues, with a view to the sustainable use of natural resources. Thus, in 2007 the following main activities were carried out:

- Regarding technical and material assistance to environmental nuclei and clubs in the whole country, 64 clubs were created and 4 were revitalised. In the same scope 99 nuclei and associations were created and 11 revitalised;

- Concerning the production and dissemination of awareness-raising and environmental promotion material, two issues of the Moçambiente magazine were produced.

Regarding Environmental Legislation and with a view to the strengthening of the institutional and legal framework for the sustainable use of natural resources the (www.legisambiente.gov.mz) database was launched. 


\section{Environmental Inspection}

With a view to ensure the implementation and adherence to environmental legislation were the following activities were carried out:

- Tourist establishments were inspected in Maputo (08), Gaza (23), Inhambane (16), Cabo-Delgado (1), Sofala (4), Tete (2), and Nampula (4);

- A total of 18 category A activities were inspected in Maputo (07), Sofala (03), Manica (02), Tete (02) Nampula (04);

- A total of 73 category B and C activities were inspected, namely 15 in Nampula, 2 in Tete, 3 in Sofala, 6 in Gaza, 13 in Maputo Province, 15 in Maputo City, 8 in Inhambane, 8 in Manica and 3 in Cabo Delgado.

\section{Multisector Response}

In the area of Health, the guidelines of the National Sanitation Campaign aimed at the environment and hygiene promotion were disseminated in all Provinces, Municipalities, and civil society organisations;

- An evaluation was carried out of the hygienic quality of commercialised bottled water; an evaluation of the microbiological quality of borehole and well water consumed in the national hospitals, as well as of water and soils contaminated by the explosion of the Mahlazine Ammunition Depot;

- The National Food Codex Committee of Mozambique, a body responsible for the preparation and implementation of Mozambican food quality standards, was created;

- A rapid evaluation was carried out of biomedical waste in 56 health units of Maputo City and Gaza, Sofala, Nampula and Zambezia Provinces, having culminated in the preparation of a draft action plan for hospital waste of Maputo Central Hospital and the management of biomedical waste of José Macamo General Hospital and Angoche Rural Hospital.

- Vaccination against yellow fever was made compulsory for all passengers coming from countries in which this disease is endemic.

- A seminar was held for the dissemination and study of the National and International Health Regulation.

In the area of National Defence patrols and inspections of the seacoast continued in fixed and mobile positions in Ponta de Ouro, Inhaca, Inhassoro, Angoche, Bazaruto Archipelago and Quirimbas Archipelago, and the lighthouse centres.

In the area of Peri-urban and Rural Sanitation 20,997 new latrines in the periurban and rural areas were constructed, benefiting 104,985 people.

In the Environment area Law 19/2007 on Environmental Planning was approved and was disseminated in Manica, where 30 technicians were trained in town planning methodologies, the preparation of detailed plans and the validation of the manual of basic town and country planning techniques.

In the Land Management component 3,003 applications were processed, corresponding to $1,976,121.56$ ha, mostly in Niassa, Sofala and Zambezia, having been granted 1,502, with a total area of 591,532.2 ha. 
In the forest and wildlife resources management component in Agriculture, 12 forest concessions were approved in Cabo Delgado (1), Nampula (1), Zambezia (1), Tete (4), Sofala (1), Inhambane (3) and in Gaza (1);

- A total of 18 management plans were approved in Cabo Delgado (1), Nampula (4), Zambezia (3), Tete (5), Sofala (1), Inhambane (3) and Gaza (1);

- A total of 22 forest explorations were involved in community management initiatives;

- A total of 533 land lots with DUAT were inspected in the whole country. Of these, 132 lots are fully used, 80 partially used, 137 lots are not used and 51 were cancelled;

- A total of 28 training sessions against forest fires were held.

- In the scope of tourist infrastructure building a length of $1 \mathrm{~km}$ of the airstrip Banhine National Park was rehabilitated.

- Maintenance was carried out of $30 \mathrm{~km}$ of roads and 2 bridges in Chimanimani National Reserve.

- A length of $37 \mathrm{~km}$ of roads was rehabilitated and maintained in Zinave National Park.

- The technical evaluation of the proposals following the tender for the preparation of the management plan for Chimanimani National Reserve was concluded.

- The $1^{\text {st }}$ draft of the Tourism Development Plan of the Quirimbas National Park was concluded;

- A company was contracted for the updating and implementation of the management plan for the Maputo Special Reserve;

- The 2008-2012 management plan of the Bazaruto Archipelago National Park was updated;

- Nine public toilets were rehabilitated in llha de Moçambique, Nampula Province (5) Metangula, Niassa Province (2), Manhiça, Maputo Province (1) and Macia, Gaza Province (1).

In the area of Mineral Resources environmental education was given and monitoring of traditional mining activities carried out in Manica, Zambezia and Nampula Provinces, and the Environmental Impact Studies (EIA) in the areas 1, 2, 4 and 5 of the Rovuma Basin were approved.

In the area of Energy, the environmental management sector strategy and respective environmental guidelines for power transmission lines were prepared, and hearing seminars were organised in Nampula, Sofala and Maputo Provinces;

- An environmental licence was acquired for the Aeolian Potential Study Project;

- A study was done on the Energy Potential for Clean Development Mechanisms (CDM) projects; 
- Sector technicians were trained in the implementation of environmental guidelines.

\section{FOOD SECURITY AND NUTRITION}

In this area continuity was given to activities aimed at guaranteeing cross-the cutting approach to food security and nutrition, as well as achieving a harmonised national response for the mitigation of food insecurity situations (InSAN) among the population in general and malnutrition in under-fives.

In institutional terms, the following main activities were carried out:

- Preparation and approval of the Food Security and Nutrition Strategy (ESAN II);

- Preparation and approval of the Action Plan for Food Security and Nutrition (PASAN);

- Execution, in February, May and October, of evaluations and monitoring of severe vulnerability in the whole country.

As a result of this monitoring, it was observed that between March and October 2007 the food security situation was stable with an unchanged number of 520,000 people in a situation of extreme food insecurity until the next harvest, in March 2008.

- It should be noted that the floods that affected the Zambezi Valley provinces, cyclone Favio and the droughts in the Southern and Central Regions of the country, which together led to the loss of 369,000 ha of various crops, contributed to this situation.

\section{Availability of food}

A availability of food at household level is crucial for the reduction of the number of people in a situation of vulnerability, and agricultural production and livestock breeding are of capital importance as well as fish production, above all traditional fishing. As a matter of fact:

- A total of 2.2 million tons of cereals were produced in the 2006/07 agricultural campaign, a growth of $3.4 \%$ compared to the 2.1 million tons produced in 2005/06;

- A total of 367,000 tons of beans were produced, representing a growth of $0.6 \%$ compared to $2005 / 06$;

- A total of 8.1 million tons of cassava were produced, corresponding to an increase of $8.1 \%$ compared to the $2005 / 06$ campaign;

- In livestock breeding, an overall figure of 1,425,884 heads of cattle was attained;

- A total of 19,829.5 tons of beef, pork and chickens were produced, representing an increase of $41 \%$ compared to the $14,106.2$ tons produced in the previous campaign;

- A total of $1,352,405$ litres of milk and 2,557,415 dozens of consumption eggs were produced; 
- In fishing 87,902 tons of catch were produced, of which 67,784 tons $(77 \%)$ by the traditional fishing sector and the remaining 20,118 tons (23\%) shared between commercial fishing and aquaculture.

With the levels of production achieved and as a reflex of the effects of floods, the cyclone and droughts, in October 2007 food reserves at household level were practically exhausted in the Southern Region and considerably reduced in the Central and Northern Region of the country, compared to May of the same year.

\section{Access}

Households' (HHs) access to food, particularly cereals, decreased, above all in the Southern Region, among others factors due to price escalations, the rural population's limited purchasing power and the limited physical availability of food.

- The more vulnerable HHs' sources of income are quite limited, due to the fall of agricultural production, which affected their food purchasing power. However, the availability of food products on the country's main markets remained in general at a reasonable level.

In relation to the increase of food prices it was observed that:

- Prices on the markets of the Southern Region, especially of maize, increased from May 2007 onwards, following the normal seasonal curve but with levels above the prices practiced in 2006 and above the average of the last five years.

- Prices in the Northern and Central Regions of the country stayed below those practiced in 2006 and below the average of the last 5 years.

\section{The use of food}

Even with the impact of the disasters, the food situation until October 2007 is considered to be normal, taking into account the Insufficient Growth $(\mathrm{Cl})$ Rate indicator and there were no signs of alarm.

- This normality is the result of interventions carried out in the whole country aimed at providing food aid to the affected population, as well as of the implementation of nutritional surveillance programmes and vitamin $A$ supplementation for under-fives.

- The situation of the Low Weight at Birth (LWB) indicator was preoccupying, the situation remained stationary with less than $0.2 \%$ to $0.3 \%$ compared to the $11.5 \%$ observed in 2006 , a figure above the acceptable limit of $7 \%$. The occurrence of endemic diseases such as malaria and diarrhoea has probably contributed to the continuation of these levels.

\section{Food and nutritional aid and social protection}

With a view to minimize food shortages and nutrition deficiencies:

- A total of 259,500 people in the areas affected by the floods and cyclone Favio received food aid;

- A total of 400,000 primary school children, 40,000 boarding students and 4,800 refugees in the Marretane Camp in Nampula received aid; 
- A total of 9,779 children were deparasited and another 9,142 received vitamin A supplements, of the 46,369 children attended by the Routine Food Supplementation Programme in Maputo, Gaza, Manica, Sofala and Tete Provinces.

- A total of 112,977 beneficiaries of the Food Subsidy Programme were attended, of whom 72,274 women (64\%) and 40,703 men (36\%).

\section{E. SCIENCE AND TECHNOLOGY}

In the area of Science and Technology (S\&T) efforts in 2007 were concentrated on the development of the National Science and Technology and Innovation System to allow that S\&T activities are performed in a coordinated and efficient way. Thus, among other activities carried out for the achievement of the defined objectives, the following stand out:

\section{Scientific research}

- The rehabilitation works of the building for the establishment of a Ethnobotanic Research Centre in Maputo City or Maputo Province are in progress; meanwhile, the discussion about the respective draft bylaws is ongoing;

- The (2005-2006) biennial report of Science, Technology and Innovation Indicators of Mozambique was produced and published, which allows an evaluation of the performance of the Science and Technology System and an increase of the efficiency of the S\&T policies formulated in the System;

- A total of 15 multidisciplinary expeditions were made in 15 districts of the country, for the resolution of problems identified during previous expeditions in the scope of the identification of constraints and practical solutions in 30 Mozambican districts;

- Courses were developed for subsequent training of technicians in the scope of technological diffusion, innovation and transfer through Regional Science and Technology Centres.

\section{Transfer of technologies and innovation}

- A provincial innovators database was created and updated and 43 innovators were registered at national level and 11 innovations in the Industrial Property Institute (IPI);

- Seminars were held in Cabo Delgado, Sofala and Inhambane Provinces and 5 technological demonstrations were realized in Cabo Delgado Province (Pemba), Nampula (Nampula City), Manica (Chimoio), Inhambane and Maputo, in the scope of the realization of innovating technological demonstrations in the Provinces

- The plot for the establishment of the technological incubator in Chókwè was legalized, the costs of the rehabilitation of technicians' houses evaluated and the tender for the rehabilitation of the future Technological Incubator's premises was prepared.

\section{Information and Communication Technologies}

- The conclusion of the TORs for the acquisition of equipment and the rehabilitation of the management centre is in progress, in the scope of the 
creation of the Internet Network connecting at least 6 Research and Higher Education Institutions.

- The National Library was computerised and the computerization of the Historical Archives is in progress.

- The Virtual Cotton Museum was created, with prominence for the collection and systematisation of contents in several institutions and the design of the structure and the development of the Virtual Cotton Museum.

- The creation of a Science and Technology Database and Portal with information on agriculture and livestock breeding (the conservation and processing of agricultural produce in the country) is being concluded;

- A total of 311 teachers of the 290 foreseen were trained in all provinces of the country, with the exception of Cabo Delgado, in the scope of the training of teacher trainers in Information and Communication Technologies;

- The MzBusiness Library was created and information collected from poverty studies, existing in Research and Higher Education Institutions and similar organisations.

\section{Science Dissemination and Promotion}

- Videos were produced in the Umbeluzi experimental field, especially videos on yellowish sweet potatoes, improved maize and the xigutsa irrigation hand-pump, in the scope of the production of audiovisual and digitalised materials about adequate techniques and knowledge for the solution of the specific problems of each region, as a way to disseminate available knowledge to the rural communities.

- The $5^{\text {th }}$ Science and Technology Exhibition was held in Maputo, with 60 exhibitors.

- Talks and scientific courses were given in the country and also 8 scientific demonstrations in schools in Maputo City and Province in the scope of the dissemination of leading-edge technologies to Maputo's academic communities.

\section{Multisector response}

In the area of Youth and Sports an Information Technology Dissemination Centre was created in Chiúre and 2 are being concluded in Ancuabe and Montepuez Districts in Cabo Delgado Province, and

- A total of 30 youths were trained in basic computer packages in Gaza Province and candidate teachers were selected in Nampula, Sofala and Cabo Delgado Provinces.

In the area of Communications the coverage of 116 sites (provincial and district capitals) by the fixed network and of 85 sites by the mobile network was concluded;

- The construction of the Beira-Caia-Quelimane, Quelimane-Nampula and Nampula-Cuamba-Mocuba sections of the fixed telephony backbone was concluded; and

- The GSM-based communications systems (mobile telephony) in the Pemba, Quelimane, Pebane, Tete, Lichinga and Chimoio meteorological stations were modernized. 
In the area of Health the launching of a public tender was prepared for the expansion of the data and Internet/e-mail network for the José Macamo General Hospital, ISCISA and the Machava General Hospital (Maputo City), the Beira Central Hospital, the Nampula Central Hospital and the Provincial Directorates of Tete and Niassa.

- The first draft of the test report of the cholera vaccine Project, of Cuban origin, was prepared;

- The fieldwork of the evaluation study of the health service consumption pattern and related factors was concluded;

- The final report of the mapping of intestinal parasites and bilharzias in schools in the country's Northern Region was prepared;

- The fieldwork of the study on "HIV/AIDS-related Behaviours, Attitudes, Knowledge and Standards of health workers in Mozambique" was concluded;

- The video cassette on Traditional Practices and the Transmission of HIVIAIDS was translated into the Nhungué, Xichangana and Emakua local languages and was distributed to all Health Units of the country;

- The information about the level of prevalence of HIVIAIDS in Mozambique was updated to about $16 \%$, with a higher percentage of infected women $(56 \%)$;

- Consultations of chronic patients in 12 health units of Maputo City were implemented, in the scope of the study to evaluate the impact of chronic diseases on households, namely diabetes, high blood pressure, obesity and cerebrovascular disease (CVD).

In Agriculture, in the scope of the dissemination of agricultural technologies 3 new technological packages were made available for the control of pests and diseases; and 3 new technological packages for the improvement and processing of animal species.

In the area of Energy, the first biodigestor for the testing of biogas production is being loaded in the scope of the results of the biogas project and favourable results are being expected.

In Public Service the Electronic Staff Information Subsystem (e-SIP) was created through the transformation of the Staff Information Subsystem (SIP).

In the area of Justice services interconnection in all provincial capitals through Govnet was concluded, covering the criminal and commercial registration services, and

- The connection of the High Court to the e-government network was concluded and the establishment of the intranet network in the courts and their connection to the e-governo network is in progress.

\section{F. RURAL DEVELOPMENT}

The Government continued its efforts aimed at ensuring that national policies and programmes assume an explicit pro-rural nature and engendering a change in the current capital accumulation pattern in national economy and has also started the implementation of the Rural Development Strategy (EDR).

\section{Rural competitiveness and accumulation}


- A seminar was held on "The PAMA Experience and Options for a Market Opportunities Programme for Rural Communities", with a view to debating the acquired experience and its implementation and collecting contributions for the formulation of a new rural market programme.

The PAMA is implemented in Cabo Delgado (Montepuez, Balama, Namuno, Chiúre and Ancuabe), Niassa (Cuamba, Maúa and Marrupa) and Maputo (Boane, Moamba and Magude) Provinces. As a result, a total length of $446 \mathrm{~km}$ of roads was rehabilitated and 149 bridges and 300 aqueducts were constructed by the programme.

- The number of contracts between producers and the market was quadruplicated;

- $30 \%$ of the associations had access to credit and prepayments;

- The prices of products soled by the producers through the associations increased by $20-25 \%$;

- Productivity of the main cash crops increased, namely of tomatoes (from 12 to 30 tons/ha), cabbages (from 10 to 20 tons/ha), green beans (from 4 to 8 tons/ha) and peppers (from 3 to 4 tons/ha).

- The $1^{\text {st }}$ Session of the Intersector Commission on the Local Economic Development Programme was held, as well as a National Seminar on Local Economic Development in Mozambique and the Role of Local Economic Development Agents (ADELs) in District Development;

- The ADEL of Inhambane was created and preparations were made for the creation of ADELs in Niassa, Tete and Cabo Delgado;

- An International Meeting of the Art Gold Mozambique Programme was held in Rome for mobilizing financing for the Cabo Delgado, Nampula, Gaza and Maputo ADELs' programmes and projects;

- The methodological and strategic procedures of the project proposals from Nampula and Cabo Delgado Provinces and the Municipality of Maputo were analysed, in the scope of the follow-up of the Rome Meeting recommendations;

- Spanish Government Funds for the implementation of the Programme were made available;

- The establishment of the Ntantha Community Radio in Chifunde District in Tete was started in the scope of rural communication;

- In the associative organisation area the preparation of the draft Strategic Government Action Plan to Support the Rural Associative Movement was concluded;

- About 437 new associations were registered under Decree-Law 2/2006, facilitating the registration of Agricultural and Livestock Rearing Associations, adding up to a total of 3,237 registered associations in the whole country.

\section{Rural Finance Activities}

- A total of 59 micro-finance agencies are functioning, assisting a total of 157,000 clients; 
- A National Meeting was held on Development Funds with the motto "The role of Development Funds in Socio-Economic Development of the Country and the Challenge of Greater Coordination of Efforts for Increasing the Impact in the Communities". As a result, the matrices of priority activities for the 14 Development Funds to operate in the country were prepared.

- The rural micro-finance/finance support programme was prepared, to complement the rural finance activities.

- Credits were granted to 12,000 producers and a repayment rate of $98.5 \%$ was achieved, in the scope of the implementation of the Decentralized Credit Project for the Family Sector. This project operates in Maputo and Cabo Delgado Provinces (Montepuez, Ancuabe, Namuno and Balama) and grants credits to rural producers and informal sellers in the peri-urban areas through the self-managed Community Funds;

- Approval was given to the institutionalisation plan for the 5 Base Community Funds ( 3 in Maputo and 2 in C. Delgado), managed by a National Union of Community Fund Associations for savings and loans and the respective central financial management system of the Union of Community Funds;

- Tenders were launched for the contracting of a company or institution to provide technical assistance about HIVIAIDS in the workplace, and for the training of trainers in the micro-finance area in partnership with the International Labour Organisation;

- A Memorandum of Understanding was signed for the training of micro-finance operators in the field of inclusive finance, in the scope of the "Constructing an Inclusive Finance Sector in Mozambique" project;

- Two category I microprojects (a maximum value of 90,000.00 MT) were financed, aimed at the creation of wild chickens and the supply of agricultural inputs in Mocuba, in the scope of the Rural Development Support Project in Zambezia (PRODEZA). The rehabilitation of rice production and processing infrastructures in Maganja da Costa District was also financed;

- The Kukumbi activities aimed at strengthening local governance were financed.

- Computer equipment, office and meeting room furniture and 20 motorcycles were acquired for Mutarara and Morrumbala Districts, in the scope of the Small Market-Oriented Producers Development Project.

\section{Rural Production}

- The draft of the Integrated Development Programme for Rural Women was concluded and will be implemented in a first phase in 6 districts, namely Magude (Maputo), Chókwè, Xai-Xai (Gaza), Zavala, Homoíne and Inharrime (Inhambane). The Programme is aimed at the promotion of associative forms of organisation, income-generating activities, women's literacy classes and social education and water supply.

\section{Infrastructures and rural entrepreneurship}


- The draft of the Rural Infrastructure and Entrepreneurship Promotion Programme was concluded and will be implemented in a pilot phase in Bilene District in Gaza Province.

\section{Coordination, Supervision and institutional support}

- Training in Local Economic Development modules was given to 27 universitylevel technicians to be placed in the districts of Cabo Delgado Province; and

- The Provincial Planning Support Team (EPAP) of Gaza Province was trained in rural development coordination and promotion, with emphasis on programmes and projects, Local Economic Development Agencies and other rural development initiatives.

\section{Multisector response}

\section{a) Rural Financing}

In the area of Industry and Trade, 61 projects aimed at the rehabilitation of the rural trade network, and 12 rural financial institution projects were financed by FARE;

- Credit was granted to 8 companies in Nampula (3), Zambezia (1), Inhambane (2) and Gaza (2) Provinces, in the scope of the IV Security Fund of BClFomento SARL credit to cashew nut producer/processing companies.

In the area of Fisheries credits were granted to 239 traditional fishermen in Niassa (13); Nampula (13); Tete (65); Sofala (1); Manica (102); Inhambane (34); Gaza (10) and Maputo (1) Provinces, on the basis of rotational credit funds, and

- Loans were granted to 3 Micro-Finance Institutions (MFIs), namely the Small Industry Promotion Fund (FFPI), AMODER and GAPI, which perform the role of retailers for the beneficiary communities.

\section{b) Social and productive infrastructures}

In the area of Agriculture 3,470 ha of irrigation schemes were rehabilitated in Niassa (94), Nampula (70), Tete (20), Zambezia (45), Sofala (110), Inhambane (821), Gaza (2.300) and Maputo (60) Provinces and the rehabilitation of the drainage system of the Lower Limpopo (in Xai-Xai) was concluded, turning 1,300 ha viable for production.

In the area of Fisheries, in the scope of the integrated community development projects the construction of three schools in Sofala (Buzi and Machanga) was concluded and another 2 schools in Nampula (Moma) are being concluded;

- The construction of 5 health units, of which 2 in Zambezia and 3 in Sofala, was concluded;

- A total of 19 houses for health staff were constructed in Nampula (13), Zambezia (2) and Sofala (4) Provinces;

- A total of 62 water sources were constructed/rehabilitated in Nampula (16), Zambezia (25), and Sofala (21) Provinces, as well as 2 water captation systems of the Health Centres in Angoche and Mogincual in Nampula Province;

- Maintenance was carried out of a length of $92.5 \mathrm{~km}$ of access roads to the fishing centres in Nampula and a total length of $264.5 \mathrm{~km}$ of roads and community accesses were opened in Nampula $(8.5 \mathrm{~km}$ of community 
accesses) and Zambezia (256 km of roads) and $57 \mathrm{~km}$ of roads in Sofala are being rehabilitated.

- An ice factory was established in Machanga.

In the area of Tourism, 2 fruit markets with a capacity for 40 vendors each were constructed in Macia (Gaza) and Manhiça (Maputo) Districts.

\section{c) Rural access to technology and innovation}

In the area of Telecommunications the installation of transmission equipment was concluded in Ile, Mopeia (Zambezia), Chemba, Chibabava, Maríngue (Sofala) and Machaze (Manica) Districts, the implementation of the second phase of the VSAT system was concluded in Massangena, Mabalane and Chicualacuala, and the installation of Rural Telecommunications Systems was concluded in Gaza Province.

In the area of Science and Technology the plot on which the Technological Incubator will be established was legalized and a tender was launched for the rehabilitation of the Technological Incubator plant; and

- A total of 15 multidisciplinary expeditions were made in 15 districts in the 3 regions of the country for the resolution of concrete problems identified during previous expeditions.

In the area of Agriculture producer awareness-raising campaigns about the lethal coconut-tree yellowing disease were launched in the affected provinces (Cabo Delgado, Zambezia, Inhambane), using various means of communication and warning signs were placed at the entrance of Inhambane and Zambezia Provinces to strengthen domestic quarantine to the lethal coconut-tree yellowing disease in those provinces, and

- A total of 191 hours of radio broadcasts were carried out for the dissemination of technical messages.

\section{G. DISASTERS}

The Government continued its efforts aimed at reducing the country's vulnerability to disasters as well as minimizing their effects on the economy and on the population lives. To this end the Master Plan for the Prevention and Mitigation of Disasters was created as action instrument. On the other hand, the Contingency Plan for rendering assistance to the population victim of disasters was implemented. In overall terms, main areas of action were prevention and early warning, response and mitigation.

\section{Prevention and early warning}

The SARCOF and INAM climate forecast indicated for Mozambique a precipitation regime similar to that of 2006, with normal rains, but tending to above normal for the period of January to March 2007, which could result in floods in the main basins and in the occurrence of droughts in the Southern and Central Regions and imposed the strengthening of preventive and early warning measures, which were:

- Rain gauges were installed in the Districts of Matutuíne, Moamba (Maputo), Chókwè, Guijá, Chibuto (Gaza), Angoche, Memba, Nacala-a-Velha, Nacala- 
Porto, Mossuril, Nampula (Nampula), Quissanga, Ibo, Mocimboa da Praia and Mecufi (Cabo Delgado), Lichinga and Lago (Niassa).

- The early warning system was disseminated for the Zambezi floods, Cyclone Favio and other cyclones threatening the Mozambican coast.

As a result of the forecasts made, 515,10 people were affected by various disasters, namely,

- Floods in the Zambezi Basin, affecting Zambezia, Tete, Manica and Sofala Provinces;

- Cyclone Favio, which affected Inhambane, Sofala and Manica Provinces;

- Strong winds accompanied by rains and inundations in the whole country, with the exception of Tete and Cabo Delgado Provinces;

- Droughts in Maputo, Gaza, Inhambane, Sofala and Manica Provinces, which affected [???], without human losses, as a result of the timely withdrawal and rescue of the affected population.

Table 55: Population in risk of disasters and affected in the $2006 / 07$ season

\begin{tabular}{|c|c|c|c|c|c|c|c|}
\hline \multirow{3}{*}{ Província } & \multirow{3}{*}{$\begin{array}{l}\text { Populacao* } \\
\text { (INE) }\end{array}$} & \multicolumn{6}{|c|}{$2006 / 2007$} \\
\hline & & \multicolumn{2}{|c|}{ Cheias/Inind. } & \multicolumn{2}{|c|}{ Ciclones/V.Fortes } & \multicolumn{2}{|c|}{ Seca } \\
\hline & & PC & Afectado & PC & Afectados & PC & Afectados \\
\hline Maputo & $2,208,000$ & 29,903 & & 10,850 & 3,053 & 35,551 & 48,597 \\
\hline Gaza & $1,277,000$ & 40,077 & & 61,158 & 1,835 & 137,878 & 28,856 \\
\hline Inhambane & $1,350,000$ & 52,332 & & 77,596 & 141,059 & 77,495 & 28,774 \\
\hline Manica & $1,281,000$ & & 4,370 & & 16,375 & 20,000 & 8,200 \\
\hline Sofala & $1,601,000$ & 62,973 & 58,961 & 11,754 & 24,815 & 40,000 & 5,151 \\
\hline Zambezia & $3,627,000$ & 41,773 & 36,489 & 87,850 & 1,786 & 45,000 & \\
\hline Tete & $1,473,000$ & 47,451 & 71,299 & & & 91,950 & \\
\hline Nampula & $3,588,000$ & 25,479 & & 524,131 & 15,314 & 50,000 & \\
\hline Cabo Delgadd & $1,585,000$ & 6,299 & 5,000 & 22,530 & & 44,938 & \\
\hline Niassa & 972,000 & & 410 & & 15,366 & 0 & \\
\hline TOTAL & $18,962,000$ & 306,287 & 176,529 & 795,869 & 219,603 & 542,812 & 119,578 \\
\hline
\end{tabular}

\section{Source: Provinces}

- The explosion of the Mahlazine Ammunition Depot, causing the death of 104 people and 515 wounded, and the total destruction of 126 houses and partial destruction of another 5,434 houses.

\section{Response}

To guarantee a rapid, effective and timely response to the effects of the disasters, the following activities were carried out:

- Four districts situated in the arid and semi-arid zones, namely Mabote, Funhalouro, Massangena and Chigubo were mapped.

- Georeferencing was carried out of 731 water infrastructures (boreholes, wells, dams, irrigation schemes, lakes, rivers), schools and health units in Funhalouro (424) and Mabote (307) districts. 
- A total of 118 Risk Management Committees were created in the whole country, comprising 1415 members, 101 Committees were trained and 45 were equipped, as shown in the table below.

Table 56: Distribution of Local Disaster Risk Management Committees

\begin{tabular}{|c|c|c|c|c|c|}
\hline Província & $\begin{array}{l}\text { Qtd de comités } \\
\text { Criados }\end{array}$ & \begin{tabular}{|l|} 
Qtd \\
comités \\
Capacitados
\end{tabular} & $\mid \begin{array}{l}N \\
\text { Membros }\end{array}$ & \begin{tabular}{|l||} 
Comités \\
Equipado \\
$\mathbf{s}$
\end{tabular} & $\begin{array}{l}\text { Comités } \\
\text { por } \\
\text { Equipar }\end{array}$ \\
\hline Maputo & 0 & 0 & 0 & 0 & \\
\hline Map. Cidade & 6 & 6 & 61 & 0 & 6 \\
\hline Gaza & 6 & 2 & 40 & 0 & 40 \\
\hline Inahambane & 50 & 48 & 590 & 20 & 30 \\
\hline Manica & 6 & 6 & 60 & 0 & 6 \\
\hline Sofala & 30 & 27 & 440 & 25 & 5 \\
\hline Tete & 0 & 0 & 0 & & \\
\hline Zambézia & 7 & 4 & 448 & 0 & \\
\hline Nampula & 4 & 4 & 56 & 0 & \\
\hline C. Delgado & 7 & 2 & 56 & 0 & \\
\hline Niassa & 2[ & 2 & 64 & 0 & \\
\hline Total & 118 & 101 & 1415 & 45 & 87 \\
\hline
\end{tabular}

Source: INGC/Provinces

- Relief and rescue means were pre-positioned in the Southern (Vilankulos) and Central (Caia) Regional Directorates and in the National Emergency Operations Centre (CENOE, in Maputo);

- A total of 275 people of 57 districts, of whom 115 technicians, 41 District Permanent Secretaries and 115 youth voluntaries, were trained in disaster risk management;

- Contacts were made with the Italian Civil Protection, aimed at the institutionalisation of the National Civil Protection Unit in Mozambique; and

- The Disaster Risk Management Project (Pro-GRC) was implemented, aimed at the institutionalisation of the Local Disaster Risk Management Committees in Manica, Sofala and Inhambane Provinces, and the Institutional Disaster Risk Management Capacity Building Project in the Northern Region of the country.

\section{Mitigation}

With a view to mitigate the effects or manifestations of the various disasters:

- A total of 28 water sources were rehabilitated or constructed in the arid and semi-arid districts of Funhalouro, Mabote, Chigubo and Massangena, benefiting 1,400 families;

- A dam with a capacity of $2,000 \mathrm{~m}^{3}$ was constructed in the Changana River valley in Chigubo District for irrigation and the captation of water for the consumption of the population;

- A cistern was rehabilitated in Mabote District, benefiting 500 families;

- The construction of 40 cisterns in Chigubo and Massangena Districts and of a water tank in Saúte (Chigubo) is in progress, as well as the installation of a 
water supply system in Dindiza (Chigubo), in the scope of the reformulation of the large-capacity community cistern construction project in Chigubo District.

- Extension technicians of Mabote, Funhalouro, Chigubo and Massangena Districts were trained in rainwater captation and conservation techniques, in conservation agriculture;

- A demonstration field was established using rainwater captation and conservation techniques, together with the principles of conservation agriculture;

- A total of 15 peasants/promoters were trained in rainwater captation and conservation techniques in conservation agriculture, and in the peasant-topeasant training/extension methodology, aimed at transforming peasants into trainers and promoters in their localities;

- About $700 \mathrm{~kg}$ of seeds of various quick-growing crops were sown, benefiting 274 people, and 274 ha of cassava were planted, benefiting 150 families;

- A programme for the development of Chigubo District and adjacent areas was prepared, comprising 4 priority projects, namely arts and crafts, canhu industrialization, cattle breeding and the respective meat and hides industry (industrial arts) and the establishment of a sales shop and the maintenance of the projects at local level and supplying basic foodstuffs to the residents.

In the scope of the mitigation of the effects of the various disasters affected the country:

- A total of 265,814 victims of natural disasters received foodstuffs, tents, kitchenware, construction materials, water and sanitation in the 73 accommodation centres in Quelimane (9), Nicoadala (1), the Zambezi Valley (54), the Búzi Basin (9) (see table below).

Table 57: Emergency food aid supplied to disaster victims

\begin{tabular}{|c|c|c|c|c|c|c|c|c|c|c|}
\hline \multirow[b]{2}{*}{ Local } & \multirow[b]{2}{*}{\begin{tabular}{|c|} 
beneficiáfio \\
$\mathrm{s}$
\end{tabular}} & \multirow[b]{2}{*}{$\begin{array}{c}\text { Alimen. } \\
\text { (ton) }\end{array}$} & \multicolumn{8}{|c|}{ Bens de Socorro } \\
\hline & & & Tenda & Lonas & $\begin{array}{c}\text { Oleado } \\
(\mathrm{m})\end{array}$ & Colchöes & Mantas & $\begin{array}{c}\text { Kits } \\
\text { Cozinha }\end{array}$ & $\begin{array}{l}\text { Redes } \\
\text { Mosq }\end{array}$ & $\begin{array}{c}\text { Chapas } \\
\text { zinco }\end{array}$ \\
\hline V. fortes e inund. & 46,533 & 144 & 12 & & 12,710 & & 2,586 & 4,787 & 753 & 722 \\
\hline Ciclone Favio & 54,818 & 206 & 233 & 10,589 & 5,577 & & 4,247 & 5,735 & 6,456 & 14,050 \\
\hline Cheias no Zambeze & 163,000 & & & & & & & & & \\
\hline Expl do Paiol & 1,463 & 135 & 198 & 21 & & 26 & 203 & 37 & 83 & 296 \\
\hline Total & 265,814 & 485 & 443 & 10,610 & 18,287 & 26 & 7,036 & 10,559 & 7,292 & 15,068 \\
\hline
\end{tabular}

Source: CENOE, Provinces

- The demarcation and attribution of plots for the resettlement of 30 thousand flood-affected families in Zambezia, Tete, Manica and Sofala was concluded, according to the table below: 
Table 58: Demarcated and attributed plots, until 9 June

\begin{tabular}{|c|c|c|c|c|c|}
\hline Provincia & Talhoes Nec. & Demarcados & Atribuidos & $\begin{array}{l}\text { Nível de realiz. } \\
\text { demarc. (\%) }\end{array}$ & $\begin{array}{l}\text { Nível de real. } \\
\text { atribuições (\%) }\end{array}$ \\
\hline Sofala & 4.000 & 6.374 & 4.540] & 159,4 & 71,2 \\
\hline Zambezia & 8.200 & 10.304 & 3.894 [ & 125,7 & 37,8 \\
\hline Tete & 13.703 & 11.154 & 11.154 & $81,4]$ & 100,0 \\
\hline Manica & 1.020 & 1.351 & 1.204 & 132,5 & 89,1 \\
\hline Total & 26.923 & 29.183 & 20.792 & $\overline{108,4}$ & $\overline{71,2}$ \\
\hline
\end{tabular}

\section{Source: Provinces}

- Emergency operations management documents were prepared, namely monitoring guides, occupational activities in the resettlement centres, Phase II of the resettlement plan;

- The construction of houses and social infrastructures in the resettlement centres was monitored, as presented in the table below:

Table 59: Construction of houses by province, until 9 November

\begin{tabular}{|c|r|r|r|r|c|}
\hline \multirow{2}{*}{ Provinc } & \multicolumn{6}{|c|}{ Construção de Casas } \\
\cline { 2 - 6 } & $\begin{array}{c}\text { Plano para } \\
\mathbf{2 0 0 7}\end{array}$ & Fundacao & Alvenaria & Cobertura & \% Execucao \\
\hline TETE & 500 & 120 & 126 & 42 & $\mathbf{8}$ \\
\hline ZAMBEZIA & 305 & 356 & 198 & 37 & $\mathbf{1 2}$ \\
\hline MANICA & 300 & 67 & 21 & 14 & $\mathbf{5}$ \\
\hline SOFALA & 1,012 & 218 & 70 & 39 & $\mathbf{4}$ \\
\hline Total & $\mathbf{2 , 1 1 7}$ & $\mathbf{4 2 0}$ & $\mathbf{1 6 8}$ & $\mathbf{4 4}$ & $\mathbf{2}$ \\
\hline
\end{tabular}

- A total of 3,743 construction works were concluded, corresponding to $69 \%$ of the 5,459 houses affected by the Mahlazine Ammunition Depot explosions in Maputo City and Province, as presented in the following table: 
Table 60: Reconstruction of houses in Maputo City

\begin{tabular}{|c|c|c|c|c|c|}
\hline Neighb ourhoods & $\begin{array}{l}\text { Total no. of } \\
\text { affected } \\
\text { houses }\end{array}$ & Works in progress & $\begin{array}{c}\text { Works } \\
\text { concluded }\end{array}$ & $\begin{array}{l}\text { Total no. of } \\
\text { interventions }\end{array}$ & $\begin{array}{l}\text { Level of } \\
\text { coverage }\end{array}$ \\
\hline Malhazine & 434 & 656 & 121 & 777 & $179 \%$ \\
\hline 25 de Junho A & 28 & & 28 & 28 & $100 \%$ \\
\hline 25 de Junho B & 4 & 4 & & 4 & $100 \%$ \\
\hline Bagamoyo & 32 & 70 & 95 & 165 & $516 \%$ \\
\hline Magoanine A & 69 & 39 & 87 & 126 & $183 \%$ \\
\hline Magoanine B & 51 & 6 & 53 & 59 & $116 \%$ \\
\hline Magoanine C & 1120 & 113 & 258 & 371 & $33 \%$ \\
\hline Malanga & 6 & & 6 & 6 & $100 \%$ \\
\hline Chamanculo A & 2 & & 2 & 2 & $100 \%$ \\
\hline Polana Canico B & 3 & & 3 & 3 & $100 \%$ \\
\hline Zimpeto & 1300 & 227 & 616 & 843 & $65 \%$ \\
\hline Mahotas & 219 & 131 & 155 & 286 & $131 \%$ \\
\hline G. Dimitr ov & 744 & 400 & 227 & 627 & $84 \%$ \\
\hline Laulane & 64 & 12 & 48 & 60 & $94 \%$ \\
\hline B. Fer roviar io & 8 & & 12 & 12 & $150 \%$ \\
\hline 3 de Fever eir o & 130 & 20 & 80 & 100 & $77 \%$ \\
\hline Hulene B & 50 & 10 & 28 & 38 & $76 \%$ \\
\hline Albazine & 23 & & 37 & 37 & $161 \%$ \\
\hline Maval ane B & 6 & & 6 & 6 & $100 \%$ \\
\hline Mavalane A & 5 & & 5 & 5 & $100 \%$ \\
\hline Jardim & 1 & & & 0 & $0 \%$ \\
\hline Costa do sol & 6 & & 6 & 6 & $100 \%$ \\
\hline TOTAL & 4.305 & 1.688 & 1.873 & 3.561 & $83 \%$ \\
\hline
\end{tabular}

Table 61: Reconstruction of houses in Maputo Province

\begin{tabular}{|l|c|c|c|c|c|}
\hline Neighbourh. & $\begin{array}{c}\text { Total no. of } \\
\text { affected houses }\end{array}$ & $\begin{array}{c}\text { Works in } \\
\text { progress }\end{array}$ & $\begin{array}{c}\text { Works } \\
\text { concluded }\end{array}$ & $\begin{array}{c}\text { Total no. of } \\
\text { interventions }\end{array}$ & $\begin{array}{c}\text { Level of } \\
\text { coverage }\end{array}$ \\
\hline Zona Verde & 559 & 25 & 746 & 771 & $138 \%$ \\
\hline Kongolote & 393 & 17 & 832 & 849 & $216 \%$ \\
\hline 1. de Maio & 79 & & 143 & 143 & $181 \%$ \\
\hline Ndlavela & 55 & & 81 & 81 & $147 \%$ \\
\hline Cumbeza & 20 & & 12 & 12 & $60 \%$ \\
\hline Infulene D & 6 & & 6 & 6 & $100 \%$ \\
\hline Trevo & 1 & & 1 & 1 & $100 \%$ \\
\hline São Dâmaso & 3 & & 5 & 5 & $167 \%$ \\
\hline Intaka & 7 & & 7 & 7 & $100 \%$ \\
\hline T 3 & 31 & & 37 & 37 & $119 \%$ \\
\hline \multicolumn{1}{|c|}{ Total } & 1.154 & 42 & 1870 & 1.912 & $166 \%$ \\
\hline
\end{tabular}

In the same scope, all bereaved families received coffins, mourning clothes, foodstuffs for the exequies, vigil, the eighth day and sixth month of eternal memory;

- 70 patients were sent to the various clinics of Maputo Central Hospital, received treatment during three months and their health has now improved;

- Between July and December, 310 food parcels were distributed, benefiting 84 families;

- 123 school kits and clothing were distributed, benefiting 54 vulnerable and 69 orphaned children; 
- 111 orphaned children and 30 widows were identified, as well as families in a situation of extreme poverty, due to this incident; their respective widow's pensions have already been fixed and the procedures to be followed for having for having access have been communicated.

\section{Multisector response}

In the area of Tourism 7,127.25 thousand Meticais were disbursed, corresponding to $65 \%$ of the $10,986.50$ thousand Meticais approved for financing 36 projects, of which 25 for micro-credits and 11 for post-floods and cyclone Favio assistance.

In the area of Trade, 17,739 tons of food (17,394 tons of maize and 345 of beans) were acquired by WFP in Sofala, Tete and Nampula Provinces, in the scope of local purchases by humanitarian organisations to assist the victims of natural disasters.

- A total of 17,376 children were deparasited by the Health sector in the 4 provinces affected by floods (Zambezia, Tete, Manica and Sofala). Another 16,115 children received vitamin A supplements.

- A total of 10 machines were distributed by the Science and Technology area for the production of blocks in the resettlement centres in Zambezia (6), Sofala (3) and Manica (1) Provinces.

- A total of 62 hydroclimatic stations were rehabilitated by the Water sector, of which 24 hydrological and 38 pluviometric stations.

- Also in the Water sector, the executives projects and tender documents were concluded for the construction of 50 small dams in the arid districts of Gaza, Inhambane, Sofala and Manica Provinces, while the conditions of the foundations of the dams in Tete still have to be re-evaluated.

In the scope of dam rehabilitation and construction in the Water sector the rehabilitation of the Massingir Dam was concluded and the hydromechanical equipment of the Macarretane Dam is being replaced.

- Financing was ensured for the rehabilitation of the Nacala and Corumana Dams; and

- Contacts were started with the Banco Comercial e de Investimentos to intermediate the engagement of a financier for the construction of the Bue Maria Dam in the Púngue River.

In the scope of emergencies, the National Defence sector participated in rendering humanitarian assistance to the population affected by disasters, especially in rescue operations for flood victims in the Zambezi Valley and in the mitigation of the effects of cyclone Favio in Inhambane, Manica and Sofala Provinces;

- Participation in the transport and installation of tents in the accommodation centres, the construction of latrines, as well as in cutting and transporting firewood, to support the disaster-struck population.

In the scope of the Emergency Programme, determined for the National Defence area after the explosions of the Mahlazine Ammunition Depot, more than $95 \%$ of the projected obsolete explosive materials and equipment in the ammunition depots in 
the whole country were collected and destroyed. The remaining $5 \%$ corresponds to an accumulation of shells and other remains. In general terms, all projected materials were destroyed.

- In terms of activities, 323 tons of explosives scattered in the neighbourhoods adjacent to the Mahlazine Ammunition Depot were collected and removed.

- 1,908 ton of obsolete explosives were destroyed.

- A selection and reclassification of the ammunition until then stored in the military depots of the three regions of the country was carried out.

- A total of 20 ammunition and weapon depots were constructed in Maputo (10), Sofala (5) and Nampula (5) Provinces and active ammunition was transferred to the new depots.

Awareness-raising campaigns targeting the population and the public in general about the danger of mines and other military explosive materials were launched and are ongoing.

\section{H. DEMINING}

The Mine Action Programme In Mozambique aims at the reduction of the impact of the presence of anti-personnel mines on the communities, and to ensure strict observance of the provisions of the Ottawa Convention on the Prohibition of the Use, Storage, Production and Transfer of Anti-personnel Mines and on their destruction. The results achieved in the year 2007 were the following:

\section{Demining activities}

- Slightly over 2 million $\mathrm{m}^{2}$ were cleared and 1.4 million $\mathrm{m}^{2}$ examined;

- A total of 855 mines and 934 live explosives were removed and destroyed;

- The number of affected villages decreased from 91 at the end of 2006 to 27 at the end of 2007;

- The number of affected areas decreased from 237 to 32 , and the total area suspected to be mined decreased from 60 million $\mathrm{m}^{2}$ to 420 thousand $\mathrm{m}^{2}$;

- As a result of these activities, the mine-free areas were increased and put at the disposal of the population and economic sectors for carrying out economic and social activities, especially agricultural land and infrastructures, such as roads, bridges, railways, power transmission lines and telecommunication lines.

- Three humanitarian operators were involved in the demining operations: APOPO (Gaza), Handicap International (Inhambane, Sofala and Manica) and The Halo Trust (Nampula, Zambezia, Tete, Sofala, Manica, Inhambane, Gaza and Maputo).

- A total of 6 mine detector rats were accredited and another 17 were reaccredited and ceremonies were held to hand over 32 cleared fields, of which 2 in Tete, 3 in Sofala, 24 in Inhambane and 3 in Maputo. 


\section{Predominant impacts of mines}

- The results achieved last year show that there are still, though at a limited scale, threats of the presence of landmines in the country, with 27 affected villages, covering 46.5 thousand directly affected people in an area of 420 thousand $\mathrm{m}^{2}$.

- The significant reduction of the remaining areas is due to the cancelling of the areas that were considered remaining by the impact research done in $2000 / 2001$, as it was concluded that they don't pose any danger; the remaining areas were confirmed and included in the group of areas currently known for the presence of mines.

However, new research, the "Exhaustive Research and Base Study" done in 2007 in the Central and Southern Regions of the country, namely in Tete, Manica, Sofala, Inhambane, Gaza and Maputo Provinces, concluded:

- The existence of 484 new zones confirmed as being mined, with a total area of about 9 million $\mathrm{m}^{2}$, as presented by the following table:

Table 61: New zones confirmed as being mined (2007)

\begin{tabular}{|l|c|c|r|}
\hline \multicolumn{1}{|c|}{ Province } & Districts & Mined areas & $\begin{array}{r}\text { Estimated area in } \\
\mathbf{m}^{\mathbf{2}}\end{array}$ \\
\hline TETE & 8 & 19 & 918,589 \\
\hline MANICA & 4 & 47 & 945,406 \\
\hline SOFALA & 12 & 104 & $2,532,846$ \\
\hline INHAMBANE & 13 & 251 & $3,720,474$ \\
\hline GAZA & 3 & 13 & 275,216 \\
\hline MAPUTO & 6 & 50 & $\mathbf{8 , 9 9 4 , 7 7 9}$ \\
\hline Overall Total & $\mathbf{4 6}$ & $\mathbf{4 8 4}$ & \\
\hline
\end{tabular}

- The existence of 375 mine-suspected zones, namely:

- A total length of $688 \mathrm{~km}$ of 33 roads is suspected to be mined;

- 69 live explosives demolition tasks (EOD);

- 6 combat zones;

○ 267 mine-suspected zones, with a total area of about 16 million $\mathrm{m}^{2}$.

- The following were identified as part of the landmine problem in the country:

- The borders with South Africa, Zimbabwe, Zambia, Malawi and Swaziland;

- The Power Transmission Lines to Beira (Line I and II), the Chicamba Dam in Manica Province, the Beira-Machipanda Railway and the Limpopo Railway in Gaza Province.

In the international context the following activities should be mentioned:

- Participation of Mozambique in the Meeting of the States Parties to the Ottawa Convention in Jordan, in which progress made by the States Parties in 
the implementation of the Convention were analysed and appeals made to affected countries unable to reach the target to submit requests for extension.

- Realization in Maputo of an International Workshop on the Mine Action Programme in Mozambique, in which the experience of the country in the implementation of the Mine Action Programme was discussed, and

- Contributions were collected for the conclusion of the PNAM 2008-2012 for the formulation of a request for an extension of the 2009 term for Mozambique to conclude demining, in the scope of the Ottawa Convention.

\section{Accidents and assistance to mine victims}

- A significant decrease of the number of victims and respective obits compared to 2006;

- A total of 11 accidents with exploded landmines and other explosives were reported, against 18 occurred in 2006

- A total of 24 victims were reported, of which 14 obits and 10 wounded, against 36 victims, with 19 obits and 16 wounded in 2006.

- Mainly children were hit, with 10 victims $(42 \%)$ of the total number of victims, followed by men (33\%), while in these two groups there was the highest percentage of obits $(36 \%)$.

- The intersector coordination mechanism was strengthened and a working group was created for the dissemination of information about the mechanisms to assist mine victims and survivors in the country.

\section{Area of civic education about the danger of mines}

- A total of 140 awareness-raising talks about the danger of landmines were given, covering 36,281 people in the Districts of Matutuíne and Boane (Maputo province), Beira, Caia, Chemba, Cheringoma, Gorongosa, Marromeu and Muanza (Sofala), Gondola and Sussundenga (Manica), Mutarara (Tete), Alto Molócuè and Mocuba (Zambezia), Namialo and Nampula (Nampula).

\section{Multisector response}

In the area of National Defence a total area of 1,025,361 $\mathrm{m}^{2}$ was demined and 6,289 mines of various types were destroyed all over the country and around economic objects, namely electric power transmission lines and railways.

- In the area of Energy a total length of $229 \mathrm{~km}$ for rural electrification power lines was demined in the scope of the rural electrification project of Zambezia.

\section{PUBLIC FINANCE}

Pursuing the objectives laid down in the Economic and Social Plan and in the State Budget for 2007, the Budget Policy aimed at ensuring the financing of the priority sector activities to fight absolute poverty and achieve socio-economic development, as well as to guarantee a more rational use of public resources and medium-term budget sustainability. On the other hand, in 2007 an effort was made to improve the management of Public Finance, including the decentralization of budget execution, 
the enlargement of e-SISTAFE to all State Sectors and a few State Bodies, and the operationalisation of the functioning of the Mozambican Tax Authority with a view to the enlargement of the tax base and the increase of State revenue collection.

\section{Budget balance}

In 2007 expenditure amounted to 60,025.00 million MT, against 72,915.2 million MT planned for 2007, corresponding to a level of budget execution of $82.3 \%$, divided in 99.0\% for Current Expenditure, $64.1 \%$ for Investment Expenditure and $54.0 \%$ for Financial Transactions. Compared to 2006, this overall budget execution level was $18.1 \%$ higher in nominal terms and $15.3 \%$ higher in real terms.

Table 62: 2007 Budget Balance

BUDGET BALANCE

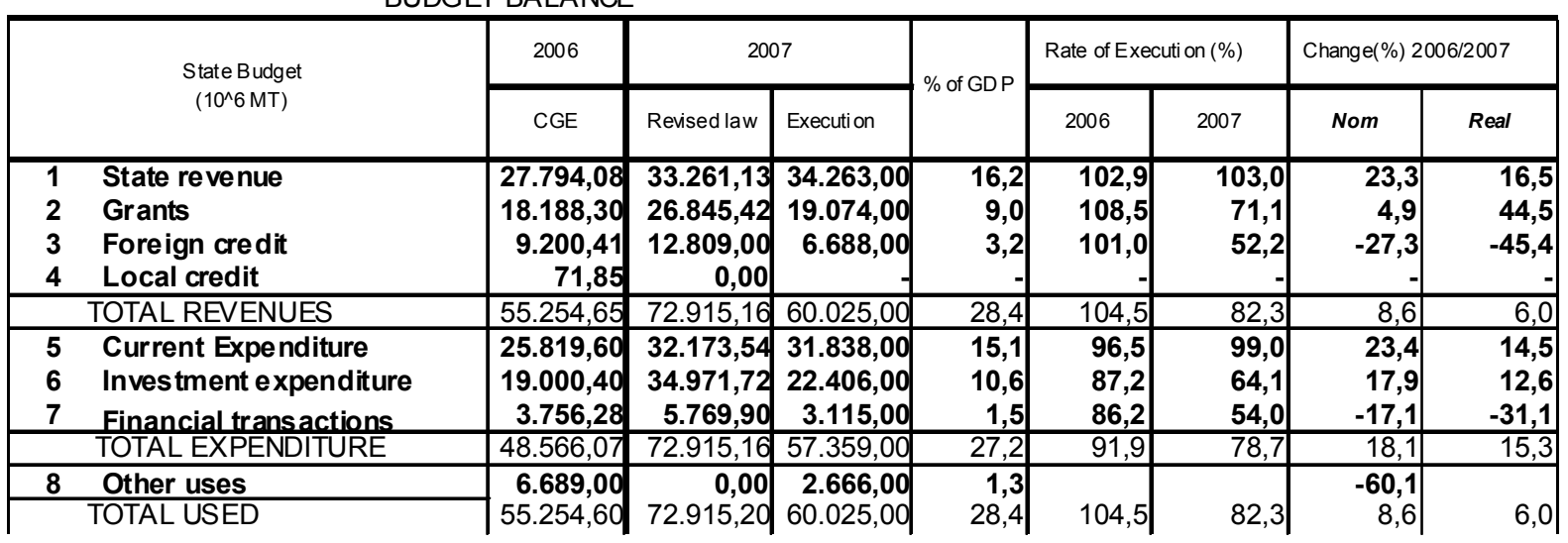

The low level of execution of the external resources component, which ended up influencing the overall level of resource execution, was basically due to the fact that:

- In the $1^{\text {st }}$ half of the year there were delays in external funds becoming available, particularly in the health sector;

- A few projects included in the 2007 State Budget, such as the ARA-SUL project for the rehabilitation of the Massingir and Macarretane Dams, with ADB financing, did not obtain disbursements during the year; and

- The financing agreements of other projects, also included for 2007 , were only signed in the middle of 2007, and their implementation was therefore postponed to 2008, namely the following projects: (i) EDU-2007-0021 Education III; and (ii) Rehabilitation of National Road no. 1, financed by the World Bank for the Milange - Mocuba, Jardim - Benfica, Xai-Xai Chissibuca, Massinga - Nhachengue sections, and financed by the European Union for the Beira - Inchope and Beira - Machipanda sections.

These situations, which dictated the low level of execution of external resources, resulted from constraints in the accomplishment of certain conditions required for the credits and disbursements to take place.

Of the total volume of resources of $72,915.2$ million MT planned for 2007, execution amounted to $60,025.0$ million MT, corresponding to a level of execution of $82.3 \%$, in which State Revenue attained $103 \%$, Grants $71.1 \%$, and External Credit $52.2 \%$, against 2006 levels of $102.9 \%, 108.5 \%$ and $101 \%$ respectively. We should emphasize the effort to increase State revenue collections, which exceeded the 
amount planned and internal indebtedness was therefore not resorted to for financing budget expenditure.

Concerning the budget balance achieved in the period in analysis, of the total volume of mobilized resources, expenditure amounted to $57,359.0$ million MT, in other words $78.7 \%$ of planned annual budget appropriation.

On the appropriations side, Current Expenditure absorbed 31,838.0 million MT, Investment Expenditure 22,406.0 million MT and Financial Transactions 3,115.0 million MT, representing $99.0 \%, 64.1 \%$ and $54.0 \%$ of planned appropriation, respectively.

\section{State revenue}

For 2007 the revised Budget Law planned the collection of State Revenue to the value of 33,261.1 million MT, distributed in 26,532.3 million MT of Tax Revenue, 2,539.9 million MT of Non-Tax Revenue, 2,328.5 million MT of Consignment Revenue and 1,860.3 million MT of Capital Revenue.

Table 63: 2007 State Revenue

\begin{tabular}{|c|c|c|c|c|c|c|c|c|}
\hline \multicolumn{9}{|c|}{ STATE REVENUE - 2007} \\
\hline \multirow{2}{*}{$\begin{array}{l}\text { STATE REVENUE } \\
\quad(10 \wedge \mathrm{MT})\end{array}$} & 2006 & \multicolumn{2}{|c|}{2007} & \multirow{2}{*}{$\%$ of GDP } & \multicolumn{2}{|c|}{$\begin{array}{c}\text { Rate of } \\
\text { Execution (\%) }\end{array}$} & \multicolumn{2}{|c|}{ Change $2006 / 2007$} \\
\hline & CGE & Rev. Law & Execution & & 2006 & 2007 & (nominal) & (real) \\
\hline STATE REVENUE & $27.794,1$ & $33.261,1$ & $34.263,0$ & 16,2 & 101,9 & 103,0 & 23,3 & 16,5 \\
\hline Tax rev enue & $22.142,1$ & $26.532,3$ & $27.764,9$ & 13,1 & 101,1 & 104,6 & 25,4 & 19,1 \\
\hline Income tax & $6.351,4$ & $7.555,4$ & $9.266,9$ & 4,4 & 109,7 & 122,7 & 45,9 & 34,9 \\
\hline Tax on goods \& services & $14.490,1$ & $17.221,9$ & $17.029,0$ & 8,1 & 99,8 & 98,9 & 17,5 & 13,5 \\
\hline Other taxes & $1.300,6$ & $1.755,0$ & $1.469,0$ & 0,7 & 81,3 & 83,7 & 12,9 & 4,7 \\
\hline Non-tax revenue & $2.670,0$ & $2.539,9$ & $2.454,2$ & 1,2 & 119,1 & 96,6 & $-8,1$ & 15,0 \\
\hline Consignment revenue & $1.767,4$ & $2.328,5$ & $2.194,2$ & 1,0 & 79,8 & 94,2 & 24,1 & 14,9 \\
\hline Capital revenu & $1.214,5$ & $1.860,3$ & $1.849,6$ & 0,9 & 142,9 & 99,4 & 52,3 & 40,8 \\
\hline
\end{tabular}

The effective execution of State Revenue amounted to 34,263.0 million MT, corresponding to an execution of $103.0 \%$. Tax Revenue contributed to this level of execution with $104.6 \%$ basically due to the conjugation of the growth of economic activities with the improvement of the efficiency of the tax machine in the collection of revenue.

A contribution was equally made to this result by the attribution of 190,006 NUITs, against 150,000 planned, representing a realization of more than $100 \%$ of taxpayers registered in the whole country, of which 186,368 were attributed to individuals and 3,651 to legal persons.

In Income Tax the planned targets were exceeded by $22.7 \%$. Indeed, the IRPC attained a level of execution of $133.9 \%$ in relation to the set target, IRPS attained $114.2 \%$ and Special Gambling Tax 102.3\%.

The collection of Tax on Goods and Services suffered a level of nonaccomplishment of $1.1 \%$ in relation to the planned target. However, in real terms compared to 2006 it increased by $13.5 \%$, partly due to the greater collection of Value-Added Tax (VAT), which increased by 1.3 percentage points (pp). 
In Other Taxes 1,469.0 million MT were collected against a target fixed at 1,755.0 million MT, representing an execution of $86.2 \%$. Even so, there was a nominal growth of $4.7 \%$ when compared to previous year's collection.

Non-Fiscal Revenue attained an execution of $96.6 \%$ against a target of $2,539.9$ million MT.

Realizations of compensation of pensions and survivors' pension and rent were poor, staying $6.6 \mathrm{pp}$. and $11.4 \mathrm{pp}$. respectively below the planned target. It should be emphasized that regarding the rent item there was a decrease of the levels of collection due to the continuous reduction of the State housing park.

The levels of collection of own revenue were significant at central level and lower at district level, as 1,110.3 million MT were collected in the period in analysis, of a plan fixed at 995.7 million MT, corresponding to a level of execution of $111.5 \%$.

A volume of 1,849.6 million MT were collected in Capital Revenue against a plan of $1,860.3$ million MT, in other words with a level of execution of $99.4 \%$, which was greatly influenced by the revenue from the mining concession contract awarded to Companhia Vale do Rio Doce.

\section{State Expenditure}

\section{Current Expenditure}

An execution of $99.0 \%$ was achieved of the respective annual appropriation of $32,174.0$ million MT, in other words an execution of $31,845.0$ million MT, representing a growth of $14.5 \%$ in real terms and $23.4 \%$ in nominal terms, compared to the same period of the previous year.

In Current Expenditure an execution of $99.0 \%$ was achieved, in other words, $31,651.0$ million MT, representing a growth of $13.7 \%$ in real terms and $23.1 \%$ in nominal terms, compared to 2006.

In Capital Expenditure the level of execution was $88.5 \%$ of the respective annual appropriation, in other words 194.0 million MT, with a growth, in real terms, of $74.0 \%$ compared to 2006.

Table 64: Operating Expenditure

\begin{tabular}{|c|c|c|c|c|c|c|c|c|}
\hline \multirow{2}{*}{$\begin{array}{l}\text { Operating } \\
\text { Expenditure } \\
\left(10^{\wedge} 6 \mathrm{MT}\right)\end{array}$} & \multirow{2}{*}{$\frac{2006}{C G E}$} & \multicolumn{2}{|c|}{2007} & \multirow[b]{2}{*}{$\%$ of GDP } & \multicolumn{2}{|c|}{ Rate of Execution (\%) } & \multicolumn{2}{|c|}{ Change 2006/2007 } \\
\hline & & Rev.Law & $\begin{array}{l}\text { Realização } \\
\text { Until 29/12/07 }\end{array}$ & & 2006 & 2007 & Nom. & Real \\
\hline Current expenditure & $25.706,3$ & $31.970,0$ & $31.651,0$ & 14,9 & 96,6 & 99,0 & 23,1 & 13,7 \\
\hline Staff expenditure & $12.983,0$ & $16.091,0$ & $16.091,0$ & 7,6 & 97,4 & 100,0 & 23,9 & 14,6 \\
\hline Goods \& Services & $5.773,7$ & $6.607,0$ & $6.568,0$ & 3,1 & 99,6 & 99,0 & 13,8 & 5,7 \\
\hline Debt servicing costs & $1.391,0$ & $1.326,0$ & $1.277,0$ & 0,6 & 88,7 & 97,0 & $-7,7$ & $-12,3$ \\
\hline Current transfers & $4.555,0$ & $5.983,0$ & $5.782,1$ & 2,7 & 96,3 & 97,0 & 26,9 & 18,9 \\
\hline Subsidies to companies & 312,5 & 378,0 & 344,6 & 0,2 & 96,0 & 91,2 & 10,5 & 2,0 \\
\hline Other current expenditure & 698,0 & $1.573,0$ & $1.573,0$ & 0,7 & 80,5 & 100,0 & 125,4 & 108,4 \\
\hline Receivables & 4,0 & 12,0 & 9,0 & 0,0 & 39,0 & 73,6 & 125,0 & 112,6 \\
\hline Capital Expenditure & 102,9 & 203,0 & 194,0 & 0,1 & 91,9 & 96,0 & 88,5 & 74,0 \\
\hline TOTAL & $25.819,6$ & $32.174,0$ & $31.845,0$ & 15,1 & 96,6 & 99,0 & 23,4 & 14,5 \\
\hline
\end{tabular}

Staff Expenditure attained an execution of $100 \%$, in other words 16,091.0 million MT, of which 14,714.0 million MT for the payment of Salaries and Remunerations and 
1,377.3 million MT for Other Staff Expenditure. This budget line increased by $23.9 \%$ in nominal terms and $14.6 \%$ in real terms, compared to 2006 .

The execution of Expenditure with Goods and Services was $99.0 \%$, i.e., 6,568.0 million MT, representing a growth in nominal terms of $13.8 \%$ compared to 2006 .

The execution of Debt Servicing Costs was 1,277.0 million MT, which represents $97.0 \%$ of the annual budget appropriation, corresponding to a decrease in real terms of $12.3 \%$ compared to 2006 , due to the decrease of external interest payments, resulting from the external debt relief of which Mozambique has benefited.

Current Transfers attained an execution of $97.0 \%$, at the value of 5,782.1 million MT, representing a growth of $12.3 \%$ in real terms, compared to 2006 . Of this amount, 1,088.0 million MT were Transfers to Public Administrations, 744.0 million MT were Transfers to Private Administrations, 4,308.0 million MT were Transfers to Families and 128.0 million MT were Transfers Abroad.

The amount of 344.6 million MT corresponded to the execution of Allowances, in other words $91.2 \%$ of the respective budget appropriation, and to a growth of $2.0 \%$ in real terms, compared to 2006 .

The execution of Other Current Expenditure was 1,573.0 million MT, i.e., $100.0 \%$ of the annual budget appropriation and representing a growth of $108.4 \%$ in real terms, compared to 2006.

In the period in analysis expenditure of Receivables amounted to 9.0 million MT, i.e., $73.6 \%$ of the respective annual budget appropriation, corresponding to growth in real terms of $112.6 \%$, compared to 2006.

\section{Investment Expenditure}

The level of execution of Investment Expenditure attained $64.1 \%$, in other words, $22,406.0$ million MT against a target of 34,971.7 million MT, representing a growth in nominal terms of $17.9 \%$ compared to 2006 .

Investment expenditure of the internal component attained 9,147.0 million MT, representing $98.9 \%$ of the annual budget appropriation and a growth in real terms of $29.3 \%$ compared to 2006 .

Table 65: Investment Expenditure

\begin{tabular}{|c|c|c|c|c|c|c|c|c|}
\hline & & INVESTMEN & EXPENDITUR & 2007 & & & & \\
\hline \multirow{2}{*}{$\begin{array}{l}\text { INVESTMENT EXPENDITURE } \\
(10 \wedge \mathrm{MT})\end{array}$} & \multirow{2}{*}{$\begin{array}{l}2006 \\
\text { CGE }\end{array}$} & \multicolumn{2}{|c|}{2007} & \multirow[b]{2}{*}{$\%$ of GDP } & \multicolumn{2}{|c|}{ Rate of Execution } & \multicolumn{2}{|c|}{ Change $2005 / 2006$} \\
\hline & & $\begin{array}{l}\text { Reylaw } \\
\text { I } \Delta \mathrm{i}\end{array}$ & Execution & & 2006 & 2007 & Nom. & Real \\
\hline Internal Component & $6.542,0$ & $2.249,0$ & $9.147,0$ & 4,3 & $100,0 \%$ & $\mathbf{9 8 , 9} \%$ & $39,8 \%$ & 29,3 \\
\hline External Component & $12.458,0$ & $25.723,0$ & $13.259,0$ & 6,3 & $76,5 \%$ & $51,5 \%$ & $6,4 \%$ & 7,2 \\
\hline Grants & $7.623,0$ & $18.563,0$ & $10.636,0$ & 5,0 & $72,4 \%$ & $57,3 \%$ & $39,5 \%$ & 40,5 \\
\hline Credits & $4.836,0$ & $7.562,4$ & $2.622,0$ & 1,2 & $85,1 \%$ & $36,6 \%$ & $-45,8 \%$ & $-45,4$ \\
\hline TOTAL & $19.000,0$ & $34.971,7$ & $22.406,0$ & 10,4 & $83,6 \%$ & $64,1 \%$ & $17,9 \%$ & 14,8 \\
\hline
\end{tabular}

As a consequence of what was mentioned above in relation to external revenue, there was also a low level of execution of investment expenditure in the external component (of only $51.5 \%$ ), which was basically due to the following reasons: 
- A few projects that were included in the 2007 State Budget, such as the ARASUL project for the rehabilitation of the Massingir and Macarretane Dams, with ADB financing, had no disbursements during the year.

- Financing agreements for other projects, also included for 2007 , were only signed in the middle of 2007 and therefore their implementation was delayed to the year 2008, namely the following projects: (i) EDU-2007-0021 Education III; and (ii) Rehabilitation of National Road no. 1, financed by the World Bank for the Milange - Mocuba, Jardim - Benfica, Xai-Xai - Chissibuca and Massinga - Nhachengue sections and with European Union financing for the Beira - Inchope and Beira - Machipanda sections.

\section{Execution of expenditure for the PARPA Priority Sectors}

As the data until now available show, and excluding Debt Charges, the resources allocated to the PARPA priority sectors represent $61.1 \%$ of total expenditure made. The Education and Health sectors together have absorbed 18,851.0 million MT, i.e., $58.3 \%$ of total expenditure made in the PARPA priority sectors.

Of the planned annual appropriation of $41,411.4$ million MT for the PARPA priority sectors, $32,337.0$ million MT, i.e., $78.1 \%$ of the planned annual appropriation, were as a matter of fact allocated, representing a growth in real terms of 9.9 percentage points compared to the execution of 2006.

Table 66: Expenditure in the PARPA Priority Sectors

\begin{tabular}{|c|c|c|c|c|c|c|c|c|}
\hline \multirow[b]{3}{*}{ Values in million $M T n$} & \multirow{3}{*}{2006} & THE PARPA P & RIORITY SE & TTORS - 2 & & & & \\
\hline & & \multicolumn{2}{|c|}{2007} & \multirow[b]{2}{*}{$\%$ of GDP } & \multicolumn{2}{|c|}{ Rate of Execution } & \multicolumn{2}{|c|}{ Change 2006/2007 } \\
\hline & & Law (Rev.) & Execution & & 2006 & 2007 & (nominal) & (real) \\
\hline Total expenditure (excl. debt charges) & $43.429,00$ & $65.819,00$ & $52.968,00$ & 25,1 & 90,5 & 80,5 & 22,0 & 16,2 \\
\hline \multirow[t]{2}{*}{ Total expenditure in the priority sectors } & $28.078,00$ & $41.411,00$ & $32.337,00$ & 15,3 & 89,9 & 78,1 & 15,2 & 9,9 \\
\hline & & & & & & & - & \\
\hline Education & $8.797,0$ & $13.635,0$ & $11.781,0$ & 5,6 & 97,1 & 86,4 & 33,9 & 26,7 \\
\hline Health & $6.048,0$ & $8.941,0$ & $7.070, d$ & 3,4 & 90,6 & 79,1 & 16,9 & 13,3 \\
\hline Infrastructures & $7.298,0$ & $10.886,0$ & $6.955,0$ & 3,3 & 83,1 & 63,9 & $-4,7$ & $-8,2$ \\
\hline Agriculture and Rural Development & $1.989,0$ & $2.746,6$ & $1.854,0$ & 0,9 & 81,3 & 67,5 & $-6,8$ & $-9,0$ \\
\hline Governance, security and judicial syst. & $3.534,0$ & $4.678,0$ & $4.171,0$ & 1,9 & 90,0 & 89,2 & 18,0 & 9,9 \\
\hline Other priority sectors & 412,0 & 524,0 & 506,0 & 0,2 & 87,5 & 96,5 & 22,8 & 13,7 \\
\hline
\end{tabular}

The provisional execution of the infrastructures and agriculture sectors decreased by $8.2 \%$ and $9.0 \%$ respectively, compared to 2006 . The remaining priority sectors increased compared to 2006, particularly the education sector with a growth in real terms of $26.7 \%$. 
Table 67: Percentage Distribution of Expenditure in the PARPA Priority Sectors

\begin{tabular}{|l|c|c|c|c|}
\hline \multicolumn{2}{|c|}{ Values in million MTn } & 2006 & 2007 & \multirow{2}{*}{ Change 2006/2007 } \\
\cline { 2 - 4 } & CGE & Revised Lan & Execution & \\
\hline \multicolumn{2}{|c|}{ As percentage of total expenditure excluding debt charges } \\
\hline Total expenditure in priority sectors & $64,7 \%$ & $62,9 \%$ & $61,1 \%$ & $-3,6 \%$ \\
Education & & & \\
Health & $20,3 \%$ & $20,7 \%$ & $22,2 \%$ & $2,0 \%$ \\
Infras tructures & $13,9 \%$ & $13,6 \%$ & $13,3 \%$ & $-0,6 \%$ \\
Agriculture and Rural De ve lopment & $16,8 \%$ & $16,5 \%$ & $13,1 \%$ & $-3,7 \%$ \\
Governance, security and judicial syst. & $4,6 \%$ & $4,2 \%$ & $3,5 \%$ & $-1,1 \%$ \\
Other priority sectors & $8,1 \%$ & $7,1 \%$ & $7,9 \%$ & $-0,3 \%$ \\
\hline
\end{tabular}

Implemented policy measures

\section{a) In the scope of the tax system}

- Assessment of the current tax system, particularly regarding the 1999 VAT and the 2003 IRPS and IRPC, resulting in the approval by the Assembly of the Republic of the Laws approving the VAT, IRPC and IRPS Codes;

- Reformulation and approval of the new Succession and Donation Tax Code, establishing moderate rates and simplifying the procedures for the determination and payment of this tax;

- Adoption of the tax dissemination strategy, with special relevance for the fiscal education and training of Tax Administration employees and taxpayers;

- Reformulation and approval of the Autarchies Finance and Property Law, introducing changes to the previous Autarchies Finance Law;

- Continuation of the registration of taxpayers with computerized support, aimed at the enlargement of the tax base. A total of 190,019 new NUITs were attributed against 150,000 NUITs planned, adding up to a total of 581,493 taxpayers, against 391,487 taxpayers registered until at the end of 2006 .

- Consolidation of the Tax Authority structures and approval of their Strategic and Management Plans and of their Information Technology Development Plan for all taxes, including customs payments, as well as the preparation and approval of the computer system project for the collection network (etributação) and start of the tax bankarization activities.

- Establishment of an inspection post in Vamize, Cabo Delgado.

- Construction of inspection posts and employees houses in: Ponta de Ouro (Maputo), Mpengo, Machipanda, Inchope and Macossa (Manica), Cassacatiza and Mucumbura (Tete), Mambucha and Solidja (Zambezia), Ibo, Palma, Quionga, Nangade (Cabo Delgado), Mandimba and Nova Madeira (Niassa), in addition to enclosures in Namaacha (Maputo), Changara and Cuchamano (Tete).

- Continuation of the harmonization of national legislation with International Conventions, particularly the Kyoto Convention on the simplification of customs procedures and the Convention on the Harmonized Merchandise Codification System. 
- Implementation of the tariff reduction from $25 \%$ to $20 \%$ in trade relations with third countries, and for SADC countries from $20 \%$ to $10 \%$, from $7.5 \%$ to $4.0 \%$ and from $5.0 \%$ to $3.0 \%$.

- Revision and approval of the Specific Consumption Tax Code (ICE).

- Continuation of the computerization of the National Tax Authority Network of Mozambique.

- Execution of a technical-economic viability study and preparation of the respective project for the establishment of the Ressano-Garcia Dry Port and signing, with South Africa, of an Agreement for the establishment of One-Stop Borders between the two Countries.

- Intensification of the execution of post-despatch audits, in the scope of the implementation of the merchandise evaluation agreement of the World Trade Organisation, to discourage customs fraud and recover revenue.

b) In the scope of Public Expenditure

- A total of 17,951 pensions were fixed, of which 3,675 are civilian and 14,276 are military pensions.

- Conclusion of the preparation of the Financial Administration and Accounting Procedures Manual.

\section{c) In the Scope of the enlargement of e-SISTAFE}

- Decentralization of the power and capacity of budget execution through eSISTAFE, implementing it in more sectors, all Ministries and a few bodies at central level and provincial.

- Implementation from September 2007 of direct expenditure payment into the creditor account, which allowed that until the end of November $200794.87 \%$ of budget execution was done through this modality.

- Design and implementation of the Multi-Currency Single Treasury Account (CUT), with a view to stimulate the integration of external funds currently executed outside the State Budget and the CUT into the budget and the Single Treasury Account, with the UTRAFE having been the pilot institution for its implementation.

- Development of the e-SISTAFE Budgeting Module (MEO). With this module, fully integrated into e-SISTAFE, the sector Administration and Finance Departments prepared the 2008 budget directly in the e-SISTAFE environment. 


\section{STRATEGIC PARPA II MATRIX}

The Strategic Matrix indicators were defined during the preparation of PARPA II (2006 - 2009), on the basis of the Government Programme (2005 - 2009), for the monitoring and evaluation of key activities for poverty reduction and the promotion of medium-term economic growth. Accordingly, the activities, indicators and targets of the Strategic Matrix for 2007 are presented here, as well as the related five-year objectives and targets. Please, note that the forty shaded indicators were selected as Performance Assessment Framework (PAF) indicators to report on the Programme Aid Partners' (PAPs) decisions regarding their commitments in the scope of Direct Support to the State Budget. It should be noted that a complete version of the Strategic Matrix, including a list of acronyms and abbreviations can be consulted at the site: http://www.mpd.gov.mz/

\begin{tabular}{|c|c|c|c|}
\hline Objective & $\begin{array}{c}\text { Results Indicator } \\
\text { [Verification Source] }\end{array}$ & $\begin{array}{l}\text { Base } \\
2005\end{array}$ & $\begin{array}{l}\text { Planning / Target } \\
2009\end{array}$ \\
\hline \multirow{3}{*}{$\begin{array}{l}\text { G.1. Reduce Poverty } \\
\text { (par. 109) }\end{array}$} & $\begin{array}{l}\text { G.1.1. Poverty incidence rate (par. 1) } \\
\text { [Poverty and Well-Being in Mozambique: } 3^{\text {rd }} \text { National Evaluation] }\end{array}$ & $\begin{array}{l}54 \% \\
(2003)\end{array}$ & $45 \%$ \\
\hline & $\begin{array}{l}\text { G.1.2. \% of under-fives with low weight by age (par. 215) } \\
\text { [Demographic and Health Inquiry] }\end{array}$ & $\begin{array}{l}24 \% \\
(2003)\end{array}$ & $18 \%$ \\
\hline & $\begin{array}{l}\text { G.1.3. Gender Development Index according to the defined targets } \\
\text { [Overall Gender Development Indicator and other reports, MPD] }\end{array}$ & $\begin{array}{l}0.3 \\
(2003)\end{array}$ & 0.4 \\
\hline \multirow{3}{*}{$\begin{array}{l}\text { G.2. Promote rapid, sustainable and comprehensive } \\
\text { economic growth } \\
\text { (par. 109) }\end{array}$} & $\begin{array}{l}\text { G.2.1. Real average annual GDP growth (Table 8) } \\
\text { [Macro Framework, MPD] }\end{array}$ & $\begin{array}{l}7.8 \% \\
(2002-2005)\end{array}$ & $\begin{array}{l}7.0 \% \\
(2006-2009)\end{array}$ \\
\hline & $\begin{array}{l}\text { G.2.2. Real average annual GDP per capita growth } \\
\text { [INE - Statistical Yearbook] }\end{array}$ & $(2002-2005)$ & $\begin{array}{l}4.0 \% \\
(2006-2009)\end{array}$ \\
\hline & $\begin{array}{l}\text { G.2.3. Inequality (GINI coefficient) } \\
\text { [IAF] }\end{array}$ & $0.42(2003)$ & 0.44 \\
\hline $\begin{array}{l}\text { G.3. Ensure strict macroeconomic management } \\
\text { (par. 488) }\end{array}$ & $\begin{array}{l}\text { G.3.1. Average annual inflation rate (Table 8) } \\
\text { [INE - Statistical Yearbook] }\end{array}$ & $\begin{array}{l}12.3 \% \\
(2002-2005)\end{array}$ & $\begin{array}{l}<10 \% \\
(2006-2009)\end{array}$ \\
\hline \multirow{3}{*}{$\begin{array}{l}\text { G.4. Improve the quality of public service to the citizens } \\
\text { (par. 282) }\end{array}$} & $\begin{array}{l}\text { G.4.1. \% of the population with easy access to a Health Unit, in other words, at } \\
\text { a distance of less than } 30 \text { minutes (8) } \\
\text { [IAF] }\end{array}$ & $36 \%$ & $45 \%$ \\
\hline & $\begin{array}{l}\text { G.4.2. Net enrolment rate at } 6 \text { years of age in the } 1 \text { st Grade - Girls } \\
\text { [MEC Statistics] }\end{array}$ & $56 \%$ & $70 \%$ \\
\hline & $\begin{array}{l}\text { G.4.3. Level of public "confidence" in the Justice administration (to be } \\
\text { ascertained through a survey, carried out by the UTRESP, on the basis of } \\
\text { citizen's feelings) }{ }^{\star *} \\
\text { [UTRESP] }\end{array}$ & $\mathrm{n} / \mathrm{d}$ & $70 \%$ \\
\hline
\end{tabular}


G.5. Check the propagation of HIV/AIDS (par. 199)

5.1. No. of new cases of HIVIAIDS per day (par. 200)

[Report on the Revision of the HIV Epidemiological Surveillance data]
500

350

Note: *The overall indicators summarize the fundamental PARPA II objectives, though it is recognised that their accomplishment depends on a joint effort between the Government,

civil society and the cooperation partners.

${ }^{* *}$ This indicator should be refined, as "confidence" is a relative concept.

\section{MACRO-ECONOMICS AND POVERTY - POVERTY ANALYSIS AND MONITORING SYSTEMS}

\begin{tabular}{|c|c|c|c|c|c|c|c|c|}
\hline Objective & $\begin{array}{c}\text { Results Indicator } \\
\text { [Verification Source] }\end{array}$ & $\begin{array}{l}\text { Base } \\
2005\end{array}$ & $\begin{array}{l}\text { Target } \\
2009\end{array}$ & $\begin{array}{l}\text { Achievements } \\
\text { (Actions) }\end{array}$ & $\begin{array}{l}\text { Respon } \\
\text {-sibility }\end{array}$ & $\begin{array}{l}\text { Product/ Execution } \\
\text { Indicator } \\
\text { [Verification Source] }\end{array}$ & $\begin{array}{l}\text { Targ } \\
\text { et } \\
2007\end{array}$ & Outcome \\
\hline \multirow{3}{*}{$\begin{array}{l}\text { 1. Make adequate, precise, } \\
\text { disaggregated and timely } \\
\text { information on the } \\
\text { implementation of the } \\
\text { PARPA available to all key } \\
\text { agents } \\
\text { (pars. } 621 \text { \& 622) }\end{array}$} & \multirow[t]{3}{*}{$\begin{array}{l}\text { 1.1. Key agents well } \\
\text { informed about the } \\
\text { implementation of the } \\
\text { PARPA } \\
\text { [RAI] }\end{array}$} & \multirow[t]{3}{*}{$\begin{array}{l}\text { PARPA I } \\
\text { RAI not } \\
\text { prepared }\end{array}$} & \multirow{3}{*}{$\begin{array}{l}\text { RAI } \\
\text { prepared } \\
\text { and } \\
\text { published } \\
\text { with an } \\
\text { assessment } \\
\text { of } \\
\text { performanc } \\
\text { e relative to } \\
\text { the PARPA } \\
\text { II indicators }\end{array}$} & $\begin{array}{l}\text { Carry out at least one Provincial Poverty } \\
\text { Observatory (OPP) in each province }\end{array}$ & MPD & $\begin{array}{l}\text { 1.a. No. of provinces } \\
\text { with executed OPPs } \\
\text { [Syntheses of the OPP } \\
\text { on the OP } \\
\text { website and at the } \\
\text { DNP] }\end{array}$ & 11 & 11 \\
\hline & & & & $\begin{array}{l}\text { Approval and implementation of the PARPA II } \\
\text { Communication Strategy }\end{array}$ & MPD & $\begin{array}{l}\text { 1.b. Action Plan was } \\
\text { prepared and } \\
\text { implemented } \\
\text { [Action Plan] }\end{array}$ & $x$ & \\
\hline & & & & $\begin{array}{l}\text { Realization of the DNEAP study programme aimed } \\
\text { at an analysis of PARPA's impact }\end{array}$ & $\begin{array}{l}\text { MPD - } \\
\text { DNEAP }\end{array}$ & $\begin{array}{l}\text { 1.c. Studies assessing } \\
\text { the impact of PARPA } \\
\text { activities on the } \\
\text { reduction of poverty } \\
\text { done and disseminated } \\
\text { [Study programme and } \\
\text { related documents } \\
\text { published] }\end{array}$ & $x$ & $x$ \\
\hline \multirow{2}{*}{$\begin{array}{l}\text { 2. Harmonize the short and } \\
\text { medium-term planning, } \\
\text { budgeting and monitoring } \\
\text { instruments } \\
\text { (par. 621) }\end{array}$} & \multirow{2}{*}{$\begin{array}{l}\text { 2.1. Level of harmonization } \\
\text { between the planning, } \\
\text { budgeting and monitoring } \\
\text { documents (PES, BdPES, } \\
\text { OE, REO, CGE, CFMP, } \\
\text { PARPA II) } \\
\text { [Independent Assessment } \\
\text { Study] }\end{array}$} & \multirow[t]{2}{*}{$\begin{array}{l}\text { Lack of } \\
\text { harmoni } \\
\text { zation }\end{array}$} & \multirow[t]{2}{*}{$\begin{array}{l}\text { PES, } \\
\text { BdPES, } \\
\text { OE, PARPA } \\
\text { and CFMP } \\
\text { considered } \\
\text { harmonized }\end{array}$} & $\begin{array}{l}\text { Strategic Matrix annexed to the PES and BdPES at } \\
\text { central and provincial level and consistency with } \\
\text { the text guaranteed }\end{array}$ & $\begin{array}{l}\text { MPD / } \\
\text { DPPFs }\end{array}$ & $\begin{array}{l}\text { 2.b. \% of strategic } \\
\text { indicators integrated } \\
\text { into the PES and } \\
\text { reported on in the } \\
\text { BdPES } \\
\text { [PES and BdPES] }\end{array}$ & $100 \%$ & \\
\hline & & & & $\begin{array}{l}\text { Preparation of Government staff at all levels so as } \\
\text { to facilitate the production of the PES/OE and the } \\
\text { BdPES, consistent with the guidebook (i.e. unified } \\
\text { directions and methodology disseminated) }\end{array}$ & MPD & $\begin{array}{l}\text { 2.c. PES/OE and } \\
\text { BdPES (central) } \\
\text { produced according to } \\
\text { the guide } \\
\text { [National PES/OE] }\end{array}$ & $x$ & $x$ \\
\hline
\end{tabular}

MACRO-ECONOMY AND POVERTY - PUBLIC FINANCE MANAGEMENT

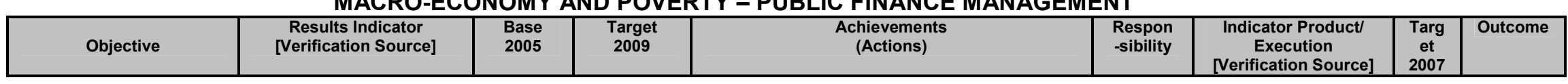


MACRO-ECONOMY AND POVERTY - PUBLIC FINANCE MANAGEMENT

\begin{tabular}{|c|c|c|c|c|c|c|c|c|}
\hline Objective & $\begin{array}{c}\text { Results Indicator } \\
\text { [Verification Source] }\end{array}$ & $\begin{array}{l}\text { Base } \\
2005\end{array}$ & $\begin{array}{c}\text { Target } \\
2009\end{array}$ & $\begin{array}{l}\text { Achievements } \\
\text { (Actions) }\end{array}$ & $\begin{array}{l}\text { Respon } \\
\text {-sibility }\end{array}$ & $\begin{array}{c}\text { Indicator Product/ } \\
\text { Execution } \\
\text { [Verification Source] }\end{array}$ & $\begin{array}{c}\text { Targ } \\
\text { et } \\
2007\end{array}$ & Outcome \\
\hline \multirow[t]{5}{*}{$\begin{array}{l}\text { 3. Improve the efficiency } \\
\text { and effectiveness of public } \\
\text { funds management } \\
\text { (pars. 289 \& 494) }\end{array}$} & \multirow[t]{5}{*}{$\begin{array}{l}\text { 3.1. Aggregate expenditure as } \\
\text { a } \% \text { of the approved State } \\
\text { Budget }(\mathrm{OE})\end{array}$} & \multirow[t]{5}{*}{$90 \%$} & \multirow{5}{*}{$\begin{array}{l}\geq 95 \% \text { and } \\
\leq 105 \% \\
\text { (The same } \\
\text { targets for } \\
2007 \text { and } \\
2998 \text { ) }\end{array}$} & \multirow[t]{2}{*}{$\begin{array}{l}\text { Allocation of public resources according to the } \\
\text { PARPA-Il objectives, taking the allocation for } \\
\text { priority sectors as indicated in the PARPA as } \\
\text { reference (Table 17) }\end{array}$} & \multirow{2}{*}{$\begin{array}{l}\text { MF - } \\
\text { DNO / } \\
\text { MPD - } \\
\text { DNP }\end{array}$} & $\begin{array}{l}\text { 3.a. Budget allocation } \\
\text { in the MTFF in line with } \\
\text { PARPA II } \\
\text { [MTFF and PARPA II] }\end{array}$ & $x$ & $x$ \\
\hline & & & & & & $\begin{array}{l}\text { 3.b. Allocation of the OE } \\
\text { in line with the MTFF } \\
\text { [MTFF and OE] }\end{array}$ & $x$ & $x$ \\
\hline & & & & \multirow[t]{2}{*}{$\begin{array}{l}\text { Improvement of Budget and Cash flow } \\
\text { Management }\end{array}$} & \multirow[t]{2}{*}{$\begin{array}{l}\text { MF - } \\
\text { DNO / } \\
\text { DNCP / } \\
\text { DNT }\end{array}$} & $\begin{array}{l}\text { 3.c. Current } \\
\text { expenditure budget } \\
\text { execution rate in the } \\
\text { Education and Health } \\
\text { sectors } \geq \text { overall } \\
\text { execution rate } \\
\text { [REO] }\end{array}$ & $x$ & $\begin{array}{l}\text { The } \\
\text { Education } \\
\text { and } \\
\text { Health } \\
\text { sectors } \\
\text { absorbed } \\
58.6 \% \text { of } \\
\text { total } \\
\text { expenditur } \\
\text { e in in } \\
\text { PARPA's } \\
\text { priority } \\
\text { sectors }\end{array}$ \\
\hline & & & & & & $\begin{array}{l}\text { 3.d. Current } \\
\text { expenditure budget } \\
\text { execution rates at } \\
\text { provincial and district } \\
\text { level in year } n>\text { rates } \\
\text { in year } n-1 \\
\text { [REO] }\end{array}$ & $x$ & \\
\hline & & & & $\begin{array}{l}\text { Increase in the budgeting orientated by the objectives of } \\
\text { the Government }\end{array}$ & $\begin{array}{l}\text { MPD / } \\
\text { MF }\end{array}$ & $\begin{array}{l}\text { 3.e. Start of } \\
\text { programme budgeting } \\
\text { (OP) for inclusion in the } \\
\text { OE 2009 } \\
\text { [MPD and MF] }\end{array}$ & $\begin{array}{l}\text { OE } \\
2008 \\
\text { with } \\
\text { a few } \\
\text { OP } \\
\text { pilots }\end{array}$ & $\begin{array}{c}\text { Programm } \\
\text { e } \\
\text { budgeting } \\
\text { was } \\
\text { started in } \\
2008 \text { for } \\
\text { the } \\
\text { Agricultur } \\
\text { e, Public } \\
\text { Works } \\
\text { and } \\
\text { Education } \\
\text { sectors }\end{array}$ \\
\hline
\end{tabular}


MACRO-ECONOMY AND POVERTY - PUBLIC FINANCE MANAGEMENT

\begin{tabular}{|c|c|c|c|c|c|c|c|c|}
\hline Objective & $\begin{array}{c}\text { Results Indicator } \\
\text { [Verification Source] }\end{array}$ & $\begin{array}{l}\text { Base } \\
2005\end{array}$ & $\begin{array}{c}\text { Target } \\
2009\end{array}$ & $\begin{array}{l}\text { Achievements } \\
\text { (Actions) }\end{array}$ & $\begin{array}{l}\text { Respon } \\
\text {-sibility }\end{array}$ & $\begin{array}{c}\text { Indicator Product/ } \\
\text { Execution } \\
\text { [Verification Source] } \\
\end{array}$ & $\begin{array}{c}\text { Targ } \\
\text { et } \\
2007 \\
\end{array}$ & Outcome \\
\hline & & & & & & $\begin{array}{l}\text { 3.f. Research on the } \\
\text { Localization of Public } \\
\text { Expenditure ("PETS") } \\
\text { executed on a bi-annual } \\
\text { basis } \\
\text { [MF and MPD] }\end{array}$ & $\begin{array}{c}\text { Initiat } \\
\text { ed } \\
\text { and } \\
\text { effect } \\
\text { ively } \\
\text { carrie } \\
\text { d out } \\
\text { at } \\
\text { MEC } \\
\text { (Educ } \\
\text { ation) } \\
\text { level }\end{array}$ & \\
\hline & & & & Direct execution of the budget through the e-SISTAFE. & $\begin{array}{c}\text { MF/ } \\
\text { Ministries }\end{array}$ & $\begin{array}{l}\text { 3.g. Number of } \\
\text { Ministries, State organs } \\
\text { and UGEs } \\
\text { [MF] }\end{array}$ & $\begin{array}{c}25 \\
\text { Minis } \\
\text { tries, } \\
\text { organ } \\
\mathrm{s} \text { and } \\
\text { at } \\
\text { least } \\
291 \\
\text { UGE } \\
\end{array}$ & $\begin{array}{l}\text { All } \\
\text { Ministries } \\
\text { and a few } \\
\text { organs at } \\
\text { central } \\
\text { and } \\
\text { provincial } \\
\text { level }\end{array}$ \\
\hline & & & & $\begin{array}{l}\text { Development, connection to e-SISTAFE and } \\
\text { implementation of the modules to support an } \\
\text { efficient budget execution }\end{array}$ & UTRAFE & $\begin{array}{l}\text { 3.h. Modules } \\
\text { developed and } \\
\text { implemented } \\
\text { [SISTAFE ABP06-09, } \\
\text { annual review e- } \\
\text { SISTAFE CF and Joint } \\
\text { Review] }\end{array}$ & $\begin{array}{l}\text { CUF } \\
\text { (Payr } \\
\text { oll), } \\
\text { Reve } \\
\text { nue }\end{array}$ & \\
\hline \multirow{2}{*}{$\begin{array}{l}\text { 4. Increase the } \\
\text { comprehensiveness of the } \\
\text { State Budget } \\
\text { (pars. } 133 \& 179 \text { ) }\end{array}$} & $\begin{array}{l}\text { 4.1. \% of own and } \\
\text { consigned revenue in the } \\
\text { OE, of total initial revenue } \\
\text { [OE, REO and CGE] }\end{array}$ & $\mathrm{N} / \mathrm{d}$ & & Inclusion of own and consigned revenue in the $\mathrm{OE}$ & $\begin{array}{l}\text { MF - } \\
\text { ATM } \\
(\mathrm{DGI})\end{array}$ & $\begin{array}{l}\text { 4.a. Revenue collection } \\
\text { value of the current } \\
\text { year higher than in the } \\
\text { previous year } \\
{[\mathrm{OE}]}\end{array}$ & $\mathrm{x}$ & $\mathrm{x}$ \\
\hline & $\begin{array}{l}\text { 4.2. \% of external resources } \\
\text { executed by the CUT } \\
\text { [PAPs' PAF Technical Note] }\end{array}$ & $\mathrm{N} / \mathrm{d}$ & $\begin{array}{l}60 \% \\
(2007: 45 \% \text {; } \\
2008: 55 \%)\end{array}$ & $\begin{array}{l}\text { Inclusion of the large majority of external funds in } \\
\text { the OE. }\end{array}$ & $\begin{array}{l}\text { MF - } \\
\text { DNCPI } \\
\text { DNO }\end{array}$ & $\begin{array}{l}\text { 4.b. \% of external funds } \\
\text { included in the OE } \\
\text { [OE and PAPs' PAF } \\
\text { Matrix] }\end{array}$ & $82 \%$ & \\
\hline $\begin{array}{l}\text { 5. Progressively increase } \\
\text { internal income and } \\
\text { broaden the tax base } \\
\text { (pars. } 487,489 \& 609 \text { ) }\end{array}$ & $\begin{array}{l}\text { 5.1. Total revenue in \% of } \\
\text { GDP } \\
\text { [OE] }\end{array}$ & $14.0 \%$ & $\begin{array}{l}16.2 \% \\
(2007: \\
15.3 \% \\
2008: \\
15.8 \%) \\
\end{array}$ & $\begin{array}{l}\text { Rationalization of the concession and improvement } \\
\text { of tax benefit management }\end{array}$ & $\begin{array}{l}\text { MF - } \\
\text { ATM / } \\
\text { MPD }\end{array}$ & $\begin{array}{l}\text { 5.a. Data used for the } \\
\text { improvement of the } \\
\text { management of } \\
\text { granted benefits } \\
\text { [MF - ATM and MPD] }\end{array}$ & $\begin{array}{l}\text { Stati } \\
\text { stics } \\
\text { publi } \\
\text { shed }\end{array}$ & \\
\hline
\end{tabular}


MACRO-ECONOMY AND POVERTY - PUBLIC FINANCE MANAGEMENT

\begin{tabular}{|c|c|c|c|c|c|c|c|c|}
\hline Objective & $\begin{array}{c}\text { Results Indicator } \\
\text { [Verification Source] }\end{array}$ & $\begin{array}{l}\text { Base } \\
2005\end{array}$ & $\begin{array}{c}\text { Target } \\
2009\end{array}$ & $\begin{array}{l}\text { Achievements } \\
\text { (Actions) }\end{array}$ & $\begin{array}{l}\text { Respon } \\
\text {-sibility }\end{array}$ & $\begin{array}{c}\text { Indicator Product/ } \\
\text { Execution } \\
\text { [Verification Source] }\end{array}$ & $\begin{array}{c}\text { Targ } \\
\text { et } \\
2007\end{array}$ & Outcome \\
\hline & & & & $\begin{array}{l}\text { Integration of the information systems } \\
\text { management into the ATM in the context of the } \\
\text { approved PDTI }\end{array}$ & $\begin{array}{l}\text { MF - } \\
\text { ATM }\end{array}$ & $\begin{array}{l}\text { 5.b. Integrated } \\
\text { information systems } \\
\text { management system in } \\
\text { the ATM in the context } \\
\text { of the approved PDTI } \\
\text { [ATM] }\end{array}$ & $\begin{array}{c}\text { Deve } \\
\text { lopm } \\
\text { ent } \\
\text { of } \\
\text { the } \\
\text { nucle } \\
\text { us of } \\
\text { the } \\
\text { ATM } \\
\text { integ } \\
\text { rated } \\
\text { syste } \\
\mathrm{m}, \\
\text { inclu } \\
\text { ding } \\
\text { the } \\
\text { integ } \\
\text { ratio } \\
\mathrm{n} \text { of } \\
\text { the } \\
\text { IT } \\
\text { infra } \\
\text { struc } \\
\text { ture }\end{array}$ & $\begin{array}{l}\text { The PDTI } \\
\text { was } \\
\text { approved } \\
\text { for all } \\
\text { taxes, } \\
\text { including } \\
\text { customs } \\
\text { duties, } \\
\text { preparatio } \\
n \text { and } \\
\text { approval } \\
\text { of the } \\
\text { collection } \\
\text { network } \\
\text { project } \\
\text { document } \\
\text { (e- } \\
\text { tributação } \\
\text { ) and start } \\
\text { of } \\
\text { activities } \\
\text { for the } \\
\text { bankarizat } \\
\text { ion of } \\
\text { taxes }\end{array}$ \\
\hline & & & & Increase of audits & $\begin{array}{l}\text { MF - } \\
\text { ATM }\end{array}$ & $\begin{array}{l}\text { 5.c. The no. of audits } \\
\text { was increased and the } \\
\text { quality improved } \\
\text { (annual recovered } \\
\text { revenue of } 0.2 \% \text { of } \\
\text { GDP) } \\
\text { [ATM] }\end{array}$ & & $\begin{array}{l}\text { Post- } \\
\text { clearing } \\
\text { audits } \\
\text { activities } \\
\text { increased }\end{array}$ \\
\hline $\begin{array}{l}\text { 6. Make the State goods } \\
\text { and services acquisition } \\
\text { system transparent and } \\
\text { efficient } \\
\text { (par. 494) }\end{array}$ & $\begin{array}{l}\text { 6.1. \% of procurement cost } \\
\text { reduction } \\
\text { [Impact assessment] }\end{array}$ & $\mathrm{N} / \mathrm{d}$ & & $\begin{array}{l}\text { Implementation and operation of the Procurement } \\
\text { System up to the district level }\end{array}$ & $\begin{array}{l}\text { MF - } \\
\text { DNPE }\end{array}$ & $\begin{array}{l}\text { 6.b. Procurement } \\
\text { System operational } \\
\text { [MF - DNPE] }\end{array}$ & $\mathrm{x}$ & \\
\hline \multirow{2}{*}{$\begin{array}{l}\text { 7. Increase the coverage } \\
\text { and efficiency of the } \\
\text { internal and external } \\
\text { auditing organs } \\
\text { (pars. } 290 \& 494 \text { ) }\end{array}$} & $\begin{array}{l}7.1 \% \text { of public expenditure } \\
\text { audited by the SCl. } \\
\text { [SCI Annual Activities } \\
\text { Report] }\end{array}$ & $\mathrm{N} / \mathrm{d}$ & & $\begin{array}{l}\text { Increase the number of organs with an operational } \\
\text { internal controls unit at central and provincial levels }\end{array}$ & IGF & $\begin{array}{l}\text { 7.a. \% of organs at } \\
\text { central and provincial } \\
\text { levels with operational } \\
\text { internal control units } \\
\text { [Annual activities report } \\
\text { on the internal } \\
\text { control sub-system, } \mathrm{SCI} \text { ] }\end{array}$ & 30 & \\
\hline & $\begin{array}{l}7.2 \% \text { of public expenditure } \\
\text { audited by the TA } \\
\text { [Annual Activities Report] }\end{array}$ & $N / d$ & & Increase the number of financial audits & TA & $\begin{array}{l}\text { 7.b. Number of financial } \\
\text { audits approved by the } \\
\text { TA [Annual activities } \\
\text { report] }\end{array}$ & 90 & \\
\hline
\end{tabular}


PILLAR I - GOVERNANCE - PUBLIC SECTOR REFORM

\begin{tabular}{|c|c|c|c|c|c|c|c|c|}
\hline Objective & \begin{tabular}{|c|}
$\begin{array}{c}\text { Results Indicator } \\
\text { [Verification } \\
\text { Source] }\end{array}$ \\
\end{tabular} & $\begin{array}{l}\text { Base } \\
2005\end{array}$ & $\begin{array}{l}\text { Target } \\
2009\end{array}$ & $\begin{array}{l}\text { Achievements } \\
\text { (Actions) }\end{array}$ & $\begin{array}{l}\text { Responsibi } \\
\text { lity }\end{array}$ & $\begin{array}{c}\text { Indicator Product/ Execution } \\
\text { [Verification Source] }\end{array}$ & $\begin{array}{l}\text { Target } \\
2007\end{array}$ & Outcome \\
\hline $\begin{array}{l}\text { 8. Restructure and } \\
\text { decentralize Government } \\
\text { structures to promote the } \\
\text { efficiency and } \\
\text { effectiveness of public } \\
\text { service } \\
\text { (par. 283) }\end{array}$ & $\begin{array}{l}8.1 \% \text { of the budget } \\
\text { managed by the } \\
\text { provinces, districts } \\
\text { and municipalities } \\
\text { [UTRESP] }\end{array}$ & $\mathrm{N} / \mathrm{d}$ & & $\begin{array}{l}\text { Conclusion of the realization of } \\
\text { the functional analysis and } \\
\text { preparation of restructuring plans } \\
\text { for all ministries and provincial } \\
\text { and district governments }\end{array}$ & $\begin{array}{l}\text { CIRESP - } \\
\text { UTRESP / } \\
\text { ANFP / } \\
\text { Public } \\
\text { Institutions }\end{array}$ & $\begin{array}{l}\text { 8.a. No. of ministries with restructuring plans } \\
\text { being implemented } \\
\text { [Ministries] }\end{array}$ & $\begin{array}{c}7 \\
\text { Ministri } \\
\text { es: } \\
\text { MIC, } \\
\text { MINAG } \\
\text { MISAU, } \\
M E C, \\
M A E, \\
M F, \\
M P D \\
\end{array}$ & \\
\hline \multirow{5}{*}{$\begin{array}{l}\text { 9. Strengthen the } \\
\text { institutional capacity of the } \\
\text { local governments } \\
\text { (par. 284) }\end{array}$} & $\begin{array}{l}9.1 \% \text { of budget } \\
\text { execution in the } \\
\text { districts and } \\
\text { municipalities } \\
\text { [MPD-MAE] }\end{array}$ & $\mathrm{N} / \mathrm{d}$ & & $\begin{array}{l}\text { Implementation of the national } \\
\text { decentralized planning and finance } \\
\text { strategies }\end{array}$ & $\begin{array}{l}\mathrm{MPD} / \mathrm{MF} / \\
\quad \mathrm{MAE}\end{array}$ & $\begin{array}{l}\text { 9.a. \% of the budget transferred to: } \\
\text { - the provinces, } \\
\text { - the districts } \\
\text { - municipalities* } \\
\text { [OE] }\end{array}$ & $\begin{array}{l}37.70 \% \\
3.36 \% \\
0.84 \%\end{array}$ & \\
\hline & \multirow[t]{4}{*}{$\begin{array}{l}9.2 \% \text { of medium } \\
\text { and higher level } \\
\text { technicians at } \\
\text { district and } \\
\text { municipality level } \\
\text { [MAE-MPD] }\end{array}$} & \multirow[t]{4}{*}{$\mathrm{N} / \mathrm{d}$} & & & MPD / MAE & $\begin{array}{l}\text { 9.b. \% of districts with Strategic District } \\
\text { Development Plans (PEDD) and Economic } \\
\text { and Social Plans (PES) and District Budgets } \\
\text { (PESOD) } \\
\text { [Districts] }\end{array}$ & $70 \%$ & \\
\hline & & & & & MAE & $\begin{array}{l}\text { 9.c. \% of operational District Consultative } \\
\text { Councils (at least } 3 \text { meetings per year) with } \\
\text { accountability to the Government } \\
\text { [MAE] }\end{array}$ & $60 \%$ & \\
\hline & & & & & MPD / MAE & $\begin{array}{l}\text { 9.d. \% of operational District Consultative } \\
\text { Councils (at least } 2 \text { meetings per year) } \\
\text { with accountability to the Government } \\
\text { [MPD/MAE] }\end{array}$ & $100 \%$ & \\
\hline & & & & $\begin{array}{l}\text { Development of municipal } \\
\text { capacity to collect revenue }\end{array}$ & MAE & $\begin{array}{l}\text { 9.e. \% of own revenue (in relation to the } \\
\text { annual budget) by category of the } 33 \\
\text { municipalities: } \\
\text { - Vilas } \\
\text { - Other towns } \\
\text { - Capitals } \\
\text { [Municipalities] }\end{array}$ & $\begin{array}{l}30 \% \\
40 \% \\
45 \%\end{array}$ & \\
\hline $\begin{array}{c}\text { 10. Reformulate the } \\
\text { service provision } \\
\text { processes to make them } \\
\text { simpler, more accessible } \\
\text { and satisfying the client's } \\
\text { needs } \\
\text { (par. 285) }\end{array}$ & $\begin{array}{l}\text { 10.1. Level of } \\
\text { citizens' } \\
\text { satisfaction with } \\
\text { key public services } \\
\text { [Annual inquiry } \\
\text { implemented by } \\
\text { civil society] } \\
\end{array}$ & $\mathrm{N} / \mathrm{d}$ & & $\begin{array}{l}\text { Connection of all public } \\
\text { institutions until district level to } \\
\text { the electronic network of the } \\
\text { Government }\end{array}$ & $\begin{array}{l}\text { MAE / MFP } \\
\text { / MCT }\end{array}$ & $\begin{array}{l}\text { 10.a. Provinces and districts connected to } \\
\text { the Government network }{ }^{*} \\
\text { [MAE] }\end{array}$ & $\mathrm{X}$ & \\
\hline
\end{tabular}


PILLAR I - GOVERNANCE - PUBLIC SECTOR REFORM

\begin{tabular}{|c|c|c|c|c|c|c|c|c|}
\hline Objective & $\begin{array}{c}\text { Results Indicator } \\
\text { [Verification } \\
\text { Source] }\end{array}$ & $\begin{array}{l}\text { Base } \\
2005\end{array}$ & $\begin{array}{c}\text { Target } \\
2009\end{array}$ & $\begin{array}{l}\text { Achievements } \\
\text { (Actions) }\end{array}$ & $\begin{array}{l}\text { Responsibi } \\
\text { lity }\end{array}$ & $\begin{array}{l}\text { Indicator Product/ Execution } \\
\text { [Verification Source] }\end{array}$ & $\begin{array}{c}\text { Target } \\
2007\end{array}$ & Outcome \\
\hline \multirow{3}{*}{$\begin{array}{l}\text { 11. Improve human } \\
\text { resource management } \\
\text { systems } \\
\text { (par. 288) }\end{array}$} & \multirow[t]{3}{*}{$\begin{array}{l}11.1 . \% \text { of senior } \\
\text { employees } \\
\text { (category }>7 \text { ) with } \\
\text { required } \\
\text { educational level of } \\
\text { for the position } \\
\text { [ANFP] }\end{array}$} & \multirow[t]{3}{*}{$\mathrm{N} / \mathrm{d}$} & \multirow[t]{3}{*}{+} & $\begin{array}{l}\text { Expansion of SIFAP coverage in } \\
\text { the scope of public servant } \\
\text { training. }\end{array}$ & MFP & $\begin{array}{l}\text { 11.a. No. of basic, medium and higher level } \\
\text { graduates per year, broken down by sex } \\
\text { [MFP] }\end{array}$ & $\begin{array}{c}\text { Basic } \\
\text { level: } \\
180 \\
\text { mediu } \\
\text { m: } \\
1197 \\
\text { higher: } \\
352\end{array}$ & $\begin{array}{l}\text { Medium-level: } 719 \quad(409 \\
\text { women and } 310 \text { men }) \\
\text { Higher: } 46\end{array}$ \\
\hline & & & & $\begin{array}{l}\text { Development and implementation of } \\
\text { the unified Personnel Information } \\
\text { System (ANFP, MF and TA) }\end{array}$ & MFP & $\begin{array}{l}\text { 11.b. Published Statistics Yearbook on public } \\
\text { servants } \\
\text { [BdPES, annual and half-yearly reports of } \\
\text { MFP, Ministries and provinces] }\end{array}$ & $\begin{array}{l}\text { Census } \\
\text { and } \\
\text { CUF }\end{array}$ & Census \\
\hline & & & & $\begin{array}{l}\text { Approval and implementation of } \\
\text { the salary and incentive policy in } \\
\text { all public institutions }\end{array}$ & MFP / CM & $\begin{array}{l}\text { 11.e. \% of employees integrated into the } \\
\text { new salary policy } \\
\text { [MFP/CM] }\end{array}$ & $25 \%$ & \\
\hline \multirow[b]{2}{*}{$\begin{array}{l}\text { 12. Strengthen the public } \\
\text { policies management } \\
\text { processes } \\
\text { (par. 286) }\end{array}$} & \multirow{2}{*}{$\begin{array}{l}\text { 12.1. Opportune } \\
\text { approval of crucial } \\
\text { policies and plans } \\
\text { [UTRESP - MAE] }\end{array}$} & \multirow[t]{2}{*}{$\mathrm{N} / \mathrm{d}$} & & $\begin{array}{l}\text { Approval of the Decentralization } \\
\text { Policy }\end{array}$ & $\begin{array}{l}\text { UTRESP / } \\
\text { CM / MAE }\end{array}$ & $\begin{array}{l}\text { 12.b. Decentralization Policy approved } \\
\text { [MAE / UTRESP] }\end{array}$ & $x$ & \\
\hline & & & & $\begin{array}{l}\text { Increase in the number of } \\
\text { municipalities }\end{array}$ & MAE & $\begin{array}{l}\text { 12.c. Proposal for the increase in the number of } \\
\text { municipalities filed with the AR } \\
\text { [MAE] }\end{array}$ & $\begin{array}{c}\text { Legislati } \\
\text { on on } \\
\text { the } \\
\text { criteria } \\
\text { approve } \\
\mathrm{d} \text { by the } \\
\mathrm{CM} \text { and } \\
\text { filed } \\
\text { with the } \\
\mathrm{AR}\end{array}$ & $\begin{array}{l}\text { The conditions of a few } \\
\text { district and administrative } \\
\text { post capitals were studied } \\
\text { and assessed }\end{array}$ \\
\hline
\end{tabular}

Note: * Does not include financial operations when calculating the targets.

** Relevant and broken down targets can be found in the Cross-Cutting Issues section, under science and technology.

PILLAR I - GOVERNANCE - LEGAL REFORM, LEGALITY AND PUBLIC ORDER

\begin{tabular}{|c|c|c|c|c|c|c|c|c|}
\hline Objective & $\begin{array}{c}\text { Results Indicator } \\
\text { [Verification } \\
\text { Source] }\end{array}$ & $\begin{array}{l}\text { Base } \\
2005\end{array}$ & $\begin{array}{c}\text { Target } \\
2009\end{array}$ & $\begin{array}{l}\text { Achievements } \\
\text { (Actions) }\end{array}$ & $\begin{array}{l}\text { Respon } \\
\text {-sibility }\end{array}$ & $\begin{array}{c}\text { Indicator Product/ Execution } \\
\text { [Verification Source] }\end{array}$ & $\begin{array}{l}\text { Target } \\
2007\end{array}$ & Outcome \\
\hline \multirow[t]{2}{*}{$\begin{array}{l}\text { 13. Improve access to } \\
\text { justice } \\
\text { (par. 292) }\end{array}$} & \multirow{2}{*}{$\begin{array}{l}\text { 13.1. \% of cases } \\
\text { attended by the } \\
\text { legal and judicial } \\
\text { assistance service } \\
\text { according to the } \\
\text { number of } \\
\text { available } \\
\text { legal assistants } \\
\text { [MINJ] }\end{array}$} & \multirow[t]{2}{*}{$\mathrm{N} / \mathrm{d}$} & & \multirow[t]{2}{*}{$\begin{array}{l}\text { Reform of the judicial } \\
\text { sponsorship and } \\
\text { assistance system }\end{array}$} & MINJ & $\begin{array}{l}\text { 13.b. Cumulative number of new legal } \\
\text { assistants trained } \\
\text { [MINJ] }\end{array}$ & 174 & $\begin{array}{l}26 \text { Justice Officials and } \\
\text { Assistant Officials for the } \\
\text { commercial sections of } \\
\begin{array}{l}\text { Nampula and Sofala } \\
\text { Provinces } \\
\text { cumulative) }\end{array} \\
\end{array}$ \\
\hline & & & & & MINJ & $\begin{array}{l}\text { 13.c. Cumulative number of IPAJ district } \\
\text { branches operational } \\
\text { [MINJ] }\end{array}$ & 75 & 38 (non-cumulative) \\
\hline
\end{tabular}


PILLAR I - GOVERNANCE - LEGAL REFORM, LEGALITY AND PUBLIC ORDER

\begin{tabular}{|c|c|c|c|c|c|c|c|c|}
\hline Objective & $\begin{array}{l}\text { Results Indicator } \\
\text { [Verification } \\
\text { Source] }\end{array}$ & $\begin{array}{l}\text { Base } \\
2005\end{array}$ & $\begin{array}{l}\text { Target } \\
2009\end{array}$ & $\begin{array}{l}\text { Achievements } \\
\text { (Actions) }\end{array}$ & $\begin{array}{l}\text { Respon } \\
\text {-sibility }\end{array}$ & $\begin{array}{l}\text { Indicator Product/ Execution } \\
\text { [Verification Source] }\end{array}$ & $\begin{array}{l}\text { Target } \\
2007\end{array}$ & Outcome \\
\hline & & & & $\begin{array}{l}\text { Improvement of the } \\
\text { functioning of } \\
\text { community courts }\end{array}$ & MINJ & $\begin{array}{l}\text { 13.e. Cumulative number of community } \\
\text { court chief-judges trained } \\
\text { [MINJ] }\end{array}$ & 812 & \\
\hline & & & & & MINJ / TS & $\begin{array}{l}\text { 13.f. Cumulative number of new } \\
\text { community courts to be opened } \\
\text { [MINJ] }\end{array}$ & 1587 & 1646 (non-cumulative) \\
\hline \multirow[t]{11}{*}{$\begin{array}{l}\text { 14. Increase the efficiency } \\
\text { and celerity in the provision } \\
\text { of legal services } \\
\text { (par. 294) }\end{array}$} & $\begin{array}{l}\text { 14.1. Quantity and } \\
\text { quality of the } \\
\text { statistical } \\
\text { information and } \\
\text { reports } \\
\text { [Justice } \\
\text { administration } \\
\text { institutions] }\end{array}$ & $\begin{array}{l}\text { Preparation } \\
\text { of master } \\
\text { plan }\end{array}$ & $\begin{array}{l}10 \text { subsystems } \\
\text { implemented }\end{array}$ & $\begin{array}{l}\text { Increase the productivity } \\
\text { of the courts }\end{array}$ & TS & $\begin{array}{l}\text { 14.a. Number of cases tried per year } \\
\text { [TS official statistics] }\end{array}$ & $\begin{array}{c}150 \\
\text { (target } \\
\text { defined } \\
\text { according } \\
\text { to the } \\
\text { number } \\
\text { of trials } \\
\text { per judge } \\
\text { per year) }\end{array}$ & 103287 \\
\hline & \multirow{10}{*}{$\begin{array}{l}\text { 14.2. Level of } \\
\text { public "confidence" } \\
\text { in the Justice } \\
\text { administration (to } \\
\text { be ascertained } \\
\text { through } \\
\text { independent } \\
\text { inquiries*s* } \\
\text { [UTRESP] }\end{array}$} & \multirow[t]{10}{*}{$N / d$} & \multirow[t]{10}{*}{$70 \%$} & & MINJ & $\begin{array}{l}\text { 14.b. \% of prisoners in jail awaiting trial } \\
\text { [MINJ] }\end{array}$ & $35 \%$ & $39 \%$ \\
\hline & & & & \multirow{7}{*}{$\begin{array}{l}\text { Physical expansion of } \\
\text { the courts and } \\
\text { institutional capacity } \\
\text { building }\end{array}$} & \multirow{4}{*}{ TS } & $\begin{array}{l}\text { 14.d. No. of provincial courts (new } \\
\text { buildings) } \\
\text { [TS Annual Report] }\end{array}$ & 3 & \\
\hline & & & & & & $\begin{array}{l}\text { 14.e. No. of district courts (new buildings) } \\
\text { [TS Annual Report] }\end{array}$ & 9 & \\
\hline & & & & & & $\begin{array}{l}\text { 14.f. Cumulative number of appointed } \\
\text { magistrates } \\
\text { [TS Annual Report] }\end{array}$ & 220 & \\
\hline & & & & & & $\begin{array}{l}\text { 14.g. Cumulative number of justice } \\
\text { officials } \\
\text { [TS Annual Report] }\end{array}$ & 757 & \\
\hline & & & & & PGR & $\begin{array}{l}\text { 14.h. Cumulative number of justice } \\
\text { officials } \\
\text { [PGR] }\end{array}$ & 281 & \\
\hline & & & & & $\begin{array}{l}\text { TS / PGR / } \\
\text { MINJ }\end{array}$ & $\begin{array}{l}\text { 14.i. Registry computerization programme } \\
\text { and case management } \\
\text { [TS Annual Report/BdPES] }\end{array}$ & $x$ & \\
\hline & & & & & CSMJ & $\begin{array}{l}\text { 14.j. Cumulative number of appointed } \\
\text { judges } \\
\text { [TS Annual Report] }\end{array}$ & 220 & \\
\hline & & & & $\begin{array}{l}\text { Modernization of the } \\
\text { registry and notary } \\
\text { services }\end{array}$ & MINJ & $\begin{array}{l}\text { 14.k. Registry and notary services } \\
\text { computerized } \\
\text { - Commercial, civil and criminal Registry } \\
\text { - Property and vehicle Registry } \\
\text { [Sector BdPES] }\end{array}$ & $\begin{array}{l}x \\
x\end{array}$ & \\
\hline & & & & $\begin{array}{l}\text { Strengthening the } \\
\text { judicial inspection } \\
\text { service capacity }\end{array}$ & CSMJ & $\begin{array}{l}\text { 14.I. No. of inspections carried out } \\
\text { [CSMJ] }\end{array}$ & 5 & \\
\hline
\end{tabular}


PILLAR I - GOVERNANCE - LEGAL REFORM, LEGALITY AND PUBLIC ORDER

\begin{tabular}{|c|c|c|c|c|c|c|c|c|}
\hline Objective & $\begin{array}{c}\text { Results Indicator } \\
\text { [Verification } \\
\text { Source] }\end{array}$ & $\begin{array}{l}\text { Base } \\
2005\end{array}$ & $\begin{array}{c}\text { Target } \\
2009\end{array}$ & $\begin{array}{l}\text { Achievements } \\
\text { (Actions) }\end{array}$ & $\begin{array}{l}\text { Respon } \\
\text {-sibility }\end{array}$ & $\begin{array}{l}\text { Indicator Product/ Execution } \\
\text { [Verification Source] }\end{array}$ & $\begin{array}{c}\text { Target } \\
2007\end{array}$ & Outcome \\
\hline & & & & $\begin{array}{l}\text { Increase of the } \\
\text { monitoring capacity so } \\
\text { as to monitor activities, } \\
\text { budgets and results }\end{array}$ & MINJ & $\begin{array}{l}\text { 14.m. Number of monitoring subsystems } \\
\text { (software) established in Sector } \\
\text { institutions } \\
\text { [MINJ] }\end{array}$ & 3 & \\
\hline & & & & \multirow{3}{*}{$\begin{array}{l}\text { Physical expansion of } \\
\text { the Attorney's Office } \\
\text { and institutional } \\
\text { capacity building }\end{array}$} & \multirow{3}{*}{ PGR } & $\begin{array}{l}\text { 14.n. Number of provincial Attorney's } \\
\text { Offices } \\
\text { [PGR Annual Report] }\end{array}$ & 3 & \\
\hline & & & & & & $\begin{array}{l}\text { 14.o. Number of district Attorney's Offices } \\
\text { [PGR Annual Report] }\end{array}$ & 8 & \\
\hline & & & & & & $\begin{array}{l}\text { 14.p. Cumulative number of appointed } \\
\text { Attorneys } \\
\text { [PGR Annual Report] }\end{array}$ & 200 & \\
\hline \multirow{2}{*}{$\begin{array}{c}\text { 15. Reform the prison } \\
\text { system so as to guarantee } \\
\text { the prisoner a treatment } \\
\text { consistent with } \\
\text { international human rights } \\
\text { standards and principles } \\
\text { (par. 296) }\end{array}$} & \multirow{2}{*}{$\begin{array}{l}\text { 15.1. Improved } \\
\text { efficiency of the } \\
\text { prison system }\end{array}$} & \multirow[t]{2}{*}{$\mathrm{N} / \mathrm{d}$} & & $\begin{array}{l}\text { Unification of the prison } \\
\text { system }\end{array}$ & \multirow[b]{2}{*}{ MINJ } & $\begin{array}{l}\text { 15.a. Laws and regulations approved } \\
\text { [MINJ] }\end{array}$ & $x$ & \\
\hline & & & & $\begin{array}{l}\text { Improvement of the } \\
\text { prison system's } \\
\text { housing conditions }\end{array}$ & & $\begin{array}{l}\text { 15.c. Rehabilitation Plan approved, } \\
\text { budgeted and being implemented } \\
\text { [MINJ] }\end{array}$ & $x$ & \\
\hline $\begin{array}{l}\text { 16. Make legislation more } \\
\text { adequate to a proper } \\
\text { functioning of the justice } \\
\text { administration } \\
\text { (par. 293) } \\
\end{array}$ & $\begin{array}{l}\text { 16.1. To be } \\
\text { defined }\end{array}$ & $\begin{array}{l}\text { To be } \\
\text { defined }\end{array}$ & & $\begin{array}{l}\text { Increase of the } \\
\text { institutional capacity to } \\
\text { put forward bills }\end{array}$ & MINJ & $\begin{array}{l}\text { 16.c. Cumulative number of staff hired } \\
\text { [MINJ] }\end{array}$ & 30 & \\
\hline \multirow{3}{*}{$\begin{array}{l}\text { 17. Strengthen the combat } \\
\text { against corruption } \\
\text { (par. 297) }\end{array}$} & \multirow{3}{*}{$\begin{array}{l}17.1 \% \text { of citizens } \\
\text { stating to have } \\
\text { been victims of } \\
\text { corruption in the } \\
\text { justice institutions } \\
\text { (UTRESP } \\
\text { Research) }\end{array}$} & \multirow[t]{3}{*}{$\mathrm{N} / \mathrm{d}$} & & $\begin{array}{l}\text { Approval and } \\
\text { implementation of the } \\
\text { national corruption } \\
\text { combat strategy in the } \\
\text { justice sector }\end{array}$ & TS / PGR & $\begin{array}{l}\text { 17.a. National Plan for strengthening the } \\
\text { capacity and integrity of the judicial } \\
\text { system } \\
\text { [TS, PGR] }\end{array}$ & $x$ & \\
\hline & & & & $\begin{array}{l}\text { Investigation and closure } \\
\text { of corruption cases }\end{array}$ & PGR & $\begin{array}{l}\text { 17.b. Number of corruption cases: } \\
\text { A) Reported } \\
\text { B) Under investigation } \\
\text { C) a- Accused } \\
\text { b- Non-accused (awaiting better evidence) } \\
\text { c- Filed } \\
\text { D) Tried } \\
\text { [PGR] }\end{array}$ & $\begin{array}{c}\text { Published } \\
\text { statistics }\end{array}$ & \\
\hline & & & & $\begin{array}{l}\text { Preparation of reports } \\
\text { and opinions about the } \\
\text { General State Accounts } \\
\text { (CGE) } \\
\end{array}$ & TA & $\begin{array}{l}\text { 17.c. Reports and opinions about the } \\
\text { CGE were issued } \\
\text { [CGE Report] }\end{array}$ & 1 & 1 \\
\hline $\begin{array}{l}\text { 18. Strengthen the } \\
\text { prevention and combat } \\
\text { against crime }\end{array}$ & $\begin{array}{l}\text { Average time } \\
\text { between detention } \\
\text { and accusation }\end{array}$ & $\mathrm{N} / \mathrm{d}$ & & $\begin{array}{l}\text { Continuation of the } \\
\text { Criminal Investigation } \\
\text { Police reform }\end{array}$ & MINT / PGR & $\begin{array}{l}\text { 18.a. PIC reformed } \\
\text { [MINT] }\end{array}$ & $x$ & \\
\hline
\end{tabular}


PILLAR I - GOVERNANCE - LEGAL REFORM, LEGALITY AND PUBLIC ORDER

\begin{tabular}{|c|c|c|c|c|c|c|c|c|}
\hline Objective & $\begin{array}{c}\text { Results Indicator } \\
\text { [Verification } \\
\text { Source] }\end{array}$ & $\begin{array}{l}\text { Base } \\
2005\end{array}$ & $\begin{array}{c}\text { Target } \\
2009\end{array}$ & $\begin{array}{l}\text { Achievements } \\
\text { (Actions) }\end{array}$ & $\begin{array}{l}\text { Respon } \\
\text {-sibility }\end{array}$ & $\begin{array}{l}\text { Indicator Product/ Execution } \\
\text { [Verification Source] }\end{array}$ & $\begin{array}{c}\text { Target } \\
2007\end{array}$ & Outcome \\
\hline \multirow[t]{2}{*}{ (par. 299) } & & & & $\begin{array}{l}\text { Improvement in the } \\
\text { quality of the services } \\
\text { rendered by the Criminal } \\
\text { Investigation Police }\end{array}$ & MINT / PGR & $\begin{array}{l}\text { 18.b. \% of cases prepared within the } \\
\text { preparation time limits } \\
\text { [MINT/PGR] }\end{array}$ & $50 \%$ & \\
\hline & & & & $\begin{array}{l}\text { Systematized } \\
\text { registration of } \\
\text { occurrences procedure }\end{array}$ & MINT / PGR & $\begin{array}{l}\text { 18.c. Systematized registration of } \\
\text { occurrences } \\
\text { [MINT] }\end{array}$ & $x$ & $x$ \\
\hline $\begin{array}{l}\text { 19. Elevate performance } \\
\text { levels of the police forces } \\
\text { (par. 301) }\end{array}$ & $\begin{array}{l}\text { 19.1. \% of citizens } \\
\text { stating to have } \\
\text { confidence in the } \\
\text { police }\end{array}$ & $\mathrm{N} / \mathrm{d}$ & & $\begin{array}{l}\text { Increase in the PRM's } \\
\text { operationalization }\end{array}$ & MINT & $\begin{array}{l}\text { 19.a. \% of cleared-up crime processes } \\
\text { [MINT] }\end{array}$ & $74 \%$ & \\
\hline
\end{tabular}

Note: *The target of this indicator is obtained by dividing the total number of sentences of all provincial judicial courts by the number of magistrates working in these instances.

**The indicator should be refined as "confidence" is a relative concept.

PILLAR II - HUMAN CAPITAL - HEALTH

\begin{tabular}{|c|c|c|c|c|c|c|c|c|}
\hline Objective & $\begin{array}{c}\text { Results Indicator } \\
\text { [Verification Source] }\end{array}$ & $\begin{array}{l}\text { Base } \\
2005 \\
\end{array}$ & $\begin{array}{l}\text { Target } \\
2009 \\
\end{array}$ & $\begin{array}{c}\begin{array}{c}\text { Achievements } \\
\text { (Actions) }\end{array} \\
\end{array}$ & $\begin{array}{l}\text { Respon } \\
\text {-sibility }\end{array}$ & $\begin{array}{c}\text { Indicator Product/ Execution } \\
\text { [Verification Source] }\end{array}$ & $\begin{array}{c}\text { Target } \\
2007 \\
\end{array}$ & Outcome \\
\hline \multirow{5}{*}{$\begin{array}{l}\text { 20. Reduce infant- } \\
\text { youth mortality rates } \\
\quad \text { (par. 428) }\end{array}$} & \multirow[t]{5}{*}{$\begin{array}{l}\text { 20.1. Infant-youth mortality } \\
\text { rate } \\
\text { [IDS] }\end{array}$} & \multirow[t]{5}{*}{$\begin{array}{l}178 \text { per } \\
\text { thousand } \\
\text { (2003) }\end{array}$} & \multirow[t]{5}{*}{$\begin{array}{l}140 \text { per } \\
\text { thousand }\end{array}$} & \multirow[t]{2}{*}{$\begin{array}{l}\text { Strengthening of the activities of the PAV, and } \\
\text { especially those of the mobile brigades } \\
\text { component }\end{array}$} & \multirow[b]{2}{*}{ MISAU - DNS } & $\begin{array}{l}\text { 20.a. DPT } 3 \text { and } \mathrm{Hb} \text { coverage rates } \\
\text { in children between } 0-12 \text { months } \\
\text { [SIMP] }\end{array}$ & $95 \%$ & $95 \%$ \\
\hline & & & & & & $\begin{array}{l}\text { 20.b. \% of children below one } \\
\text { year of age fully immunized } \\
\text { [PAV] }\end{array}$ & $65 \%$ & \\
\hline & & & & $\begin{array}{l}\text { Strengthening and expansion of Nutrition } \\
\text { Surveillance }\end{array}$ & MISAU - DNS & $\begin{array}{l}\text { 20.c. No. of observatories } \\
\text { established and operational } \\
\text { [Nutrition Programme] }\end{array}$ & 42 & \\
\hline & & & & \multirow[t]{2}{*}{$\begin{array}{l}\text { Expansion of the number of primary and } \\
\text { secondary level HUs implementing the } \\
\text { AIDI (Integrated Attention to Child } \\
\text { Diseases) strategy }\end{array}$} & MISAU - DNS & $\begin{array}{l}\text { 20.d. \% of primary level HUs in } \\
\text { which the AIDI strategy is } \\
\text { implemented } \\
\text { [Child Health] }\end{array}$ & $70 \%$ & \\
\hline & & & & & MISAU - DNS & $\begin{array}{l}\text { 20.e. \% of under-fives with } \\
\text { uncomplicated malaria treated } \\
\text { according to the malaria } \\
\text { treatment standards in force in } \\
\text { the country's Health Units (1) } \\
\text { [Malaria Programme] }\end{array}$ & $80 \%$ & \\
\hline $\begin{array}{l}\text { 21. Reduce maternal } \\
\text { mortality rates } \\
\text { (par. 426) }\end{array}$ & $\begin{array}{l}\text { 21.1. Maternal mortality rate } \\
\text { [IDS] }\end{array}$ & $\begin{array}{l}408 \text { per } \\
100000 \\
(2003)\end{array}$ & $\begin{array}{l}340 \text { per } \\
100000\end{array}$ & $\begin{array}{l}\text { Carry out campaigns on education, information } \\
\text { dissemination, awareness of community } \\
\text { leaders and of other people with } \\
\text { decision-making powers so as to increase the } \\
\text { demand of obstetric care }\end{array}$ & MISAU - DNS & $\begin{array}{l}\text { 21.a. Coverage rate of institutional } \\
\text { births } \\
\text { [SIMP] }\end{array}$ & $52 \%$ & $51.9 \%$ \\
\hline
\end{tabular}


PILLAR II - HUMAN CAPITAL - HEALTH

\begin{tabular}{|c|c|c|c|c|c|c|c|c|}
\hline Objective & $\begin{array}{c}\text { Results Indicator } \\
\text { [Verification Source] }\end{array}$ & $\begin{array}{l}\text { Base } \\
2005\end{array}$ & $\begin{array}{l}\text { Target } \\
2009\end{array}$ & $\begin{array}{l}\text { Achievements } \\
\text { (Actions) }\end{array}$ & $\begin{array}{l}\text { Respon } \\
\text {-sibility }\end{array}$ & $\begin{array}{l}\text { Indicator Product/ Execution } \\
\text { [Verification Source] }\end{array}$ & $\begin{array}{l}\text { Target } \\
2007\end{array}$ & Outcome \\
\hline & & & & $\begin{array}{l}\text { Awareness-raising and collaboration of the } \\
\text { community and NGOs for the construction } \\
\text { of pregnant women's waiting homes in all } \\
\text { district capital reference HUs, and for the } \\
\text { management of bicycle-ambulances }\end{array}$ & MISAU - DNS & $\begin{array}{l}\text { 21.b. \% of reference HUs } \\
\text { situated in the district capitals } \\
\text { with a waiting home for pregnant } \\
\text { women } \\
\text { [Reproductive Health] }\end{array}$ & $60 \%$ & $64 \%$ \\
\hline & & & & $\begin{array}{l}\text { Increase of the number of HUs providing } \\
\text { Basic Essential Obstetric Care }\end{array}$ & MISAU - DNS & $\begin{array}{l}\text { 21.c. No. of HUs per } 500,000 \\
\text { inhabitants providing Basic } \\
\text { Essential Obstetric Care (3) } \\
\text { [Reproductive Health] }\end{array}$ & 1.9 & \\
\hline \multirow{3}{*}{$\begin{array}{l}\text { 22. Reduce the weight } \\
\text { of malaria, specially in } \\
\text { the more vulnerable } \\
\text { groups } \\
\text { (par. 432) }\end{array}$} & \multirow[t]{2}{*}{$\begin{array}{l}\text { 22.1. Malaria incidence rate in } \\
\text { under-fives } \\
\text { [Epidemiology Office] }\end{array}$} & \multirow[t]{2}{*}{$\begin{array}{l}55 \text { per } \\
10000 \\
(2001)\end{array}$} & \multirow[t]{2}{*}{$\begin{array}{l}44 \text { per } \\
10000\end{array}$} & \multirow[t]{2}{*}{$\begin{array}{l}\text { Increase the use of mosquito nets and } \\
\text { insecticides }\end{array}$} & MISAU - DNS & $\begin{array}{l}\text { 22.a. \% of the population } \\
\text { benefiting from intra-domiciliary } \\
\text { spraying } \\
\text { [Malaria Programme] }\end{array}$ & $40 \%$ & \\
\hline & & & & & MISAU - DNS & $\begin{array}{l}\text { 22.b. \% of pregnant women and } \\
\text { under fives who have at least one } \\
\text { REMTI in each district without } \\
\text { spraying } \\
\text { [Malaria Programme] }\end{array}$ & $\geq 95 \%$ & \\
\hline & $\begin{array}{l}\text { 22.2. Prevalence rate of } \\
\text { malaria parasites in pregnant } \\
\text { women } \\
\text { [MISAU-DNS] }\end{array}$ & $\begin{array}{l}20 \% \\
(2001)\end{array}$ & $\begin{array}{l}\text { To be } \\
\text { defined } \\
\text { (4) }\end{array}$ & $\begin{array}{l}\text { Administration of Preventive Intermittent } \\
\text { Treatment (PIT) in pre-natal visits and } \\
\text { mobile brigades }\end{array}$ & MISAU - DNS & $\begin{array}{l}\text { 22.c. \% of pregnant women } \\
\text { among the users of pre-natal } \\
\text { visits receiving at least one dose } \\
\text { of PIT } \\
\text { [Malaria Programme] }\end{array}$ & $60 \%$ & $37.2 \%$ \\
\hline $\begin{array}{l}\text { 23. Reduce the risk of } \\
\text { vertical mother-to-child } \\
\text { HIV transmission } \\
\text { (pars. } 427 \text { \& 449) }\end{array}$ & $\begin{array}{l}\text { 23.1. \% of pregnant HIV+ } \\
\text { women receiving full } \\
\text { prophylaxis treatment in the } \\
\text { last } 12 \text { months } \\
\text { [VTP Programme] }\end{array}$ & $5 \%$ & $22 \%$ & $\begin{array}{l}\text { Increase of the number of HUs offering } \\
\text { VTP services }\end{array}$ & MISAU - DNS & $\begin{array}{l}\text { 23.a. No. of HUs with expanded } \\
\text { VTP } \\
\text { [VTP Programme] }\end{array}$ & 250 & $\begin{array}{c}386 \\
\text { (cumulative) }\end{array}$ \\
\hline \multirow{3}{*}{$\begin{array}{l}\text { 24. Reduce the impact } \\
\text { of HIV/AIDS on the } \\
\text { population } \\
\text { (par. 451) }\end{array}$} & \multirow{3}{*}{$\begin{array}{l}24.1 . \% \text { of people eligible for } \\
\text { the treatment who receive a } \\
\text { combined ARVT (anti- } \\
\text { retroviral therapy), according } \\
\text { to national protocols } \\
\text { [HIVIAIDS Programme] }\end{array}$} & \multirow[t]{3}{*}{$1.5 \%$} & \multirow[t]{3}{*}{$39 \%$} & \multirow[t]{3}{*}{$\begin{array}{l}\text { Increase national capacity for the diagnosis } \\
\text { and treatment of AIDS }\end{array}$} & MISAU - DNS & $\begin{array}{l}\text { 24.a. No. of HUs with capacity to } \\
\text { administer ARVT } \\
\text { [HIVIAIDS Programme] }\end{array}$ & 112 & 210 \\
\hline & & & & & MISAU - DNS & $\begin{array}{l}\text { 24.b. Total no. of people who } \\
\text { benefit from antiretroviral therapy } \\
\text { (ART) (5) } \\
\text { [HIVIAIDS Programme] }\end{array}$ & 96420 & 86000 \\
\hline & & & & & MISAU - DNS & $\begin{array}{l}\text { 24.C. Total no. of children who } \\
\text { benefit from paediatric ART } \\
\text { [HIVIAIDS Programme] }\end{array}$ & 11820 & \\
\hline $\begin{array}{l}\text { 25. Reduce the rate of } \\
\text { incidence of HIV } \\
\text { among the 15-24 year } \\
\text { old youth (6) } \\
\text { (par. 449) }\end{array}$ & $\begin{array}{l}25.1 \text { Prevalence rate among } \\
15-19 \text { year old youth } \\
\text { [Report on the Revision of the } \\
\text { HIV Epidemiological } \\
\text { Surveillance Data] }\end{array}$ & $5.4 \%$ & $4.2 \%$ & $\begin{array}{l}\text { Expansion of the Friends of Adolescents } \\
\text { and Youths Services (SAAJ) network to } \\
\text { the more peripheral HUs }\end{array}$ & MISAU - DNS & $\begin{array}{l}\text { 25.a. No. of HUs with SAAJ } \\
\text { [SEA Programme] }\end{array}$ & 250 & 183 \\
\hline
\end{tabular}


PILLAR II - HUMAN CAPITAL - HEALTH

\begin{tabular}{|c|c|c|c|c|c|c|c|c|}
\hline Objective & $\begin{array}{c}\text { Results Indicator } \\
\text { [Verification Source] }\end{array}$ & $\begin{array}{l}\text { Base } \\
2005\end{array}$ & $\begin{array}{c}\text { Target } \\
2009\end{array}$ & $\begin{array}{l}\text { Achievements } \\
\text { (Actions) }\end{array}$ & $\begin{array}{l}\text { Respon } \\
\text {-sibility }\end{array}$ & $\begin{array}{c}\text { Indicator Product/ Execution } \\
\text { [Verification Source] }\end{array}$ & $\begin{array}{l}\text { Target } \\
2007\end{array}$ & Outcome \\
\hline & $\begin{array}{l}\text { 25.2. Prevalence rate among } \\
\text { 20-24 year old youth } \\
\text { [Report on the Revision of the } \\
\text { HIV Epidemiological } \\
\text { Surveillance Data] }\end{array}$ & $13.9 \%$ & $10.4 \%$ & $\begin{array}{l}\text { Expansion of the number of SAAJs with } \\
\text { capacity to offer Health Counselling and } \\
\text { Testing (HCT) services }\end{array}$ & MISAU - DNS & $\begin{array}{l}\text { 25.b. No. of SAAJs with HCT } \\
\text { services } \\
\text { [SEA Programme] }\end{array}$ & 90 & 42 \\
\hline \multirow{5}{*}{$\begin{array}{l}\text { 26. Reduce iniquity in } \\
\text { access to and } \\
\text { consumption of quality } \\
\text { health services } \\
\text { (par. 103) }\end{array}$} & $\begin{array}{l}\text { 26.1. \% of the population with } \\
\text { easy access to a HU, in other } \\
\text { words, living at a distance of } \\
\text { less than } 30 \text { minutes (8) } \\
\text { [IAF] }\end{array}$ & $36 \%$ & $45 \%$ & $\begin{array}{l}\text { Rehabilitation, refunctionalization and } \\
\text { construction of new HUs in the primary } \\
\text { and secondary network }\end{array}$ & $\begin{array}{l}\text { MISAU - } \\
\text { GACOPI }\end{array}$ & $\begin{array}{l}\text { 26.a. No. of primary and } \\
\text { secondary HUs rehabilitated, } \\
\text { refunctionalized, upgraded or } \\
\text { constructed } \\
\text { [SEA Programme] }\end{array}$ & 105 & \\
\hline & $\begin{array}{l}\text { 26.2. Ratio of outpatient visits } \\
\text { per inhabitant between rural } \\
\text { and urban districts }(10) \\
\text { [MISAU-DPC] }\end{array}$ & $1 ; 1,64$ & $1 ; 1,2$ & Expansion of access to health care & MISAU - DPC & $\begin{array}{l}\text { 26.b. Outpatient visits per } \\
\text { inhabitant } \\
\text { [PES Review] }\end{array}$ & 1.1 & \\
\hline & \multirow[t]{3}{*}{$\begin{array}{l}26.3 . \% \text { of level I and II HUs } \\
\text { functioning with basic } \\
\text { resources } \\
\text { [DAM/DPC } 2007 \text { Report] }\end{array}$} & \multirow[t]{3}{*}{$\begin{array}{l}\text { To be } \\
\text { defined } \\
\text { (11) }\end{array}$} & \multirow[t]{3}{*}{$\begin{array}{l}\text { To be } \\
\text { defined } \\
\text { (11) }\end{array}$} & $\begin{array}{l}\text { Training, posting and retention of staff in } \\
\text { level I and II HUs, according to the } \\
\text { standard personnel list }\end{array}$ & MISAU - DRH & $\begin{array}{l}\text { 26.c. \% of level I and II HUs } \\
\text { functioning with the standard } \\
\text { personnel list [DAM/DPC Annual } \\
\text { Report] }\end{array}$ & (11) & \\
\hline & & & & $\begin{array}{l}\text { Equipping of the level I and II HUs, } \\
\text { according to the equipment standard }\end{array}$ & MISAU - DNS & $\begin{array}{l}\text { 26.d. \% of level I and II HUs } \\
\text { complying with the equipment } \\
\text { standard } \\
\text { [DAM/DPC Annual Report] }\end{array}$ & (11) & \\
\hline & & & & $\begin{array}{l}\text { Equipping of the level I and II HUs with } \\
\text { basic services (especially water and } \\
\text { electricity) }\end{array}$ & MISAU - DNS & $\begin{array}{l}\text { 26.e. \% of level I and II HUs II } \\
\text { equipped with basic services } \\
\text { (esp. water and electricity) } \\
\text { [DAM/DPC Annual Report] }\end{array}$ & $30 \%$ & \\
\hline
\end{tabular}

Note: (1) One of the main preoccupations of the sector in relation to malaria has been the fact that many children are not treated according to the treatment standards established at national level, and one of the objectives of the malaria programme is therefore to correct this. (2) In the text (par. 426) the coverage rate of institutional deliveries in 2005 is $48 \%$, which is the information available when the text was prepared. The updated and correct figure is $49 \%$. (3) This represents a functioning indicator of the Health Units, and not only of the existing services. The target for 2009 was defined with a view to attain a figure of 4 per 500,000 (5) This indicator also includes the number of children referred to in indicator immediately below. (6) The PARPA II text includes 15-19 year old youths (par. 449). However for the strategic matrix it was decided to (5) This indicator also includes the number of children referred to in indicator immediately below. (6) The PARPA Il text includes $15-19$ year old youths (par. 449 ). However, for the strategic matrix it was decided to HIVIAIDS S crom the HVIAIDS co that this mens 30 mis 2004-2008. How The proving understood that this means 30 minutes by foot. (9) The provincial capitals were considered as urban districts. The Provincial Hospitals were excluded from the calculation to avoid distortions of the results. (10) sector in 2007. (11) To define the base values regarding the \% of HUs functioning with basic resources, as well as the \% of HUs complying with the standard equipment and personnel list, an inquiry will be carried out in the first half-year of 2007 and a database will be set up. The targets for the following years will be defined on the basis of the results of this inquiry, with priority for the primary level.

\section{PILLAR II -HUMAN CAPITAL - EDUCATION}

\begin{tabular}{|c|c|c|c|c|c|c|c|c|}
\hline Objective & $\begin{array}{c}\text { Results Indicator } \\
\text { [Verification Source] }\end{array}$ & $\begin{array}{l}\text { Base } \\
2005\end{array}$ & $\begin{array}{l}\text { Target } \\
2009\end{array}$ & $\begin{array}{l}\text { Achievements } \\
\text { (Actions) }\end{array}$ & $\begin{array}{l}\text { Respon } \\
\text {-sibility }\end{array}$ & $\begin{array}{l}\text { Indicator Product/ } \\
\text { Execution } \\
\text { [Verification Source] }\end{array}$ & $\begin{array}{c}\text { Target } \\
2007\end{array}$ & Outcome \\
\hline $\begin{array}{l}\text { 27. Reduce the rate } \\
\text { of illiteracy } \\
\text { (par. 398) }\end{array}$ & $\begin{array}{l}\text { 27.1. Illiteracy rate } \\
\text { [Census and Inquiries] }\end{array}$ & $\begin{array}{l}53 \% \\
(2004)\end{array}$ & $43 \%$ & $\begin{array}{l}\text { Implementation of the Literacy and } \\
\text { Adult Education Strategy, literacy } \\
\text { by radio }\end{array}$ & MEC & $\begin{array}{l}\text { 27.a. No. of adults who } \\
\text { have concluded literacy } \\
\text { classes } \\
\text { [MEC] }\end{array}$ & 220000 & \\
\hline
\end{tabular}


PILLAR II -HUMAN CAPITAL - EDUCATION

\begin{tabular}{|c|c|c|c|c|c|c|c|c|}
\hline Objective & $\begin{array}{c}\text { Results Indicator } \\
\text { [Verification Source] }\end{array}$ & $\begin{array}{l}\text { Base } \\
2005\end{array}$ & $\begin{array}{l}\text { Target } \\
2009\end{array}$ & $\begin{array}{l}\text { Achievements } \\
\text { (Actions) }\end{array}$ & $\begin{array}{l}\text { Respon } \\
\text {-sibility }\end{array}$ & $\begin{array}{c}\text { Indicator Product/ } \\
\text { Execution } \\
\text { [Verification Source] }\end{array}$ & $\begin{array}{l}\text { Target } \\
2007\end{array}$ & Outcome \\
\hline \multirow{7}{*}{$\begin{array}{l}\text { 28. Guarantee } \\
\text { quality universal } \\
\text { schooling } \\
\text { (par. 400) }\end{array}$} & $\begin{array}{l}\text { 28.1. EP }(1+2) \text { net enrolment } \\
\text { rate }- \text { Total } \\
\text { [MEC Statistics] }\end{array}$ & $83 \%$ & $93 \%$ & $\begin{array}{l}\text { Construction of schools in the } \\
\text { communities }\end{array}$ & MEC & $\begin{array}{l}\text { 28.a. No. of new } \\
\text { classrooms built for } \\
\text { schools } \\
\text { [MEC Statistics] }\end{array}$ & $\begin{array}{c}1425 \\
\text { (761 updated) }\end{array}$ & 1600 \\
\hline & $\begin{array}{l}\text { 28.2. Net enrolment rate at } 6 \text { years } \\
\text { of age in the } 1 \text { st Grade - Girls } \\
\text { [MEC Statistics] }\end{array}$ & $56 \%$ & $\begin{array}{l}80 \% \\
(2007: 67 \% \\
2008: 73 \%)\end{array}$ & Recruitment of women teachers & MEC & $\begin{array}{l}\text { 28.b. \% of women } \\
\text { teachers contracted } \\
\text { annually } \\
\text { [MEC Statistics] }\end{array}$ & $37 \%$ & $44.98 \%$ \\
\hline & \multirow[t]{2}{*}{$\begin{array}{l}\text { 28.3. EP2 conclusion rate - Girls } \\
\text { [MEC Statistics] }\end{array}$} & \multirow[t]{2}{*}{$28 \%$} & \multirow[t]{2}{*}{$\begin{array}{l}50 \% \\
(2007: 27 \% \text {; } \\
2008: 40 \%)\end{array}$} & $\begin{array}{l}\text { Distribution of the EP school } \\
\text { textbooks }\end{array}$ & MEC & $\begin{array}{l}\text { 28.c. Books per student } \\
\text { per subject } \\
\text { [MEC Statistics] }\end{array}$ & 1 & \\
\hline & & & & $\begin{array}{l}\text { Increase in the proportion of } \\
\text { teachers with pedagogical training }\end{array}$ & MEC & $\begin{array}{l}\text { 28.d. \% of new teachers } \\
\text { contracted with initial } \\
\text { training } \\
\text { [MEC Statistics] }\end{array}$ & $65 \%$ & 9186 (absolute number) \\
\hline & \multirow[t]{2}{*}{$\begin{array}{l}\text { 28.4. Ratio students per teacher in } \\
\text { EP1 } \\
\text { [MEC Statistics] }\end{array}$} & \multirow[t]{2}{*}{74} & \multirow[t]{2}{*}{$\begin{array}{l}67 \\
(2007: 71 ; \\
2008: 69)\end{array}$} & Hiring of new teachers & MEC & $\begin{array}{l}\text { 28.e. No. of new teachers } \\
\text { contracted } \\
\text { [MEC Statistics] }\end{array}$ & 10000 & \\
\hline & & & & $\begin{array}{l}\text { Reduction in the number of } \\
\text { teachers teaching } 2 \text { shifts in EP1 }\end{array}$ & MEC & $\begin{array}{l}\text { 28.f. \% of teachers } \\
\text { teaching } 2 \text { shifts in EP1 } \\
\text { [MEC Statistics] }\end{array}$ & $42 \%$ & \\
\hline & $\begin{array}{l}\text { 28.5. Gross schooling rate in } \\
\text { professionalized ES1 [MEC } \\
\text { Statistics] }\end{array}$ & $21 \%$ & $30 \%$ & $\begin{array}{l}\text { Revision and implementation of } \\
\text { the Secondary Education Strategy }\end{array}$ & MEC & $\begin{array}{l}\text { 28.g. Strategy revised and } \\
\text { implemented from } 2007 \\
\text { [Secondary Education } \\
\text { Strategy and Sector PES } \\
\text { Review] }\end{array}$ & $x$ & $\begin{array}{l}\text { A diagnosis was done, } \\
\text { involving a local } \\
\text { consultancy (UEM) and } \\
\text { immediate impact } \\
\text { activities are being } \\
\text { defined to be } \\
\text { considered in } 2008\end{array}$ \\
\hline
\end{tabular}

PILLAR II -HUMAN CAPITAL - WATER AND SANITATION

\begin{tabular}{|c|c|c|c|c|c|c|c|c|}
\hline Objective & $\begin{array}{c}\text { Results Indicator } \\
\text { [Verification Source] }\end{array}$ & $\begin{array}{l}\text { Base } \\
2005\end{array}$ & $\begin{array}{l}\text { Target } \\
2009\end{array}$ & $\begin{array}{l}\text { Achievements } \\
\text { (Actions) }\end{array}$ & $\begin{array}{l}\text { Respo } \\
n \\
\text {-sibility }\end{array}$ & $\begin{array}{l}\text { Indicator Product/ } \\
\text { Execution } \\
\text { [Verification Source] }\end{array}$ & $\begin{array}{l}\text { Target } \\
2007\end{array}$ & Outcome \\
\hline \multirow{3}{*}{$\begin{array}{l}\text { 29. Increase the } \\
\text { population's access to } \\
\text { potable water in the } \\
\text { rural areas } \\
\text { (par. 455) }\end{array}$} & \multirow{3}{*}{$\begin{array}{l}\text { 29.1. \% of the population with } \\
\text { access to potable water (rural } \\
\text { areas) } \\
\text { [DPOPH and water companies' } \\
\text { annual reports] }\end{array}$} & \multirow[t]{3}{*}{$41 \%$} & \multirow[t]{3}{*}{$\begin{array}{l}53 \% \\
(48.5 \% \text { in } \\
2007)\end{array}$} & Construction of new disperse water points & $\begin{array}{l}\text { DNA / } \\
\text { DPOP } \\
\text { H's }\end{array}$ & $\begin{array}{l}\text { 29.a. Number of new } \\
\text { disperse water points that } \\
\text { were constructed } \\
\text { [DPOPH annual reports] }\end{array}$ & 1055 & 1529 \\
\hline & & & & Rehabilitation of the disperse water points & $\begin{array}{l}\text { DNA / } \\
\text { DPOP } \\
\text { H's }\end{array}$ & $\begin{array}{l}\text { 29.b. Number of } \\
\text { rehabilitated water points } \\
\text { [DPOPH annual reports] }\end{array}$ & 805 & 913 \\
\hline & & & & $\begin{array}{l}\text { Rehabilitation of the Small Water Supply } \\
\text { Systems (PSAAs) }\end{array}$ & $\begin{array}{l}\text { DNA / } \\
\text { DPOP } \\
\text { H's }\end{array}$ & $\begin{array}{l}\text { 29.c. Cumulative number } \\
\text { of rehabilitated } \\
\text { PSAAs [DPOPH annual } \\
\text { reports] }\end{array}$ & 15 & $\begin{array}{l}18 \text { and works for the } \\
\text { PSAA systems } \\
\text { reposition/repair are in } \\
\text { progress and may } \\
\text { benefit } 12,720 \text { people }\end{array}$ \\
\hline
\end{tabular}


PILLAR II -HUMAN CAPITAL - WATER AND SANITATION

\begin{tabular}{|c|c|c|c|c|c|c|c|c|}
\hline Objective & $\begin{array}{c}\text { Results Indicator } \\
\text { [Verification Source] }\end{array}$ & $\begin{array}{l}\text { Base } \\
2005\end{array}$ & $\begin{array}{c}\text { Target } \\
2009\end{array}$ & $\begin{array}{l}\text { Achievements } \\
\text { (Actions) }\end{array}$ & $\begin{array}{c}\text { Respo } \\
n \\
\text {-sibility }\end{array}$ & $\begin{array}{l}\text { Indicator Product/ } \\
\text { Execution } \\
\text { [Verification Source] }\end{array}$ & $\begin{array}{c}\text { Target } \\
2007\end{array}$ & Outcome \\
\hline \multirow{3}{*}{$\begin{array}{l}\text { 30. Increase the } \\
\text { population's access to } \\
\text { potable water in the } \\
\text { urban areas } \\
\text { (par. 455) }\end{array}$} & \multirow{3}{*}{$\begin{array}{l}\text { 30.1. \% of the population with } \\
\text { access to potable water (urban } \\
\text { areas) } \\
\text { [DPOPH and water companies' } \\
\text { annual reports] }\end{array}$} & \multirow[t]{3}{*}{$37 \%$} & \multirow[t]{3}{*}{$\begin{array}{l}53 \% \\
(40 \% \text { in } \\
2007)\end{array}$} & $\begin{array}{l}\text { Establishment of new domestic } \\
\text { connections }\end{array}$ & $\begin{array}{l}\text { DNA / } \\
\text { FIPAG }\end{array}$ & $\begin{array}{l}\text { 30.a. No. of domiciliary } \\
\text { connections established } \\
\text { [FIPAG Annual reports] }\end{array}$ & 2500 & 8502 \\
\hline & & & & Rehabilitation of existing standpipes & $\begin{array}{l}\text { DNA / } \\
\text { FIPAG }\end{array}$ & $\begin{array}{l}\text { 30.b. No. of public } \\
\text { standpipes rehabilitated } \\
\text { [FIPAG Annual reports] }\end{array}$ & 45 & 47 \\
\hline & & & & Construction of new standpipes & $\begin{array}{l}\text { DNA / } \\
\text { FIPAG }\end{array}$ & $\begin{array}{l}\text { 30.c. No. of public } \\
\text { standpipes constructed } \\
\text { [FIPAG Annual reports] }\end{array}$ & 105 & 169 \\
\hline $\begin{array}{l}\text { 31. Increase the } \\
\text { population's access to } \\
\text { sanitation services in } \\
\text { the urban areas } \\
\text { (par. 455) }\end{array}$ & $\begin{array}{l}\text { 31.1. \% of the population with } \\
\text { access to sanitation services } \\
\text { (urban areas) } \\
\text { [IDS] }\end{array}$ & $38 \%$ & $40 \%$ & $\begin{array}{l}\text { Rehabilitation of the sanitation system in } \\
\text { peri-urban areas }\end{array}$ & $\begin{array}{l}\text { DNA / } \\
\text { Municip } \\
\text { alities }\end{array}$ & $\begin{array}{l}\text { 31.b. No. of improved } \\
\text { latrines } \\
\text { [DNA annual reports] }\end{array}$ & 10200 & 9645 \\
\hline $\begin{array}{l}\text { 32. Increase the } \\
\text { population's access to } \\
\text { sanitation services in } \\
\text { the rural areas } \\
\text { (par. 455) }\end{array}$ & $\begin{array}{l}\text { 32.1. \% of the population with } \\
\text { access to sanitation services } \\
\text { (rural areas) } \\
\text { [Inquiries carried out by the INE] }\end{array}$ & $35 \%$ & $\begin{array}{l}37 \% \\
(39 \% \text { in } \\
2007)\end{array}$ & $\begin{array}{l}\text { Preparation and implementation of } \\
\text { technical, social and institutional } \\
\text { guidelines }\end{array}$ & DNA & $\begin{array}{l}\text { 32.b. Cumulative number } \\
\text { of provinces with } \\
\text { demonstration units } \\
\text { [Demonstration units] }\end{array}$ & 3 & \\
\hline
\end{tabular}

PILLAR II -HUMAN CAPITAL - HOUSING

\begin{tabular}{|c|c|c|c|c|c|c|c|c|}
\hline Objective & $\begin{array}{c}\text { Results Indicator } \\
\text { [Verification Source] }\end{array}$ & $\begin{array}{l}\text { Base } \\
2005 \\
\end{array}$ & $\begin{array}{c}\text { Target } \\
2009\end{array}$ & $\begin{array}{c}\text { Achievements } \\
\text { (Actions) }\end{array}$ & $\begin{array}{l}\text { Respon } \\
\text {-sibility }\end{array}$ & $\begin{array}{c}\text { Indicator Product/ Execution } \\
\text { [Verification Source] }\end{array}$ & $\begin{array}{l}\text { Target } \\
2007\end{array}$ & Outcome \\
\hline \multirow{2}{*}{$\begin{array}{l}\text { 33. Ensure access to } \\
\text { housing land and } \\
\text { infrastructures } \\
\text { through the } \\
\text { implementation of } \\
\text { urban development } \\
\text { programmes (par. } \\
477 \text { ) } \\
\end{array}$} & \multirow[t]{2}{*}{$\begin{array}{l}\text { 33.1. No. of households without } \\
\text { a housing plot } \\
\text { [IAF/QUIBB] }\end{array}$} & \multirow[t]{2}{*}{$20 \%$} & \multirow[t]{2}{*}{$18 \%$} & \multirow[t]{2}{*}{$\begin{array}{l}\text { Technical support to local bodies for the } \\
\text { implementation of partial land development } \\
\text { plans }\end{array}$} & \multirow[b]{2}{*}{$\mathrm{MOPH}$} & $\begin{array}{l}\text { 33.a. No. of local bodies assisted in } \\
\text { land development planning activities } \\
\text { [DNHU annual reports] }\end{array}$ & 22 & \\
\hline & & & & & & $\begin{array}{l}\text { 33.b. No. of demarcated plots } \\
\text { [DNHU annual reports] }\end{array}$ & $\begin{array}{c}13482 \\
(29207 \\
\text { updated) }\end{array}$ & 29587 \\
\hline \multirow{2}{*}{$\begin{array}{l}\text { 34. Ensure housing } \\
\text { durability through the } \\
\text { implementation of } \\
\text { housing improvement } \\
\text { programmes } \\
\text { (Par. 479) }\end{array}$} & \multirow[t]{2}{*}{$\begin{array}{l}\text { 34.1. \% of families with access } \\
\text { to adequate housing } \\
\text { [IAF/QUIBB] }\end{array}$} & \multirow[t]{2}{*}{$40 \%$} & \multirow[t]{2}{*}{$50 \%$} & \multirow[t]{2}{*}{$\begin{array}{l}\text { Support to the establishment of resource } \\
\text { centres for house building, including the } \\
\text { training of rural extension workers }\end{array}$} & \multirow[t]{2}{*}{$\begin{array}{l}\text { DNHU / } \\
\text { DPOPHs }\end{array}$} & $\begin{array}{l}\text { 34.a. No. of centres established } \\
\text { [DNHU annual reports] }\end{array}$ & 2 & $\begin{array}{c}2 \\
\text { (Inhambane } \\
\text { and } \\
\text { Nampula) }\end{array}$ \\
\hline & & & & & & $\begin{array}{l}\text { 34.b. No. of extension workers trained } \\
\text { [DNHU annual reports] }\end{array}$ & 24 & \\
\hline
\end{tabular}

PILLAR II -HUMAN CAPITAL -SOCIAL ACTION 
PILLAR II -HUMAN CAPITAL -SOCIAL ACTION

\begin{tabular}{|c|c|c|c|c|c|c|c|c|}
\hline Objective & $\begin{array}{c}\text { Results Indicator } \\
\text { [Verification Source] }\end{array}$ & $\begin{array}{l}\text { Base } \\
2005 \\
\end{array}$ & $\begin{array}{c}\text { Target } \\
2009\end{array}$ & $\begin{array}{l}\text { Achievements } \\
\text { (Actions) }\end{array}$ & $\begin{array}{l}\text { Respon } \\
\text {-sibility } \\
\end{array}$ & $\begin{array}{c}\text { Indicator Product/ Execution } \\
\text { [Verification Source] }\end{array}$ & $\begin{array}{c}\text { Target } \\
2007 \\
\end{array}$ & Outcome \\
\hline \multirow{8}{*}{$\begin{array}{l}\text { 35. Protect and attend to } \\
\text { the population groups in } \\
\text { vulnerable situations } \\
\text { (children, women, } \\
\text { handicapped persons } \\
\text { and the elderly) } \\
\text { (pars. 463, 465, } 467 \text { and } \\
469 \text { ) }\end{array}$} & $\begin{array}{l}\text { 35.1. No. of vulnerable } \\
\text { people benefiting from Social } \\
\text { Protection programmes } \\
\text { [Periodic PES/OE Reports } \\
\text { with disaggregated data per } \\
\text { Programme and target group] }\end{array}$ & $\mathrm{N} / \mathrm{d}$ & $\begin{array}{l}851,337 \\
\text { (Cumulative, } \\
2006- \\
2009)\end{array}$ & $\begin{array}{l}\text { Implementation and expansion of the Social } \\
\text { Protection programmes (Direct Social Aid, } \\
\text { Food Subsidies, Social Benefit through } \\
\text { Work, Income Generating Programme, } \\
\text { Institutional Assistance Programme for } \\
\text { Children, the Elderly and Deficiency Carriers) }\end{array}$ & $\begin{array}{l}\text { DPMAS / } \\
\text { INAS }\end{array}$ & $\begin{array}{l}\text { 35.a. Number of children, elderly } \\
\text { people, handicapped persons, women } \\
\text { who are household heads benefiting } \\
\text { from social protection programmes } \\
\text { [PES periodic reports with } \\
\text { disaggregated data per programme and } \\
\text { target } \\
\text { group] }\end{array}$ & 120,437 & 166,232 \\
\hline & \multirow{2}{*}{$\begin{array}{l}\text { 35.2. No. vulnerable of } \\
\text { children receiving assistance } \\
\text { [Periodic PES/OE - MMAS } \\
\text { reports] }\end{array}$} & 564 & 1784 & $\begin{array}{l}\text { Localization and integration of vulnerable } \\
\text { children into their families or into substitute } \\
\text { families }\end{array}$ & $\begin{array}{l}\text { DPMAS / } \\
\text { INAS / } \\
\text { OSCs }\end{array}$ & $\begin{array}{l}\text { 35.b. No. of children reintegrated } \\
\text { into families } \\
\text { [Periodic PES/OE - MMAS reports] }\end{array}$ & 250 & 3121 \\
\hline & & $10 \%$ & $30 \%$ & $\begin{array}{l}\text { Rendering assistance to children and } \\
\text { families integrating vulnerable children. }\end{array}$ & $\begin{array}{l}\text { DPMAS / } \\
\text { INAS }\end{array}$ & $\begin{array}{l}\text { 35.c. \% of children receiving } \\
\text { assistance: Health, Education, Legal } \\
\text { Aid (Registration of Birth, Financial } \\
\text { Support, Psychosocial Support, } \\
\text { Food and Nutrition Support } \\
\text { [MMAS annual reports] }\end{array}$ & $20 \%$ & \\
\hline & $\begin{array}{l}\text { 35.3. No. of vulnerable } \\
\text { handicapped persons } \\
\text { receiving assistance in } \\
\text { compensatory devices [PES - } \\
\text { MMAS periodic reports] }\end{array}$ & 1105 & 8485 & $\begin{array}{l}\text { Attribution of compensatory devices to } \\
\text { handicapped persons without own } \\
\text { resources to acquire them }\end{array}$ & $\begin{array}{l}\text { DPMAS / } \\
\text { INAS / } \\
\text { OSCs }\end{array}$ & $\begin{array}{l}\text { 35.d. No. of handicapped persons } \\
\text { who have received compensatory } \\
\text { devices } \\
\text { [PES - MMAS periodic reports] }\end{array}$ & 1650 & \\
\hline & \multirow{4}{*}{$\begin{array}{l}\text { 35.4. No. of deprived persons } \\
\text { (children, handicapped } \\
\text { persons and the elderly) } \\
\text { benefiting from institutional } \\
\text { attendance } \\
\text { [PES - MMAS periodic } \\
\text { reports] }\end{array}$} & 597 & 2127 & $\begin{array}{l}\text { Attendance of handicapped persons in } \\
\text { transit centres. }\end{array}$ & $\begin{array}{l}\text { MMAS / } \\
\text { INAS }\end{array}$ & $\begin{array}{l}\text { 35.e. No. of handicapped persons } \\
\text { attended to in transit centres } \\
\text { [PES - MMAS periodic reports] }\end{array}$ & 380 & 188 \\
\hline & & 242 & 2172 & $\begin{array}{l}\text { Attendance of handicapped persons in } \\
\text { special education institutions. }\end{array}$ & $\begin{array}{l}\text { DPMAS / } \\
\text { INAS / } \\
\text { DPEC }\end{array}$ & $\begin{array}{l}\text { 35.f. No of handicapped persons } \\
\text { attended to in special education } \\
\text { institutions } \\
\text { [PES - MMAS periodic reports] }\end{array}$ & 470 & 350 \\
\hline & & 858 & 3178 & $\begin{array}{l}\text { Attendance of elderly in elderly support } \\
\text { centres }\end{array}$ & $\begin{array}{l}\text { DPMAS / } \\
\text { INAS / } \\
\text { OSCs }\end{array}$ & $\begin{array}{l}\text { 35.g. No. of elderly attended to in } \\
\text { elderly support centres } \\
\text { [PES - MMAS periodic reports] }\end{array}$ & 600 & \\
\hline & & 2190 & 9290 & $\begin{array}{l}\text { Attendance of deprived children in } \\
\text { kindergarten }\end{array}$ & $\begin{array}{l}\text { DPMAS / } \\
\text { INAS / } \\
\text { OSCs }\end{array}$ & $\begin{array}{l}\text { 35.h. No. of deprived children } \\
\text { attended to in kindergarten } \\
\text { [PES - MMAS periodic reports] }\end{array}$ & 1800 & \\
\hline
\end{tabular}

PILLAR III - ECONOMIC DEVELOPMENT -FINANCIAL SECTOR 
PILLAR III - ECONOMIC DEVELOPMENT -FINANCIAL SECTOR

\begin{tabular}{|c|c|c|c|c|c|c|c|c|}
\hline Objective & $\begin{array}{c}\text { Results Indicator } \\
\text { [Verification Source] }\end{array}$ & $\begin{array}{l}\text { Base } \\
2005\end{array}$ & $\begin{array}{c}\text { Target } \\
2009\end{array}$ & $\begin{array}{l}\text { Achievements } \\
\text { (Actions) }\end{array}$ & $\begin{array}{l}\text { Respon } \\
\text {-sibility }\end{array}$ & $\begin{array}{l}\text { Indicator Product/ Execution } \\
\text { [Verification Source] }\end{array}$ & $\begin{array}{c}\text { Target } \\
2007\end{array}$ & $\begin{array}{c}\text { Outco } \\
\text { me }\end{array}$ \\
\hline \multirow{4}{*}{$\begin{array}{l}\text { 36. Strengthen the } \\
\text { regulation and } \\
\text { supervision of the } \\
\text { financial system so as to } \\
\text { minimize the risks of } \\
\text { financial crises and } \\
\text { financial crimes } \\
\text { (par. 500) }\end{array}$} & $\begin{array}{l}\text { 36.1 Credit to the private } \\
\text { sector as } \% \text { of GDP } \\
\text { [BM] }\end{array}$ & $13.9 \%$ & & $\begin{array}{l}\text { On-site and off-site inspection and report } \\
\text { production by BM }\end{array}$ & & $\begin{array}{l}\text { 36.a. \% of banks fulfilling the IAS/IFRS norms } \\
\text { [BM] }\end{array}$ & & \\
\hline & & & & & BM & & $100 \%$ & $100 \%$ \\
\hline & \multirow{2}{*}{$\begin{array}{l}\text { 36.2. Avoidance of the } \\
\text { use of the banking system } \\
\text { for illicit transactions; a } \\
\text { transparent banking } \\
\text { system with high } \\
\text { responsibility and } \\
\text { deontology } \\
\text { [BM] }\end{array}$} & \multirow[t]{2}{*}{$\begin{array}{l}\text { Existence } \\
\text { Law } \\
7 / 2002 \text { on } \\
\text { money } \\
\text { laundering }\end{array}$} & \multirow{2}{*}{$\begin{array}{l}\text { Occurrence of } \\
\text { illegal } \\
\text { transactions } \\
\text { through the } \\
\text { minimized } \\
\text { financial } \\
\text { system }\end{array}$} & $\begin{array}{l}\text { Effective control of the regulatory limits } \\
\text { (cf. the Foreign Exchange Law) as well as } \\
\text { the aim and objective of funds to be } \\
\text { transferred in the transactions }\end{array}$ & BM & $\begin{array}{l}\text { 36.b. Control of the limits and purposes of } \\
\text { financial transactions in agreement with the } \\
\text { Law } \\
\text { [BM] }\end{array}$ & $x$ & \\
\hline & & & & $\begin{array}{l}\text { Preparation of inspection procedures } \\
\text { targeting money laundering and adequate } \\
\text { measures taken on the basis of inspection } \\
\text { reports }\end{array}$ & BM & $\begin{array}{l}\text { 36.c. Approval and implementation of the } \\
\text { procedures } \\
\text { [BM] }\end{array}$ & $\begin{array}{l}\text { Approv } \\
\text { al of } \\
\text { procedu } \\
\text { res }\end{array}$ & \\
\hline \multirow{3}{*}{$\begin{array}{l}\text { 37. Improve the insurance } \\
\text { and social protection sector } \\
\text { (par. 503) }\end{array}$} & $\begin{array}{l}\text { 37.1. A competitive and } \\
\text { transparent insurance } \\
\text { sector, complying with } \\
\text { international standards } \\
\text { [IGS] }\end{array}$ & $\begin{array}{l}\text { Legal } \\
\text { documents } \\
\text { to be } \\
\text { approved }\end{array}$ & $\begin{array}{l}\text { All legal } \\
\text { documents } \\
\text { foreseen in } \\
\text { the Matrix } \\
\text { were } \\
\text { approved }\end{array}$ & $\begin{array}{l}\text { Preparation of: Regulation on Private } \\
\text { Pensions Funds (Private), proposals for the } \\
\text { insurance contracting law; Revision of the } \\
\text { financial guarantees regime and the } \\
\text { preparation of a transition plan for the IFRS. }\end{array}$ & IGS & $\begin{array}{l}\text { 37.a. Submission to the Council of Ministers / } \\
\text { Parliament } \\
\text { [Publications in the Government Gazette] }\end{array}$ & $\begin{array}{c}\text { Revision } \\
\text { of the } \\
\text { financial } \\
\text { guarante } \\
\text { es } \\
\text { regime. } \\
\text { Regulati } \\
\text { on on } \\
\text { the } \\
\text { private } \\
\text { pensions } \\
\text { funds }\end{array}$ & \\
\hline & \multirow[t]{2}{*}{$\begin{array}{l}\text { 37.2. Sustainability of the } \\
\text { social security system } \\
\text { guaranteed } \\
\text { [INSS] }\end{array}$} & \multirow[t]{2}{*}{$\begin{array}{l}\text { Tender for } \\
\text { the } \\
\text { selection } \\
\text { of } \\
\text { consultant } \\
\mathrm{s} \text { for the } \\
\text { realization } \\
\text { of the } \\
\text { actuarial } \\
\text { study and } \\
\text { strengtheni } \\
\text { ng the } \\
\text { system }\end{array}$} & \multirow[t]{2}{*}{$\begin{array}{l}\text { Social } \\
\text { protection law } \\
\text { implemented }\end{array}$} & $\begin{array}{l}\text { Realization of the actuarial study and the } \\
\text { design of the investments strategy and } \\
\text { preparation of regulating diplomas }\end{array}$ & INSS & $\begin{array}{l}\text { 37.b. Study concluded; investment strategy } \\
\text { being implemented; regulations in force and } \\
\text { recommendations implemented. Report on } \\
\text { periodic actuarial studies and evaluation of } \\
\text { the level of implementation. } \\
\text { [INSS] }\end{array}$ & $\begin{array}{l}\text { Realizati } \\
\text { on of the } \\
\text { actuarial } \\
\text { study } \\
\text { and } \\
\text { prepara } \\
\text { tion of } \\
\text { the } \\
\text { investm } \\
\text { ent } \\
\text { strategy }\end{array}$ & \\
\hline & & & & $\begin{array}{l}\text { Extension of coverage to other worker } \\
\text { categories (human scope) and of the } \\
\text { range of benefits (material scope) }\end{array}$ & $\begin{array}{c}\text { INSS / } \\
\text { MITRAB }\end{array}$ & $\begin{array}{l}\text { 37.c. \% of growth in terms of no. of new } \\
\text { workers registered in the Security System } \\
\text { and of the range of benefits } \\
\text { [INSS Annual Report] }\end{array}$ & $14.20 \%$ & $\begin{array}{c}42752 \\
\text { new } \\
\text { benefici } \\
\text { aries } \\
\text { (absolut } \\
\text { e } \\
\text { number } \\
\text { ) }\end{array}$ \\
\hline
\end{tabular}


PILLAR III -ECONOMIC DEVELOPMENT -PRIVATE SECTOR

\begin{tabular}{|c|c|c|c|c|c|c|c|c|}
\hline Objective & $\begin{array}{c}\text { Results Indicator } \\
\text { [Verification Source] }\end{array}$ & $\begin{array}{l}\text { Base } \\
2005\end{array}$ & $\begin{array}{c}\text { Target } \\
2009\end{array}$ & $\begin{array}{c}\text { Achievements } \\
\text { (Actions) }\end{array}$ & $\begin{array}{c}\text { Respo } \\
n \\
\text {-sibility }\end{array}$ & $\begin{array}{l}\text { Indicator Product/ Execution } \\
\text { [Verification Source] }\end{array}$ & $\begin{array}{c}\text { Target } \\
2007\end{array}$ & $\begin{array}{l}\text { Outco } \\
\text { me }\end{array}$ \\
\hline \multirow{4}{*}{$\begin{array}{l}\text { 38. Improve the business } \\
\text { environment } \\
\text { (par. 495) }\end{array}$} & \multirow{4}{*}{$\begin{array}{l}\text { 38.1. Doing Business } \\
\text { Ranking } \\
\text { [World Bank Annual } \\
\text { Report] }\end{array}$} & \multirow[t]{4}{*}{110} & \multirow[t]{4}{*}{70} & Simplification of the procedures for starting a business & $\begin{array}{l}\text { MINJ / } \\
\text { MIC }\end{array}$ & $\begin{array}{l}\text { 38.a. Number of days to start a business } \\
\text { [Annual World Bank Report "Doing Business } \\
\text { Annual Report"] }\end{array}$ & 60 & \\
\hline & & & & $\begin{array}{l}\text { Simplification of the economic activity licensing } \\
\text { procedures system in the Ministries }\end{array}$ & $\begin{array}{l}\text { MIC } \\
\text { (Inter- } \\
\text { Minister } \\
\text { ial } \\
\text { Group) } \\
\end{array}$ & $\begin{array}{l}\text { 38.b. \% of procedures simplified } \\
\text { [MIC - GASP and Interministerial Group] }\end{array}$ & $50 \%$ & \\
\hline & & & & $\begin{array}{l}\text { Adoption and adaptation of international (ISO) and } \\
\text { regional standards according to the private sector } \\
\text { needs }\end{array}$ & $\begin{array}{l}\text { INNOQ } \\
1 \\
\text { Private } \\
\text { Sector }\end{array}$ & $\begin{array}{l}\text { 38.d. Standards approved } \\
\text { [INNOQ] }\end{array}$ & 48 & 36 \\
\hline & & & & Simplification of the import and export procedures & $\begin{array}{l}\text { CSTA / } \\
\text { Banks/ } \\
\text { Ministri } \\
\text { es / } \\
\text { IPEX } \\
\end{array}$ & $\begin{array}{l}\text { 38.e. No. of days } \\
\text { [Doing Business] }\end{array}$ & 25 & \\
\hline $\begin{array}{l}\text { 39. Create employment } \\
\text { (pars. } 556 \text { and } 497)\end{array}$ & $\begin{array}{l}\text { 39.1. No. of employees in } \\
\text { the formal sector } \\
\text { [MITRAB] }\end{array}$ & 570000 & 900000 & Approval and implementation of a flexible Labour Law & $\begin{array}{l}\text { MITRA } \\
B\end{array}$ & $\begin{array}{l}\text { 39.a. Cost of hiring and firing workers* } \\
\text { [Doing Business Position] }\end{array}$ & 80 & \\
\hline \multirow[t]{2}{*}{$\begin{array}{l}\text { 40. Increase the } \\
\text { participation of local } \\
\text { entrepreneurs in the } \\
\text { Mineral Resource sector } \\
\text { (par. 550) }\end{array}$} & \multirow[t]{2}{*}{$\begin{array}{l}\text { 40.1. No. of local private } \\
\text { operators in the mining } \\
\text { sector } \\
\text { [MIREM] }\end{array}$} & \multirow[t]{2}{*}{390} & \multirow[t]{2}{*}{1000} & Realization of geological studies & MIREM & $\begin{array}{l}\text { 40.a. No. of studies } \\
\text { [MIREM] }\end{array}$ & & $\begin{array}{l}\text { Studies } \\
\text { done in } \\
\text { Tete, } \\
\text { Manica, } \\
\text { Niassa } \\
\text { and } \\
\text { Cabo } \\
\text { Delgad } \\
\text { o } \\
\end{array}$ \\
\hline & & & & Training of local mining operators & MIREM & $\begin{array}{l}\text { 40.b. Cumulative number of local mining } \\
\text { operators trained } \\
\text { [MIREM] }\end{array}$ & 17 & $\begin{array}{l}\text { Associa } \\
\text { tions in } \\
\text { Manica } \\
\text { and } \\
\text { Nampul } \\
\text { a } \\
\text { trained } \\
\text { in gold } \\
\text { extracti } \\
\text { on and } \\
\text { process } \\
\text { ing } \\
\text { techniq } \\
\text { ues }\end{array}$ \\
\hline
\end{tabular}


PILLAR III -ECONOMIC DEVELOPMENT -PRIVATE SECTOR

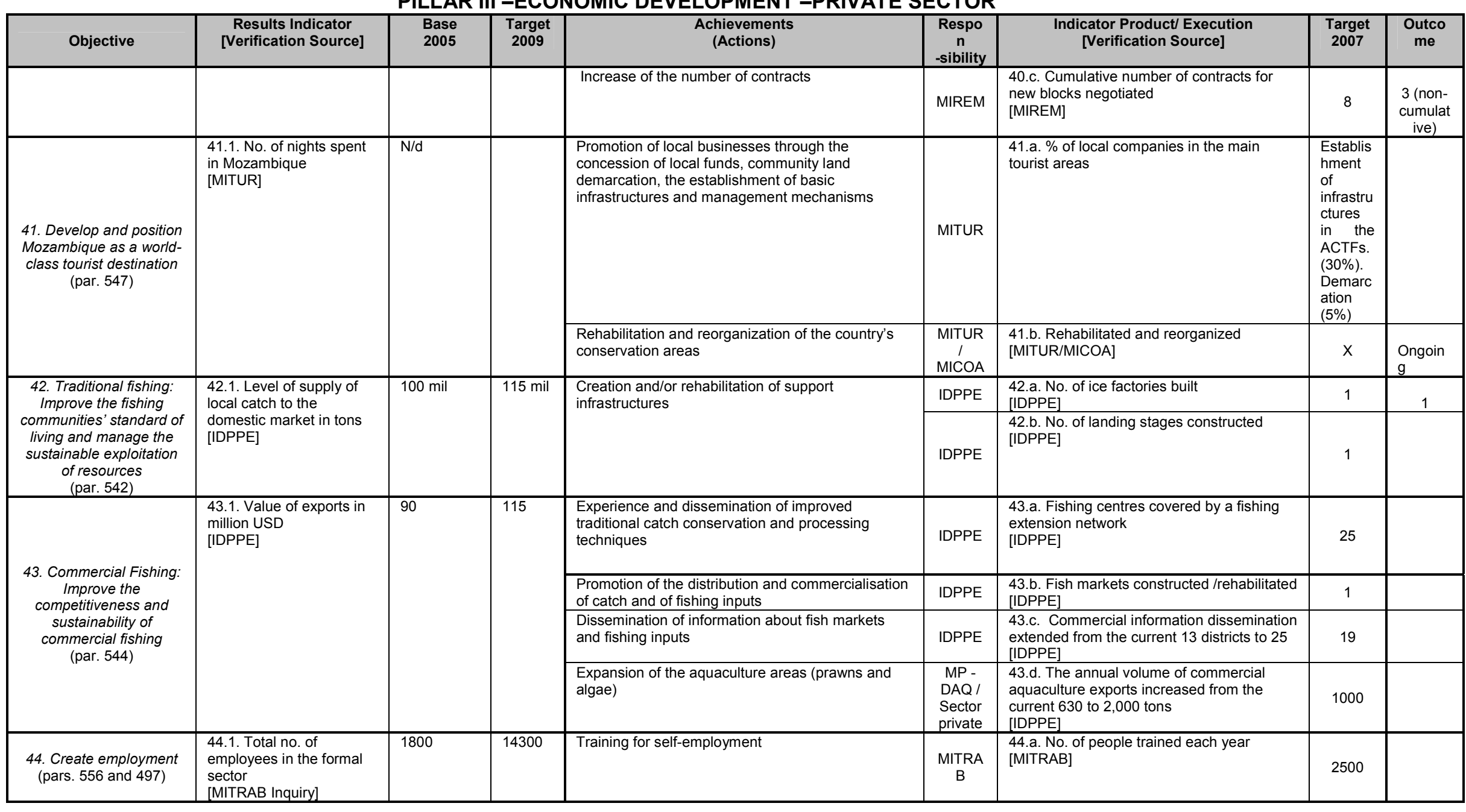

Note: *Depends on the approval of the Law.

PILLAR III -ECONOMIC DEVELOPMENT - AGRICULTURE 


\begin{tabular}{|c|c|c|c|c|c|c|c|c|}
\hline Objective & $\begin{array}{c}\text { Results Indicator } \\
\text { [Verification Source] }\end{array}$ & $\begin{array}{l}\text { Base } \\
2005\end{array}$ & $\begin{array}{c}\text { Targe } \\
t \\
2009 \\
\end{array}$ & $\begin{array}{l}\text { Achievements } \\
\text { (Actions) }\end{array}$ & $\begin{array}{c}\text { Respo } \\
n \\
\text {-sibility }\end{array}$ & $\begin{array}{l}\text { Indicator Product/ Execution } \\
\text { [Verification Source] }\end{array}$ & $\begin{array}{c}\text { Target } \\
2007\end{array}$ & $\begin{array}{c}\text { Outcom } \\
\text { e }\end{array}$ \\
\hline \multirow{2}{*}{$\begin{array}{l}\text { 45. Increase access to } \\
\text { technology and extension } \\
\text { information } \\
\text { (par. 531) }\end{array}$} & \multirow[t]{2}{*}{$\begin{array}{l}\text { 45.1. \% of assisted } \\
\text { production units that } \\
\text { adopted at least one new } \\
\text { technology } \\
\text { [TIA] }\end{array}$} & \multirow[t]{2}{*}{$28 \%$} & \multirow[t]{2}{*}{$36 \%$} & Dissemination of agricultural technologies & $\begin{array}{l}\text { MINAG } \\
- \\
\text { Agricult } \\
\text { ural } \\
\text { Extensi } \\
\text { on } \\
\end{array}$ & $\begin{array}{l}\text { 45.a. Total number of peasants assisted by the } \\
\text { public extension services, including sub- } \\
\text { contracting. } \\
\text { [REL] }\end{array}$ & 222,300 & 285,361 \\
\hline & & & & $\begin{array}{l}\text { Assessment, creation and transfer of agricultural } \\
\text { technologies adapted to the various agro-ecological } \\
\text { zones }\end{array}$ & $\begin{array}{l}\text { MINAG } \\
\text { - IIAM } \\
\text { (Resea } \\
\text { rch) }\end{array}$ & $\begin{array}{l}\text { 45.b. No. of new crop varieties made } \\
\text { available } \\
\text { [REL] }\end{array}$ & 4 & 4 \\
\hline $\begin{array}{l}\text { 46. Promote the } \\
\text { construction and } \\
\text { rehabilitation of } \\
\text { agricultural infra- } \\
\text { structures } \\
\text { (par. 531) }\end{array}$ & $\begin{array}{l}46.1 . \% \text { of agricultural } \\
\text { production units using } \\
\text { irrigation techniques } \\
{[\mathrm{TIA}]}\end{array}$ & $6 \%$ & $8 \%$ & $\begin{array}{l}\text { Construction and rehabilitation of water collecting infra- } \\
\text { structures for the agriculture sector }\end{array}$ & $\begin{array}{l}\text { MINAG } \\
-- \\
\text { Agricult } \\
\text { ural } \\
\text { service } \\
\text { s }\end{array}$ & $\begin{array}{l}\text { 46.a. Number of new irrigation hectares } \\
\text { rehabilitated with public funds and put under the } \\
\text { management of the beneficiaries } \\
\text { [REL] }\end{array}$ & 4000 & 3520 \\
\hline $\begin{array}{l}\text { 47. Increase the } \\
\text { availability and access to } \\
\text { livestock rearing inputs } \\
\text { (p. 531) }\end{array}$ & $\begin{array}{l}\text { 47.1. \% of agricultural } \\
\text { production units using at } \\
\text { least one livestock rearing } \\
\text { input (vaccination) } \\
{[\text { TIA] }}\end{array}$ & $3 \%$ & $4 \%$ & Realization of animal health campaigns & $\begin{array}{c}\text { MINAG } \\
- \\
\text { Veterin } \\
\text { ary } \\
\text { Authorit } \\
y\end{array}$ & $\begin{array}{l}\text { 47.a. Cumulative number of vaccinations } \\
\text { against Newcastle } \\
\text { [REL] }\end{array}$ & $\begin{array}{c}270,000 \\
0\end{array}$ & $\begin{array}{c}2,663,95 \\
7\end{array}$ \\
\hline \multirow{2}{*}{$\begin{array}{l}\text { 48. Improve access to } \\
\text { information and } \\
\text { agricultural markets } \\
\text { (par. 531) }\end{array}$} & $\begin{array}{l}48.1 . \% \text { of agricultural } \\
\text { production units with } \\
\text { access to market price } \\
\text { information via radio } \\
{[T I A]}\end{array}$ & $30 \%$ & $38 \%$ & $\begin{array}{l}\text { Promotion of a market opportunities information } \\
\text { service }\end{array}$ & $\begin{array}{l}\text { MINAG } \\
- \\
\text { Director } \\
\text { ate of } \\
\text { Econo } \\
\text { my }\end{array}$ & $\begin{array}{l}\text { 48.a. Cumulative number of radio broadcast } \\
\text { hours disseminating market information } \\
\text { [REL] }\end{array}$ & 173 & $\begin{array}{l}191 \\
\text { (non- } \\
\text { cumulati } \\
\text { ve) }\end{array}$ \\
\hline & $\begin{array}{l}\text { 48.2. \% of agricultural } \\
\text { production units with at } \\
\text { least one member of an } \\
\text { association } \\
\text { [TIA] }\end{array}$ & $6 \%$ & $7 \%$ & Support to and training of producer organisations & $\begin{array}{l}\text { MINAG } \\
- \\
\text { agricult } \\
\text { ural } \\
\text { Service } \\
\text { s } \\
\end{array}$ & $\begin{array}{l}\text { 48.b. Cumulative number of producer } \\
\text { associations assisted by the MINAG, } \\
\text { including outsourcing } \\
\text { [REL] }\end{array}$ & 2700 & $\begin{array}{l}2450 \\
\text { (non- } \\
\text { cumulati } \\
\text { ve) }\end{array}$ \\
\hline $\begin{array}{l}\text { 49. Promote private } \\
\text { sector development and } \\
\text { the development of value } \\
\text { chain-oriented production } \\
\text { systems } \\
\text { (par. 531) }\end{array}$ & $\begin{array}{l}\text { 49.1. Value of agricultural } \\
\text { cashew, cotton and sugar } \\
\text { exports (million USD) } \\
\text { [REL] }\end{array}$ & 95.5 & 110 & $\begin{array}{l}\text { Establishment of a quality standards framework and } \\
\text { health and phytosanitary certification standards for a } \\
\text { competitive market }\end{array}$ & $\begin{array}{c}\text { MINAG } \\
- \\
\text { Depart } \\
\text { ment of } \\
\text { Plant } \\
\text { and } \\
\text { Animal } \\
\text { Health / } \\
\text { MIC - } \\
\text { INNOQ }\end{array}$ & $\begin{array}{l}\text { 49.a. No. of health and phytosanitary } \\
\text { licences and certificates issued } \\
\text { [REL] }\end{array}$ & 3000 & 3671 \\
\hline
\end{tabular}


PILLAR III -ECONOMIC DEVELOPMENT - AGRICULTURE

\begin{tabular}{|c|c|c|c|c|c|c|c|c|}
\hline Objective & $\begin{array}{c}\text { Results Indicator } \\
\text { [Verification Source] }\end{array}$ & $\begin{array}{l}\text { Base } \\
2005\end{array}$ & $\begin{array}{c}\text { Targe } \\
t \\
2009\end{array}$ & $\begin{array}{l}\text { Achievements } \\
\text { (Actions) }\end{array}$ & $\begin{array}{l}\text { Respo } \\
n \\
\text {-sibility }\end{array}$ & $\begin{array}{l}\text { Indicator Product/ Execution } \\
\text { [Verification Source] }\end{array}$ & $\begin{array}{l}\text { Target } \\
2007\end{array}$ & $\begin{array}{c}\text { Outcom } \\
\text { e }\end{array}$ \\
\hline \multirow[b]{2}{*}{$\begin{array}{l}\text { 50. Improve the } \\
\text { communities' access to } \\
\text { natural resources in an } \\
\text { equitable manner for } \\
\text { sustainable usage and } \\
\text { management } \\
\text { (par. 533) }\end{array}$} & \multirow[t]{2}{*}{$\begin{array}{l}50.1 . \% \text { of agricultural } \\
\text { production units with } \\
\text { documented land } \\
\text { occupation } \\
\text { [MINAG] }\end{array}$} & \multirow[t]{2}{*}{$1.20 \%$} & \multirow[t]{2}{*}{$1.70 \%$} & \multirow[t]{2}{*}{$\begin{array}{l}\text { Stocktaking, mapping of land occupation, use and } \\
\text { utilization }\end{array}$} & \multirow[b]{2}{*}{$\begin{array}{l}\text { MINAG } \\
\text { - Land } \\
\text { and } \\
\text { Forests }\end{array}$} & $\begin{array}{l}50 . a . \% \text { of processes channelled and registered } \\
\text { in } 90 \text { days } \\
\text { [MINAG] }\end{array}$ & $90 \%$ & $\begin{array}{c}38 \% \\
\text { (excludi } \\
\text { ng } \\
\text { Gaza, } \\
\text { Niassa } \\
\text { and } \\
\text { Maputo) }\end{array}$ \\
\hline & & & & & & $\begin{array}{l}\text { 50.b. No. of local communities delimitated } \\
\text { and registered in the land register } \\
\text { [REL] }\end{array}$ & 220 & $\begin{array}{l}48 \\
\text { commun } \\
\text { ity } \\
\text { delimitat } \\
\text { ions, } \\
236 \\
\text { demarca } \\
\text { tions } \\
\text { and } \\
1011 \\
\text { commun } \\
\text { ity } \\
\text { consulta } \\
\text { tions }\end{array}$ \\
\hline $\begin{array}{l}\text { 51. Improve the } \\
\text { inspection of natural } \\
\text { resource exploitation } \\
\text { (par. 533) }\end{array}$ & $\begin{array}{l}\text { 51.1. No. of forest and } \\
\text { wildlife transgressions } \\
\text { reduced } \\
\text { [MINAG] }\end{array}$ & 1100 & 660 & $\begin{array}{l}\text { Inspection of the accomplishment of natural } \\
\text { resource legislation }\end{array}$ & $\begin{array}{l}\text { MINAG } \\
\text { - Land } \\
\text { and } \\
\text { Forests }\end{array}$ & $\begin{array}{l}\text { 51.a. Average area covered by an inspector } \\
\text { [REL] }\end{array}$ & 1128 & $\begin{array}{l}533 \text { land } \\
\text { lots with } \\
\text { DUAT } \\
\text { (total, } \\
\text { not per } \\
\text { inspecto } \\
\text { r) }\end{array}$ \\
\hline
\end{tabular}

PILLAR III -ECONOMIC DEVELOPMENT - INFRASTRUCTURE - ROADS

\begin{tabular}{|c|c|c|c|c|c|c|c|c|}
\hline Objective & $\begin{array}{c}\text { Results Indicator } \\
\text { [Verification Source] }\end{array}$ & $\begin{array}{l}\text { Base } \\
2005\end{array}$ & $\begin{array}{l}\text { Target } \\
2009\end{array}$ & $\begin{array}{l}\text { Achievements } \\
\text { (Actions) }\end{array}$ & $\begin{array}{l}\text { Respon } \\
\text {-sibility }\end{array}$ & $\begin{array}{l}\text { Indicator Product/ Execution } \\
\text { [Verification Source] }\end{array}$ & $\begin{array}{c}\text { Target } \\
2007\end{array}$ & Outcome \\
\hline $\begin{array}{l}\text { 52. Improve } \\
\text { passibleness } \\
\text { (par. 570) }\end{array}$ & $\begin{array}{l}52.1 . \% \text { of roads in } \\
\text { reasonable and good } \\
\text { condition* } \\
\text { [ANE Report] }\end{array}$ & $71 \%$ & $\begin{array}{l}78 \% \\
(2007: \\
76 \% \\
2008: \\
77 \%)\end{array}$ & $\begin{array}{l}\text { Rehabilitation and maintenance of the network of } \\
\text { national roads }\end{array}$ & MOPH & $\begin{array}{l}\text { 52.a. \% of km of roads } \\
\text { [ANE Report] }\end{array}$ & $76 \%$ & $70 \%$ \\
\hline
\end{tabular}

Note: ${ }^{*}$ Good condition $=$ one can safely drive at $80 \mathrm{~km} / \mathrm{h}$; reasonable condition $=$ one can safely drive at $40-50 \mathrm{~km} / \mathrm{h}$. 


\begin{tabular}{|c|c|c|c|c|c|c|c|c|}
\hline Objective & $\begin{array}{l}\text { Results Indicator } \\
\text { [Verification Source] }\end{array}$ & $\begin{array}{l}\text { Base } \\
2005\end{array}$ & $\begin{array}{l}\text { Target } \\
2009\end{array}$ & $\begin{array}{l}\text { Achievements } \\
\text { (Actions) }\end{array}$ & $\begin{array}{c}\text { Respo } \\
n \\
- \\
\text { sibility } \\
\end{array}$ & $\begin{array}{l}\text { Indicator Product/ Execution [Verification } \\
\text { Source] }\end{array}$ & $\begin{array}{l}\text { Target } \\
2007\end{array}$ & $\begin{array}{c}\text { Outco } \\
\text { me }\end{array}$ \\
\hline $\begin{array}{l}\text { 53. Improve the } \\
\text { productivity of the } \\
\text { energy sector }\end{array}$ & $\begin{array}{l}\text { 53.1. Reduction of } \\
\text { distribution losses } \\
\text { [ME] }\end{array}$ & $\begin{array}{l}\text { Lack of a } \\
\text { monitorin } \\
\text { g system }\end{array}$ & $\begin{array}{l}\text { An } \\
\text { effective } \\
\text { monitori } \\
\text { ng } \\
\text { system } \\
\text { includin } \\
\text { g } \\
\text { allocate } \\
\text { d } \\
\text { resource } \\
\text { s }\end{array}$ & $\begin{array}{l}\text { Preparation of an operational plan, regulations and } \\
\text { operator monitoring programmes (CENELEC } \\
\text { operational) }\end{array}$ & $\begin{array}{l}\text { CENEL } \\
\text { EC/ } \\
\text { ME }\end{array}$ & $\begin{array}{l}\text { 53.a. Reports about the efficiency of sector } \\
\text { operators and evaluation of the CENELEC } \\
\text { [ME] }\end{array}$ & $\begin{array}{l}\text { Assess } \\
\text { ment of } \\
\text { CENEL } \\
\text { EC } \\
\text { accomp } \\
\text { lishmen } \\
\text { t of the } \\
\text { contract } \\
\text { with } \\
\text { EDM }\end{array}$ & \\
\hline $\begin{array}{l}\text { 54. Expansion of } \\
\text { domestic power supply }\end{array}$ & $\begin{array}{l}54.1 \% \text { of people with } \\
\text { sustainable access to } \\
\text { modern power supply } \\
\text { [ME] }\end{array}$ & $7 \%$ & $10 \%$ & Expansion of the national network & $\begin{array}{l}\text { EDM / } \\
\text { ME }\end{array}$ & $\begin{array}{l}\text { 54.a. No. of new people connected to the } \\
\text { network } \\
\text { [ME] }\end{array}$ & 400000 & $\begin{array}{l}92145 \\
\text { (new } \\
\text { connect } \\
\text { ions) }\end{array}$ \\
\hline $\begin{array}{l}\text { 55. Expansion of power } \\
\text { supply to health and } \\
\text { education institutions }\end{array}$ & $\begin{array}{l}55.1 \text {. No. of new } \\
\text { institutions with } \\
\text { sustainable access to } \\
\text { modern power supply } \\
\text { outside the network } \\
\text { [ME] }\end{array}$ & $\begin{array}{l}\text { Pilot } \\
\text { planned, } \\
\text { tender } \\
\text { launched } \\
\text { for } \\
\text { project } \\
\text { implemen } \\
\text { tation }\end{array}$ & 500 & $\begin{array}{l}\text { Analysis of the existing tariff structure, subsidies, } \\
\text { policies and options with a view to the promotion of } \\
\text { investor interest, reduction of costs and the } \\
\text { implementation of a maintenance system }\end{array}$ & $\begin{array}{l}\text { FUNA } \\
\text { E / ME }\end{array}$ & $\begin{array}{l}\text { 55.a. No. of hospitals and schools having } \\
\text { access to modern power supply, and with } \\
\text { maintenance contracts for isolated systems } \\
\text { [ME] }\end{array}$ & 300 & \\
\hline
\end{tabular}

\section{CROSS-CUTTING ISSUES - GENDER}

\begin{tabular}{|c|c|c|c|c|c|c|c|c|}
\hline Objective & $\begin{array}{c}\text { Results Indicator } \\
\text { [Verification Source] }\end{array}$ & $\begin{array}{l}\text { Base } \\
2005\end{array}$ & $\begin{array}{c}\text { Targe } \\
t \\
2009 \\
\end{array}$ & $\begin{array}{l}\text { Achievements } \\
\text { (Actions) }\end{array}$ & $\begin{array}{c}\text { Respo } \\
n \\
\text {-sibility } \\
\end{array}$ & $\begin{array}{c}\text { Indicator Product/ Execution } \\
\text { [Verification Source] }\end{array}$ & $\begin{array}{l}\text { Target } \\
2007\end{array}$ & $\begin{array}{c}\text { Outco } \\
\text { me }\end{array}$ \\
\hline $\begin{array}{l}\text { 56. Promote gender } \\
\text { equality and strengthen } \\
\text { woman's empowerment } \\
\text { (pars. } 192 \text { and 193) }\end{array}$ & $\begin{array}{l}56.1 \text {. Gender integrated } \\
\text { in the planning process } \\
\text { [PES, BdPES] }\end{array}$ & $0 \%$ & $100 \%$ & $\begin{array}{l}\text { Inclusion of gender issues identified in the PARPA in the } \\
\text { PES/OE and BdPES }\end{array}$ & $\begin{array}{l}\text { Identifie } \\
\text { d } \\
\text { Ministri } \\
\text { es (in } \\
\text { coordina } \\
\text { tion } \\
\text { with } \\
\text { MMAS } \\
\text { and } \\
\text { MPD) } \\
\end{array}$ & $\begin{array}{l}\text { 56.d. PES/OE and BdPES whereby the actions, } \\
\text { budgets and progress in gender are reflected. } \\
\text { [Sector BdPES/OE and a conjunct MMAS } \\
\text { evaluation] }\end{array}$ & $\begin{array}{c}\text { MMAS, } \\
\text { MISAU, } \\
\text { MEC, } \\
\text { MINAG, } \\
\text { MINT, } \\
\text { MOPH } \\
\text { and } \\
\text { MPD. }\end{array}$ & $\begin{array}{l}\text { MMAS, } \\
\text { MISAU, } \\
\text { MEC, } \\
\text { MINAG, } \\
\text { MINT, } \\
\text { MOP, } \\
\text { MPD } \\
\text { and } \\
\text { MICOA }\end{array}$ \\
\hline
\end{tabular}

CROSS-CUTTING ISSUES - HIVIAIDS

Objective Results Indicator
[Verification Source]

\section{Base
2005}

\section{Target
2009}

Achievements
(Actions)
Respon
-sibility

Indicator Product/ Execution

[Verification Source]

Target
2007

-sibility


CROSS-CUTTING ISSUES - HIVIAIDS

\begin{tabular}{|c|c|c|c|c|c|c|c|c|}
\hline Objective & $\begin{array}{c}\text { Results Indicator } \\
\text { [Verification Source] }\end{array}$ & $\begin{array}{l}\text { Base } \\
2005\end{array}$ & $\begin{array}{c}\text { Target } \\
2009\end{array}$ & $\begin{array}{l}\text { Achievements } \\
\text { (Actions) }\end{array}$ & $\begin{array}{l}\text { Respon } \\
\text {-sibility }\end{array}$ & $\begin{array}{l}\text { Indicator Product/ Execution } \\
\text { [Verification Source] }\end{array}$ & $\begin{array}{l}\text { Target } \\
2007\end{array}$ & Outcome \\
\hline $\begin{array}{l}\text { 57. Strengthen the } \\
\text { management and } \\
\text { coordination capacity } \\
\text { and involve the whole } \\
\text { society in the fight } \\
\text { against the epidemic } \\
\text { (par. 200) }\end{array}$ & $\begin{array}{l}\text { 57.1. Composite Index } \\
\text { of national response } \\
\text { [National Response } \\
\text { M\&A System] }\end{array}$ & $82 \%$ & $95 \%$ & $\begin{array}{l}\text { Support to the sectors for preparing and } \\
\text { implementing HIVIAIDS combat plans in the } \\
\text { sector }\end{array}$ & CNCS & $\begin{array}{l}\text { 57.a. \% of OSCs and public and } \\
\text { private sector institutions trained in } \\
\text { HIVIAIDS combat programme } \\
\text { management } \\
\text { [CNCS data] }\end{array}$ & $55 \%$ & \\
\hline $\begin{array}{l}\text { 58. Reduce the } \\
\text { HIV/AIDS-related } \\
\text { stigma and } \\
\text { discrimination }\end{array}$ & $\begin{array}{l}\text { 58.1. \% of } 15 \text { to } 49 \\
\text { year old people stating } \\
\text { to accept attitudes } \\
\text { towards people living } \\
\text { with HIVIAIDS } \\
\text { [INE/IDS] }\end{array}$ & $\begin{array}{l}8 \% \text { of } \\
\text { women } \\
\text { (between } 15 \\
\text { and } 49 \\
\text { years) and } \\
16 \% \text { of men } \\
\text { (between } 15 \\
\text { and } 49 \\
\text { years) } \\
\end{array}$ & $60 \%$ & $\begin{array}{l}\text { Implementation of CNCS's national } \\
\text { communication strategy }\end{array}$ & CNCS & $\begin{array}{l}\text { 58.a. Strategy implemented } \\
\text { [CNCS Reports] }\end{array}$ & $x$ & $x$ \\
\hline $\begin{array}{l}\text { 59. Prevent the } \\
\text { transmission of HIV } \\
\text { (pars. } 193 \text { \& 449) }\end{array}$ & $\begin{array}{l}\text { 59.1. \% of sexually } \\
\text { active youths between } \\
15 \text { and } 24 \text { years stating } \\
\text { to have used condoms } \\
\text { in their last sexual } \\
\text { contact with an } \\
\text { irregular partner } \\
\text { [INE/IDS] }\end{array}$ & $\begin{array}{l}29 \% \text { of } \\
\text { young } \\
\text { women } \\
\text { (between } 15 \\
\text { and } 24 \\
\text { years) and } \\
32 \% \text { of } \\
\text { young men } \\
\text { (between } 15 \\
\text { and } 24 \\
\text { years) }\end{array}$ & $60 \%$ & $\begin{array}{l}\text { Distribution of condoms, implementation of CNCS's } \\
\text { national communication strategy and the expansion of } \\
\text { vertical transmission prevention services }\end{array}$ & CNCS/MISAU & $\begin{array}{l}\text { 59.a. \% (and number) of HIV positive } \\
\text { pregnant women who have been } \\
\text { receiving complete prophylaxis treatment } \\
\text { in the last } 12 \text { months so as to reduce the } \\
\text { risk of vertical transmission from mother } \\
\text { to baby } \\
\text { [MISAU] }\end{array}$ & $\begin{array}{c}13 \% \\
(22,500)\end{array}$ & $\begin{array}{c}16800 \\
\text { pregnant } \\
\text { women } \\
\text { received } \\
\text { Niverapine } \\
\text { prophylaxis, } \\
24320 \\
\text { received } \\
\text { prophylactic } \\
\text { bitherapy } \\
\text { and } 3647 \\
\text { started } \\
\text { ARVT } \\
\end{array}$ \\
\hline $\begin{array}{l}\text { 60. Improve the infected } \\
\text { and affected persons' } \\
\text { quality of life } \\
\text { (par. 200) }\end{array}$ & $\begin{array}{l}\text { 60.1. Proportion of } \\
\text { orphaned children (6 - } \\
17 \text { years) and non- } \\
\text { orphaned schoolgoing } \\
\text { children } \\
\text { [Demographic and } \\
\text { Health Inquiry (IDS)] }\end{array}$ & 0.8 & 1 & $\begin{array}{l}\text { Guarantee of material, food, moral and } \\
\text { psychosocial assistance to the OVCs }\end{array}$ & $\begin{array}{l}\text { CNCS / } \\
\text { MMAS }\end{array}$ & $\begin{array}{l}\text { 60.a. \% of OVCs covered by the OVC } \\
\text { Action Plan with access to at least } \\
\text { three basic services in the previous } \\
\text { two months [MMAS] }\end{array}$ & $20 \%$ & $\begin{array}{l}9800 \text { OVCs } \\
\text { attended to }\end{array}$ \\
\hline
\end{tabular}

\section{CROSS-CUTTING ISSUES - ENVIRONMENT}

\begin{tabular}{|c|c|c|c|c|c|c|c|c|}
\hline Objective & $\begin{array}{c}\text { Results Indicator } \\
\text { [Verification Source] }\end{array}$ & $\begin{array}{l}\text { Base } \\
2005\end{array}$ & $\begin{array}{l}\text { Target } \\
2009\end{array}$ & $\begin{array}{l}\text { Achievements } \\
\text { (Actions) }\end{array}$ & $\begin{array}{l}\text { Respon } \\
\text {-sibility }\end{array}$ & $\begin{array}{l}\text { Indicator Product/ Execution } \\
\text { [Verification Source] }\end{array}$ & $\begin{array}{l}\text { Target } \\
2007\end{array}$ & Outcome \\
\hline $\begin{array}{l}\text { 61. Improve spatial } \\
\text { planning } \\
\text { (par. 205) }\end{array}$ & $\begin{array}{l}\text { 66.1. No. of people } \\
\text { living in informal } \\
\text { settlements and risk } \\
\text { areas reduced } \\
\text { [Sector PES Review] }\end{array}$ & $\begin{array}{l}75 \% \text { of } \\
\text { the } \\
\text { populati } \\
\text { on } \\
\text { living in } \\
\text { informa }\end{array}$ & $\begin{array}{l}\text { \% of the } \\
\text { populatio } \\
\text { n living in } \\
\text { informal } \\
\text { settlemen } \\
\text { ts and }\end{array}$ & $\begin{array}{l}\text { Preparation and approval of district land use } \\
\text { plans }\end{array}$ & MICOA / MPD & $\begin{array}{l}\text { 61.a. Cumulative number of Strategic } \\
\text { District Development Plans (PEDD) } \\
\text { with a prepared and approved } \\
\text { integrated spatial component (land } \\
\text { use) } \\
\text { [Sector PES Review] }\end{array}$ & 26 & $\begin{array}{l}17 \text { (non- } \\
\text { cumulative) }\end{array}$ \\
\hline
\end{tabular}


CROSS-CUTTING ISSUES - ENVIRONMENT

\begin{tabular}{|c|c|c|c|c|c|c|c|c|}
\hline Objective & $\begin{array}{c}\text { Results Indicator } \\
\text { [Verification Source] }\end{array}$ & $\begin{array}{l}\text { Base } \\
2005 \\
\end{array}$ & $\begin{array}{c}\text { Target } \\
2009\end{array}$ & $\begin{array}{c}\begin{array}{c}\text { Achievements } \\
\text { (Actions) }\end{array} \\
\end{array}$ & $\begin{array}{l}\text { Respon } \\
\text {-sibility }\end{array}$ & $\begin{array}{c}\text { Indicator Product/ Execution } \\
\text { [Verification Source] }\end{array}$ & $\begin{array}{c}\text { Target } \\
2007\end{array}$ & Outcome \\
\hline & & $\begin{array}{l}\text { I } \\
\text { settlem } \\
\text { ents } \\
\text { and risk } \\
\text { areas }\end{array}$ & risk areas & $\begin{array}{l}\text { Preparation of Informal Settlement } \\
\text { Requalification Plans in Maputo City, Tete and } \\
\text { Xai-Xai; }\end{array}$ & MICOA & $\begin{array}{l}\text { 61.c. Cumulative number of urban } \\
\text { requalification plans prepared, } \\
\text { approved and being implemented } \\
\text { [Sector PES Review] }\end{array}$ & 2 & 0 \\
\hline $\begin{array}{l}\text { 62. Ensure a cross-cutting } \\
\text { environmental } \\
\text { management in the country } \\
\text { (par. 209) }\end{array}$ & $\begin{array}{l}\text { 62.1. Integration of } \\
\text { environmental issues in } \\
\text { key economic and } \\
\text { municipal sectors } \\
\text { [Sector PES Review] }\end{array}$ & $\begin{array}{l}\text { The } \\
\text { environ } \\
\text { ment } \\
\text { integrat } \\
\text { ed in } \\
\text { some } \\
\text { sectors }\end{array}$ & $\begin{array}{l}\text { The } \\
\text { environm } \\
\text { ent fully } \\
\text { integrated } \\
\text { in all key } \\
\text { economic } \\
\text { and } \\
\text { municipal } \\
\text { sectors }\end{array}$ & $\begin{array}{l}\text { Approval and dissemination of the Environmental } \\
\text { Strategy for Sustainable Development (EADS) }\end{array}$ & $\begin{array}{l}\text { MICOA / } \\
\text { Sectors / } \\
\text { Municipalities } \\
\text { / Civil Society }\end{array}$ & $\begin{array}{l}\text { 62.b. No. of environmental units } \\
\text { created } \\
\text { [Sector PES Review] }\end{array}$ & 13 & $\begin{array}{l}\text { Diagnosis } \\
\text { started of the } \\
\text { functioning of } \\
\text { the } 5 \text { existing } \\
\text { units as well } \\
\text { as the } \\
\text { opportunities } \\
\text { for the } \\
\text { creation of } \\
\text { more units }\end{array}$ \\
\hline
\end{tabular}

CROSS-CUTTING ISSUES - FOOD SECURITY AND NUTRITION

\begin{tabular}{|c|c|c|c|c|c|c|c|c|}
\hline Objective & $\begin{array}{c}\text { Results Indicator } \\
\text { [Verification Source] }\end{array}$ & $\begin{array}{l}\text { Base } \\
2005\end{array}$ & $\begin{array}{l}\text { Target } \\
2009\end{array}$ & $\begin{array}{l}\text { Achievements } \\
\text { (Actions) }\end{array}$ & $\begin{array}{l}\text { Respon } \\
\text {-sibility }\end{array}$ & $\begin{array}{l}\text { Indicator Product/ Execution } \\
\text { [Verification Source] }\end{array}$ & $\begin{array}{c}\text { Target } \\
2007\end{array}$ & Outcome \\
\hline \multirow{2}{*}{$\begin{array}{l}\text { 63. Ensure that all citizens } \\
\text { have at all times physical } \\
\text { and economic access to the } \\
\text { necessary food, so as to } \\
\text { have an active and healthy } \\
\text { life } \\
\text { (par. 210) }\end{array}$} & $\begin{array}{l}\text { 63.1. Weight to length for } \\
\text { under-fives (severe } \\
\text { malnutrition) } \\
\text { [IAF/IDS] }\end{array}$ & $4 \%$ & $\begin{array}{l}\text { Rate } \\
\text { stable } \\
\text { between } \\
0-5 \%\end{array}$ & \multirow[t]{2}{*}{$\begin{array}{l}\text { Monitoring and evaluation of chronic and } \\
\text { severe SAN; recommendations are given } \\
\text { to sectors about SAN priority activities }\end{array}$} & \multirow[t]{2}{*}{ SETSAN } & \multirow{2}{*}{$\begin{array}{l}\text { 63.a. SAN included in all sector and } \\
\text { mulitisector action plans (PES, PEDD) } \\
\text { - food and nutritional security action } \\
\text { plan (PASAN) } \\
\text { [SETSAN] }\end{array}$} & \multirow[t]{2}{*}{$X$} & \\
\hline & $\begin{array}{l}\text { 63.2. \% of population with } \\
\text { an acceptable food quality } \\
\text { [SETSAN data] }\end{array}$ & $7 \%$ & $15 \%$ & & & & & \\
\hline \multirow{2}{*}{$\begin{array}{l}\text { 64. Structure a } \\
\text { comprehensive multisector } \\
\text { and interinstitutional } \\
\text { intervention } \\
\text { (par. 218) }\end{array}$} & \multirow{2}{*}{$\begin{array}{l}64.1 \text {. SETSAN efficient and } \\
\text { effective in the } \\
\text { accomplishment of its } \\
\text { functions } \\
\text { [Review of Strategic Plan } \\
\text { Accomplishment] }\end{array}$} & \multirow[t]{2}{*}{$\begin{array}{l}\text { Lack of } \\
\text { efficiency, } \\
\text { above all } \\
\text { in the } \\
\text { provinces }\end{array}$} & \multirow[t]{2}{*}{$\begin{array}{l}\text { Efficient } \\
\text { and } \\
\text { effective }\end{array}$} & $\begin{array}{l}\text { Preparation and approval of a legal } \\
\text { SETSAN framework at national level }\end{array}$ & $\begin{array}{l}\text { SETSAN, } \\
\text { Council of } \\
\text { Ministers }\end{array}$ & $\begin{array}{l}\text { 64.a. Was prepared and approved } \\
\text { [Government Gazette] }\end{array}$ & $x$ & $\begin{array}{c}\text { Draft } \\
\text { prepared } \\
\text { for } \\
\text { discussion } \\
\end{array}$ \\
\hline & & & & $\begin{array}{l}\text { Law and Regulation for the Human Right } \\
\text { to Adequate Food (HRAF) filed with } \\
\text { Parliament for approval }\end{array}$ & SETSAN & $\begin{array}{l}\text { 64.b. Regulation filed } \\
\text { [Regulation of the HRAF Law] }\end{array}$ & $x$ & \\
\hline
\end{tabular}

\section{CROSS-CUTTING ISSUES - SCIENCE AND TECHNOLOGY}

\begin{tabular}{|c|c|c|c|c|c|c|c|c|}
\hline Objective & $\begin{array}{c}\text { Results Indicator } \\
\text { [Verification Source] }\end{array}$ & $\begin{array}{l}\text { State } \\
\text { Actual } \\
(2004)\end{array}$ & $\begin{array}{c}\text { Target } \\
2009\end{array}$ & $\begin{array}{l}\text { Achievements } \\
\text { (Actions) }\end{array}$ & $\begin{array}{l}\text { Respon } \\
\text {-sibility }\end{array}$ & $\begin{array}{l}\text { Indicator Product/ Execution } \\
\text { [Verification Source] }\end{array}$ & $\begin{array}{l}\text { Target } \\
2007\end{array}$ & Outcome \\
\hline $\begin{array}{l}\text { 65. Promote the } \\
\text { development of human } \\
\text { resources at all levels of } \\
\text { the Science and } \\
\text { Technology areas } \\
\text { (par. 224) }\end{array}$ & $\begin{array}{l}\text { 65.1. No. of } \\
\text { Mozambicans studying } \\
\text { for a masters and } \\
\text { doctorate degree in } \\
\text { the area of science } \\
\text { and technology } \\
\text { [Sector PES Review] }\end{array}$ & 660 & 1715 & $\begin{array}{l}\text { Granting of scholarships for masters and } \\
\text { doctorate courses }\end{array}$ & MCT & $\begin{array}{l}\text { 65.a. Cumulative number of Mozambicans } \\
\text { sent for advanced training in S\&T } \\
\text { [Sector PES Review] }\end{array}$ & 1187 & $\begin{array}{l}40 \text { (non- } \\
\text { cumulative) }\end{array}$ \\
\hline
\end{tabular}


CROSS-CUTTING ISSUES - SCIENCE AND TECHNOLOGY

\begin{tabular}{|c|c|c|c|c|c|c|c|c|}
\hline Objective & $\begin{array}{c}\text { Results Indicator } \\
\text { [Verification Source] }\end{array}$ & $\begin{array}{l}\text { State } \\
\text { Actual } \\
(2004) \\
\end{array}$ & $\begin{array}{c}\text { Target } \\
2009\end{array}$ & $\begin{array}{l}\text { Achievements } \\
\text { (Actions) }\end{array}$ & $\begin{array}{l}\text { Respon } \\
\text {-sibility }\end{array}$ & $\begin{array}{l}\text { Indicator Product/ Execution } \\
\text { [Verification Source] }\end{array}$ & $\begin{array}{l}\text { Target } \\
2007\end{array}$ & Outcome \\
\hline $\begin{array}{l}\text { 66. Promote subsistence } \\
\text { research and innovation } \\
\text { and the use of S\&T by poor } \\
\text { and underprivileged } \\
\text { communities } \\
\text { (par. 220) }\end{array}$ & $\begin{array}{l}66.1 \text { No. of } \\
\text { communities trained in } \\
\text { the use of appropriate } \\
\text { technologies for the } \\
\text { resolution of local } \\
\text { problems. } \\
\text { [Sector PES Review] }\end{array}$ & 8 & 32 & $\begin{array}{l}\text { Organisation of scientific expeditions to the } \\
\text { rural areas }\end{array}$ & MCT & $\begin{array}{l}\text { 66.a. cumulative number of communities } \\
\text { visited per year } \\
\text { [Sector PES Review] }\end{array}$ & 24 & $\begin{array}{l}15 \text { (non- } \\
\text { cumulative) }\end{array}$ \\
\hline \multirow{5}{*}{$\begin{array}{l}\text { 67. Promote the use of } \\
\text { ICTs for the reduction of } \\
\text { poverty and for economic } \\
\text { growth } \\
\text { (par. 227) }\end{array}$} & \multirow{5}{*}{$\begin{array}{l}\text { 67.1. Rural and urban } \\
\text { population with basic } \\
\text { access and knowledge } \\
\text { about Information and } \\
\text { Communication } \\
\text { Technologies } \\
\text { [Sector PES Review] }\end{array}$} & \multirow[t]{5}{*}{$8.40 \%$} & \multirow[t]{5}{*}{$22 \%$} & \multirow[t]{3}{*}{$\begin{array}{l}\text { Expansion of the Electronic Government } \\
\text { network }\end{array}$} & MCT & $\begin{array}{l}\text { 67.a. Cumulative number of State } \\
\text { institutions at central level connected to the } \\
\text { Electronic Government network } \\
\text { [Sector PES Review] }\end{array}$ & 70 & $\begin{array}{l}23 \text { (non- } \\
\text { cumulative) }\end{array}$ \\
\hline & & & & & MCT & $\begin{array}{l}\text { 67.b. Cumulative number of State } \\
\text { institutions at provincial level connected to } \\
\text { the Electronic Government network } \\
\text { [Sector PES Review] }\end{array}$ & 250 & $\begin{array}{l}53 \text { (non- } \\
\text { cumulative) }\end{array}$ \\
\hline & & & & & MCT & $\begin{array}{l}\text { 67.c. Cumulative number of State } \\
\text { institutions at municipal and district level } \\
\text { connected to the Electronic Government } \\
\text { network } \\
\text { [Sector PES Review] }\end{array}$ & 50 & $\begin{array}{c}1 \mathrm{CM} \\
\text { Nampula } \\
\text { (non- } \\
\text { cumulative) } \\
\end{array}$ \\
\hline & & & & $\begin{array}{l}\text { Expansion of the network of Internet access } \\
\text { points }\end{array}$ & MCT & $\begin{array}{l}\text { 67.d. Cumulative number of districts with } \\
\text { community Internet access points } \\
\text { [Sector PES Review] }\end{array}$ & 32 & \\
\hline & & & & $\begin{array}{l}\text { Implementation of the universal ICT access } \\
\text { strategy }\end{array}$ & MCT & $\begin{array}{l}\text { 67.e. Cumulative \% of mobile and fixed } \\
\text { network users } \\
\text { [Sector PES Review] }\end{array}$ & $13.10 \%$ & \\
\hline
\end{tabular}

\section{CROSS-CUTTING ISSUES - RURAL DEVELOPMENT}

\begin{tabular}{|c|c|c|c|c|c|c|c|c|}
\hline Objective & $\begin{array}{c}\text { Results Indicator } \\
\text { [Verification Source] }\end{array}$ & $\begin{array}{l}\text { Base } \\
2005\end{array}$ & $\begin{array}{l}\text { Target } \\
2009\end{array}$ & $\begin{array}{l}\text { Achievements } \\
\text { (Actions) }\end{array}$ & $\begin{array}{l}\text { Respon } \\
\text {-sibility }\end{array}$ & $\begin{array}{l}\text { Indicator Product/ Execution } \\
\text { [Verification Source] }\end{array}$ & $\begin{array}{c}\text { Target } \\
2007\end{array}$ & Outcome \\
\hline \multirow{4}{*}{$\begin{array}{l}\text { 68. Increase the } \\
\text { competitiveness and } \\
\text { accumulation of the rural } \\
\text { economy } \\
\text { (par. 237) }\end{array}$} & \multirow{4}{*}{$\begin{array}{l}68.1 \text { Average rural } \\
\text { income per capita } \\
\text { [EDR-IAF monitoring } \\
\text { reports] }{ }^{\star} \text { to be } \\
\text { negotiated with the INE }\end{array}$} & \multirow[t]{4}{*}{ USD 263} & \multirow[t]{4}{*}{$\begin{array}{l}\text { USD } \\
310\end{array}$} & $\begin{array}{l}\text { Coordination of the implementation process of the } \\
\text { Local Economic Development Agencies }\end{array}$ & $\begin{array}{l}\text { MPD - } \\
\text { DNPDR }\end{array}$ & $\begin{array}{l}\text { 68.a. Cumulative number of operational Local } \\
\text { Financial and Economic Development Agencies } \\
\text { [DNPDR monitoring reports] }\end{array}$ & 8 & \\
\hline & & & & $\begin{array}{l}\text { Expansion of the Agricultural Markets Support } \\
\text { Programme (PAMA) experience to the whole } \\
\text { country }\end{array}$ & $\begin{array}{l}\text { MPD - } \\
\text { DNPDR }\end{array}$ & $\begin{array}{l}\text { 68.b. Cumulative number of provinces with } \\
\text { an Agricultural Markets Support } \\
\text { Programme } \\
\text { [DNPDR, PAMA monitoring reports] }\end{array}$ & 8 & \\
\hline & & & & $\begin{array}{l}\text { Facilitation of the registration of agricultural and } \\
\text { livestock breeders' associations }\end{array}$ & $\begin{array}{l}\text { MPD - } \\
\text { DNPDR }\end{array}$ & $\begin{array}{l}\text { 68.c. Cumulative number of legalized } \\
\text { associations functioning in a sustainable } \\
\text { way } \\
\text { [DNPDR monitoring reports] }\end{array}$ & 50 & \\
\hline & & & & Promotion of rural communication & $\begin{array}{l}\text { MPD - } \\
\text { DNPDR / } \\
\text { ICS - RM }\end{array}$ & $\begin{array}{l}\text { 68.d. Cumulative number of functioning } \\
\text { community radios and television sets } \\
\text { [DNPDR monitoring reports] }\end{array}$ & 16 & \\
\hline
\end{tabular}


CROSS-CUTTING ISSUES - RURAL DEVELOPMENT

\begin{tabular}{|c|c|c|c|c|c|c|c|c|}
\hline Objective & $\begin{array}{c}\text { Results Indicator } \\
\text { [Verification Source] }\end{array}$ & $\begin{array}{l}\text { Base } \\
2005 \\
\end{array}$ & $\begin{array}{c}\text { Target } \\
2009 \\
\end{array}$ & $\begin{array}{c}\text { Achievements } \\
\text { (Actions) }\end{array}$ & $\begin{array}{l}\text { Respon } \\
\text {-sibility }\end{array}$ & $\begin{array}{c}\text { Indicator Product/ Execution } \\
\text { [Verification Source] }\end{array}$ & $\begin{array}{c}\text { Target } \\
2007 \\
\end{array}$ & Outcome \\
\hline \multirow{2}{*}{$\begin{array}{l}\text { 69. Create a favourable } \\
\text { environment for the } \\
\text { exercise of rural finance } \\
\text { activities } \\
\text { (par. 235) }\end{array}$} & \multirow[t]{2}{*}{$\begin{array}{l}69.1 . \% \text { of the rural } \\
\text { population with access } \\
\text { to credit } \\
\text { [DNPDR monitoring } \\
\text { reports] }\end{array}$} & \multirow[t]{2}{*}{$5 \%$} & & $\begin{array}{l}\text { Approval of the rural finance and micro-finance } \\
\text { policy and strategy and its implementation in } \\
\text { the whole country }\end{array}$ & $\begin{array}{l}\text { MPD - } \\
\text { DNPDR / } \\
\text { FARE }\end{array}$ & $\begin{array}{l}\text { 69.a. Cumulative number of rural finance } \\
\text { and micro finance institutions successfully } \\
\text { adopting the approved sector policy and } \\
\text { strategy } \\
\text { [DNPDR, FARE monitoring reports] }\end{array}$ & 35 & \\
\hline & & & & $\begin{array}{l}\text { Dissemination of the policies and coordination } \\
\text { of the finance institutions' activities and } \\
\text { updating of the client data bank }\end{array}$ & $\begin{array}{l}\text { MPD - } \\
\text { DNPDR / } \\
\text { FARE } \\
\end{array}$ & $\begin{array}{l}\text { 69.b. Cumulative number of micro finance } \\
\text { institution clients } \\
\text { [DNPDR, FARE monitoring reports] }\end{array}$ & 125,000 & \\
\hline
\end{tabular}

Note: *Number of rural finance institutions adopting the rural finance policy and strategy.

CROSS-CUTTING ISSUES - DISASTERS

\begin{tabular}{|c|c|c|c|c|c|c|c|c|}
\hline Objective & $\begin{array}{c}\text { Results Indicator } \\
\text { [Verification Source] }\end{array}$ & $\begin{array}{l}\text { Base } \\
2005\end{array}$ & $\begin{array}{c}\text { Target } \\
2009\end{array}$ & $\begin{array}{c}\text { Achievements } \\
\text { (Actions) }\end{array}$ & $\begin{array}{l}\text { Respon } \\
\text {-sibility }\end{array}$ & $\begin{array}{c}\text { Indicator Product/ Execution } \\
\text { [Verification Source] }\end{array}$ & $\begin{array}{l}\text { Target } \\
2007\end{array}$ & Outcome \\
\hline \multirow{2}{*}{$\begin{array}{l}\text { 70. Reduce the negative } \\
\text { impact of disasters } \\
\text { (par. 244) }\end{array}$} & \multirow[t]{2}{*}{$\begin{array}{l}\text { 70.1. No. of people } \\
\text { assisted by UNAPROC } \\
\text { [PES Review] }\end{array}$} & \multirow[t]{2}{*}{0} & & \multirow[t]{2}{*}{$\begin{array}{l}\text { Establishment of a National Civil Protection } \\
\text { Unit } \\
\text { (UNAPROC) }\end{array}$} & \multirow{2}{*}{$\begin{array}{l}\text { INGC / MINT / } \\
\text { MDN / MISAU } \\
\text { / CVM }\end{array}$} & $\begin{array}{l}\text { 70.a. No. of training and rescue and relief } \\
\text { centres created } \\
\text { [Review of PES] }\end{array}$ & 2 & \\
\hline & & & & & & $\begin{array}{l}\text { 70.b. No. of UNAPROC members trained } \\
\text { [PES Review] }\end{array}$ & & \\
\hline
\end{tabular}

\section{CROSS-CUTTING ISSUES - DEMINING}

\begin{tabular}{|c|c|c|c|c|c|c|c|c|}
\hline Objective & $\begin{array}{c}\text { Results Indicator } \\
\text { [Verification } \\
\text { Source] }\end{array}$ & $\begin{array}{l}\text { Base } \\
2005\end{array}$ & $\begin{array}{l}\text { Target } \\
2009\end{array}$ & $\begin{array}{l}\text { Achievements } \\
\text { (Actions) }\end{array}$ & $\begin{array}{l}\text { Respon } \\
\text {-sibility }\end{array}$ & $\begin{array}{l}\text { Indicator Product/ Execution } \\
\text { [Verification Source] }\end{array}$ & $\begin{array}{c}\text { Target } \\
2007\end{array}$ & Outcome \\
\hline \multirow{2}{*}{$\begin{array}{l}\text { 71. Ensure greater } \\
\text { human freedom of } \\
\text { movement and the } \\
\text { availability of land for } \\
\text { their use } \\
\text { (par. 251) }\end{array}$} & \multirow{2}{*}{$\begin{array}{l}\text { 71.1. Increase of } \\
\text { cleared or } \\
\text { demined areas } \\
\text { [IND data] }\end{array}$} & \multirow{2}{*}{$\begin{array}{l}30 \\
\text { million } \\
\mathrm{m}^{2}\end{array}$} & \multirow[t]{2}{*}{$\begin{array}{l}50 \text { million } \\
\mathrm{m}^{2}\end{array}$} & Reduction of the suspected area & IND & $\begin{array}{l}\text { 71.a. Cumulative suspected area, in million } \mathrm{m}^{2} \\
\text { [IND data] }\end{array}$ & 86 & $\begin{array}{l}266 \text { (non- } \\
\text { cumulative) }\end{array}$ \\
\hline & & & & $\begin{array}{l}\text { Coordination of the demining activities and of } \\
\text { the destruction of localized unexploded } \\
\text { devices }\end{array}$ & IND & $\begin{array}{l}\text { 71.b. Cumulative cleared area, in million } \mathrm{m}^{2} \\
\text { [IND data] }\end{array}$ & 30 & $\begin{array}{c}32 \text { fields } \\
\text { (non- } \\
\text { cumulative) }\end{array}$ \\
\hline
\end{tabular}


